\title{
DADOS RADIOMÉTRICOS OBTIDOS NOS NÍVEIS TERRESTRE E ORBITAL NA AVALIAÇÃO DE SOLOS
}

\section{PETERSON RICARDO FIORIO}

\author{
Tese apresentada à Escola Superior de \\ Agricultura "Luiz de Queiroz", Universidade de \\ São Paulo, para obtenção do título de Doutor \\ em Agronomia, Área de Concentração: Solos e \\ Nutrição de Plantas.
}

P I R A C I C A B A

Estado de São Paulo - Brasil

Maio - 2002 


\section{DADOS RADIOMÉTRICOS OBTIDOS NOS NÍVEIS TERRESTRE E ORBITAL NA AVALIAÇÃO DE SOLOS}

\section{PETERSON RICARDO FIORIO}

Engenheiro Agrônomo

Orientador: Prof. Dr. JOSÉ ALEXANDRE M. DEMATTÊ

Tese apresentada à Escola Superior de Agricultura "Luiz de Queiroz", Universidade de São Paulo, para obtenção do título de Doutor em Agronomia, Área de Concentração: Solos e Nutrição de Plantas.

P I R A C I C A B A

Estado de São Paulo - Brasil

Maio - 2002 


\section{Dados Internacionais de Catalogação na Publicação (CIP) DIVISÃO DE BIBLIOTECA E DOCUMENTAÇÃO - ESALQ/USP}

Fiorio, Peterson Ric a rdo

Dados radiométric os obtidos nos níveis terrestre e orbital na a valiação de solos / Peterson Ric ardo Fionio. -- Piracicaba, 2002.

$198 \mathrm{p}$.

Tese (Doutorado) - Escola Superior de Agricultura Luiz de Queiroz, 2002. Bibliografia.

1. Levantamento do solo 2. Mapeamento do solo 3. Radiometria 4. Reflectância espectral 5. Sensoria mento remoto I. Título

CDD 631.4028

"Permitida a cópia total ou parcial deste documento, desde que citada a fonte - $\mathrm{O}$ autor" 


\section{Aos meus Avós}

Não digas: Este que me deu corpo é meu Pai

Esta que me deu corpo é minha Mãe

Muito mais teu Pai e tua Mãe são os que te fizeram

Em espírito

E esses foram sem número

Sem nome

De todos os tempos

Deixaram o rastro pelos caminhos de hoje

Todos os que já vieram

E andam fazendo-te dia a dia

Os de hoje, e os de amanhã.

(Cecília Meireles)

\section{Em especial}

Os maiores homens que conheci, a cujo olhar nem a terra, nem o céu tinham segredos, eram humildes e sabiam perfeitamente o grau de respeito que cabia a cada criatura.

De alguém que se orgulha em chamá-lo

\section{de avô}

\section{OFEREÇO}




\title{
Aos meus pais
}

Antonio Carlos e Rosemari

A maior necessidade deste mundo é de confiança e de amor

\section{Aos meus irmãos}

Anderson e Vinícius

Por todos esses anos de convivência e de amor mútuo

\section{Aos meus familiares}

Sejam sempre os mesmos

Sempre outros

Mas sempre...dentro de tudo

\author{
A Karina pela fundamental \\ inspiração, dedicação e \\ amor na realização desse \\ trabalho
}




\section{AGRADECIMENTOS}

A Deus, que é a força de todas as crenças, de todos os povos, em qualquer parte do Universo

Ao meu Orientador Prof. Dr. José Alexandre Melo Demattê, pela amizade, dedicação e confiança que depositou em mim. Sem dúvida contribuindo para transformar-me nesse profissional de hoje.

Ao Prof. Dr. Marcos Rafael Nanni, pela grande amizade e ajuda na tese.

Ao Prof. Dr. Antônio Roberto Formaggio, pela grande contribuição e atenção dispensada.

À Fundação de Amparo e Pesquisa do Estado de São Paulo - FAPESP, pelo financiamento desse trabalho.

A Comissão de Pós-graduação do curso de Solos e Nutrição de Plantas da ESALQ/USP, pela oportunidade concedida, Prof. Dr. Álvaro Pires da Silva, Prof. Dr. Luis Reynaldo Ferracciú Alleoni, Prof. Dr. Pablo Vidal Torrado e Prof. Dr. Francisco Antonio Monteiro.

A todos os funcionários do Departamento de Ciência do Solo, pela amizade e ajuda dispensada.

Ao Engenheiro Agrônomo Marcelo Corrêa Alves do Centro de Informática na Agricultura (CIAGRI) da ESALQ/USP pelo auxílio na área de estatística. 
Aos amigos de curso, que também ajudaram de uma forma ou de outra na concretização desse trabalho, Aline, Rogério (Várzea), Caio, Márcio, Tiago e Miguel. 


\section{SUMÁRIO}

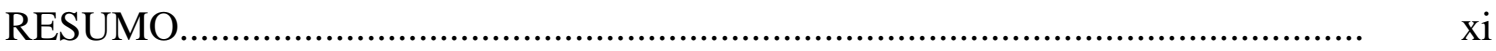

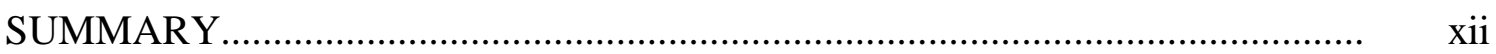

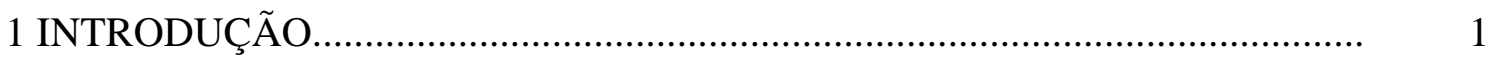

2 REVISÃO DE LITERATURA...................................................................

2.1 Sensoriamento remoto orbital nos levantamentos pedológicos........................... 5

2.2 Caracterização pedológica com auxilio da reflectância........................................ 11

2.3 Relação entre dados espectrais e atributos dos solos........................................... 18

2.4 Predição dos atributos dos solos através da suas resposta espectral.................... 23

3 GEOPROCESSAMENTO E TOPOSSEQUÊNCIAS NA DETERMINAÇÃO DE LEVANTAMENTOS DE SOLOS EM DIFERENTES ESCALAS.................. 27

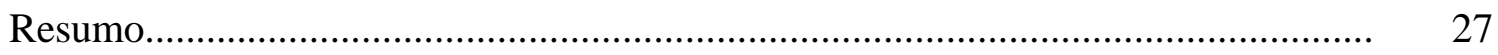

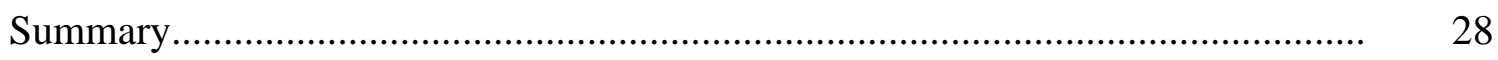

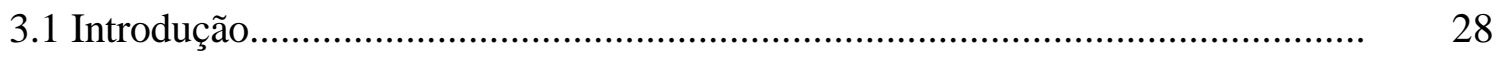

3.2 Material e Métodos.......................................................................................... 31

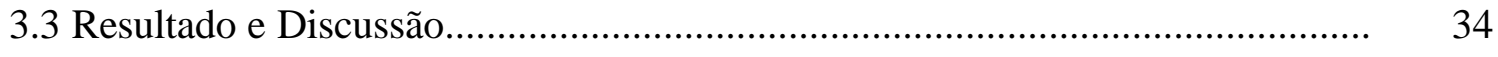

3.3.1 Caracterização dos solos e variabilidade espacial nas topossequências........... 34

3.3.2 Comparação entre os níveis de levantamento pedológicos............................... 39 


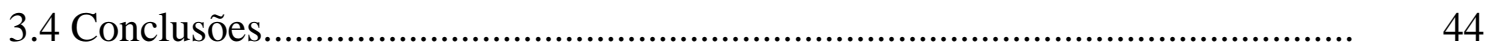

4 ANÁLISES ESPECTRAIS, ORBITAIS E TERRESTRES NA CARACTERIZAÇÃO E DISCRIMINAÇÃO DE SOLOS EM SEQÜÊNCIAS

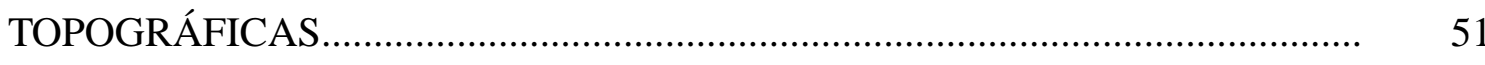

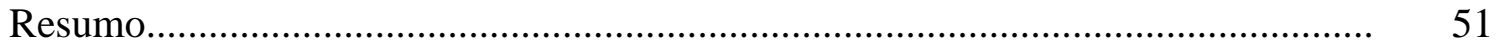

Summary

4.1 Introdução............................................................................................

4.2 Material e Métodos....................................................................................... 56

4.2.1 Caracterização da área de estudo.................................................................... 56

4.2.2 Obtenção dos dados espectrais.................................................................... 58

4.2.3 Análise estatística dos dados espectrais........................................................ 60

4.3 Resultados e Discussão................................................................................. 62

4.3.1 Caracterização qualitativa das curvas espectrais nas topossequências............ 62

4.3.2 Comparação das curvas obtidas nas topossequências e os tipos descritos em literatura

4.3.3 Limites de unidades de mapeamento estabelecidos pelo método estatístico

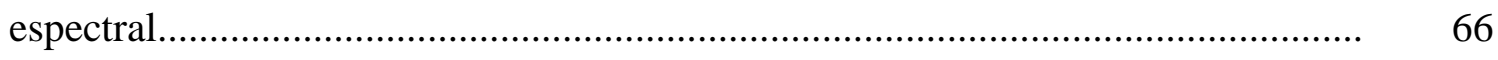

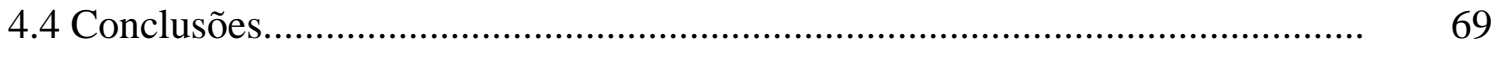

5 EQUAÇÕES DISCRIMINANTES DE SOLOS UTILIZANDO - SE CARACTERÍSTICAS ESPECTRAIS DE LABORATÓRIO E

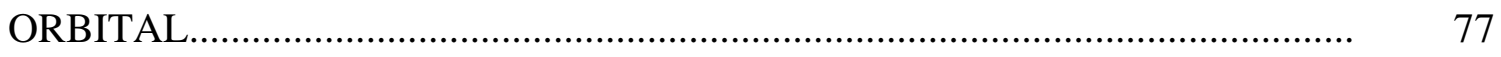

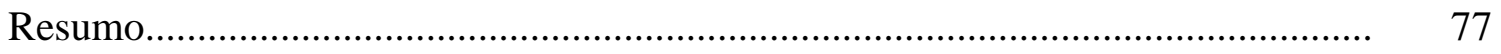


Summary

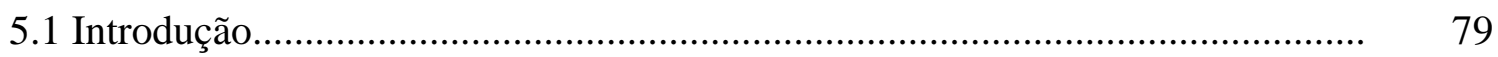

5.2 Material e Métodos....................................................................................... 81

5.2.1 Caracterização da área de estudo............................................................... 81

5.2.2 Obtenção dos dados espectrais...................................................................... 82

5.2.3 Análise estatística dos dados espectrais......................................................... 84

5.3 Resultados e Discussão................................................................................. 86

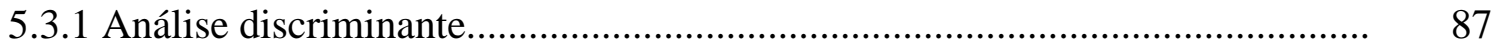

5.3.2 Análise das equações discriminantes ge radas.................................................. 88

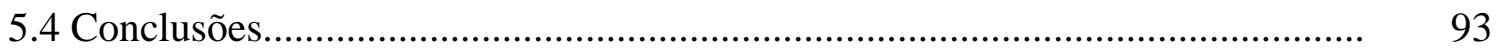

6 REGRESSÕES LINEARES MÚLTIPLAS UTILIZANDO-SE DADOS ESPECTRAIS OBTIDOS POR SENSORES EM LABORATÓRIO E ORBITAL, NA ESTIMATIVA DE ATRIBUTOS DO SOLO................................................. 102

Resumo

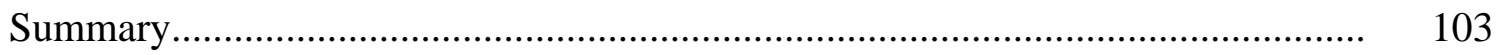

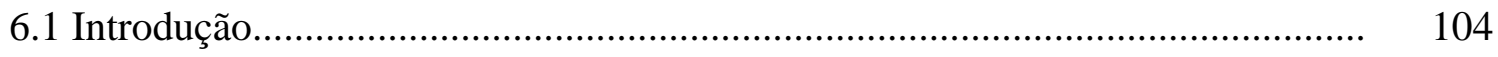

6.2 Material e Métodos............................................................................................ 107

6.2.1 Caracterização da área de estudo.................................................................. 107

6.2.2 Obtenção dos dados espectrais.................................................................... 108

6.2.3 Análise estatística e comparação dos resultados.................................................. 110

6.3 Resultados e Discussão............................................................................. 113

6.3.1 Equações de regressão múltipla...................................................................... 113 
6.3.2 Estimativa do ferro por sensores e relação com a classificação de solos........ 118

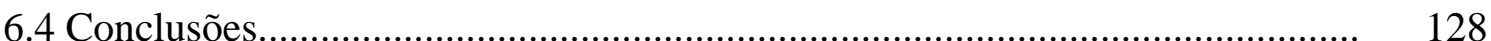

7 QUATIFICAÇÃO DE ATRIBUTOS DOS SOLOS DA REGIÃO DE BARRA BONITA, SP, POR SUA ENERGIA ELETROMAGNÉTICA

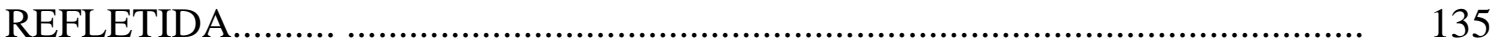

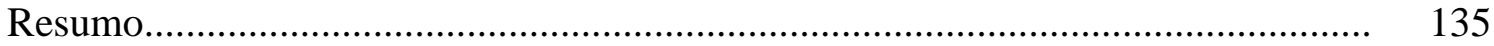

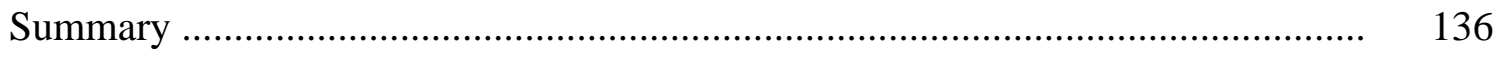

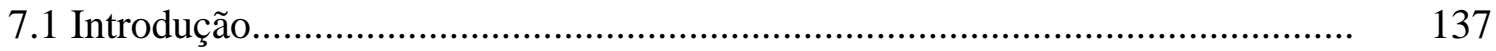

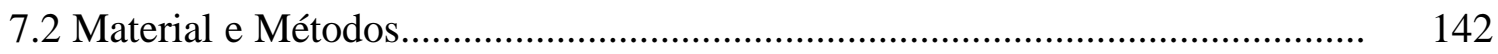

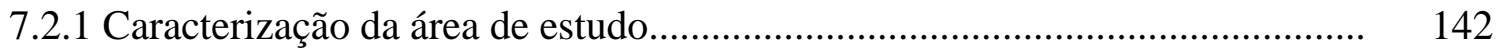

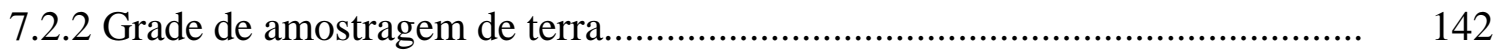

7.2.3 Obtenção dos dados espectrais nível laboratorial......................................... 143

7.2.4 Obtenção dos dados espectrais nível orbital................................................. 144

7.2.5 Análise estatística dos dados espectrais................................................ 145

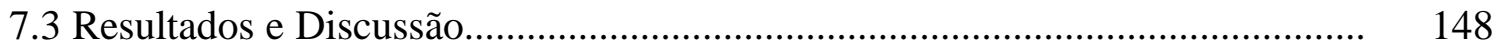

7.3.1 Estimativa dos atributos do solo pela resposta espectral obtida com sensor

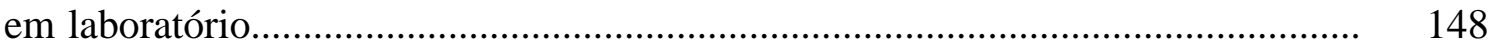

7.3.2 Estimativa dos atributos do solo pela resposta espectral de sensor orbital...... 154

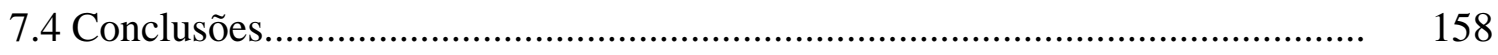

8 CONCLUSÕES GERAIS........................................................................ 170

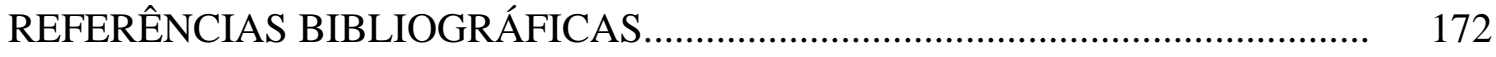




\title{
DADOS RADIOMÉTRICOS OBTIDOS NOS NÍVEIS TERRESTRE E ORBITAL NA AVALIAÇÃO DE SOLOS
}

\author{
Autor: PETERSON RICARDO FIORIO \\ Orientador: Prof. Dr. JOSÉ ALEXANDRE M. DEMATTÊ
}

\section{RESUMO}

As áreas agrícolas vêm se tornando cada vez mais tecnificadas, onde o conhecimento das características físicas, químicas e mineralógicas dos solos se torna imprescindível para maximizar a produtividade. O Brasil possui uma grande extensão territorial, sendo que a maior parte não possui mapas de solos compatíveis com as necessidades agrícolas. Torna-se necessário fornecer subsídios à pesquisa pedológica referente ao aperfeiçoamento de técnicas que venham auxiliar os levantamentos de solos, tornando-os mais ágeis e econômicos. Para tanto, foram traçados os seguintes objetivos: caracterizar o comportamento espectral de solos nos níveis de campo, laboratório e orbital; correlacionar as alterações dos solos ao longo de topossequências com o caráter espectral; verificar a separabilidade das unidades de mapeamento e quantificar atributos dos solos através das respostas radiométricas; avaliar a eficiência 
prática da técnica. O trabalho foi conduzido em Barra Bonita, SP, onde predominam diferentes unidades de solos tais como LATOSSOLOS, ARGISSOLOS, CAMBISSOLOS e NITOSSOLOS com texturas de arenosas a muito argilosas. Na área foram demarcados pontos para amostragem em forma de grade (100 x $100 \mathrm{~m})$. Todos os pontos de coleta foram georreferenciados, foram realizadas tradagens nas profundidades 0-20 e 80-100 cm. As amostras de terra foram encaminhadas ao laboratório para análises físicas, químicas. Foram obtidos dados espectrais através de espectroradiômetro em laboratório e campo. Foi realizado um mapa de solos detalhado pelo método convencional, incluindo a caracterização de perfis. Através dos dados espectrais obtidos nos níveis orbital e laboratório foram geradas equações discriminantes para os solos e equações lineares de regressão múltipla para vários atributos do solo. Os atributos dos solos foram comparados com valores estimados pelas equações e os valores determinados nas análises de laboratório para verificar a veracidade dos dados espectrais e a variabilidade da metodologia proposta. $\mathrm{Na}$ medida em que ocorrem alterações dos solos ao longo de uma topossequência, o comportamento espectral detectado pelos sensores, se altera. A análise descritiva das curvas espectrais descritas em literatura fornece poucos detalhes na discriminação de solos. É possível discriminar solos por sensor terrestre e orbital com 81 e $40 \%$ de acerto respectivamente. A estimativa de teores de ferro por sensores terrestre e orbital auxilia na classificação de solos. É possível quantificar atributos do solo como areia, argila e ferro por sensores em laboratório, e, com menor índice de significância por sensores orbitais. 


\title{
RADIOMETRIC DATA OBTAINED BY TERRESTRIAL AND ORBITAL LEVELS IN THE EVALUATION OF SOILS
}

\author{
Author: PETERSON RICARDO FIORIO \\ Adviser: JOSÉ ALEXANDRE M. DEMATTÊ
}

\section{SUMMARY}

The agricultural areas are becoming more and more technified, where the knowledge of the physical, chemical and mineralogical characteristics of soils becomes indispensable to maximize crop productivity. Brazil possesses a great territorial extension, and most of the areas do not possess soil maps compatible with the agricultural needs. Modern technological improvements signal the necessity of supplying data to soil research, especially those areas regarding soil survey, with the objective of turning soil survey more agile and economic. The following objectives were traced: characterize the spectral behavior of soils in field, laboratory and orbital levels; correlate the alterations of soils along toposequences with the spectral character; verify the discrimination of mapping units and quantify attributes of the soils through their spectral responses; evaluate the practical efficiency of the technique. The work was done 
in Barra Bonita, SP, where Oxisol, Alfisol, Inceptisol e Ultisol with textures of sandy to very loamy dominate. In the study area, samples were taken following a 100 x $100 \mathrm{~m}$ grid. All the points were georeferenced and soil samples were obtained in the depths 020 and $80-100 \mathrm{~cm}$. The soil samples were taken to the laboratory for physical and chemical analyses. After that, the spectral data were obtained using a spectroradiometer in laboratory, field and orbital levels. A detailed soil maps was done by the conventional method, including the characterization of profiles. Through the spectral data obtained in the orbital and laboratory levels, discriminant equations were generated for the soils and linear equations of multiple regression for several attributes of the soil. The soil attributes were compared with values quantified by the equations and values determined in laboratory analyses to verify the accuracy of the spectral data and the variability of the methodology proposal. As the soils modifications occur along a toposequence, the spectral behavior detected by the sensors becomes different. The descriptive analysis of the spectral curves described in literature supplies few details of soil discrimination. It is possible to discriminate soils by terrestrial and orbital sensors with 81 and $40 \%$ of success, respectively. The estimation of the iron content by terrestrial and orbital sensors aids in the classification of soils. It is possible to quantify attributes of the soil as sand, clay and iron using a sensor in the laboratory, and, with smaller accuracy by orbital sensors. 


\section{INTRODUÇÃO}

O uso intensivo dos solos brasileiros demanda um conhecimento mais pormenorizado das suas propriedades físicas, químicas, biológicas e mineralógicas. Por muitos anos, esforços têm sido concentrados em levantamentos pedológicos, mas por diversos motivos, a maioria dos Estados contam com levantamentos de baixa expressão cartográfica, como os de reconhecimento de alta intensidade. Poucas áreas possuem levantamentos nos níveis detalhado ou semidetalhado, os quais podem ser utilizados para projetos agropecuários mais específicos.

Traçando-se um comparativo, nos Estados Unidos da América a taxa de mapeamento de solos varia de 120 a 240 ha por dia, para levantamentos detalhados, ou 288.000 ha levantados anualmente (Morse, 1999). No Brasil, o mais recente material refere-se ao mapa de reconhecimento de solos do Estado de São Paulo (nível de reconhecimento), publicado por Oliveira et al. (1999), sendo este uma compilação de dados anteriormente cartografados. Além deste, os Estados brasileiros contam, na sua maioria, com mapas de reconhecimento de solos, em escalas de publicação em torno de 1:500.000, ou exploratórios, com escala cartográfica menor que 1:1.000.000. Dentre todos, apenas o Estado de São Paulo possui mapas com expressão cartográfica maior, com 22 quadrículas mapeadas em escala de 1:100.000. Observa-se, portanto, a grande 
disparidade entre os dois países que, no entanto, buscam a mesma meta: produzir mais alimentos e fibras, com menor custo e reduzido impacto ambiental.

Uma das técnicas que pode auxiliar nesse mapeamento é o sensoriamento remoto, sendo que a fotopedologia é a mais antiga e utilizada até os dias de hoje. Com o advento de novos sensores de detecção de informações ambientais, técnicas mais modernas começaram a se desenvolver. Neste aspecto, o estudo do caráter espectral vem promovendo uma série de trabalhos que demonstram sua potencialidade na caracterização e discriminação de solos.

Com a evolução dos sensores remotos e sistemas computacionais, a utilização da integração entre a análise de imagens orbitais e sistemas de informações geográficas tem sido utilizada como meio de facilitar estes levantamentos.

Os estudos iniciaram-se com fotografias obtidas de grande altitude, passando para os sensores multiespectrais MSS, e atualmente os sensores TM-Landsat e HRVSPOT. A curto prazo, existe uma clara tendência da melhoria da resolução espectral dos sensores orbitais. Já encontra-se em operação sensores hiperespectrais como o ASTER (Advanced Spaceborne Thermal Emission and Reflection Radiometer), com quatorze canais distribuídos nas faixas do visível, infravermelho próximo e infravermelho termal. Entre 2000 e 2001, sensores com mais de 100 canais estarão gerando dados para uma comunidade de usuários caracterizada por uma enorme diversidade de aplicações nos mais diferentes campos do conhecimento e, dentre eles, o mapeamento pedológico. Torna-se, portanto, imprescindível o desenvolvimento de metodologias para melhor utilização desta nova tecnologia. 
Os estudos ora desenvolvidos têm a importância de comprovar, primeiramente, a potencialidade dessa técnica embora, a maioria dos trabalhos tenham se preocupado com o estudo e caracterização dos solos, desconectados de uma de suas principais aplicações: o levantamento e mapeamento.

No Brasil, o monitoramento dos solos por meio de imagens orbitais pode ser de grande utilidade, haja visto sua extensão territorial, e enorme diversidade de solos, assim como a ocorrência de regiões de desenvolvimento agrícola contrastante.

Entretanto, poucos são os trabalhos que procuram caracterizar os solos em níveis categóricos mais detalhados utilizando os dados do TM-Landsat, apesar de seu potencial comprovado por trabalhos nacionais e internacionais (Myers, 1975; Westin \& Frazee, 1976; Myers, 1983; Agbu et al., 1990; Vettorazzi \& Couto, 1990; Rocha, 1993; Nanni, 1995; Nanni \& Rocha, 1997).

Além deste aspecto, a utilização do sensoriamento remoto tem grande potencial no complemento das informações necessárias para o melhor desenvolvimento agrícola junto à recentemente denominada agricultura de precisão (Moran et al., 1997).

A questão básica levantada para o desenvolvimento deste trabalho foi: “Teria o sensoriamento remoto, utilizando-se de dados de reflectância obtidos nos níveis laboratorial e orbital, condições de discriminar solos e quantificar seus atributos auxiliando, desta forma, os procedimentos adotados para levantamentos pedológicos?" A hipótese a ser testada é a de que há possibilidade de discriminação dos solos bem como estimativa de seus atributos, uma vez que cada solo, como indivíduo, apresenta atributos diferenciadores, que por sua vez, podem alterar a energia eletromagnética refletida. 
Para tanto, este trabalho foi conduzido em uma área agrícola para avaliação espectral de solos, tendo como principais objetivos:

- Caracterização do comportamento espectral de solos nos níveis de laboratório, campo e orbital, e sua correlação com as propriedades físicas e químicas.

- Correlacionar as alterações dos solos ao longo de topossequiências com o caráter espectral, para os três níveis de aquisição;

- Verificar a separabilidade das unidades de mapeamento através das respostas radiométricas;

- Testar uma metodologia para aplicação dos dados espectrais como auxílio no levantamento de solos convencional;

- Verificar a possibilidade de quantificação dos atributos dos solos utilizando sensores terrestre e orbital. 


\section{REVISÃO DE LITERATURA}

\subsection{Sensoriamento remoto orbital nos levantamentos pedológicos}

As imagens da terra, obtidas por satélites Landsat, começaram a ser adquiridas a partir de julho de 1975 (Westin \& Frazee, 1976). Tais imagens, segundo os autores, são aplicáveis aos levantamentos de solos.

O inventário sobre solos pode ser realizado pelos métodos convencionais como os sistemas de classificação de solo determinado por Brasil (1960) e Soil Survey Staff (1975), respectivamente para o Brasil e para Estados Unidos. Por outro lado, o solo também pode ser avaliado por métodos mais modernos como os iniciados por Goosen (1968), Westin \& Frazee (1976) e Venkataratnam (1980). Geralmente os métodos convencionais são trabalhosos, caros e demorados, quando comparados com as modernas técnicas de mapeamento (Dwivedi, 1985; Singh \& Dwivedi, 1986). Da mesma forma que a classificação de solos evoluiu no Brasil (Camargo et al., 1987; Embrapa, 1999) e nos EUA (Soil Survey Staff, 1994), as técnicas auxiliares também o fizeram. Neste aspecto, o sensoriamento remoto vem se destacando como uma importante ferramenta, que pode auxiliar no reconhecimento de solos (Demattê, 1999). 
A incorporação de imagens de satélites dentro de um programa de mapeamento de solos, para delineamento de seus limites, tem se tornado extremamente significativo (Agbu et al., 1990). Embora o perfil do solo não possa ser avaliado através de dados remotamente sensoriados, comentam os autores, as características fisionômicas da terra, indicativas das condições de superfície e subsuperfície, podem ser.

Neste sentido, Madeira Netto et al. (1993a) comentam que tais imagens tem sido muito utilizadas de maneira indireta nos estudos pedológicos, onde procura-se relacionar os solos através de atributos de uma imagem que são caracterizadoras das unidades de paisagem.

O uso de sensores remotos multiespectrais em conjunto com técnicas de análise computacional para estudo de solos, tem efetivamente auxiliado em trabalhos de levantamento, podendo esta tecnologia, ser utilizada no mapeamento das condições de superfície da terra sobre pequenas áreas, com razoável grau de precisão (Kristof \& Zachary, 1974).

As imagens de satélite, segundo Hilwig et al. (1974), são influenciadas pelas condições da superfície da erra e secundariamente por fatores tais como absorção atmosférica, irregularidades do sistema, etc. As condições de superfície terrestre incluem a cobertura vegetal (tipo e quantidade), a umidade da superfície, textura superficial do solo, cor da superfície do solo, erosão, afloramentos rochosos, tamanho e forma das rampas, etc.

Myers (1975) comenta que a maior parte das informações pedológicas podem não vir diretamente das imagens, mas sim de informações associadas, além de trabalhos de campo e o conhecimento do pesquisador. 
Através de mapas preliminares de solos produzidos através de sensores multiespectrais é possível acelerar os processos de levantamento de solos de uma região em considerável extensão, podendo adicionar características a serem obtidas através de cuidadosa análise das propriedades das imagens (Myers, 1983). Da mesma forma, a interpretação visual das imagens orbitais traz resultados bastante satisfatórios, com a possibilidade de estratificação da região estudada em áreas homogêneas, tornando possível o planejamento global das atividades de campo e diminuindo o número de observações, que acarreta redução dos trabalhos de levantamento, com aumento da precisão dos traçados de limites entre as unidades de solos (Vettorazzi \& Couto, 1990).

Westin \& Frazze (1976) comparando mapas de paisagem obtidos através de imagens Landsat, com os mapas de associação de solos corrente mostrou que, mais unidades de solos foram separadas com a utilização das imagens combinadas com checagens de campo, do que as encontradas nos mapas convencionais de associação de solos, fato este também registrado por Singh \& Dwivedi (1989). Segundo esses autores, um mapa de solos em pequena escala foi obtido através de interpretação visual e delineamento de unidades fisiográficas sobre imagens MSS - Landsat conjuntamente com dados relativos à litologia, topografia e dados coletados a campo, obtendo 93,3\% de precisão com respeito a delineamento dos limites entre as unidades dos solos.

Segundo Hilwig et al. (1974), na maioria dos casos, a parte superficial dos solos é reflexo das condições que ocorrem no interior do perfil, os autores comentam existir uma forte razão da análise do uso de imagens MSS na condução de levantamentos de solos. 
A delimitação de determinadas unidades de mapeamento, que nem sempre são visíveis nas fotografias pancromáticas devido à cobertura vegetal e ao uso da terra, podem ser realizadas com maior facilidade através do uso de imagens multiespectrais (Mulders \& Epema, 1986).

Através de análise visual preliminar, fundamentada nos elementos fotointerpretativos, Santos et al. (1990) obtiveram a individualização de unidades fisiográficas em imagens TM-Landsat espectralmente homogêneas, que possibilitaram a confecção de mapas preliminares de solos, a nível de reconhecimento de alta intensidade $(1: 100.000)$.

Utilizando métodos fotointerpretativos, Vettorazzi \& Couto (1990) delimitaram unidades fisiográficas sobre imagens TM-Landsat cópias papel em duas escalas, através da compartimentação de áreas obtidas pela análise visual do relevo, sombras e textura fotográfica e da rede de drenagem superficial decalcada. Tais unidades serviram para a elaboração de mapas de solos em duas escalas, cujo objetivo foi o de analisar a exatidão de classificação dos mapas em relação a uma verdade terrestre. Os autores concluíram haver diferenças significativas entre as escalas e entre os solos para cada escala, ressaltando a superioridade técnica da escala 1:100.000 em relação à 1:250.000, para este tipo de trabalho.

Estudos sobre a capacidade do TM - Landsat para preparo de vários tipos de mapas de solos foram realizados na Índia por Biswas \& Singh (1991). Os resultados permitiram concluir que as possibilidades da composição colorida utilizada para a avaliação do solo e dos recursos da terra são grandes, com elevada redução no tempo utilizado para o mapeamento de grandes áreas. Além disso, estabeleceram que, em 
comparação com fotografias aéreas, as imagens TM possuem vantagens para diferenciação do material de superfície mas, quando são conjuntamente utilizadas para o mesmo fim, o trabalho de mapeamento torna-se mais eficaz. Os autores concluem ainda que as imagens orbitais tornam-se boas ferramentas especialmente para a avaliação dos solos e dos recursos da terra em geral.

Em estudos comparativos entre fotointerpretação de imagens MSS/RBV Landsat e fotografias aéreas, para obtenção de unidades fisiográficas utilizadas no mapeamento convencional de solos à nível de reconhecimento com detalhe, Donze li et al. (1983) concluíram que a utilização de tais imagens, em associação com imagens de radar na escala 1:250.000, possibilitou a definição de unidades de mapeamento com estreita correlação.

A importância da utilização de dados remotamente sensoriados no nível orbital para levantamentos pedológicos é destacado por Nanni (1995) e Nanni \& Rocha (1997), que dispuseram de imagens TM-Landsat e HRV-Spot na diferenciação de unidades fisiográficas através de análise multivariada.

Coleman et al. (1991) descrevem que, em um contínuo esforço que possa auxiliar no desenvolvimento de técnicas, tanto para os atuais como para os futuros sensores orbitais, podem ser utilizados mais efetivamente no preparo de mapas de solos, capacidade de uso e de produção.

Atualmente o processamento digital de imagens orbitais é aplicado com sucesso em diversas áreas, como em levantamentos geológicos (Vincent, 1999), no inventário e levantamento do uso da terra, visando a discriminação e monitoramento de culturas (Borges et al., 1993; Zermiani et al., 1999). 
Os recentes resultados de pesquisas têm se mostrado promissores no que diz respeito à utilização das técnicas de sensoriamento remoto como apoio em levantamento de solos. Isto tem estimulado estudos quanto à influência de diferentes propriedades e características dos solos em relação à sua reflectância, tornando-se uma ferramenta das mais importantes na aplicação das Geociências (Epiphanio \& Formaggio, 1990).

Os métodos para estudo de solos, conforme Andronikov \& Dobrovolskiy (1991), estão baseados no fato de que diferentes solos e tipos de culturas agrícolas absorvem e emitem radiação eletromagnética em diferentes comprimentos de ondas do espectro eletromagnético. Como resultado, cada complexo solo-agricultura possui um padrão de resposta espectral, como mostrado em fotografias aéreas e imagens orbitais. Os autores comentam ainda que a acurácia na identificação de áreas ocupadas por diferentes tipos de solos está aumentando, como também o seu conteúdo, especialmente com respeito à estrutura de sua cobertura, tornando o trabalho de campo menos dispendioso e em tempo reduzido.

Demattê et. al. (2001) compararam várias metodologias para levantamento de solos e observaram que os métodos utilizando sensoriamento remoto produziram mapas muito similares ao levantamento detalhado, realizado pelo método tradicional. Ainda segundo os autores o uso de fotografias, mapas planialtimétricos e informações de radiometria de laboratório com análise estatística apresentou o melhor resultado.

No Brasil, o monitoramento dos solos por meio de imagens orbitais poderia ser de grande utilidade, haja visto sua extensão territorial, sua enorme diversidade de solos, assim como a ocorrência de regiões de desenvolvimento agrícola contrastante. Entretanto, poucos são os trabalhos que procuram caracterizar os solos em níveis 
taxonômicos mais elevados utilizando os dados do TM/Landsat, apesar de seu potencial comprovado por trabalhos internacionais. Além deste aspecto, a utilização do sensoriamento remoto tem grande potencial no complemento das informações necessárias para o melhor desenvolvimento agrícola junto à recentemente denominada agricultura de precisão (Moran et al., 1997).

\subsection{Caracterização pedológica com auxilio da reflectância}

A medida dos valores de reflectância de um corpo ou alvo ao longo do espectro eletromagnético é definida como o seu comportamento espectral. Como diferentes alvos

podem apresentar respostas espectrais características, podemos, devido a esta propriedade, identificá-los na natureza (Sabins Jr., 1987). Dentre os diversos alvos passíveis de serem observados, o solo tem merecido especial atenção por muitos pesquisadores. Os trabalhos que surgiram ao longo do tempo sobre o comportamento espectral dos solos definem sua real importância como meio de identificação e de sua caracterização (Rosa, 1990).

Os sistemas de sensoriamento remoto detectam a intensidade da radiação eletromagnética emitida, refletida ou espalhada por um objeto em um comprimento de onda característico e particular. Em decorrência das condições de terreno, ocorrem variações na intensidade de radiação eletromagnética que são comumente manifestadas pela variação de brilho e luminância sobre as imagens (Sabins Jr., 1987).

Segundo Stoner \& Baumgardner (1981), a reflectância do solo é uma propriedade cumulativa derivada do comportamento espectral inerente da combinação 
heterogênea de seus componentes tais como o tamanho de partícula, estrutura do solo, rugosidade superficial, umidade, porcentagem de matéria orgânica, quantidade de minerais carbonatados, presença ou não de quartzo e óxidos de ferro. A correlação entre os constituintes dos solos e sua reflectância tem sido apresentados por diversos autores (Bowers \& Hanks, 1965; Myers, 1975; Gerbermann \& Neher, 1979; Cipra et al., 1980; King, 1985; Sabins Jr., 1987; Frazier \& Cheng, 1989; Demattê, 1995).

Segundo Baumgardner \& Stoner (1982), muitos pesquisadores têm se defrontado com o dilema de não serem capazes de entender ou explicar as causas de muitas das variações na reflectância da superfície dos solos. Este dilema é fato desde os primeiros estudos de solos com dados multiespectrais de sensores tanto montados em plataformas aéreas como espaciais. Alguns novos sensores, comentam os autores, por possuírem diferentes bandas espectrais possibilitam, através da análise digital de seus dados, classificarem cenas da paisagem em diversas categorias espectralmente separáveis, com base nas diferenças de fácil percepção existentes entre uma e outra banda espectral dos sensores.

Coleman et al. (1991) descreveram que nos estudos pedológicos, utilizando-se respostas espectrais é necessário, para tal, um melhor entendimento das relações existentes entre a reflectância espectral dos solos e os importantes parâmetros diferenciadores dos mesmos. Os autores observam ainda que, se bandas espectrais significativamente associadas com específicas propriedades dos solos podem ser identificadas, então acurada estimativa das propriedades dos solos, através de dados de reflectância espectral, poderá ser realizada para facilitar o delineamento de unidades de solos. 
Recentes avanços na tecnologia de sensores remotos têm demonstrado sua importância ao obter a radiância com alta resolução espectral para cada posição (pixel), sendo um dos exemplos de maior evolução nesta área o Airbone Visible Infrared Imaging Spectroradiometer, designado de AVIRIS (Vane et al., 1993). Tal instrumento permite obter imagens espectrais de radiação refletida no intervalo 400 a $2500 \mathrm{~nm}$ com resolução de $10 \mathrm{~nm}$, e com 224 bandas.

Baptista et. al. (1999) manipularam matematicamente bandas do sensor hiperespectral AVIRIS, visando a discretização espacial dos diferentes teores de argila em uma mancha de solo exposto, obtendo um alto coeficiente de determinação $(0,80)$.

Com tal tecnologia, é de se esperar um maior detalhamento espectral indicando inclusive bandas de absorção importantes na identificação de rochas, minerais, vegetação e solos, desde que se considere que a resolução espacial seja suficiente para representar cada tipo de superfície para cada dado espectral. Entretanto, os dados do AVIRIS continuam sendo ainda muito restritos, tendo-se por outro lado, farta disposição de dados do satélite Landsat.

A identificação de solos e inclusive o seu mapeamento tem sido feito experimentalmente através da reflectância espectral em sensor instalado em avião por Fedchenko et al. (1976). Posteriormente, Weismiller et al. (1977) estudaram imagens MSS/Landsat como meio para acelerar e melhorar a qualidade de mapas e levantamento de solos. Mais recentemente, Epemea (1986) e Saha et al. (1990) analisaram imagens TM/Landsat no mapeamento de solos. Por sua vez, Palacios-Orueta \& Ustin (1996) verificaram a importância do AVIRIS no estudo de solos, comparando com dados de 
laboratório, notando grande correlação, e concluindo que os solos puderam ser discriminados usando os resultados de ambos os níveis de aquisição de dados.

De acordo com Epiphanio et al. (1992), a reflectância, assim como outras propriedades importantes do solo, é influenciada não somente pela composição química dos seus constituintes, como também pelo tamanho, arranjamento das partículas e presença de água no solo, além de sua textura e estrutura.

Estudos de Condit (1970) mostraram que as curvas espectrais dos solos podem apresentar 3 Tipos. Posteriormente foram incorporados mais 2 Tipos por Stoner \& Baumgardner (1981), que utilizaram equipamentos menos limitados. Os Tipos de curvas são listados a seguir.

Tipo 1: exibem preferencialmente baixa reflectância, com uma declividade aumentando suavemente, o que lhes imprime um formato côncavo característico, desde $320 \mathrm{~nm}$ até cerca de $1000 \mathrm{~nm}$. Segundo Stoner \& Baumgardner (1981), de 1000 a $1300 \mathrm{~nm}$ a declividade é praticamente constante para estes solos, uma característica não observada por Condit (1970), devido ao intervalo espectral limitado dos aparelhos usados.

Tipo 2: são caracterizadas por uma declividade geralmente decrescente até $600 \mathrm{~nm}$, seguida por um mergulho de 600 a $700 \mathrm{~nm}$. A declividade decrescendo acima de 0,75 $\mu \mathrm{m}$. O resultado é uma curva de formato convexo desde o visível até $1300 \mathrm{~nm}$.

Tipo 3: mostra uma declividade íngreme levemente decrescente em 0,60 $\mu \mathrm{m}$, seguindose um leve mergulho de 620 a $740 \mathrm{~nm}$, com a declividade decrescendo até quase zero ou mesmo tornando-se negativa de 760 a $880 \mathrm{~nm}$, a declividade cresce com o aumento dos comprimentos de onda. 
Tipo 4: essas curvas exibem uma declividade decrescente desde 880 até $1000 \mathrm{~nm}$, com a declividade decrescendo até zero, e tornando-se negativa de 1000 a 1300 nm.

Tipo 5: essas curvas apresentam uma declividade decrescente até zero quando passa a negativa de 750 a $1300 \mathrm{~nm}$.

Em geral, os Tipos de curvas se distinguem entre si, sendo que o Tipo 1 apresenta um alto teor de matéria orgânica (> $2 \%$ ), que diminui sua reflectância, e com textura moderada a fina. Solos com curvas do Tipo 2 apresentam baixo teor de matéria orgânica e médio teor de ferro (1-4 \%), tendem a ser melhor drenados e mais pobres em matéria orgânica que solos do Tipo 1. São observados conteúdos moderadamente altos de ferro livre, alto teor de matéria orgânica e textura moderadamente grosseira na maioria dos solos que apresentam curvas do Tipo 3. O quarto Tipo foi observado em solos com altos conteúdos de matéria orgânica e ferro. Solos que mostram o quinto Tipo de curva apresentam altos conteúdos de ferro e textura fina, com baixos teores de matéria orgânica (Stoner \& Baumgardner, 1981).

Segundo Moraes (1996), enquadram-se na curva do Tipo 1 os solos Podzolizados e os Cambissolos, na do Tipo 2 o Latossolo Amarelo e a Areia Quartzosa, na do Tipo 3 o Latossolo Una e o Latossolo Vermelho-Amarelo, na do Tipo 4 o Latossolo VermelhoEscuro e no Tipo 5 o Latossolo Roxo e o Latossolo Roxo Una.

Segundo Demattê (1995), através de análises descritivas dos Tipos de curvas espectrais de acordo com Condit (1970) e Stoner \& Baumgardner (1981), foi possível separar os solos estudados em dois grupos, os originados de rochas básicas com curvas do Tipo 3 e 4 para Brunizem Avermelhado e Tipo 5 para Latossolo Roxo e Terra Roxa 
Estruturada, e os solos originados de rochas ácidas com curvas do Tipo 3. Todas as curvas apresentam baixa reflectância.

As rochas básicas dão origem aos solos de albedo mais baixo, seguidas pelas intermediárias e as ácidas, cujos valores de reflexão, em geral são mais altos (Formaggio et al., 1996).

As curvas espectrais das camadas superficiais, dos solos originados de rochas básicas (basalto), são semelhantes às curvas da segunda camada, porém com maior albedo (Demattê \& Garcia, 1999).

Os Mollisolos podem ser distinguidos facilmente dos Alfisolos por curvas de reflectância (Cipra et al., 1971). Segundo esses mesmos autores, um Entisolo arenoso de cor clara apresenta curvas espectrais similares aos Alfisolos.

Formaggio et al. (1996) testando em laboratório 109 amostras de superfície e subsuperfície, de 13 classes de solos, obtiveram quatro padrões de curvas espectrais, sendo identificados pela forma das curvas e pela intensidade de reflectância influenciados pelo teor de óxidos de ferro, teor de matéria orgânica e material de origem. Os solos estudados foram agrupados, segundo o critério de comportamento espectral.

Em relação aos solos tropicais Valeriano et al. (1995) relatam que raramente temse estudado suas características do ponto de vista do sensoriamento remoto. Comentam ainda que os padrões de reflectância de diferentes tipos de solos são de fundamental importância para muitas aplicações a respeito das técnicas de sensoriamento remoto, sendo que os levantamentos sobre a reflectância, caracterização e experimentação dos principais solos brasileiros podem trazer dados úteis para as atividades ligadas ao sensoriamento remoto. 
Epiphanio \& Formaggio (1988) comentam que a análise quantitativa de imagens digitais sobre o comportamento espectral de alvos deve ser feita com dados de reflectância, por ser o meio mais adequado para a sua caracterização e não com números digitais (ou níveis de cinza). Comentam ainda que na transformação de tais números em valores de reflectância torna-se necessária a eliminação do efeito da atmosfera. Para tanto, devem ser utilizadas equações adequadamente adaptadas para cada banda utilizada na produção das imagens digitais.

Demattê (1995) utilizou equações discriminantes para estabelecer classes de solos derivados de rochas eruptivas básicas e ácidas utilizando como variáveis preditoras 13 bandas selecionadas dentro do espectro eletromagnético ótico. Os resultados obtidos foram bastante satisfatórios, podendo-se estabelecer classes de solos através das equações.

Nanni (2000) verificou a possibilidade de discriminar solos através de análises estatística utilizando informações radiometricas, nos níveis de laboratório, com 22 bandas e 13 alturas, e orbital com as bandas 1, 2, 3, 4, 5 e 7 do TM-Landsat 5. Ainda segundo o autor o acerto global na discriminação de solos para equações de laboratório foi de $90,7 \%$ e para as equações orbitais o acerto global foi de $50 \%$.

Estudos recentes (Galvão \& Vitorello, 1998) mostram que os solos podem ser avaliados também pela denominada "linha do solo". Segundo Huete (1989) e Baret et al. (1993), os dados de reflectância de um solo, sem a interferência da vegetação, quando relacionada às bandas 4 e 3 do TM, dispõem-se ao longo de uma linha imaginária a 45 graus do eixo. Baret et al. (1993) destacam ainda que a rugosidade e umidade interferem nos resultados da linha do solo. 
Além disso, o sensoriamento remoto vem sendo cada vez mais estudado como técnica auxiliar em pedologia como verificado por Baumgardner et al. (1985) e Irons et al. (1989). Além disso, Huete (1996) destaca a importância dos estudos espectrais em laboratório como base para o nível orbital. Odeh \& MacBratney (2000) comprovaram que a utilização do sensoriamento remoto e técnicas estatísticas, foram as mais eficientes e menos onerosas, na avaliação de solos.

\subsection{Relação entre dados espectrais e atributos dos solos}

Uma série de trabalhos têm sido desenvolvidos na área de interpretação das feições de absorção e da própria curva espectral tanto em minerais de rochas (Grove et al., 1992 e Vitorello \& Galvão, 1996) como em solos (Epiphanio et al., 1992).

\section{a) Minerais de argila silicatados}

Em estudo em laboratório, Bowers \& Hanks (1965) observaram que as reflectâncias para a caulinita foram maiores que as da bentonita. Atribuem o ocorrido às características de microestrutura e baixa densidade da bentonita. Com relação ao tamanho de partículas, esses autores observaram que, à medida em que diminui o seu tamanho, aumenta a reflectância para os minerais de argila caulinita e bentonita.

Em relação aos minerais de argila de solos, uma parte dos trabalhos tem sido direcionado ao estudo da caulinita e minerais 2:1, entre eles a montmorilonita. A curva de reflectância para tais minerais apresenta bandas centradas em 1400 e 2200 nm, devido às vibrações das moléculas de água e grupos $\mathrm{OH}^{-}$das estruturas destes minerais. A montmorilonita, como apresenta moléculas de água entre as camadas unitárias, bandas 
de absorções fortes ocorrem também em 1400 e 1900 nm (Hunt \& Salisbury, 1970), pois a banda em 1900 nm é devida às vibrações de moléculas de água, também verificado por Ben-Dor et al. (1999).

Sendo assim, solos contendo dominância de caulinita apresentam bandas de absorção fracas em 1400 e $1900 \mathrm{~nm}$. No caso da maior presença de minerais 2:1, como a montmorilonita, a intensidade das bandas de absorção em 1400 e em 1900 nm vai ser bem maior do que num solo caulinítico, como aliás já foi constatado por Demattê (1995) e Demattê et al. (1998b) trabalhando com Brunizem Avermelhado. Da mesma forma Grove et al. (1992) verificaram que minerais do grupo 2:1 como a vermiculita também apresentam banda forte em $1900 \mathrm{~nm}$.

Apesar de haver coincidência na feição de absorção em 2200 nm para estes dois minerais, a forma das bandas é diferente. Hauff et al. (1990) e, posteriormente, Kruse et al. (1991) discutiram a identificação da caulinita e da esmectita em materiais contendo a mistura destes minerais, assim como aventaram a possibilidade de quantificação da caulinita considerando sua feição de absorção assimétrica em $2200 \mathrm{~nm}$. Os solos com predominância de minerais 2:1 não apresentam feição nítida da caulinita em 2200 nm, justamente por que está atuando o mineral 2:1 conjuntamente nesta banda. O mineral 1:1 apresenta o "degrau" característico no formato da banda de absorção (Demattê et al., 1998 a), enquanto que o mineral 2:1 também promove absorção nesta banda, mas sem o degrau.

\section{b) Óxidos de ferro}

Tanto a goethita como a hematita são os óxidos de ferro de grande ocorrência em ambiente tropical, e são formados através da pedogênese com a oxidação do $\mathrm{Fe}^{2+}$ dos 
minerais primários. A dominância de uma forma ou de outra deve-se a fatores pedoclimáticos, se bem que ambos minerais podem ocorrer num único solo (Schwertmann \& Taylor, 1977; Macedo \& Briant, 1987).

Tais minerais apresentam características distintas ao longo da curva espectral, características estas que são responsáveis pela cor, avermelhada para hematita e parda amarelada e amarelada, para goethita.

Scherman \& Waite (1985) determinaram as posições das feições de absorção nas curvas espectrais, assim como as intensidades relativas das diversas formas destes óxidos.

Stoner \& Baumgardner (1981) concluíram que, por volta de 700 e de 900 nm, podem ser vistas as bandas de absorção devidas à influência do $\mathrm{Fe}_{2} \mathrm{O}_{3}$. Em solos pobres em ferro, pode ser observada uma faixa mais estreita de absorção em $900 \mathrm{~nm}$.

Uma das transições eletrônicas está centrada em $530 \mathrm{~nm}$ para hematita e em 480 nm para a goethita. Kosmas et al. (1984) verificaram que a hematita absorve mais energia que a goethita principalmente na faixa dos $500 \mathrm{~nm}$, posteriormente comprovado por Demattê \& Garcia (1999), verificando este efeito em solos desenvolvidos de basalto.

Demattê (1999) trabalhando com solo ricos em hematita como o Brunizém Avermelhado, Terra Roxa Estruturada e Latossolo Roxo, estabeleceu valores de intensidade de reflectância bem menor do que os apresentados por solos com teores menores, como o Latossolo Vermelho-Escuro e os Podzólicos Vermelho-Escuros.

Frasier (1991) demonstrou as relações existentes entre os índices derivados das bandas do TM para as formas de ferro nos solos. Tal autor verificou a possibilidade de identificação dos tipos de óxidos, se hematita ou goethita, em regiões áridas usando a 
relação TM3/TM1. Esta mesma relação foi usada também por Okamoto et al. (1993) para avaliar depósitos de sedimentos avermelhados.

Os minerais pesados e opacos, muito abundantes em solos derivados de rochas eruptivas básicas, entre eles a magnetita e a ilmenita, devido à sua opacidade, alteram todo o espectro óptico reduzindo a reflectância (Hunt et al., 1971). As absorções responsáveis pela opacidade têm sido atribuído por Streus \& Wood (1979) à transferência de carga entre os íons de ferro e entre os íons de ferro e oxigênio.

Madeira Netto (1993) verificou que, para solos ricos em minerais opacos como a magnetita e a ilmenita, a reflectância normalmente decresce em quase toda a extensão da curva após a remoção da matéria orgânica.

Madeira Netto et al. (1993 b) comentam que as vibrações moleculares das hidroxilas presentes na caulinita e na gibbsita são responsáveis por bandas de absorção centradas respectivamente a 2205 e a $2265 \mathrm{~nm}$. A presença de magnetita e de ilmenita pode alterar as intensidades de absorção da caulinita e de gibbsita. Demattê (1995) observou que solos com teores semelhantes de ferro total mostraram diferenças significativas nas faixas de 400 a $700 \mathrm{~nm}$ e 800 a $1100 \mathrm{~nm}$ referentes ao ferro. $\mathrm{O}$ autor atribui essas diferenças, aos teores e às formas de ferro encontradas nos solos estudados.

\section{c) Matéria Orgânica}

As variações na intensidade da reflectância na curva espectral se devem ao teor da matéria orgânica num solo assim como à sua natureza. Um dos primeiros estudos sobre os efeitos da natureza da matéria orgânica na curva espectral foi feito por Obukhov \& Orlov (1964), que verificaram a baixa reflectância da curva espectral devida aos ácidos húmicos. Henderson et al. (1992) salientaram que tais efeitos se devem à 
grande variação molecular dos constituintes do ácido húmico, tais como os grupos fenólicos e seus produtos de oxidação, os aminoácidos e seus produtos de condensação. A natureza das relações entre a composição da matéria orgânica e a reflectância do solo não é ainda inteiramente entendida (Demattê et al., 1998c).

Os ácidos húmicos têm uma reflectância extremamente baixa $(<2 \%)$ em toda a curva espectral e os ácidos fúlvicos atingem uma reflectância máxima de $20 \%$ a 750 nm (Vinogradov, 1981). Demattê \& Garcia (1999) verificaram que os diferentes constituintes da matéria orgânica podem alterar diferenciadamente os dados espectrais, porém, alertam para as dificuldades em se detectar qual o elemento atuante.

Autores como Courault \& Girard (1988) verificaram que a remoção da matéria orgânica resultou num aumento na curva de reflectância em toda sua extensão, entre 400 e $2500 \mathrm{~nm}$, embora na faixa antes dos $1300 \mathrm{~nm}$ as diferenças sejam pequenas. Madeira Netto (1993) verificou que as alterações nas curvas espectrais em solos muito intemperizados após a remoção da matéria orgânica se deve a diversas combinações como no próprio teor de matéria orgânica, no teor de óxido de ferro, na presença ou não de minerais pesados e opacos.

Baumgardner et al. (1970) mostram que em quantidades superiores a $2 \%$, a matéria orgânica pode provocar um efeito de mascaramento na contribuição que os outros constituintes dão para a característica espectral do solo, na região refletiva do espectro eletromagnético. Entretanto, Epiphanio et al. (1992) determinaram um valor de 2,6\%, enquanto que Demattê (1995) chegou a observar que teores de até 2,9 \% não mascararam a contribuição de outros constituintes do solo. 
Mathews et al. (1973) relatam que o tipo de mineral de argila influencia a forma e a intensidade da curva de reflectância em toda a faixa de 500 a $2600 \mathrm{~nm}$. Obtiveram diferentes curvas espectrais para caulinita, nontronita e ilita. Estes autores também observaram que a faixa espectral entre 500 e $1200 \mathrm{~nm}$ foi a que melhor diferenciou, o mesmo solo, com e sem óxidos de ferro, no horizonte B. A remoção de matéria orgânica, por sua vez, proporciona um aumento de reflectância entre 400 e 1300 nm.

\subsection{Predição dos atributos dos solos através da suas resposta espectral}

A possibilidade de estender as medidas espectrais de solos, obtidas em condições de laboratório, para as condições de campo tem importantes implicações na aplicação de técnicas de sensoriamento remoto para levantamento de solos e monitoramento de degradação da terra (Stoner et al.,1980).

Baptista et al. (1999) salientam que todo trabalho envolvendo dados de sensoriamento remoto pode dar um rumo, mas as quantificações dos atributos dos solos necessitam ainda de trabalhos de campo para que os parâmetros obtidos pela manipulação das imagens possam ser correlacionadas com os obtidos in loco.

Montgomery (1976) apresenta uma correlação significativa, ao nível de $1 \%$, entre "matiz" e porcentagem de $\mathrm{Fe}_{2} \mathrm{O}_{3}$ e entre "valor" e porcentagem de argila ou teor de matéria orgânica.

Dados espectrais obtidos de oito solos do nordeste do Alabama, usando um espectrorradiômetro de campo, foram utilizados para avaliar a efetividade da reflectância espectral na diferenciação entre solos de propriedades semelhantes e identificar a melhor 
combinação de bandas espectrais na estimativa de propriedades dos solos selecionadas (Coleman et al., 1991). Altas correlações foram encontradas entre os dados espectrais e as variáveis dos solos estudados. Os solos típicos foram suficientemente diferenciados com base tanto nas propriedades espectrais como nas propriedades físicas e químicas dos solos. Os resultados indicaram que bandas selecionadas do espectro eletromagnético são importantes no desenvolvimento de modelos que poderão significativamente predizer propriedades dos solos através de dados espectrais.

Quando se deseja predizer as propriedades químicas dos solos através de uma medida espectral é inevitável o confronto com questões em relação ao conteúdo dos componentes do solo e a importância do fator de interação destes (Schreier, 1977). Enquanto isto é possível pela minimização do efeito de alguns fatores, no laboratório, por meios artificiais, as medidas espectrais obtidas por sensores aerotransportados são mais complexas de serem analisadas e correlacionadas com as propriedades dos alvos, uma vez que eles contêm o efeito integrado de todos os parâmetros.

Henderson et al. (1992) estudando a faixa espectral de 400 a $2500 \mathrm{~nm}$, concluíram que se pode prever teores de matéria orgânica em solos, porém, não a sua composição. A reflectância nas bandas do visível (425 a $695 \mathrm{~nm}$ ) foram as melhores correlacionadas com os teores de matéria orgânica de solos originados de mesmo material de origem.

Coleman \& Montgomery (1990) descrevem equações obtidas através de regressão multivariada entre dados espectrais e propriedades físicas e químicas dos solos que podem prever tais propriedades, mas estas são geograficamente dependentes, 
mesmo se são desenvolvidas a partir de informações obtidas de plataformas orbitais ou diretamente da superfície terrestre.

Em estudo sobre a possibilidade da utilização de dados de radiância espectral do TM-Landsat para diferenciação da superfície de solos com propriedades similares, Coleman \& Montgomery (1987) concluíram que o sensor possibilita a diferenciação dos solos de uma mesma ordem, mas sua resolução espacial ainda torna os resultados comprometedores em relação aos limites separativos. No entanto, o sensor não possibilita estabelecer equações de previsão das características dos solos com acurácia apresentando variabilidade menor que $40 \%$.

Por sua vez, Madeira Netto et al. (1993a) estabeleceram, através da relação entre bandas TM/Landsat, índices de hematita que foram desenvolvidos baseados na reflectância difusa de várias amostras de latossolos. Ao final, os autores conseguiram, através do índice, individualizar as classes Latossolo Vermelho-Escuro e Latossolo Vermelho-Amarelo de acordo com os teores de hematita contidos nas amostras superficiais de cada solo, definidos pelas imagens TM/Landsat.

Outros elementos como titânio, ferro e alumínio apresentaram correlação com os dados digitais em níveis de cinza das bandas 3, 4, 5 e 7 do TM/Landsat (Riedel et al., 1988). Por outro lado, Epiphanio \& Formaggio (1988) comentam que a análise quantitativa de imagens digitais sobre o comportamento espectral de alvos deve ser feita com dados de reflectância, por ser o meio mais adequado para a sua caracterização e não com números digitais em níveis de cinza. Tais resultados indicam a necessidade de mais avaliações comparativas entre esses dois dados. 
Demattê (1995), através de dados radiométricos obtidos em laboratório e utilizando espectrorradiômetro IRIS estabeleceu, a caracterização do comportamento espectral de cinco solos do Estado do Paraná desenvolvidos sobre rochas eruptivas básicas e ácidas. Dentre os resultados o autor destaca que, através da análise das feições de absorção e de intensidade de reflectância, foi possível separar os diferentes solos.

Demattê \& Garcia (1999) estabeleceram equações de regressão multivariada para predição de diversos atributos de solos desenvolvidos sobre rochas eruptivas. Dentre os atributos analisados, as melhores correlações foram encontradas para os teores de ferro, argila, $\mathrm{Al}_{2} \mathrm{O}_{3}$, titânio, manganês e caulinita.

Nanni (2000) utilizando 22 bandas e 13 alturas para os dados de radiometria de laboratório, verificou para areia, silte, argila, matéria orgânica, $\mathrm{SiO}_{2}, \mathrm{TiO}_{2}$ e $\mathrm{Fe}_{2} \mathrm{O}_{3}$ altos coeficientes de determinação, com valores de $\mathrm{r}^{2}$ acima de 0,91. Ainda segundo o autor utilizando as bandas TM-Landsat foi possível obter coeficientes de determinação superiores a 0,8 para argila, $\mathrm{SiO}_{2}, \mathrm{TiO}_{2}$ e $\mathrm{Fe}_{2} \mathrm{O}_{3}$.

Nanni \& Demattê (2001) utilizando equações lineares de regressão múltipla, estimaram valores de atributos dos solos com dados radiométricos em dois níveis de aquisição, laboratório e orbital, sendo esses dados comparados com os valores determinados por análises químicas e físicas. Os resultados não apresentaram diferenças significativas, a $1 \%$ de probabilidade entre as médias dos valores estimados e valores determinados para argila, soma de bases e CTC. 


\section{GEOPROCESSAMENTO E TOPOSSEQUÊNCIAS NA DETERMINAÇÃO DE LEVANTAMENTOS DE SOLOS EM DIFERENTES ESCALAS}

\section{Resumo}

O objetivo desse trabalho foi caracterizar e avaliar os solos da região de Barra Bonita, SP, por meio de topossequências e variabilidade espacial. Além disso, utilizout se o geoprocessamento para avaliar mapas de solos em diferentes níveis de detalhamento. Para tanto, foram locados 473 pontos em uma grade de 100 x $100 \mathrm{~m}$, os quais foram georreferenciados e amostrados. Com o resultado das análises de solos e observações de campo, foi possível confeccionar dois mapas de solos, com diferentes níveis de detalhamento. Esses mapas foram comparados com um levantamento semidetalhado utilizando-se um Sistema de Informações Geográficas. O estudo das topossequências contribuiu para uma melhor detecção das mudanças das unidades de solos na área. Os mapas detalhado tradicional e "detalhado por textura" diferiram do semidetalhado em $35 \%$ e $44 \%$, respectivamente. Ambos os mapas detalhados apresentaram maior número de unidades de mapeamento em relação ao semidetalhado, sendo o tradicional com 11 unidades de mapeamento, detalhado por textura com 28 e o semidetalhado com apenas 3 unidades. 


\section{GEOPROCESSING AND TOPOSSEQUENCES TO DETERMINE SOIL SURVEY IN DIFERENT SCALES}

\section{Summary}

The objective of this work was to characterize and evaluate the soils of an area located at Barra Bonita, SP, based on toposequences and space variability. Soil maps at different scales were compared by geoprocessing techniques. 474 points in a grid of 100 x $100 \mathrm{~m}$, were georreferenced and soil samples collected. With the chemical, physical and field results, it was possible to develop two maps of soils, one at a detailed scale and another specific for texture. These maps were compared with a semi detailed map by crossed tabulations in a Geographical Information System (GIS). The study based on toposequences contributed for a better detection of the changes between the soil units in the area. The detailed soil map and the texture map differ of the semi detailed map in $35 \%$ and $44 \%$ respectively. Both maps presented larger number of soil units than the semi detailed, being the traditional with 10 units, detailed by texture with 28 and the semi detailed with just 3 units.

\subsection{Introdução}

Um dos principais fatores a ser considerado em relação a sustentabilidade agroecológica é o solo. Ele é a base para a produção de alimentos e sua utilização vem aumentando gradativamente. Por outro lado, o solo é um recurso natural não renovável a curto prazo e encontra-se disponível em quantidade limitada. Esses fatores nos levam 
a verificar a necessidade de esforços na sua preservação. Para tanto, é necessário o conhecimento de seus atributos e variabilidade espacial, que só é possível quando se tem em mãos levantamentos pedológicos em escalas compatíveis com os objetivos desejados. Neste aspecto, o Brasil possui grande extensão territorial e mapas de solos na maioria de reconhecimento (Oliveira, 1988). Segundo Olmos Iturri Larach et al. (1981), os levantamentos de solos nos níveis semidetalhado e detalhado correspondem a aproximadamente $0,25 \%$ da área do país, no nível de reconhecimento $17,1 \%$ e no exploratório 75,6\%. Segundo estes autores existem dados disponíveis de levantamentos da maior parte do território nacional contidos em mapas pedológicos e textos explicativos, porém com caráter generalizado e sem manter o mesmo grau de uniformidade.

Por muitos anos, principalmente entre 1965 e 1985, esforços foram concentrados na realização de levantamentos pedológicos. Porém, por diversos fatores, poucos Estados contam com levantamentos mais detalhados que os de reconhecimento. Nos Estados Unidos a taxa de mapeamento de solos varia de 120 a 240 ha por dia, para levantamentos detalhados, ou 288.000 ha de levantamentos anuais (Morse, 1999). No Brasil, um material recente refere-se ao mapa de reconhecimento dos solos do Estado de São Paulo publicado por Oliveira \& Prado (1999), que é uma compilação e reavaliação de dados anteriormente cartografados e adequados ao novo sistema de classificação de solos vigente (Embrapa, 1999).

Berg \& Oliveira (2000) ressaltam que existem problemas não resolvidos sobre a determinação da variabilidade espacial dos solos que afetam sua qualidade. Portanto, a variabilidade espacial deve ser quantificada e adequada a mapas de escalas compatíveis 
com os objetivos. Berg \& Klamt (1997b), sugerem que existe alta variabilidade de atributos físicos e químicos de solo, implicando em diferenças na variação dos solos em diferentes escalas. Isso foi verificado por Demattê et al. (1999), onde o mapa detalhado apresentou um número muito maior de unidades de mapeamento em relação ao semidetalhado da mesma área. Tal observação nos leva a questionar os níveis de levantamento e número de unidades de solos por eles determinados. Mesmo por que, a determinação da variabilidade espacial de solos é um trabalho árduo e oneroso (Burrough, 1993). Portanto, a comparação de mapeamentos de solos em diferentes escalas contribui para um melhor entendimento da variabilidade espacial do solo, dando suporte para o desenvolvimento, refinamento e homogeneização dos métodos de levantamentos.

O desenvolvimento de técnicas que melhorem os níveis de mapeamento são a base para um adequado planejamento do uso da terra, justamente numa época em que se predomina a conscientização ambiental. Neste aspecto, vários trabalhos de planejamento que visam à diminuição do impacto causado pelas ações antrópicas, tendo como informação básica os solos, vêm sendo desenvolvidos (Koffler, 1996; Fiorio et al., 2000). As tomadas de decisão em planejamento, geralmente têm, como base, mapas pedológicos. Quando esse mapa não corresponde aos objetivos requeridos, todo o planejamento é comprometido, daí a necessidade de melhor avaliarmos os níveis de levantamento já existentes. O fato é que o mapeamento de solos pode ser usado em combinação com outros fatores para quantificar erros e incertezas, auxiliando a determinar fatores que podem afetar todo um planejamento e a produtividade, tais como a erodibilidade dos solos, talhonamento, auxílio na coleta de amostras de terra para fins 
de fertilidade, racionalização na aplicação de fertilizantes, programas de conservação dos solos e sistemas de uso da terra.

Esses fatos levaram a reacender discussões sobre a necessidade dos levantamentos pedológicos bem como a própria "extinção" dos pedológos (Dalmolin, 1999; Demattê, 1999). "Se todos concordam com a importância do levantamento de solos no sistema ambiental e produtivo, por que poucos trabalhos discutem tal assunto?”. A resposta pode estar na necessidade de implementação de novas tecnologias que auxiliem os levantamentos pedológicos, melhorando sua qualidade e grau de detalhamento.

Portanto, o presente trabalho tem por objetivo caracterizar e avaliar solos ocorrentes m região de Barra Bonita, SP, por meio de topossequências. Além disso, mapas de solos em diferentes níveis de detalhamento e escalas foram comparados utilizando-se técnicas de geoprocessamento. Diferenças entre um mapa detalhado e um semidetalhado são, por definição, esperadas, porém o que é logico também deve ser analisado para nortear os futuros levantamentos.

\subsection{Material e Métodos}

A área localiza-se a sudoeste do Estado de São Paulo, na região de Barra Bonita, SP. É delimitada pelas coordenadas geográficas $22^{\circ} 26^{\prime} 2,37^{\prime \prime}$ - $22^{\circ} 23^{\prime} 16,53^{\prime \prime}$ latitude sul e $48^{\circ} 31^{\prime} 24,22^{\prime \prime}-48^{\circ} 27^{\prime} 51,77^{\prime \prime}$ longitude oeste. A área tem 473 ha cultivados com cana-de-açúcar em altitudes variando entre 550 e 710 metros do nível médio acima do mar. O clima da região, segundo a classificação de Köppen, é do tipo Cwa, clima 
mesotérmico (Sentelhas et al., 1998). A litologia é representada pela ocorrência da Formação Serra Geral, a qual se caracteriza por compreender um conjunto de derrames basálticos entre os quais se intercalam arenitos com as mesmas características da Formação Botucatu. Aparece ainda a Formação Itaqueri do grupo Bauru predominando arenitos com cimento argiloso na maior parte da área (IPT, 1981).

O mapa clinográfico da área foi obtido, via mesa digitalizadora, a partir dos mapas planialtimétricos na escala 1:10.000. As curvas de nível possibilitaram a produção de um modelo numérico de terreno que após fatiamento, no Sistema de Processamento de Informações Georreferenciadas, Spring (INPE, 1999), gerou quatro classes de declividade seguindo as preconizadas por Embrapa (1999) sendo: plano (0 a $3 \%$ ), suave ondulado (3 a 8\%), ondulado (8 a 20\%) e forte ondulado (20 a $40 \%$ ).

No mapa base, gerado a partir do planialtimétrico, foi estabelecido os limites da área de estudo com o Sistema de Posicionamento Global. Posteriormente, uma grade regular de 100 x 100 metros foi plotada sobre o mapa base e demarcada no campo com distanciômetro (feixe de infravermelho). Cada interseção da grade gerou um ponto de amostragem, que foi marcado m campo com uma estaca, perfazendo um total de 473 pontos. A malha de 100 x 100 metros, produziu no campo uma densidade de observação de 1 ponto por hectare como estabelecidos para levantamentos detalhados (Embrapa, 1989 e 1995). Os pontos estaqueados foram numerados, georreferenciados e amostrados, com trado, nas profundidades 0-20 e 80-100 cm, e denominadas de Camadas A e B, respectivamente, referentes aos horizontes A e B. A cor do solo foi obtida úmida com colorímetro Minolta CR 300 para cor de Munsell (Post et al., 1994; Campos, 2002). Foram realizadas análises químicas (Raij et al., 1987), granulométricas e ferro total 
(Camargo et al., 1987). Com o resultado das análises foram determinados os locais de 6 perfis de solos que foram descritos (Lemos \& Santos, 1996) e classificados (Embrapa, 1999).

As principais topossequências ocorrentes na área foram caracterizadas. As unidades de mapeamento foram delimitadas com auxílio do mapa base, permitindo gerar dois mapas. Primeiro foi desenvolvido um mapa de solos nível detalhado, denominado de "detalhado tradicional", classificado de acordo com Embrapa (1999). Nesse caso foram consideradas as características principais de cada classe de solo, chegando ao $2^{\circ}$ nível categórico (subordens) e, em alguns casos, ao $3^{\circ}$ nível categórico (grandes grupos), no caso dos Eutroférricos, diferenciando-se por serem mais argilosos e apresentarem maiores teores de ferro observados no campo e confirmados por análises. O segundo mapa, "detalhado por textura", difere do primeiro na classificação do solo, considerando a textura para separar unidades de mapeamento. A textura média (151-350 $\mathrm{g} \mathrm{kg}^{-1}$ de argila) foi dividida em 2 classes: “média 1", 151-250 $\mathrm{g} \mathrm{kg}^{-1}$ de argila e "média 2", 251-350 $\mathrm{g} \mathrm{kg}^{-1}$ de argila. As demais classes foram assim designadas: arenosa, $<150 \mathrm{~g} \mathrm{~kg}^{-1}$ de argila, argilosa (3), $351-600 \mathrm{~g} \mathrm{~kg}^{-1}$ de argila e muito argilosa (4), $\geq 600 \mathrm{~g} \mathrm{~kg}^{-1}$ de argila, sendo que os números (1, 2, 3 e 4) na legenda e no texto, representam as classes de textura anteriormente descritas. Nesse levantamento foi considerado um maior número de características dos solos, chegando ao $4^{\circ}$ e $5^{\circ}$ níveis categóricos (subgrupos e família). Dessa forma, utilizourse o $5^{\circ}$ nível categórico para separar mais detalhadamente as unidades de mapeamento. 
O mapa semidetalhado foi adquirido das quadrículas de Brotas (Oliveira et al., 1981a) e Jaú (Oliveira et al., 1981b) na escala de publicação 1:100.000 e mapa base 1:50.000, realizado pelo Instituto Agronômico, IAC. A nomenclatura dos solos do levantamento semidetalhado foi aproximada às vigentes (Embrapa, 1999). Dessa forma onde era LE3+LRd+TE2, pela classificação atual temos, LV+LVef+Nvef; onde era LE1+LE2, agora temos LV e onde era PV1, temos PV. Todos os mapas foram digitalizados utilizando o módulo de edição vetorial do Spring e comparados por geoprocessamento pelo módulo tabulações cruzadas. Esse procedimento consiste na comparação entre as áreas de dois em dois planos de informação, onde se considera como acerto as áreas que apresentam as mesmas informações, e erros as áreas com informações diferentes (INPE, 1999).

\subsection{Resultados e Discussão}

\subsubsection{Caracterização dos solos e variabilidade espacial nas topossequências}

Com o intuito de melhor caracterizar a distribuição dos solos na área de estudo, foram plotadas duas topossequências, sendo que ambas iniciam no mesmo ponto de tradagem, que se refere ao solo RQo (Figura 1,2).

A topossequência 1, caracteriza-se por altitudes que variam de 550 a 710 m, com extensão de $1200 \mathrm{~m}$ e influência do mesmo material de origem, o arenito da formação Itaqueri. O NEOSSOLO QUARTZARÊNICO Órtico típico (RQo), ocupa cerca de 50 ha, e caracteriza-se por apresentar textura $<150 \mathrm{~g} \mathrm{~kg}^{-1}$ de argila, estando com média de 
$122 \mathrm{~g} \mathrm{~kg}^{-1}$, sendo solos de baixa fertilidade, verificado pela baixa CTC, com mineralogia predominando o quartzo $(\mathrm{Ki}>2)$ e com caráter álico (Tabela 1). Ocorre principalmente em declives de 3 - 8\% com 26,4 ha nesta classe de relevo (Tabela 2), em altitude média de 705 m, sendo formado a partir do arenito. A posição elevada no relevo, juntamente com o material de origem, promoveram uma maior infiltração e um menor escoamento superficial, o que levou a formação de um solo profundo, concordando com França \& Demattê (1993) e com intensa lixiviação de bases, de acordo com Oliveira et al. (1992).

Seguindo na topossequência verifica-se a presença do LATOSSOLO VERMELHO Distrófico típico, textura média 1 (LVd-1) (Figura 1). Apresenta-se com baixa CTC e V\%, o que pode ser explicado pelo seu estágio avançado de intemperismo $(\mathrm{Ki}<2)$, com predomínio de óxidos e caulinita e cores mais vermelhas com matiz 1.5 YR (Tabela 1). Esta unidade de mapeamento representa sozinha 212,13 ha (45\% do total da área), sendo que 105,44 ha ou 22\% está em declive de 3 a $8 \%$ (Tabela 2), com altitude média entre 705 e 680 m, ratificando a ocorrência desses solos em relevo plano a suave ondulado. O LATOSSOLO VERMELHO-AMARELO Distrófico textura média 1 (LVAd-1) se assemelha ao LVd-1 e RQo, diferindo nos teores e tipos de óxidos de ferro sendo que a coloração do LVAd-1 e RQo é mais amarela, com matiz 3.0 YR (Tabela 1). Pelo Sistema Brasileiro de Classificação de Solos, a cor do solo tem um novo significado, sendo responsável pela diferenciação, principalmente para os Argissolos e Latossolos, no nível categórico (subordens), considerando a notação Munsell (Embrapa, 1999). Na área de estudo, vários Latossolos com características granulométricas e químicas semelhantes, como no caso o LVd-1 e LVAd-1, foram classificados em subordens diferentes obedecendo a cor estabelecida na leitura do 
colorímetro e o intervalo rígido da classificação; visualmente era difícil a sua separabilidade com a carta de cor. Tais observações concordam com Campos (2002), que observou que o colorímetro foi mais preciso.

O ARGISSOLO VERMELHO Distrófico abrúptico, textura média 2 (PVd-2) (Figura 1), tem baixa fertilidade, verificada pela CTC e V\%, o que condiz com o material de origem de arenito, o $\mathrm{Ki}<2$ confirma a presença dos óxidos de ferro e caulinita. O matiz 2.7 YR, mais amarelo na superfície e $1.8 \mathrm{YR}$, vermelho em subsuperficie, evidencia uma maior influência da argila e óxidos de ferro, na cor vermelha (Schwertmann \& Taylor, 1977), o que auxiliou na diferenciação dos horizontes durante a descrição do perfil (Tabela 1). Esse solo caracteriza-se pela mudança textural abrupta e encontra-se em cotas de $670 \mathrm{~m}$ (Figura 1). Esses solos ocorrem na maioria (26,12 ha em um total de 29,82 ha) em declives mais acentuados que os LVs, na faixa de 8 a $20 \%$. Na área como um todo a ocorrência foi baixa, 6,3\% (Tabela 2). A mudança textural abrupta e a situação de relevo em que esse solo se encontra, ratificam a sua alta susceptibilidade a erosão, podendo vir a causar o assoreamento do canal de drenagem (Figura 1), concordando com Fiorio et al. (1999).

Na topossequência 1, à margem direita da encosta, têm-se o ARGISSOLO VERMELHO-AMARELO Distrófico abrúptico (PVAd-2) que inicia na drenagem em cota de $560 \mathrm{~m}$ de altitude até $675 \mathrm{~m}$ (Figura 1). As características granulométricas e químicas desse solo são semelhantes às do PVd-2 (Tabela 1). Ocupa apenas 3,0 ha do total da área de estudo, onde $100 \%$ desse total encontra-se em declives de 8 a $20 \%$ (Tabela 2). A mudança textural abrupta e a situação de relevo, à semelhança do PVd-2, promovem uma alta susceptibilidade à erosão, também podendo causar assoreamento no 
canal de drenagem (Fiorio et al., 1999). Como os Latossolos, os Argissolos diferenciamse no segundo nível categórico (subordens) pela cor (Embrapa, 1999). A matiz 2.8 YR para o PVAd-2, obtida pelo colorímetro, está muito próxima do limite estabelecido para cor vermelho, que é de a 2.5 YR, porém mais amarela, o que o leva a ser classificado como vermelho-amarelo. Na mesma situação, utilizando-se a carta de cores, a diferenciação visual entre 2.5 e 2.8 YR poderia não ser perceptível, o que mudaria a sua classificação para vermelho, concordando com Campos (2002), (Tabela 1).

O LATOSSOLO VERMELHO Distrófico típico textura média 2 (LVd-2) difere do LVd-1 na textura do horizonte B, com $269 \mathrm{~g} \mathrm{~kg}^{-1}$ de argila, e na declividade. Dos 12,98 ha existentes na área, 10,58 ha $(81,5 \%)$ estão em declives de 8 a $20 \%$ (Tabela 2). Nota-se que ambos os solos, PVAd-2 e LVd-2, apresentam-se com o mesmo intervalo de declividade 8 a 20\%, porém o primeiro apresenta declividades mais próximas dos $20 \%$ enquanto o segundo mais próximas dos $8 \%$, o que está condizente com a formação desses solos e com a posição que ocupam na topossequência. Tais resultados concordam com Berg \& Klamt (1997a) cujas observações indicaram que a variação espacial de solos semelhantes, porém, em regiões diferentes podem ser análogos. O fato da variabilidade ser similar em relevos dominados por solos do mesmo grupo taxonômico, como foi o caso dos principais solos da topossequência 1, permite inferir estratégias para a racionalização do número de amostragens de terra, diminuindo os custos.

A topossequência 2 (Figura 2) caracteriza-se pela influência do diabásio e do arenito. As características verificadas para o RQo e LVd-1 são as mesmas da topossequência 1, sendo solos profundos, de baixa fertilidade e desenvolvidos de material retrabalhado do arenito (Tabela 1). Diferenciam-se pela presença do LVd-1 em 
quase toda a encosta até as proximidades do canal de drenagem, aparecendo em declividades variáveis (Figura 1 e Tabela 2). Nas cotas mais baixas, ocorre a mudança de unidade de mapeamento para um ARGISSOLO VERMELHO Eutrófico abrúptico textura argilosa (PVe-3), o qual apresenta boa fertilidade no horizonte B conforme pode ser verificado pela elevada CTC e V\%; apresenta matiz 2.0 YR. A mudança de textura abrúpta do PVe-3, juntamente com o predomínio de 11,01 ha ou $85 \%$ de sua área em declives de 8 a $20 \%$, mais próximo dos $20 \%$, ocasiona uma alta susceptibilidade à erosão (Tabela 2). O problema se agrava com a proximidade da drenagem, concordando com Fiorio et al. (1999).

Por sua vez, foi observado do outro lado da encosta (Topossequência 2), nas cotas mais baixas, solos pouco profundos, como o CAMBISSOLO HÁPLICO Tb Eutrófico típico (Cxbe-3). A posição dessa unidade na encosta é a mesma do PVe-3, do outro lado da encosta. Tal fato demonstra a complexidade em se tratar lados opostos de uma vertente como iguais. Ou seja, a variabilidade do material subjacente tem importância fundamental na detecção dessas variações. O Cxbe-3, predomina em declives de 8 a 20\%. Caracteriza-se pela boa fertilidade, com CTC de 88,8 mmol $_{\mathrm{c}} \mathrm{kg}^{-1}$ no horizonte $\mathrm{A}$ e $58,5 \mathrm{mmol}_{\mathrm{c}} \mathrm{kg}^{-1}$ no horizonte $\mathrm{B}$, alto $\mathrm{V} \%$ e argila de atividade baixa (Tb), condizentes com a proximidade do material de origem, o diabásio (Tabela 1). Para solos relativamente mais jovens espera-se valores de $\mathrm{Ki}>2$, o que não foi verificado para o Cxbe-3 com $\mathrm{Ki}$ 1,52, tal valor geralmente está relacionado a solos mais intemperizados com presença de óxidos de ferro e caulinita, porém Oliveira et al. (1992) registram Cambissolos com índices $\mathrm{Ki}<0,6$. 
Dos 25,93 ha do LATOSSOLO VERMELHO Distrófico típicos textura argilosa (LVd-3), 23,64 ha estão em declividades de 8 a $20 \%$, cerca de $91 \%$ do seu total. Os LVd-3 caracterizam-se pela baixa fertilidade, CTC e V \% baixos, e $\mathrm{Ki}$ de 1,72 indicando mineralogia oxídica e caulinítica, o que está de acordo com observações de Oliveira et al. (1992).

Tanto o Cxbe-3 quanto LVd-3 têm sua gênese diferenciada. Os Latossolos apresentam-se como solos profundos devido ao maior intemperismo, enquanto que os Cambissolos, por definição são solos relativamente jovens e menos profundos, sendo geralmente associados às declividades mais acentuadas (Oliveira et al., 1992). Em ambos os casos esses solos encontram-se na mesma classe de declive de 8 a $20 \%$. Supõem-se, então, que o Latossolo está mais próximo dos $8 \%$ de declive, enquanto que o Cambissolo dos 20\% (Figura 1). Entre as cotas de $660 \mathrm{~m}$ e $700 \mathrm{~m}$ ocorre o ARGISSOLO VERMELHO Eutrófico abrúpto textura média 2 (PVe-2) e LVd-1. Tal fato vem confirmar as afirmações anteriores de que a mudança de declividade condicionou a mudança da unidade de mapeamento. Onde o terreno apresentou uma rampa mais declivosa, dentro do intervalo de 8 a 20\%, verifica-se a formação do B textural (PVe-2) de textura arenosa/média 2, e nas declividades mais amenas encontrase o LVd-1 (Figura 1 e Tabela 2). O PVe-2 difere apenas na textura em relação ao PVe3 próximo a drenagem.

\subsubsection{Comparação entre os níveis de levantamento pedológicos}


Neste trabalho foram utilizados três mapas pedológicos. Nos mapas detalhado tradicional e detalhado por textura, foram obtidas 5 ordens de solos, NEOSSOLOS, ARGISSOLOS, NITOSSOLOS, LATOSSOLOS e CAMBISSOLOS (Figura 2 b,c).

Das 28 unidades de mapeamento, do mapa detalhado por textura (escala base 1:10.000), o RQo, Cxb-2,3 e 4, LVA-1,2 e 3, PA-1 e 2, PVA-1, 2, 3 e 4, somam $44 \%$ do total da área e não apresentaram classes similares no levantamento semidetalhado (escala base 1:50.000) (Figura 2 a, c)(Tabela 3). Do total de 186 ha, da unidade LE3+LRd+TE2, do semidetalhado, apenas $27,4 \%$ (51 ha) coincidiram com suas respectivas unidades no mapa detalhado por textura (LV-3+LVef-3 e 4+Nvef-3 e 4) (Tabela 3). As unidades LE1+LE2 foram as que melhor coincidiram com as unidades do mapa detalhado por textura com $63 \%$ (185,8 ha) do total. Para o PV-1 com apenas 1 ha no mapa semidetalhado, obteve-se $100 \%$ de coincidência com o PV-2 do mapa detalhado por textura, porém, a representatividade desse solo é bem maior, no detalhado por textura, chegando a ocupar 29,94 ha. Somando-se todos os acertos desse cruzamento, temos 265,79 ha, cerca de $56 \%$ de coincidências entre o mapa detalhado por textura e o mapa semidetalhado.

Comparando o levantamento detalhado tradicional (Figura 2b) e o semidetalhado (Figura 2a) podemos observar um acerto de 118,98 ha entre as unidade LE3+LRd+TE2 e as unidades semelhantes do detalhado tradicional. Ainda para as unidades LE1+LE2 foi verificado um acerto em 185,8 ha e para o PV-1 apenas 1 ha, totalizando 304,78 ha cerca de $64,47 \%$ de acerto entre os mapas cruzados e um erro de $35 \%$ (Tabela 3 ). Com a diminuição do detalhamento na delimitação das unidades de mapeamento temos um aumento na porcentagem de acertos entre os cruzamentos do levantamento 
semidetalhado. Mesmo assim, o erro de $35 \%$ entre o levantamento semidetalhado e o detalhado tradicional é considerável, podendo vir a comprometer trabalhos de planejamento caso venham a ser utilizados os levantamentos disponíveis atualmente. Segundo Embrapa (1989), os levantamentos semidetalhados devem atender a projetos de colonização de áreas, loteamentos rurais, estudos integrados de microbacias ou projetos onde a intensidade de uso dos solos não seja alta. No levantamento detalhado tradicional os objetivos são atender a projetos conservacionistas na fase de execução, projetos de irrigação e drenagem e de particular interesse para recomendações de manejo e uso dos solos. A escolha da escala de trabalho está diretamente relacionada com o objetivo a ser alcançado, escalas maiores permitem maior número de informações e maior detalhamento, enquanto que escalas menores, embora impliquem em menor custo e tempo para obtenção dos dados, tendem a fornecer informações generalizadas e agrupadas (Bouma, 1989).

As diferenças encontradas nas tabulações cruzadas podem ser melhor observadas verificando a metodologia empregada, expressa por: número de observações no campo, área mínima mapeável (a.m.m.), escala de publicação e o número de classes (Tabela 4). Para a execução do mapa de solos detalhado tradicional e detalhado por textura, foram realizadas 473 tradagens em uma área de aproximadamente 473 ha, ou seja 1 observação por hectare. O número de observações no levantamento semidetalhado foi bem inferior, sendo de 4 a 8 observações na área de estudo ou próxima a ela, originando 3 unidades de mapeamento, sendo 2 associações (Figura 2a). De fato, a diferença de observações é considerável e tem responsabilidade direta na variação de unidades de mapeamento. Por outro lado, o número de amostragens pode ser reduzido e os limites 
melhor determinados quando se utilizam técnicas auxiliares. Para os levantamentos de solos semidetalhados usa-se, geralmente, a fotopedologia, onde as fotografias aéreas e o conhecimento do fotointérprete na delimitação de unidades de solos, possibilita uma diminuição do número de observações de campo e aumento na detecção das unidades de mapeamento. Demattê et al. (2001) comparando diferentes métodos de levantamentos de solos, concluiu que a utilização da fotopedologia, mapas planialtimétricos e dados de radiometria de laboratório, resultaram num levantamento de solos muito semelhante ao levantamento detalhado tradicional e superior ao semidetalhado. Prado (2000) conclui que utilizando-se da fotopedologia pode-se perfeitamente diminuir o número de prospecções representativas das referidas unidades de mapeamento, sem contudo prejudicar a qualidade do mapeamento de solos. No entanto, para o levantamento semidetalhado, próximo às drenagens não foram verificadas mudanças nas unidades de mapeamento, as quais poderiam ter sido evidenciadas melhorando seu o detalhamento.

Comparando os mapas pedológicos detalhado por textura e detalhado tradicional com o semidetalhado, nota-se grandes diferenças no número de unidades de mapeamento determinadas (Tabela 4). Dent \& Young (1981) recomendam, para mapas semidetalhados, a utilização de mapas básicos em escala 2 a 2,5 vezes maior que a escala de publicação. Embrapa (1989) indica que para mapeamentos semidetalhados, a escala base mínima é de 1:50.000 e a escala de publicação máxima de 1:100.000. Verifica-se que o mapa semidetalhado da Figura 2a utilizourse dos limites máximos sugeridos para a sua confecção. Tais fatos contribuíram para as diferenças no número de unidades de mapeamento destes mapas. Além disso, a própria metodologia utilizada na sua elaboração, utilizando-se como área mínima mapeável (a.m.m.), uma parcela menor 
que 40 ha, com intensidade de observações entre 0,3 a 0,4 contribui para o fato (Embrapa, 1989). Para o levantamento detalhado tradicional e detalhado por textura temos o mapa na escala de 1:10.000, com área mínima mapeável (a.m.m.), uma parcela menor que 0,04 ha com 1 observação por hectare. Tais observações estão de acordo com Bouma (1989), para quem escalas maiores permitem maior número de informações e maior detalhamento e escalas menores tendem a generalizar e agrupar informações (Tabela 4).

Diferenças entre um mapa detalhado e um semidetalhado são, por definição, esperadas. A questão é avaliar os limites dessa diferença. Nos levantamentos detalhado tradicional e detalhado por textura há ocorrência de 11 e 28 unidades de mapeamento, respectivamente, que diferem quanto à textura, o que não pode ser levado em consideração quando observamos o levantamento semidetalhado, que apresentou 3 classes de solos, onde as unidades formadas não condizem totalmente com a realidade da área, como verificado pelas porcentagens de erros nos cruzamentos dos mapas. Esses resultados concordam com observações de Demattê et al. (1999 e 2001), para os quais levantamentos semidetalhados da região de Piracicaba e Mogi Guaçú apresentaram diferenças de até $400 \%$ no número de unidades de mapeamento em relação ao detalhado. Com a utilização de fotografias aéreas escala 1:35.000, Demattê et al. (2001) determinaram $300 \%$ mais unidades fisiográficas que o mapa semidetalhado da mesma área, pela observação em fotografias aéreas, sem incursões no campo. 


\subsection{Conclusões}

1- A avaliação da declividade e das topossequências foi importante na determinação dos limites das unidades de mapeamento, permitindo identificar áreas de maior risco de erosão.

2- As classes de declividade utilizadas nesse trabalho não foram adequadas em alguns casos devido a amplitude dos intervalos, principalmente, entre 8 e $20 \%$, por vezes não permitem caracterizar as mudanças de unidades de mapeamento na topossequência.

3- As texturas média 1 e média 2 propostas nesse trabalho facilitaram a identificação das unidades de mapeamento principalmente para B texturais com caráter abrúpto. Além disso, facilitaram também a identificação de solos como RQo e LV-1 com características próximas.

4- As tabulações cruzadas no SIG, evidenciaram as diferenças entre os levantamentos de solos. O levantamento semidetalhado apresentou uma coincidência de unidades de mapeamento de $56 \%$ com o levantamento detalhado por textura e $65 \%$ com o detalhado tradicional. O mapa detalhado apresentou um número de 8 unidades de mapeamento a mais que o semidetalhado. 
Tabela 1. Dados médios dos atributos químicos e granulométricos das unidades de mapeamento da área de estudo.

\begin{tabular}{|c|c|c|c|c|c|c|c|c|c|c|c|c|c|c|c|c|c|c|c|c|c|c|}
\hline \multirow{2}{*}{$\begin{array}{c}\text { Sigla } \\
\text { Solo }\end{array}$} & \multirow{2}{*}{$\mathrm{N}^{2}$} & \multirow{2}{*}{$\begin{array}{c}\text { Cama- } \\
\mathrm{da}^{3}\end{array}$} & \multirow{2}{*}{$\begin{array}{c}\mathrm{pH} \\
\mathrm{H}_{2} \mathrm{O}\end{array}$} & \multirow{2}{*}{$\begin{array}{l}\mathrm{MO}^{4} \\
\mathrm{~g} / \mathrm{kg}\end{array}$} & \multirow{2}{*}{$\begin{array}{c}\mathrm{P} \\
\mathrm{mg} / \mathrm{kg}\end{array}$} & \multirow{2}{*}{$\begin{array}{c}\mathrm{K} \\
---\end{array}$} & \multirow[t]{2}{*}{$\mathrm{Ca}$} & \multirow[t]{2}{*}{$\mathrm{Mg}$} & \multirow{2}{*}{$\frac{\mathrm{Al}}{\mathrm{mmo}}$} & \multirow{2}{*}{$\frac{\mathrm{H}}{\mathrm{kg}---}$} & \multirow[t]{2}{*}{$\mathrm{SB}$} & \multirow{2}{*}{$\begin{array}{c}T \\
---\end{array}$} & \multirow[t]{2}{*}{$\mathrm{V}$} & \multirow[t]{2}{*}{$\mathrm{m}$} & \multirow{2}{*}{ Areia } & \multirow{2}{*}{$\begin{array}{l}\text { Silte } \\
- \text {-g/kg }\end{array}$} & \multirow{2}{*}{ Argila } & \multicolumn{3}{|c|}{ Cor úmida } & \multirow{2}{*}{$\begin{array}{c}\mathrm{Fe}_{2} \mathrm{O}_{3} \\
\mathrm{~g} / \mathrm{kg}\end{array}$} & \multirow[t]{2}{*}{$\mathrm{Ki}$} \\
\hline & & & & & & & & & & & & & & & & & & Matiz & Valor & Croma & & \\
\hline \multirow{2}{*}{\multicolumn{2}{|c|}{ CXbe-3 }} & $\mathrm{A}$ & 5,4 & 18,7 & 8,7 & 3,5 & 40,3 & 12,7 & 0,7 & 32,3 & 56,5 & 88,8 & 64,0 & 1,3 & 287 & 200 & 513 & $4,2 \mathrm{YR}$ & 3,6 & 1,7 & 144 & 1,75 \\
\hline & & B & 5,7 & 9,3 & 4,3 & 0,5 & 32,3 & 18,3 & 0,0 & 7,3 & 51,1 & 58,5 & 86,7 & 0,0 & 400 & 140 & 460 & 2,7YR & 3,6 & 2,2 & 149 & 1,52 \\
\hline \multirow{2}{*}{\multicolumn{2}{|c|}{ LVAd-1 }} & A & 5,4 & 12,1 & 24,4 & 2,3 & 15,8 & 5,7 & 1,1 & 16,2 & 23,7 & 39,9 & 60,5 & 6,7 & 778 & 50 & 173 & $3,1 \mathrm{YR}$ & 3,7 & 2,1 & 24 & 1,93 \\
\hline & & B & 4,7 & 11,3 & 3,0 & 1,0 & 6,4 & 2,3 & 7,1 & 28,1 & 9,7 & 37,8 & 24,0 & 47,9 & 762 & 31 & 207 & 3,0YR & 3,7 & 2,4 & 35 & 1,81 \\
\hline \multirow{2}{*}{\multicolumn{2}{|c|}{ LVd-1 }} & A & 5,3 & 12,2 & 14,1 & 2,0 & 13,1 & 5,0 & 1,3 & 18,3 & 20,1 & 38,4 & 53,0 & 8,0 & 812 & 36 & 152 & 2,7YR & 3,5 & 1,9 & 21 & 2,06 \\
\hline & & B & 4,6 & 11,7 & 2,2 & 1,1 & 3,6 & 1,7 & 7,7 & 21,6 & 6,4 & 27,9 & 22,9 & 56,1 & 789 & 24 & 187 & $1,5 \mathrm{YR}$ & 3,6 & 2,4 & 27 & 1,78 \\
\hline \multirow{2}{*}{\multicolumn{2}{|c|}{ LVd-2 }} & A & 5,1 & 13,3 & 7,8 & 1,9 & 12,6 & 5,1 & 1,9 & 22,6 & 19,7 & 42,3 & 48,8 & 9,5 & 775 & 45 & 180 & $2,0 \mathrm{YR}$ & 3,4 & 1,8 & 30 & 2,12 \\
\hline & & B & 4,6 & 12,1 & 2,1 & 0,8 & 5,6 & 1,6 & 11,5 & 26,6 & 8,1 & 34,7 & 23,5 & 55,1 & 701 & 30 & 269 & $1,9 \mathrm{YR}$ & 3,7 & 2,6 & 38 & 1,99 \\
\hline \multirow{2}{*}{\multicolumn{2}{|c|}{ LVd-3 }} & A & 5,1 & 19,0 & 4,1 & 3,4 & 18,2 & 7,2 & 1,6 & 33,2 & 28,8 & 62,0 & 46,3 & 6,0 & 537 & 90 & 373 & 2,9YR & 3,5 & 2,0 & 122 & 1,56 \\
\hline & & B & 5,0 & 13,0 & 2,5 & 0,5 & 9,1 & 3,7 & 5,4 & 28,0 & 13,3 & 41,3 & 31,7 & 25,8 & 440 & 89 & 471 & $2,0 \mathrm{YR}$ & 3,6 & 2,1 & 134 & 1,72 \\
\hline \multirow{2}{*}{\multicolumn{2}{|c|}{ PVAd-2 }} & A & 4,9 & 10,5 & 4,5 & 1,4 & 9,5 & 4,0 & 3,0 & 13,0 & 14,9 & 27,9 & 53,0 & 17,5 & 850 & 30 & 120 & $2,2 \mathrm{YR}$ & 3,4 & 1,6 & 25 & 2,41 \\
\hline & & B & 4,6 & 9,5 & 3,0 & 1,5 & 11,0 & 3,5 & 3,0 & 17,5 & 16,0 & 33,5 & 44,0 & 25,0 & 685 & 30 & 285 & $2,8 \mathrm{YR}$ & 3,7 & 2,4 & 40 & 1,91 \\
\hline PVd-2 & & A & 5,1 & 12,8 & 5,4 & 1,9 & 9,5 & 4,4 & 2,5 & 21,2 & 15,8 & 36,9 & 42,8 & 14,1 & 843 & 46 & 111 & $2,7 \mathrm{YR}$ & 3,6 & 2,0 & 25 & 2,05 \\
\hline & & B & 4,7 & 7,2 & 2,4 & 1,4 & 9,4 & 3,0 & 6,2 & 25,7 & 13,8 & 39,5 & 35,2 & 27,2 & 695 & 25 & 281 & $1,8 \mathrm{YR}$ & 3,7 & 2,5 & 38 & 1,81 \\
\hline PVe-2 & & A & 5,2 & 14,8 & 4,9 & 2,2 & 10,6 & 4,6 & 2,2 & 21,1 & 17,4 & 38,5 & 44,4 & 12,6 & 839 & 40 & 121 & $2,8 \mathrm{YR}$ & 3,5 & 2,0 & 32 & 2,27 \\
\hline & & B & 5,2 & 8,6 & 2,4 & 1,6 & 16,9 & 4,2 & 2,1 & 15,2 & 22,6 & 37,8 & 60,0 & 9,1 & 696 & 24 & 280 & $1,8 \mathrm{YR}$ & 3,7 & 2,5 & 49 & 1,74 \\
\hline PVe-3 & & A & 5,1 & 18,6 & 5,3 & 2,7 & 15,8 & 6,7 & 1,8 & 34,5 & 25,2 & 59,7 & 42,0 & 7,3 & 711 & 79 & 210 & 3,3 YR & 3,5 & 2,0 & 83 & 1,77 \\
\hline & & B & 5,4 & 12,5 & 2,5 & 0,6 & 32,6 & 6,4 & 1,1 & 16,1 & 39,6 & 55,7 & 71,9 & 2,7 & 507 & 59 & 434 & 2,0YR & 3,6 & 2,1 & 136 & 0,98 \\
\hline RQo & & A & 5,3 & 11,0 & 7,8 & 1,6 & 10,9 & 4,3 & 1,5 & 16,9 & 16,8 & 33,8 & 52,0 & 9,6 & 840 & 34 & 126 & $3,1 \mathrm{YR}$ & 3,6 & 2,0 & 17 & 2,22 \\
\hline & & B & 4,7 & 8,8 & 2,8 & 1,1 & 4,3 & 1,8 & 6,5 & 17,3 & 7,2 & 24,5 & 29,9 & 50,3 & 847 & 31 & 122 & 2,9YR & 3,7 & 2,3 & 19 & 2,09 \\
\hline
\end{tabular}

TCAMBISSOLOS HÁPLICOS Tb Eutróficos, textura argilosa (CXbe-3), LATOSSOLOS VERMELHO-AMARELOS Distróficos, textura média (LVAd-1), LATOSSOLOS VERMELHOS Distróficos, textura média 1, 150 - 250 g/kg (LVd-1), LATOSSOLOS VERMELHOS Distróficos, textura média 2, 250 - 350 g/kg (LVd-2), LATOSSOLOS VERMELHOS Distróficos textura argilosa (LVd-3), ARGISSOLOS VERMELHO-AMARELOS Distróficos, textura média 2 (PVAd-2), ARGISSOLOS VERMELHOS Distróficos, textura média 2 (PVd-2), ARGISSOLOS VERMELHOS Eutróficos, textura média 2 (PVe-2), ARGISSOLOS VERMELHOS Eutróficos, textura argilosa (PVe-3), NEOSSOLOS QUARTZARÊNICOS Órticos(RQo)

${ }^{2}$ Número de Repetições para cada unidade de mapeamento da área de estudo

${ }^{3}$ Camadas: A $(0-20 \mathrm{~cm})$ e B $(80-100 \mathrm{~cm})$, referentes aos horizontes A e B

${ }^{4}$ Matéria Orgânica 
Tabela 2. Valor em ha do cruzamento entre unidade de mapeamento do levantamento Detalhado por textura e a declividade.

\begin{tabular}{|c|c|c|c|c|c|}
\hline \multirow{2}{*}{$\begin{array}{c}\text { Siglas }^{1} \\
\text { Solos }\end{array}$} & \multicolumn{4}{|c|}{ Declividade $^{2}$} & \multirow{2}{*}{$\begin{array}{c}\text { TOTAL } \\
\text { ha }\end{array}$} \\
\hline & $(0-3 \%)$ & $(3-8 \%)$ & $(8-20 \%)$ & $(20-40 \%)$ & \\
\hline RQo & 1,52 & 26,42 & 21,92 & 0,00 & 49,85 \\
\hline CXb-2 & 0,00 & 0,55 & 1,45 & 0,00 & 2,00 \\
\hline Cxbe-3 & 0,00 & 0,67 & 2,07 & 0,22 & 2,96 \\
\hline $\mathrm{CXb}-4$ & 0,00 & 0,91 & 1,09 & 0,00 & 2,00 \\
\hline CXef-1 & 0,00 & 0,00 & 2,00 & 0,00 & 2,00 \\
\hline LVAd-1 & 1,68 & 10,39 & 7,90 & 0,00 & 19,97 \\
\hline LVA-2 & 0,00 & 2,58 & 3,38 & 0,00 & 5,97 \\
\hline LVA-3 & 0,00 & 0,05 & 3,76 & 0,19 & 4,00 \\
\hline LVd-1 & 41,85 & 105,44 & 64,47 & 0,37 & 212,13 \\
\hline LVd-2 & 0,00 & 2,40 & 10,58 & 0,00 & 12,98 \\
\hline LVd-3 & 0,00 & 2,25 & 23,64 & 0,05 & 25,93 \\
\hline LV-4 & 0,00 & 3,38 & 8,59 & 0,03 & 12,00 \\
\hline Lvef-3 & 0,00 & 0,13 & 2,87 & 0,00 & 3,00 \\
\hline Lvef-4 & 0,00 & 1,54 & 5,63 & 0,78 & 7,94 \\
\hline NV-3 & 0,00 & 0,65 & 1,33 & 0,00 & 1,97 \\
\hline NV-4 & 0,00 & 4,38 & 8,81 & 0,77 & 13,96 \\
\hline Nvef-3 & 0,23 & 2,66 & 1,03 & 0,00 & 3,92 \\
\hline Nvef-4 & 0,24 & 2,97 & 6,51 & 0,24 & 9,96 \\
\hline PA-1 & 0,00 & 0,49 & 0,51 & 0,00 & 1,00 \\
\hline PA-2 & 0,00 & 0,65 & 0,32 & 0,00 & 0,97 \\
\hline PVA-1 & 0,00 & 1,97 & 4,89 & 0,00 & 6,86 \\
\hline PVAd-2 & 0,00 & 0,00 & 3,00 & 0,00 & 3,00 \\
\hline PVA-3 & 0,00 & 0,00 & 1,00 & 0,00 & 1,00 \\
\hline PVA-4 & 0,00 & 0,00 & 2,00 & 0,00 & 2,00 \\
\hline PV-1 & 2,07 & 6,38 & 10,52 & 0,00 & 18,98 \\
\hline PVd,e-2 & 0,00 & 3,70 & 26,12 & 0,00 & 29,82 \\
\hline PVe-3 & 0,00 & 1,99 & 11,01 & 0,00 & 13,00 \\
\hline PV-4 & 0,00 & 1,11 & 0,81 & 0,00 & 1,93 \\
\hline TOTAL (ha) & 47,59 & 183,66 & 237,20 & 2,64 & 472,7 \\
\hline
\end{tabular}

T'Nomenclatura de acordo com Embrapa (1999).

${ }^{2}$ Intervalos de declive de acordo com Embrapa (1999). 
Tabela 3. Valor em ha da tabulação cruzada entre os levantamentos pedológicos de diferentes níveis.

\begin{tabular}{|c|c|c|c|c|}
\hline \multirow{2}{*}{$\begin{array}{c}\text { Mapa detalhado por textura } \\
(\mathbf{1 : 1 0 . 0 0 0 )})^{(\mathbf{1})} \\
\text { Solos }\end{array}$} & \multicolumn{3}{|c|}{$\begin{array}{c}\text { Mapa Semidetalhado } \\
(1: 50.000)^{(1)}\end{array}$} & \multirow[b]{2}{*}{ TOTAL } \\
\hline & $\begin{array}{c}\text { LE3+LRd+TE2 }{ }^{(4)} \\
\text { LV-3+LVef-3 e } 4+N v e f-3 \text { e } 4^{(5)}\end{array}$ & $\begin{array}{c}\text { LE1+LE2 } \\
\text { LV-1 +LV- } 2\end{array}$ & $\begin{array}{c}\text { PV1 } \\
\text { PV }\end{array}$ & \\
\hline $\mathrm{RQo}^{(3)}$ & $5,00^{(2)}$ & $44,97^{(2)}$ & $0,00^{(2)}$ & 49,97 \\
\hline $\mathrm{CXb}-2$ & 2,00 & 0,00 & 0,00 & 2,00 \\
\hline $\mathrm{CXb}-3$ & 3,00 & 0,00 & 0,00 & 3,00 \\
\hline $\mathrm{CXb}-4$ & 2,00 & 0,00 & 0,00 & 2,00 \\
\hline CXef-1 & 2,00 & 0,00 & 0,00 & 2,00 \\
\hline LVA-1 & 3,00 & 17,00 & 0,00 & 20,00 \\
\hline LVA-2 & 2,00 & 4,00 & 0,00 & 6,00 \\
\hline LVA-3 & 4,00 & 0,00 & 0,00 & 4,00 \\
\hline LV-1 & 31,00 & 181,80 & 0,00 & 212,80 \\
\hline LV-2 & 9,00 & 4,00 & 0,00 & 13,00 \\
\hline LV-3 & 26,00 & 0,00 & 0,00 & 26,00 \\
\hline LV-4 & 12,00 & 0,00 & 0,00 & 12,00 \\
\hline LVef-3 & 3,00 & 0,00 & 0,00 & 3,00 \\
\hline LVef-4 & 8,00 & 0,00 & 0,00 & 8,00 \\
\hline NV-3 & 2,00 & 0,00 & 0,00 & 2,00 \\
\hline NV-4 & 14,00 & 0,00 & 0,00 & 14,00 \\
\hline NVef-3 & 3,99 & 0,00 & 0,00 & 3,99 \\
\hline NVef-4 & 10,00 & 0,00 & 0,00 & 10,00 \\
\hline PA-1 & 0,00 & 1,00 & 0,00 & 1,00 \\
\hline PA-2 & 0,00 & 1,00 & 0,00 & 1,00 \\
\hline PVA-1 & 0,98 & 5,98 & 0,00 & 6,97 \\
\hline PVA-2 & 0,00 & 3,00 & 0,00 & 3,00 \\
\hline PVA-3 & 1,00 & 0,00 & 0,00 & 1,00 \\
\hline PVA -4 & 2,00 & 0,00 & 0,00 & 2,00 \\
\hline PV-1 & 6,00 & 13,00 & 0,00 & 19,00 \\
\hline PV-2 & 19,00 & 9,94 & 1,00 & 29,94 \\
\hline PV-3 & 13,00 & 0,00 & 0,00 & 13,00 \\
\hline PV-4 & 2,00 & 0,00 & 0,00 & 2,00 \\
\hline TOTAL (ha) & 186,0 & 285,7 & 1,0 & 472,7 \\
\hline Mapa detalhado tradicional & $\mathrm{LE} 3+\mathrm{LRd}+\mathrm{TE} 2^{(4)}$ & LE1+LE2 & PV1 & TOTAL \\
\hline$(1: 10.000)^{(1)}$ & $\mathrm{LV}+\mathrm{LVef}+\mathrm{Nvef}^{(5)}$ & LV & PV & \\
\hline $\mathrm{CXb}$ & 7,00 & 0,00 & 0,00 & 7,00 \\
\hline CXef & 2,00 & 0,00 & 0,00 & 2,00 \\
\hline LVA & 9,00 & 21,00 & 0,00 & 30,00 \\
\hline LV & 78,00 & 185,80 & 0,00 & 263,80 \\
\hline LVef & 11,00 & 0,00 & 0,00 & 11,00 \\
\hline NV & 16,00 & 0,00 & 0,00 & 16,00 \\
\hline NVef & 13,99 & 0,00 & 0,00 & 13,99 \\
\hline PA & 0,00 & 2,00 & 0,00 & 2,00 \\
\hline PVA & 3,98 & 8,98 & 0,00 & 12,97 \\
\hline PV & 40,00 & 22,94 & 1,00 & 63,94 \\
\hline RQo & 5,00 & 44,97 & 0,00 & 49,97 \\
\hline TOTAL (ha) & 185,97 & 285,70 & 1,00 & 472,67 \\
\hline
\end{tabular}

Escala do mapa base

2 Área em ha de coincidência ou erro entre os levantamentos detalhado tradicional e semi-detalhado e detalhado por textura e semi-detalhado

${ }^{3}$ Nomenclatura de acordo com a nova classificação Embrapa (1999)

${ }^{4}$ Nomenclatura de acordo com o mapa original Oliveira et al. (1981)

${ }^{5}$ Aproximação realizada no trabalho entre as nomenclaturas do mapa semidetalhado e nomenclatura Embrapa (1999) 
Tabela 4. Comparação entre os níveis de levantamento de solos.

\begin{tabular}{lccccc}
\hline & $\begin{array}{c}\mathrm{N}^{0} \mathrm{de} \\
\text { tradagens }\end{array}$ & $\begin{array}{c}\text { (a.m.m. }^{(1)} \\
\mathrm{m}^{2}\end{array}$ & $\begin{array}{c}\text { Escala mapa } \\
\text { Base }\end{array}$ & $\begin{array}{c}\text { Escala } \\
\text { publicação }\end{array}$ & $\begin{array}{c}\mathrm{N}^{0} \text { de classes } \\
\text { de solos }\end{array}$ \\
\hline Detalhado tradicional & 473 & 31,62 & $1: 10.000$ & $1: 10.000$ & 11 \\
Detalhado Textura & 473 & 31,62 & $1: 10.000$ & $1: 10.000$ & 28 \\
Semi detalhado & $4^{(2)}$ & 632,40 & $1: 50.000$ & $1: 100.000$ & 3 \\
\hline
\end{tabular}

\footnotetext{
(1) Área mínima mapeável - (a.m.m.) $=\left[\text { Escala } x(0,4)^{1 / 2} / 100\right]^{2}$;

${ }^{(2)}$ Valores supostos realizados na área em função das informações dos mapeamentos.
} 


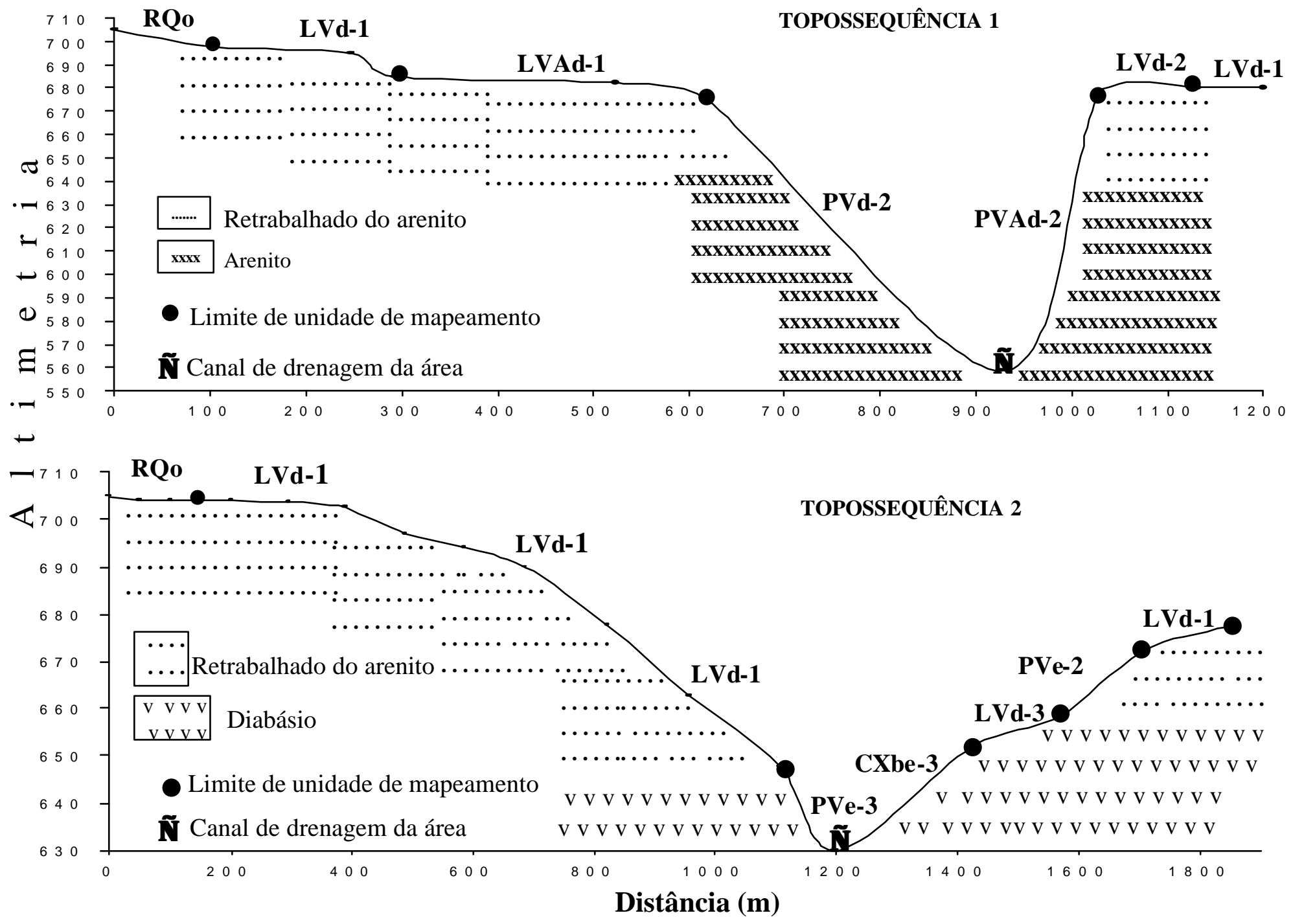

Figura 1 - Variabilidade espacial dos solos nas principais topossequências da área de estudo. 

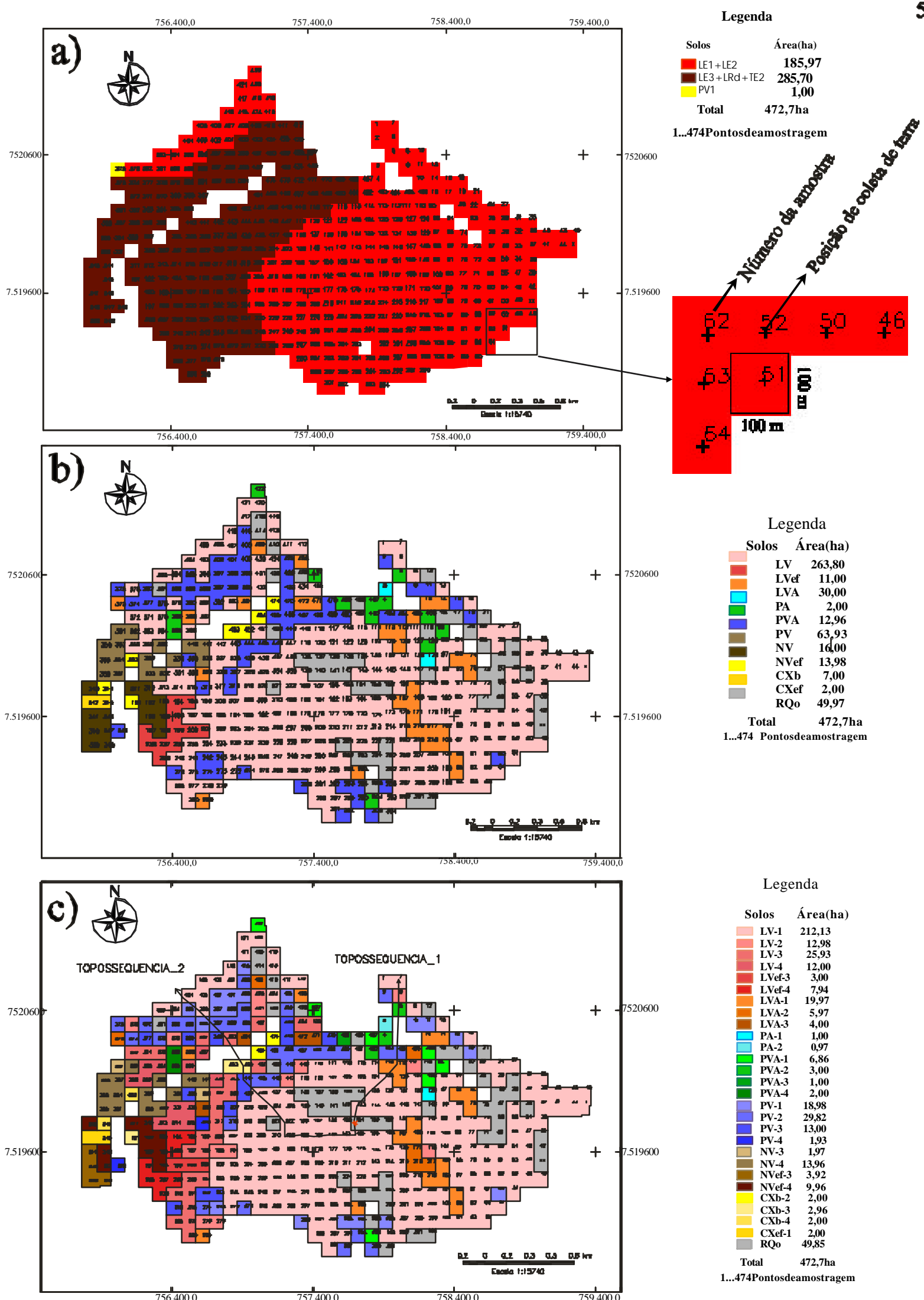

Figura 2- Mapas representativos dos lovantamentos de pedológicos e grade do amostragem de terra: a) semidetalhado (Oliveira et al., 1981); b) Detalhado tradicional; c) Detalhado por textura e posicāa das topossequetncias na arrea de estudo. 


\section{ANÁLISES ESPECTRAIS, ORBITAIS E TERRESTRES NA CARACTERIZAÇÃO E DISCRIMINAÇÃO DE SOLOS EM SEQÜÊNCIAS TOPOGRÁFICAS}

Resumo

O objetivo do presente trabalho foi avaliar a possibilidade de discriminar os solos em topossequências, por diferentes níveis de aquisição espectrais (orbital, campo e laboratório), pela utilização de duas metodologias: a caracterização qualitativa e estatística das curvas espectrais, comparando os resultados com avaliações pedológicas de campo. Foram estabelecidas duas topossequências e nelas demarcados pontos eqüidistantes em $100 \mathrm{~m}$, onde foram coletadas amostras de terra nas profundidades 0-20 e 80-100 cm, designadas de A e B, respectivamente, todas georreferenciadas. Das amostras de solos foram extraídas informações pertinentes ao levantamento pedológico como a cor, análises químicas, granulométricas e de ferro total. Com o resultado das análises foram determinados os locais dos perfis de solos, os quais foram descritos e classificados. A obtenção dos dados espectrais foi realizada em três níveis, sendo para o orbital utilizada as bandas 1, 2, 3, 4, 5 e 7 do TM-Landsat, devidamente corrigidas, no 
campo, utilizou-se o sensor o FieldSpec Spectroradiometer e em laboratório o sensor IRIS.

\section{ORBITAL AND TERRESTRIAL SPECTRAL ANALYSIS ON THE CHARACTERIZATION AND DISCRIMINATION OF SOILS ON TOPOGRAPHIC SEQUENCES}

\section{Summary}

The objective of the present work was to evaluate the possibility on discrimination of soils in topossequences, by different spectral acquisition levels (field, laboratory and orbital), using two methodologies: qualitative and statistical characterization of the spectral curves, comparing the results with field pedologic evaluations. Two topossequences were established and points were demarcated each 100 $\mathrm{m}$, where earth samples were collected in the depths 0-20 and 80-100 cm, all georreferenced. From soil samples were extracted information about soil survey as the colour, chemical, granulometric and total iron content analyses. With this results the profiles places were determined, after that they were described and classified. The spectral data were obtained in three levels, for orbital data the bands used were 1, 2, 3, 4, 5 and 7 of TM-Landsat 5, properly corrected, in the field, the sensor was FieldSpec Spectroradiometer was used and in laboratory the IRIS sensor. 


\subsection{Introdução}

O monitoramento dos solos é um dos grandes desafios dos cientistas. Os solos são a base para a produção de alimentos e a intensidade de sua utilização vem aumentando significativamente. Por outro lado, o solo é um recurso natural não renovável a curto prazo e encontra-se disponível em quantidade limitada. Torna-se, então, esforços na sua preservação e utilização racional. Para tanto, é necessário o conhecimento de seus atributos químicos e físicos bem como a sua espacialização, que só é possível quando se tem em mãos levantamentos pedológicos em escalas compatíveis com os vários tipos de demanda. Neste aspecto, o Brasil possui grande extensão territorial, porém, mapas de solos na maioria no nível de reconhecimento (Oliveira, 1988).

Por muitos anos, principalmente entre 1965 e 1985, esforços foram concentrados na realização de levantamentos pedológicos. Porém, por diversos fatores, poucos Estados contam com levantamentos a níveis mais detalhados que os de reconhecimento. Nos Estados Unidos da América, a taxa de mapeamento de solos varia de 120 a 240 ha por dia, para levantamentos detalhados, ou 288.000 ha de levantamentos anuais (Morse, 1999). No Brasil, um dos mais recentes materiais refere-se ao mapa de reconhecimento dos solos do Estado de São Paulo publicado por Oliveira et al. (1999), sendo essa uma compilação e reavaliação de dados anteriormente cartografados e adequados ao novo sistema de classificação de solos vigente (Embrapa, 1999).

Esses fatos levaram a reacender discussões sobre a necessidade dos levantamentos pedológicos bem como em relação a quase inexistência de pedológos no 
Brasil (Dalmolin, 1999). Essa discussão leva ao seguinte questionamento: "Se todos concordam com a importância do levantamento de solos no sistema ambiental e produtivo, por que poucos trabalhos discutem tal assunto?" A resposta pode estar na necessidade de implementação de novas tecnologias nos levantamentos pedológicos, que melhorem sua qualidade e grau de detalhamento (Demattê, 2001).

Nos últimos 30 anos a espectroscopia tem sido utilizada na diferenciação de tipos de solos. As pesquisas revelaram que solos com características diferentes podem ser discriminados por medidas de reflectância, como realizado por Condit (1972). Com o desenvolvimento de novos sensores (Madeira Netto, 1996), a exploração científica do sensoriamento remoto no estudo de solos vem se aprimorando, bem como novas metodologias (Palacios-Orueta \& Ustin, 1996). O estudo de características dos solos por meio de técnicas espectrais tem auxiliado técnicos e pesquisadores no seu reconhecimento (Zhang et al., 1992; Csillag et al., 1993; Formaggio et al., 1996). Um melhor entendimento de como tais características dos solos atuam na reflectância deve ser buscado cada vez mais e nos mais diferentes ambientes, como afirmam Henderson et al. (1989) e Ben-Dor (2002).

No processo de levantamento de solos existem várias fases, que vão desde a marcação de pontos de observação, caracterização dos solos na paisagem e delimitação das unidades de mapeamento (Embrapa, 1989). Grande parte dos trabalhos atua na caracterização espectral dos solos (Formaggio, 1983; Epiphanio et al., 1992), que vem auxiliar numa dessas etapas, porém, sem estabelecer relações com as variações ao longo do relevo. Poucos trabalhos relacionam as alternâncias de classes de solos numa topossequência com os dados espectrais, como realizado por Demattê et al. (1998). A 
compartimentação detalhada das unidades geomórficas de uma vertente, é de grande importância na avaliação dos processos morfogenéticos responsáveis pela retirada, translocação e deposição de sedimentos ao longo de uma encosta. Tais processos desempenham papel decisivo no comportamento morfopedológico, sendo muitas vezes condicionadores de diferenciações topossequenciais das propriedades do solo (Gerrard, 1981). Demattê \& Marconi (1991) observaram a relação entre o grau de evolução de solos e sua posição na paisagem e concluíram que tais relaçães são dependentes da maior ou menor drenagem. Ou seja, existe a necessidade de relacionar as variações dos solos ao longo de uma topossequência com o sensoriamento remoto.

Os trabalhos de base (sensores terrestres) para o entendimento das relações entre reflectância e atributos dos solos, apesar de poucos no Brasil (Formaggio et al., 1996; Galvão et al., 1997), mostra-se extensa no exterior (Stoner \& Baumgardner, 1981; Henderson et al., 1992; Ben-Dor \& Banin, 1995). Trabalhos com sensores no nível orbital também têm sido realizados como os de Agbu et al. (1990) e Nanni \& Rocha (1997). Entretanto, conforme verificado por Ben-Dor (2002), a escassez de dados espectrais obtidos por sensores nesse nível ainda é grande. Por sua vez, se não temos padrões espectrais de dados orbitais, como colocar em prática o sensoriamento remoto a serviço do monitoramento do solo, como afirmado no início?

A modernização dos sensores, as novas metodologias com diferentes níveis de aquisição, bem como a melhor compreensão das características espectrais solopaisagem, podem vir a ser de extrema importância para diminuir o custo e o tempo gasto para confecção de mapas pedológicos em escalas compatíveis com as reais necessidades agronômicas brasileiras. 
O objetivo do presente trabalho foi avaliar a possibilidade de discriminar os solos em topossequências, por diferentes níveis de aquisição espectral (orbital, campo e laboratório), pela utilização de duas metodologias: a caracterização qualitativa e estatística das curvas espectrais, comparando os resultados com avaliações pedológicas de campo. Os solos apresentam estreita correlação com o comprimento de onda, significando que os seus atributos podem afetar a reflectância de maneira diferenciada nas diferentes regiões do espectro óptico (Henderson et al., 1992). Considerando que numa topossequência, os processos pedogenéticos de formação dos solos e da paisagem, proporcionam atributos dos solos diferenciados, e que cada atributo influencia a energia refletida, é de se esperar que ela se modifique ao longo da vertente.

\subsection{Material e Métodos}

\subsubsection{Caracterização da área de estudo}

A área localiza-se ao sudoeste do Estado de São Paulo, na região de Barra Bonita. É delimitada pelas coordenadas geográficas $22^{\circ} 26^{\prime} 2,37^{\prime \prime}$ - $22^{\circ} 23^{\prime} 16,53^{\prime \prime}$ latitude sul e $48^{\circ} 31^{\prime} 24,22^{\prime \prime}$ - 48 $27^{\prime} 51,77^{\prime \prime}$ longitude oeste. Apresenta 473 ha, cultivados com cana-de-açúcar em altitudes variando entre 520 e 710 metros do nível médio do mar. O clima da região, baseado na classificação de Köppen, é do tipo Cwa, clima mesotérmico (Sentelhas et al., 1998). A Iitologia é representada principalmente pela ocorrência da Formação Serra Geral, a qual se caracteriza por compreender um conjunto de derrames de basalto entre os quais se intercalam arenitos com as mesmas 
características da Formação Botucatu. Aparece ainda a Formação Itaqueri do grupo Bauru que se caracteriza por arenitos com cimento argiloso, folhelhos e conglomerados, predominando os arenitos (IPT, 1981).

Foram estabelecidas duas topossequências e nelas demarcados pontos equidistantes em $100 \mathrm{~m}$, onde foram coletadas amostras de terra nas profundidades 0-20 e 80-100 cm, designadas de Camadas A e B, respectivamente, referentes aos horizontes A e B. A cor do solo foi obtida na forma úmida com o equipamento Minolta CR 300 com chip para cor de Munsel (Post et al., 1994; Campos, 2002). Foram realizadas análises químicas (Raij et al., 1987), granulométricas e de ferro total (Camargo et al., 1987). Com o resultado das análises foram determinados os locais dos perfis de solos, os quais foram descritos (Lemos \& Santos, 1996) e os solos classificados de acordo com Embrapa (1999). Para fins de comparação, os solos foram discriminados por classes de textura sendo: Arenosa $\left(<150 \mathrm{~g} \mathrm{~kg}^{-1}\right.$ de argila), Média 1 (1) $\left(>150 \mathrm{e}<250 \mathrm{~g} \mathrm{~kg}^{-1} \mathrm{de}\right.$ argila), Média 2 (2) (>250 e <350 $\mathrm{g} \mathrm{kg}^{-1}$ de argila), Argilosa (3) (>350 e <600 g kg ${ }^{-1}$ de argila) e Muito Argilosa (4) ( > $600 \mathrm{~g} \mathrm{~kg}^{-1}$ de argila). Assim, foram obtidas as seguintes classes de solos nas duas topossequências, sendo: CAMBISSOLOS HÁPLICOS Tb Eutrófico, textura argilosa, >350 e <600 $\mathrm{g} \mathrm{kg}^{-1}$ (Cxbe-3), LATOSSOLOS VERMELHOAMARELOS Distróficos, textura média 1150 - $250 \mathrm{~g} \mathrm{~kg}^{-1}$ (LVAd-1), LATOSSOLOS VERMELHOS Distróficos, textura média 1 (LVd-1), LATOSSOLOS VERMELHOS Distróficos, textura média 2, 250 - $350 \mathrm{~g} \mathrm{~kg}^{-1}$ (LVd-2), LATOSSOLOS VERMELHOS Distróficos, textura argilosa (LVd-3), ARGISSOLOS VERMELHO-AMARELOS Distróficos, textura arenosa/média 2 (PVAd-2), ARGISSOLOS VERMELHOS Distróficos, textura arenosa/média 2 (PVd-2), ARGISSOLOS VERMELHOS 
Eutróficos, textura arenosa/média 2 (PVe-2), ARGISSOLOS VERMELHOS Eutróficos, textura média/argilosa (PVe-3), NEOSSOLOS QUARTZARÊNICOS Órticos (RQo).

\subsubsection{Obtenção dos dados espectrais}

Para o nível orbital, foi utilizada uma cena TM-Landsat-5 nas bandas 1, 2, 3, 4, 5 e 7. Após definida a área, foi realizado o corte na imagem no programa IMPIMA (INPE, 1999). A imagem de satélite apresenta para cada pixel um valor de nível de cinza (Crósta, 1992). Conforme descrito por Epiphanio \& Formaggio (1988), a análise quantitativa de imagens digitais sobre o comportamento espectral de alvos deve ser feita com os dados em reflectância, por ser uma grandeza física intrínseca dos alvos, ao passo que os números digitais são valores transformados para a obtenção das imagens orbitais. Os valores de níveis de cinza devem ser transformados em reflectância e devidamente ajustados aos efeitos atmosféricos e posteriormente os números digitais convertidos em valores de reflectância real. Para tanto, foi utilizado o modelo 5S (Simulação do Sinal do Satélite dentro do Espectro Solar) (Tanré et al., 1992) e detalhadamente descrito por Zullo Jr. (1994). Após o processo de conversão e correção, o nível de cinza zero presente na imagem passou a corresponder à reflectância 0 \% e o nível de cinza 255, à reflectância $100 \%$.

Para adequar o posicionamento da imagem com a verdade de campo, a correção geométrica se faz necessária; dessa forma, utilizaram-se as cartas planialtimétricas SF22-Z-B-II-4-SE-B，SF-22-Z-B-III-3-SO-A，SF-22-Z-B-III-3-SO-C e SF-22-Z-B-II-4SE-D elaboradas em escala 1:10.000 pela Coordenadoria de Ação Regional - Divisão 
Cartográfica - da secretária de economia e planejamento do Estado de São Paulo, no ano de 1980, além de pontos obtidos no campo com GPS. Objetivando manter o valor do pixel o mais semelhante possível ao seu valor original, utilizou-se o método de interpolação do vizinho mais próximo, corrigindo apenas as distorções de escala, deslocamento ou rotação existentes entre a imagem e a projeção terrestre (Crósta, 1992). Uma vez registrada, a cena foi visualizada em composição colorida R/G/B, bandas 1/2/3 e 4/5/7 e cruzadas, ou seja, sobrepostas ao plano de informação que continha os pontos de amostragem nas topossequências e obtidos os valores de reflectância para cada banda possibilitando gerar curvas espectrais orbitais.

Para obtenção dos dados espectrais de campo, foi utilizado o FieldSpec Spectroradiometer, que recobre a faixa espectral entre 450 e $2.500 \mathrm{~nm}$ com resolução espectral de $1,4 \mathrm{~nm}$ entre 450 e $1.050 \mathrm{~nm}$ e $3 \mathrm{~nm}$ de 1.050 a $2.500 \mathrm{~nm}$. A geometria utilizado foi: placa padrão branca com 100 \% de reflectância calibrada pela Labsphere (1996); distância de $1 \mathrm{~m}$ entre alvo-sensor (na direção da cintura do operador); fonte de iluminação o sol, procurando obter as amostras em dias sem nuvens com boa intensidade luminosa. As amostragens foram realizadas num mesmo período do dia, das 10:00 hs às 14:00 hs. Em cada ponto de amostragem foi obtida a média de 50 leituras. A interferência marcante da água e da atmosfera observada na curva espectral, fez necessário eliminar partes das curvas nas faixas de 1.350-1.450 e 1.790-2.000 nm e não considerando-se os valores acima de $2.400 \mathrm{~nm}$.

Para a obtenção dos dados espectrais de laboratório, foi utilizado o sensor InfraRed Intelligent Spectroradiometer, IRIS (Geophysical \& Environmental Research Corporation, 1996), que recobre a faixa espectral entre 450 e $2.500 \mathrm{~nm}$. As amostras do 
horizonte A foram secas em estufa a $45^{\circ} \mathrm{C}$ por 24 horas, moídas e peneiradas (malha de 2 $\mathrm{mm}$ ), para homogeneização dos efeitos da umidade e rugosidade (Epiphanio et al., 1992). Posteriormente, as amostras foram acondicionadas em placas de petri e iluminadas por uma lâmpada halógena de 650 W. Utilizourse a placa padrão, com 100 \% de reflectância calibrada pela Labsphere (1996). A geometria utilizada foi: $61 \mathrm{~cm}$ lâmpada-alvo e alvo-sensor: $27 \mathrm{~cm}$. Posteriormente, os dados passaram por um software (Conviris), que calibrou os dados da placa de referência e realizou uma filtragem destes, eliminando o excesso de ruídos, para facilitar a interpretação. A relação entre a energia refletida pelo alvo e a energia refletida pela placa de referência gerou o fator de reflectância bidirecional (Nicodemus et al., 1977). Foram realizadas três leituras em cada amostra, sendo utilizada a curva espectral média nas discussões.

As curvas espectrais obtidas em laboratório e campo, foram avaliadas por análises qualitativas (descritivas) quanto aos tipos, de acordo com Formaggio et al. (1996). Também foram observados intervalos de comprimento de onda característicos tais como: 400-600 e 780-1.190 nm relacionados as faixas de atuação dos óxidos de ferro; as inflexões presentes em 1.400, 1.900 e 2.200 nm, relacionadas principalmente à presença de grupos $\mathrm{OH}^{\top}$ na estrutura dos minerais silicatados, $2.265 \mathrm{~nm}$ gibssita e 2.393 nm com provável presença de MgOH (Vitorello \& Galvão, 1996).

\subsubsection{Análise estatística dos dados espectrais}

Com o objetivo de definir grupos homogêneos mediante a união de células em função de seus valores quantitativos, foi utilizada a análise de grupamentos ou "Cluster 
Analysis" (Average Linkage), com o programa Statistical Analysis System (SAS, 1999). A análise de grupamentos consiste numa variedade de técnicas e algoritmos cujo objetivo é o de juntar unidades em grupos semelhantes. Para tanto, primeiramente foram determinadas, mediante avaliação de todas as curvas espectrais dos solos, as principais bandas que poderiam auxiliar na sua discriminação, bem como indicar as tendências nas curvas. Foram selecionadas para os dados espectrais de laboratório 22 bandas (em $\mathrm{nm}$ ): B1: 450-481, B2: 481, B3: 481-596, B4: 596-710, B5: 710-814, B6: 814-975, B7: 9751350, B8: 1350-1417, B9: 1417, B10: 1417-1449, B11: 1449-1793, B12: 1793-1831, B13: 1865-1927, B14: 1927, B15: 1927-2102, B16: 2101-2139, B17: 2139-2206, B18: 2206, B19: 2206-2258, B20: 2258, B21: 2258-2389, B22: 2389-2498, H1: 469-532, H2: 532-768, H3: 768-876, H4: 876-1353, H5: 1353-1411, H6: 1411-1439, H7: 14391783, H8: 1860-1923, H9: 1923-2120, H10: 2120-2206, H11: 2206-2258, H12: 22582389, H13: 2389-2498, sugeridas por Nanni (2000) e ilustradas na Figura 1. Para os dados espectrais de campo, as bandas $8,9,10,12,13,14,15,20,21,22$ e alturas 4, 5, 6, 12 e 13 não participaram das análises estatísticas devido à interferência da água e da atmosfera. Para os dados orbitais foram utilizadas as bandas TM-Landsat-5 (em nm): B1 450-520, B2 520-600, B3 630-690, B4 760-900, B5 1150-1750, B7 2080-2350.

\subsection{Resultados e Discussão}

A classificação dos solos nas topossequências foi realizada de acordo com Embrapa (1999), onde o horizonte diagnóstico subsuperficial identifica a ordem do solo. Porém, no presente trabalho objetivourse comparar a utilização de sensores em três 
níveis, laboratório, campo e orbital, os quais analisaram apenas as amostras de superfície, horizonte A. Estas amostras podem ser separadas em dois grupos, um mais argiloso com cores amarelas ou vermelhas em superfície e outro mais arenoso, com cores mais amarelas (Tabela 1). Dessa forma serão discutidos três métodos de avaliação dessas curvas nas topossequências: a) o qualitativo; b) a comparação dos tipos de curvas de acordo com Formaggio et al. (1996); e c) o método estatístico; sempre visando separar as curvas em grupos semelhantes para fins de diferenciação de limites de mapeamento de solos.

\subsubsection{Caracterização qualitativa das curvas espectrais nas topossequências}

Para curvas de laboratório, campo e orbitais na primeira topossequência (Figura 2), parece não haver descritivamente diferenciação de grupos entre os solos observados. Tal fato se justifica pela textura mais arenosa do horizonte superficial, na seguinte ordem crescente de teores de argila: PVA-2 $\left(120 \mathrm{~g} \mathrm{~kg}^{-1}\right)<\mathrm{PV}-2\left(121 \mathrm{~g} \mathrm{~kg}^{-1}\right)<$ RQo $(126$

$\left.\mathrm{g} \mathrm{kg}^{-1}\right)<\mathrm{LV}-1\left(151 \mathrm{~g} \mathrm{~kg}^{-1}\right)<\mathrm{LVA}-1\left(173 \mathrm{~g} \mathrm{~kg}^{-1}\right)<\mathrm{LV}-2\left(180 \mathrm{~g} \mathrm{~kg}^{-1}\right)$ o que faz com que a intensidade de reflectância das curvas e suas feições de absorção se assemelhem, principalmente para as curvas de laboratório (Figura 2a). Para as curvas de campo e orbitais, são verificadas diferenças de intensidade, principalmente para os comprimentos de onda de 1.550 - $1.750 \mathrm{~nm}$ (Banda 5) e 2.080 - $2.350 \mathrm{~nm}$ (Banda 7) (Figuras 2b, c). A intensidade de reflectância para os solos nas curvas de campo e orbital mantém-se basicamente na mesma ordem, a qual difere nas curvas de laboratório. Sendo a textura, teor de óxidos de ferro, matéria orgânica, material de origem e cor desses solos muito 
semelhantes (Tabela 1) a diferença entre os ambientes de coleta dos dados, sem controle (campo e orbital) e controlado (laboratório) pode ter interferido nas respostas espectrais, onde a umidade do solo assume papel importante, pois interfere diretamente na intensidade da curva. Segundo Ben-dor (2002), sem controle do meio, a interpretação dos dados é dificultada, pois a energia eletromagnética interage com a atmosfera (gases e partículas de aerossol) causando interpretações errôneas, mesmo quando se realizam as correções necessárias.

Na segunda topossequência (Figura 3), observou-se que as curvas espectrais para os três níveis estudados, promoveram a formação de dois grupos. Um primeiro com solos mais argilosos (PV-3, Cxb-3 e LV-3) com baixa intensidade de reflectância entre (10 e $20 \%$ ) e maiores teores de ferro, observados pela maior concavidade centrada a 850 nm (Demattê \& Garcia, 1999), concordando com observações de Epiphanio et al. (1992) e as análises (Tabela 1). Para o segundo grupo de solos, mais arenosos (RQo, LV-1, PV-2), a intensidade de reflectância é maior (entre 20 e $35 \%$ ) e apresentam menores teores de óxidos de ferro, com menor absorção centrada em $850 \mathrm{~nm}$, comprovado pelas análises (Figura 3).

A maior diferenciação entre as intensidades de reflectância entre os grupos pode ser notada principalmente nos comprimentos de onda das bandas $5(1.550-1.750 \mathrm{~nm})$ e 7 (2.080-2.350 nm). Segundo Demattê et al. (2000), o aumento dos teores de ferro e argila pode ser observado com uma diminuição da intensidade de reflectância próximo à banda 5 (1.550-1.750 nm), o que está de acordo com as curvas espectrais (Figura 3). Drury \& Hunt (1988) obtiveram bons resultados na interpretação de rochas básicas e ultrabásicas, através da observação de curvas espectrais obtidas do TM-Landsat 5 nas bandas 4 (760 a 
$900 \mathrm{~nm}), 5(1550$ a $1750 \mathrm{~nm})$ e 7 (2080 a $2350 \mathrm{~nm})$. Para Davis et al. (1987), a análise de imagens do TM-Landsat permitiu a diferenciação de rochas basálticas e sedimentares do sudoeste dos Estados Unidos da América, para as bandas 1, 4 e 5 a ideal.

Nos três níveis de aquisição de dados, as curvas espectrais seguiram as mesmas tendências para os diferentes solos na topossequência 1. Sendo que para a topossequência 2, a análise qualitativo separou dois grupos de solos (um argiloso e outro arenoso).

\subsubsection{Comparação das curvas obtidas nas topossequências e os tipos descritos em}

\section{literatura}

Observando a Figura 4, pode-se comparar as curvas espectrais obtidas nas duas topossequências, para laboratório e campo, com os quatro padrões espectrais descritos por Formaggio et al. (1996). Na primeira topossequência, em todas as curvas espectrais de laboratório e de campo (RQo, LV-1, LVA-1, PV-2, PVA-2, LV-2), o padrão que mais se assemelha é o tipo d, onde, entre $450 \mathrm{~nm}$ e $1.000 \mathrm{~nm}$ há a influência dos óxidos de ferro, com maior absorção nos comprimentos de onda menores que 550 nm (Figura 4) (Demattê \& Garcia, 1999). Tal absorção está relacionada a presença de formas trivalentes de ferro $\left(\mathrm{Fe}^{+3}\right)$ as quais, segundo Hunt et al. (1970), ocorrem devido à transferência de carga metal-ligante $\left(\mathrm{Fe}^{+3}-\mathrm{O}^{-2}\right)$ centralizado no ultravioleta, mas cujo flanco de baixa energia se situa no domínio do visível. Esses solos apresentam baixos teores de ferro (entre $17 \mathrm{~g} \mathrm{~kg}^{-1}$ e $49 \mathrm{~g} \mathrm{~kg}^{-1}$ ), o que está de acordo com os resultados observados por Formaggio et al. (1996), que também verificaram a banda de absorção 
centrada em $850 \mathrm{~nm}$ atribuída aos óxidos de ferro, sendo um dos fatores que diferenciam o tipo a do tipo d entre 450 e 1000 nm (Figura 4).

Para as curvas de campo é interessante chamar a atenção entre 2300 e 2450 nm, onde a curva padrão tem uma tendência descendente, o que não é verificado nas curvas de campo que se mantêm constantes (Figura 4).

Na topossequência 2, para os dados de laboratório e de campo, os solos PV-3, Cxb-3 e LV-3 apresentam curvas espectrais semelhantes e foram classificados como tipo a (Figura 4). Em comum esses solos apresentam o mesmo material de origem (basalto), tendo uma textura mais argilosa, com teores de ferro variando de 84 e $144 \mathrm{~g} \mathrm{~kg}^{-1}$, porém com cores mais amareladas em superfície (entre 2.9 e 4.2 YR), maiores teores de goethita e cores mais vermelhas em subsuperficie, maior presença de hematita (Tabela 1). Para Formaggio et al. (1996), a curva padrão tipo a apresenta elevados valores de ferro total (> $180 \mathrm{~g} \mathrm{~kg}^{-1} \mathrm{e}<400 \mathrm{~g} \mathrm{~kg}^{-1}$ ), o que não condiz com os valores observados para os solos em estudo, porém encaixando-se nos outros aspectos como, cor, intensidade de reflectância e baixas feições de absorção no visível e infravermelho. Para o RQo, LV-1 e PV-2, as curvas espectrais foram classificadas como tipo d, para os dados de laboratório e campo. Esses solos apresentam como material de origem arenitos com cimento argiloso, textura arenosa em superfície, cores amareladas (2.7 YR a 3.1 YR) e baixos teores de ferro total, condizendo com os resultados obtidos por Formaggio et al. (1996).

Para fins de diferenciação de unidades de mapeamento utilizando os padrões citados por Formaggio et al. (1996), as curvas de laboratório e campo na topossequência 1 permaneceram no mesmo grupo, tipo d. Para a topossequência 2, tanto as curvas de 
laboratório como as de campo, obtiveram dois grupos o tipo a e o tipo d. A comparação com os tipos de curvas descritos por Formaggio et al. (1996) e a caracterização qualitativo das curvas, levaram aos mesmos resultados em relação a grupos de mapeamento.

\subsubsection{Limites de unidades de mapeamento estabelecidos pelo método estatístico espectral}

A análise de cluster, tanto para a primeira como para a segunda topossequência, separou as curvas de laboratório em três grupos (G1, G2 e G3), para os dados orbitais em dois grupos (G1 e G2). Para os dados de campo, três grupos na primeira topossequência (G1, G2 e G3) e cinco grupos na segunda topossequência (G1, G2, G3, G4 e G5) (Figura 5 e 6). O método estatístico, de certa forma, promoveu uma maior diferenciação de grupos quando comparados com os resultados obtidos nos métodos qualitativo e comparação entre os tipos de curvas, os quais estão sujeitos à subjetividade do classificador. O que está de acordo com Vettorazzi (1988) para o qual aplicação da análise estatística orientou a operação de agrupamento de indivíduos semelhantes de maneira a eliminar parcialmente a subjetividade.

Na primeira topossequência, para os resultados de laboratório, o G1 é formado pela maioria das classes de solos, exceto o PVA2 que foi colocado sozinho no G2 e o LV1 que aparece no G1 e no G3 (Figura 5). Tal fato pode ser explicado pela baixa diferenciação das amostras do horizonte $\mathrm{A}$, em relação à textura, cor, matéria orgânica e material de origem (Tabela 1). As curvas espectrais apresentam feições semelhantes, 
variando de um grupo para outro principalmente pela intensidade de reflectância (Figura 5). Para as curvas de campo, o G1 é representado por RQo, LV1, LVA1; o G2 pelo LV1 e PV2 e o G3 pelo LV1 e LV2 (Figura 5). Pode-se notar que os solos sofreram uma distribuição diferente quando comparados aos dados de laboratório, o que pode ser devido a diferença existente entre o ambiente controlado e o não controlado que é mais influenciado pela umidade de campo e fatores atmosféricos (Ben-Dor, 2002). As curvas espectrais apresentam as mesmas feições dentro dos grupos variando principalmente de intensidade. Para o G2, apesar de intensidades diferentes entre as curvas PV2 e o LV1, pode-se observar em $2.200 \mathrm{~nm}$ uma maior absorção pelos minerais 1:1 (Figura 5), concordando com Hauff et al. (1990). Para o cluster das curvas orbitais, a maior diferenciação nas intensidades de reflectância entre os grupos está próxima às bandas 5 e 7, que estão associadas às diferenças de teores de argila e de ferro (Demattê et al., 1999) (Tabela 1) e concordam com observações de Demattê et al. (2000).

Com relação à distribuição espacial dos grupos na topossequência, para os três níveis, parece não haver coincidência com a verdade de campo, devido principalmente à semelhança entre as análises químicas e físicas das amostras. Mesmo assim, o método estatístico promoveu maior separabilidade dos dados, podendo nortear o traçado de limites de unidades de mapeamento. A aplicação de análise de grupamentos e a criação de dendogramas como procedimento adotado para a delimitação de unidades homogêneas para auxiliar a confecção de mapas pedológicos vem mostrando potencial, como destacam Nanni (1995) e Nanni \& Demattê (2001).

Na segunda topossequência, as curvas de laboratório, campo e orbital, os pontos de amostragem estão agrupados no G1, com solos RQo e LV1 textura arenosa, baixos 
teores de matéria orgânica e cores mais amarelas (Tabela 1). Dessa forma apresentam maior intensidade de reflectância (25-35 \%) e feições de absorção bem evidentes para as curvas de laboratório e campo, em $850 \mathrm{~nm}$ para óxidos de ferro, $1.950 \mathrm{~nm}$ para água e grupos $\mathrm{OH}$ (apenas nas curvas de laboratório) e em $2.200 \mathrm{~nm}$ para a caulinita (Stoner \& Baumgardner, 1981; Formaggio et al., 1996) (Figura 6). O G3 para as curvas de laboratório e campo e o G2 para curvas orbitais representam os solos com textura mais argilosa (PV3, Cxb3 e LV3), com uma intensidade de reflectância menor (15-19 \% para laboratório, 10-15\% campo e 10-22\% orbital). Tal fato evidencia, para as curvas de laboratório e campo, menores feições de absorção em $1.950 \mathrm{~nm}$ (água e grupos $\mathrm{OH}$ ) e $2.200 \mathrm{~nm}$ (caulinita); segundo Stoner \& Baumgardner (1981), as baixas refletividades no visível e no infravermelho são devidas à presença de magnetita, proveniente do intemperismo do basalto. Ainda segundo Hunt et al. (1971) a magnetita é um mineral tipicamente opaco e praticamente sem feições espectrais no visível e no infravermelho próximo. O que está de acordo com os resultados discutidos para o G3 para laboratório e campo (Figura 6), e curvas orbitais diferenciando-se mais próximo às bandas 5 e 7.

Nos grupos restantes de campo G2 (LV1), G4 (PV2 e LV1) e G5 (LV1), predomina textura arenosa, porém com curvas espectrais de intensidades diferentes, sendo o G5 com maior intensidade (35-45\%), o G4 com intensidades semelhantes ao G1 (25-30 \%) e o G2 (16-24 \%). Devido às características químicas e físicas dos solos desses grupos, esperava-se um comportamento espectral com menor variação de intensidade, sendo que o G4, apesar de apresentar uma intensidade semelhante ao G1 entre 1.000 e $1.800 \mathrm{~nm}$, a curva se mantém na horizontal, enquanto que as curvas do G1 nesse mesmo intervalo têm um comportamento ascendente (Figura 6). O G2, com 
menor intensidade pode ter sofrido alguma interferência de fatores não controlados no campo como umidade (Ben-dor et al., 1999).

\subsection{Conclusões}

1 - As curvas espectrais obtidas por sensores em laboratório e campo foram equivalentes às curvas padrões estabelecidas pela literatura.

2 - A textura dos solos influenciou na intensidade de reflectância das curvas espectrais em todos os níveis de aquisição de dados sensoriados. Foi possível verificar nas topossequências a separabilidade dos níveis de textura dos solos, mesmo quando essas características eram muito semelhantes.

3 - As alterações das características dos solos ao longo das topossequências, foram detectados pelos dados de energia refletida das amostras de terra, auxiliando na determinação dos pontos de ruptura dos limites das unidades de solos.

4 - A análise qualitativa ou descritiva padronizada pela literatura, mostra-se "presa" a regras pré-estabelecidas, o que concorre para dificultar a discriminação pormenorizada das curvas espectrais. 
Tabela 1. Dados médios dos atributos químicos e granulométricos das unidades de mapeamento da área de estudo.

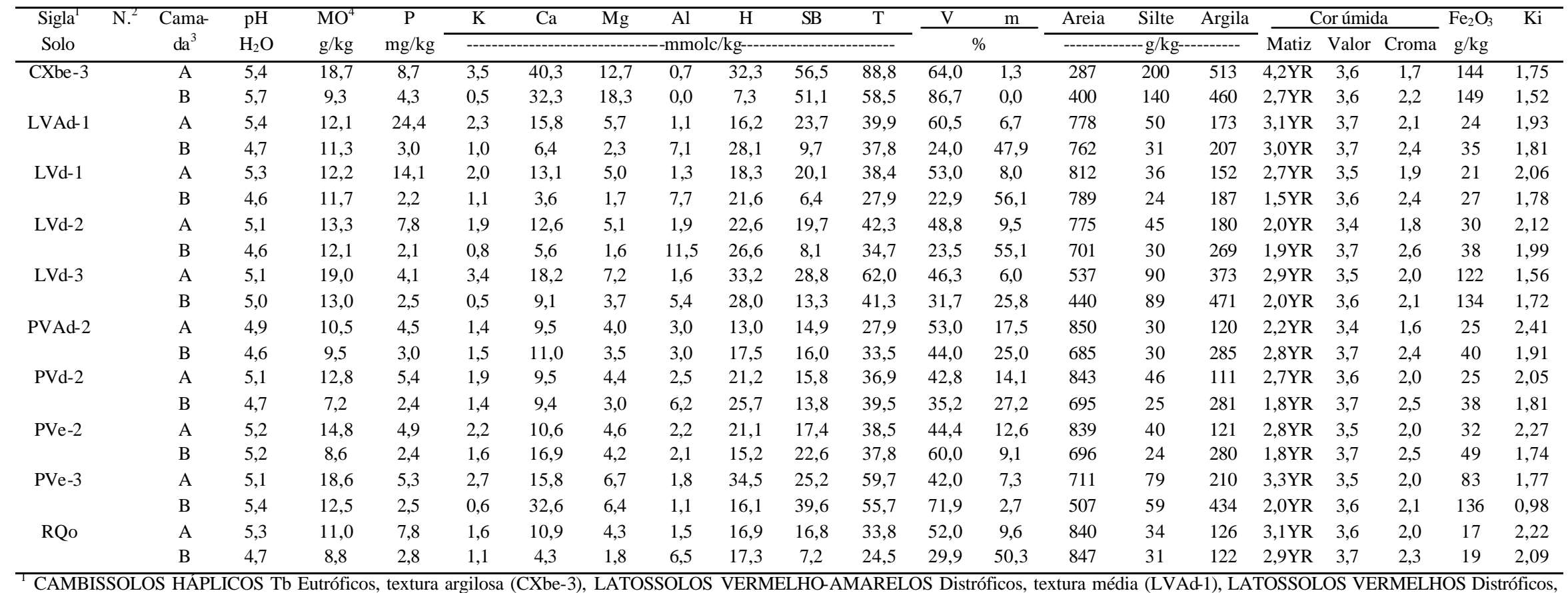

textura média 1, 150 - 250 g/kg (LVd-1), LATOSSOLOS VERMELHOS Distróficos, textura média 2, 250 - 350 g/kg (LVd-2), LATOSSOLOS VERMELHOS Distróficos, textura argilosa (LVd-3), ARGISSOLOS VERMELHO-AMARELOS Distróficos, textura média 2 (PVAd-2), ARGISSOLOS VERMELHOS Distróficos, textura média 2 (PVd-2), ARGISSOLOS VERMELHOS Eutróficos, textura

média 2 (PVe-2), ARGISSOLOS VERMELHOS Eutróficos, textura argilosa (PVe-3), NEOSSOLOS QUARTZARÊNICOS Órticos (RQo)

2 Número de Repetições para cada unidade de mapeamento da área de estudo

3 Camadas: A $(0-20 \mathrm{~cm})$ e B $(80-100 \mathrm{~cm})$, referentes aos horizontes A e B

${ }^{4}$ Matéria Orgânica 

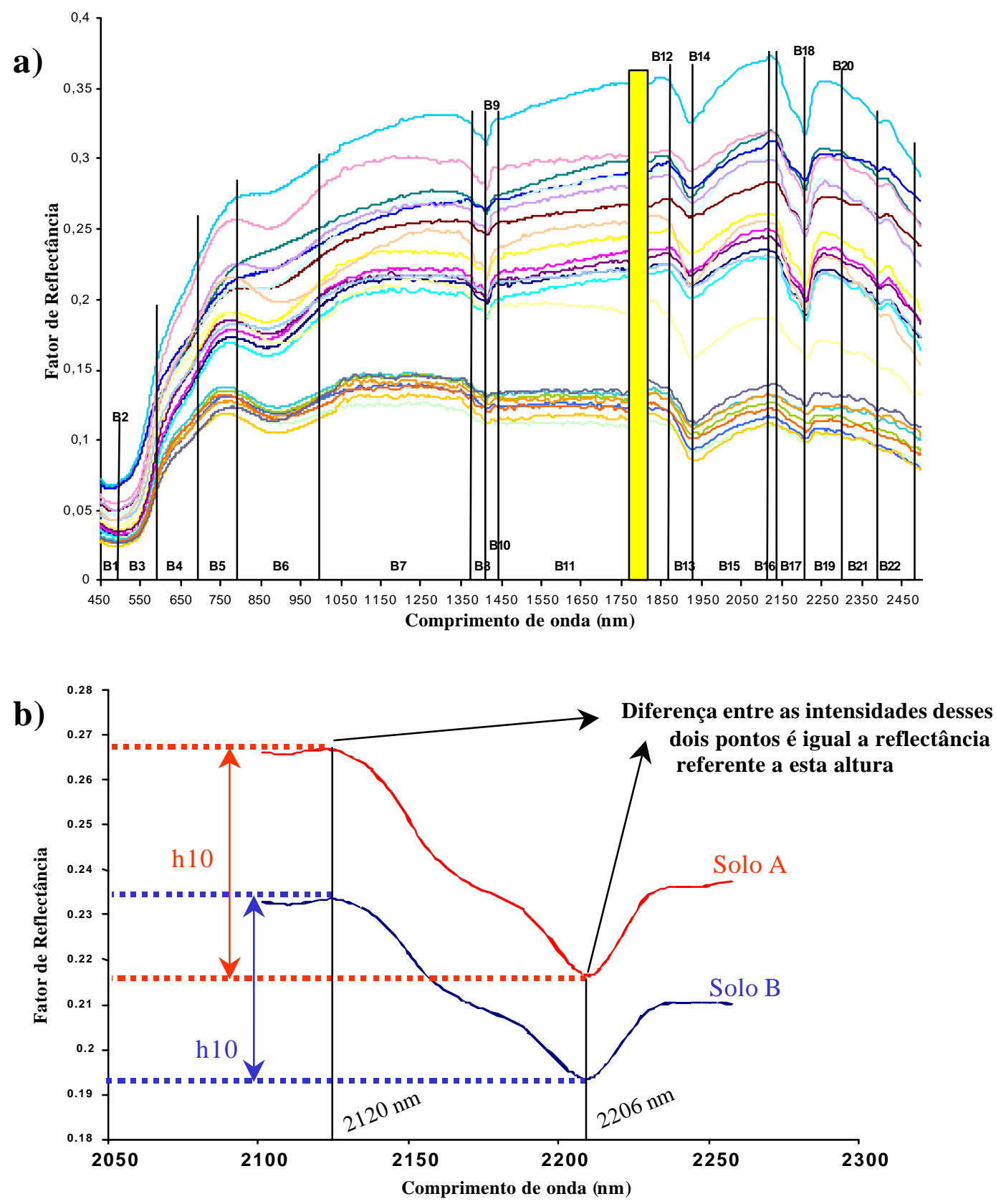

Figura 1 - Representação das 22 bandas e obtenção das 13 alturas onde: a) 2 bandas escolhidas pela interpretação visual de uma série de curvas espectrais obtidas em laboratório, sendo a faixa preenchida em amarelo representa um intervalo do espectro ótico descartado para a análise, por apresentar uma região de inflexão derivado do sistema eletrônico do sistema IRIS. b) obtenção da altura entre a crista e o vale da inflexão observada no intervalo entre 2.120 e 2.206 nm. Fonte:(Nanni, 2000). 

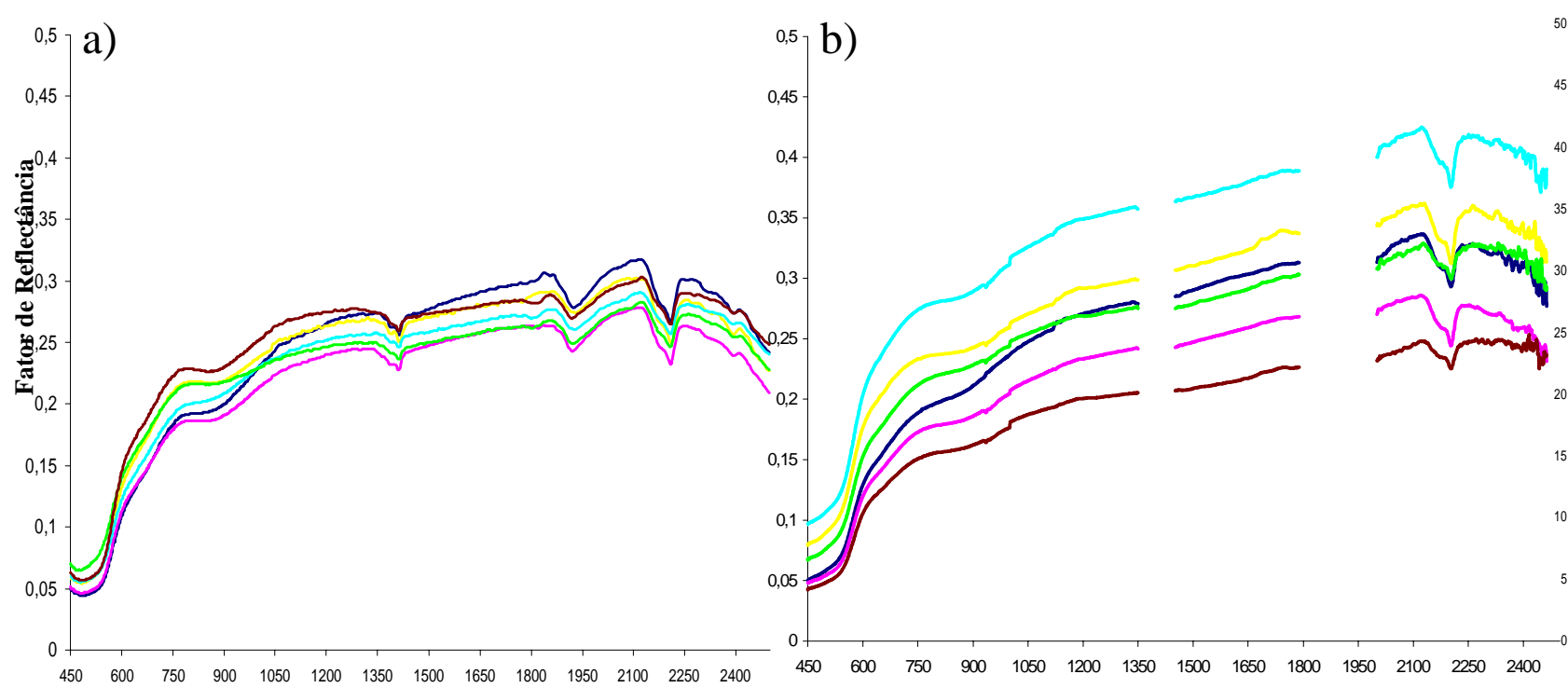

${ }^{50}$ c)

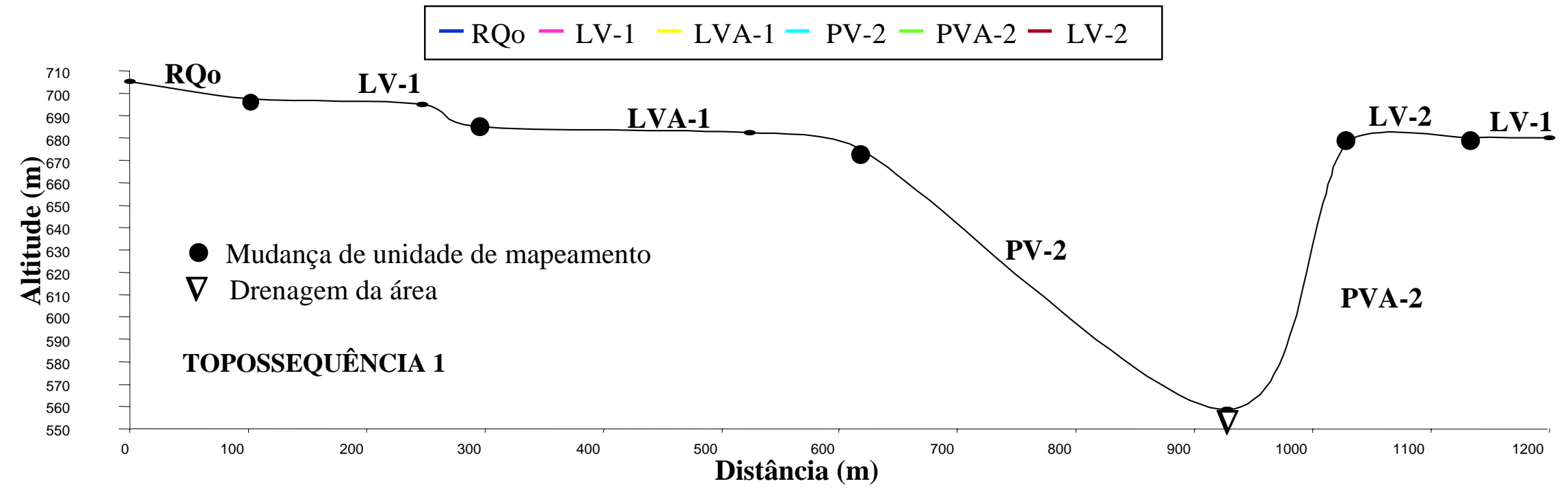

Figura 2 - Representação das curvas espectrais nos níveis Laboratório (a), Campo (b) e Orbital (c) na topossequência 1 da área de estudo. 


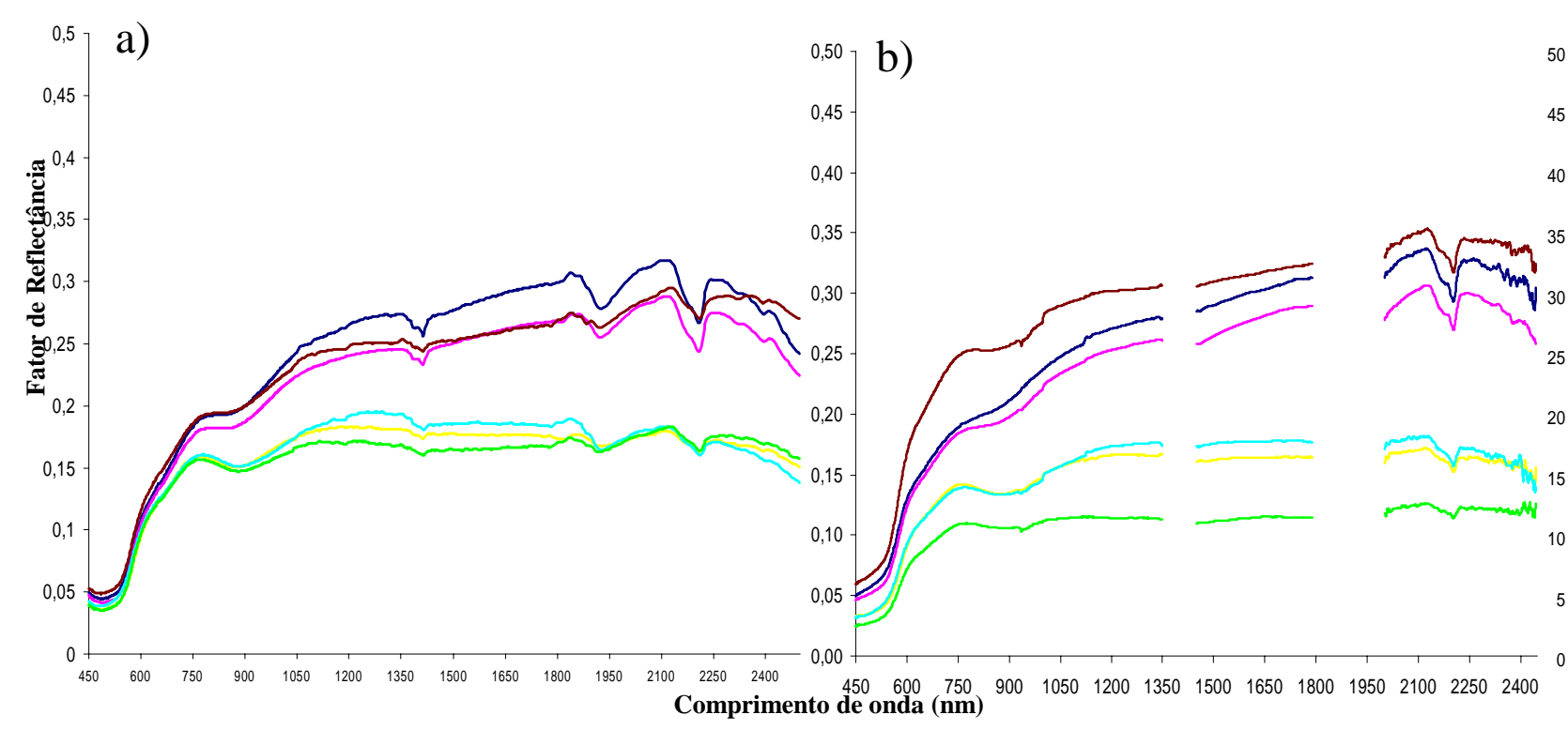

c)

Comprimento de onda (nm)

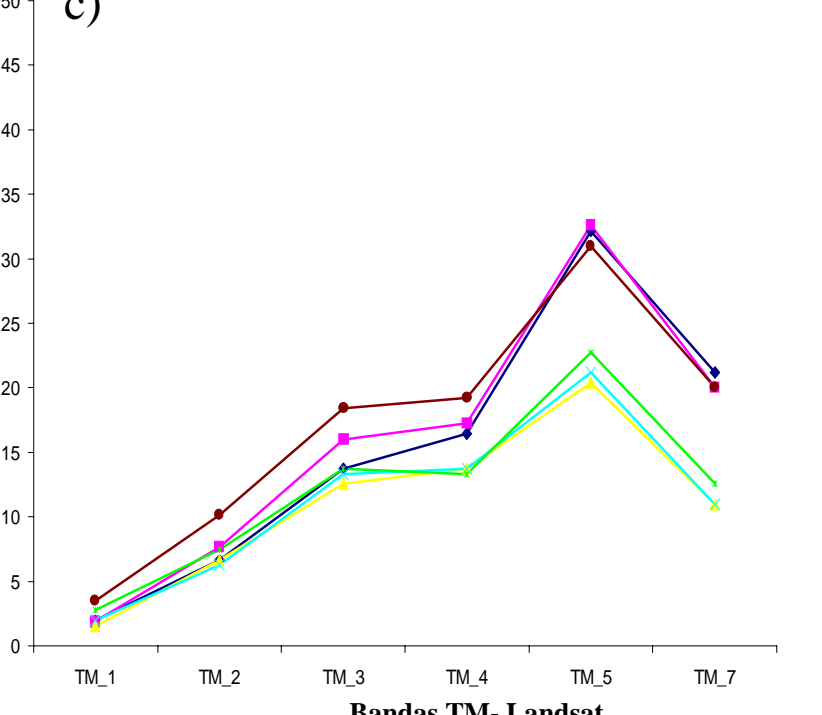

$-\mathrm{RQo}-\mathrm{LV}-1-\mathrm{PV}-3-\mathrm{CXb}-3-\mathrm{LV}-3-\mathrm{PV}-2$

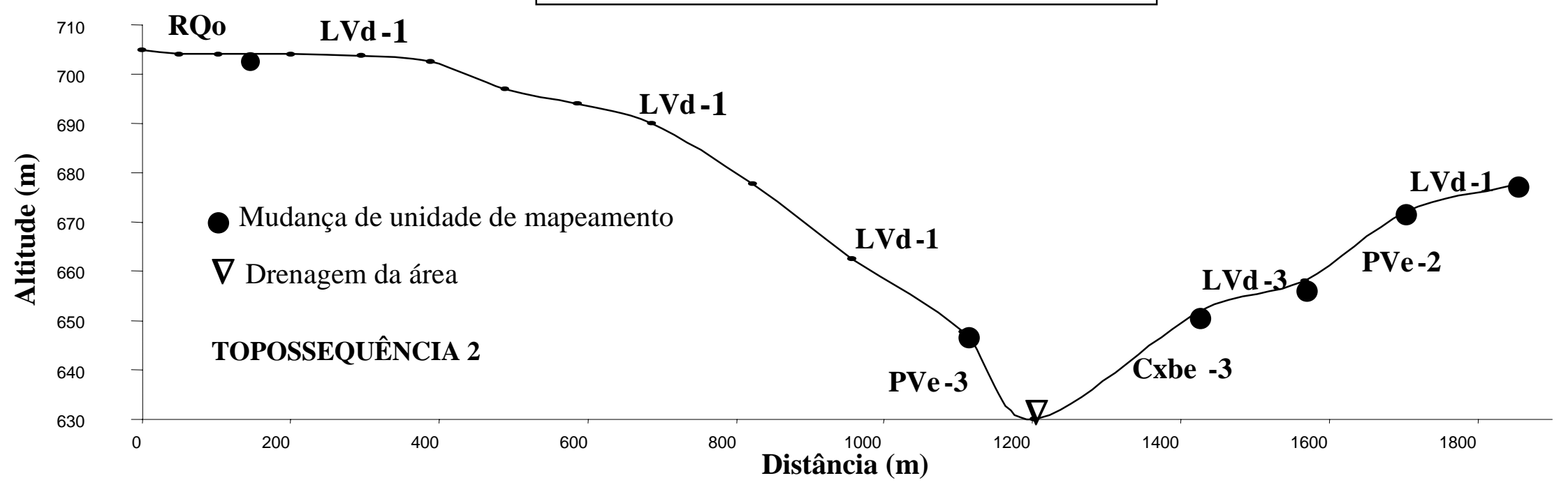

Figura 3 - Representação das curvas espectrais nos níveis Laboratório (a), Campo (b) e Orbital (c) na topossequência 2 da área de estudo. 


\section{Topossequência 1}

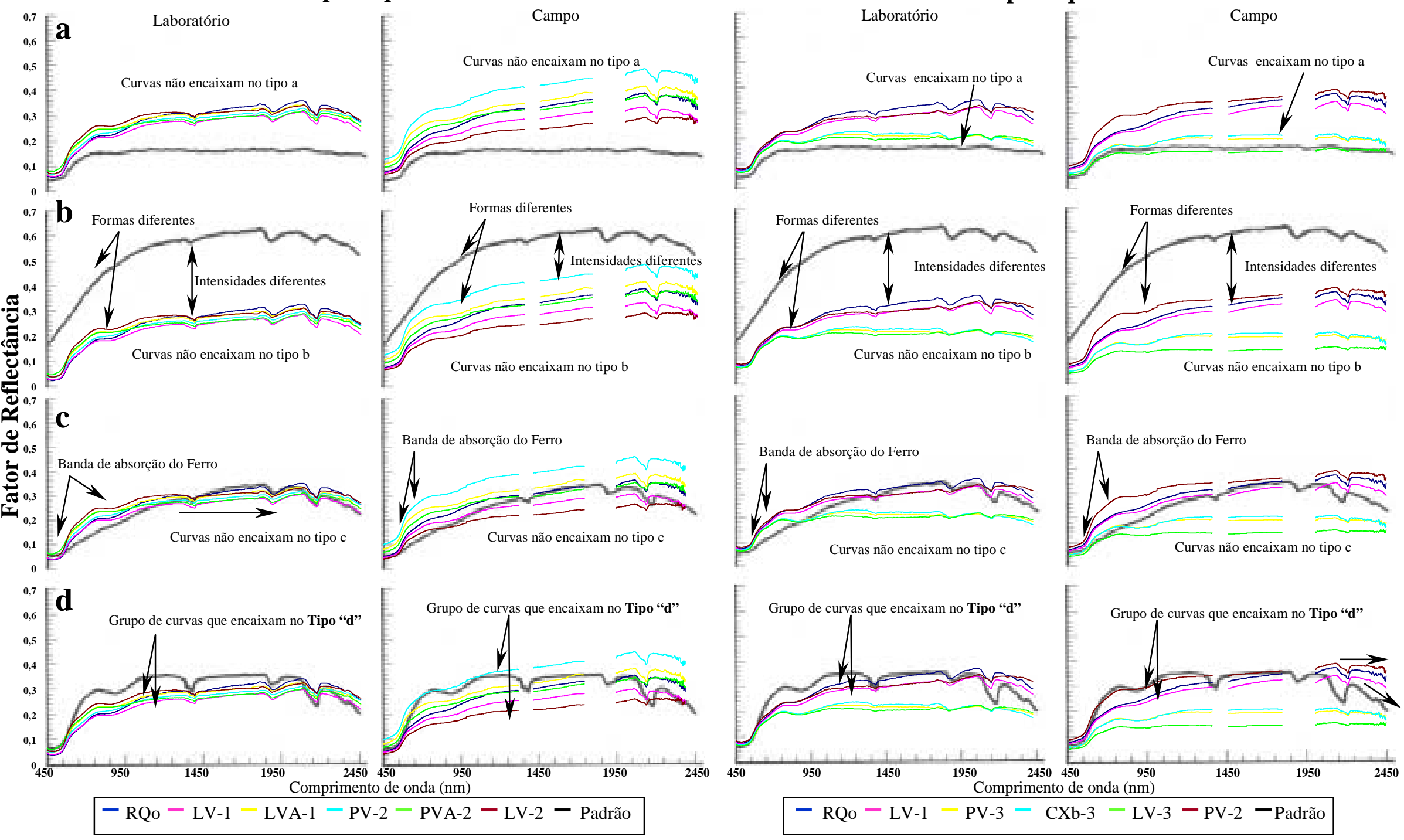

Figura 4 - Comparação entre as curvas espectrais obtidas nas topossequências da área de estudo e as curvas padões obtidas por Formaggio et al. (1996), onde: a) curva espectral típica do horizonte Al de um Latossolo Roxo da região de Araras (SP); b) curva espectral típica do horizonte Ap de um Podzólico Vermelho-Amarelo da região de Piracicaba (SP); c) curva espectral típica do horizonte A11 de um Latossolo Húmico da região de Campinas (SP); d) curva espectral típica do horizonte Ap de um Podzólico Vermelho-Escuro da região de Tiête (SP). 

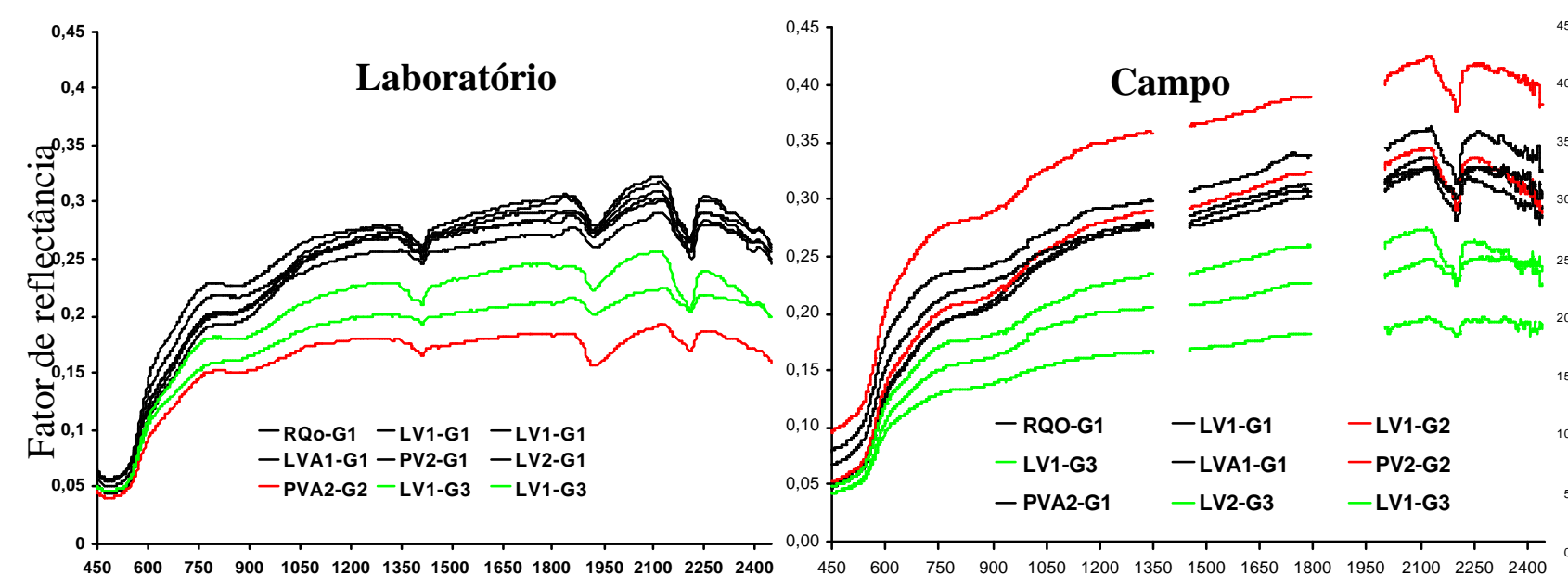

Comprimento de onda $(\mathrm{nm})$

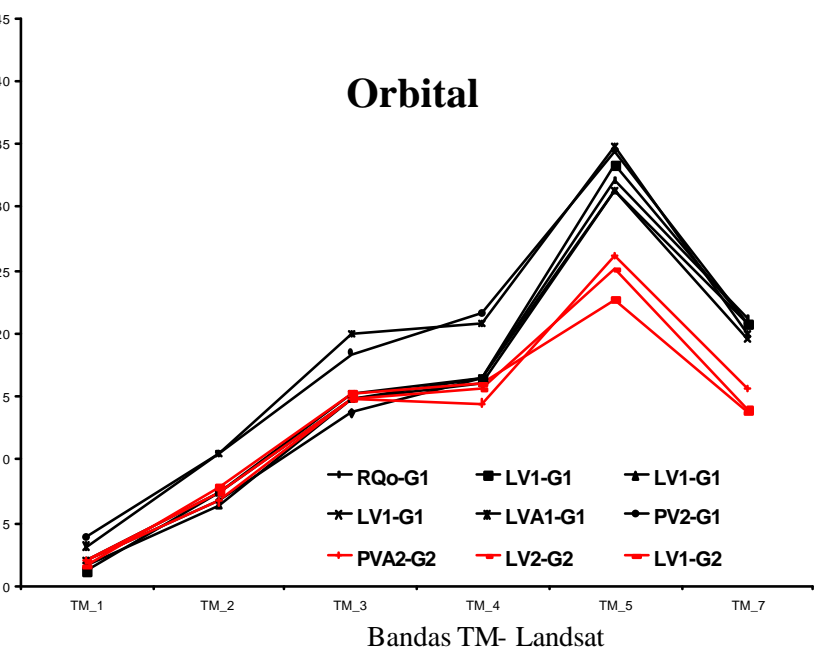

Orbital

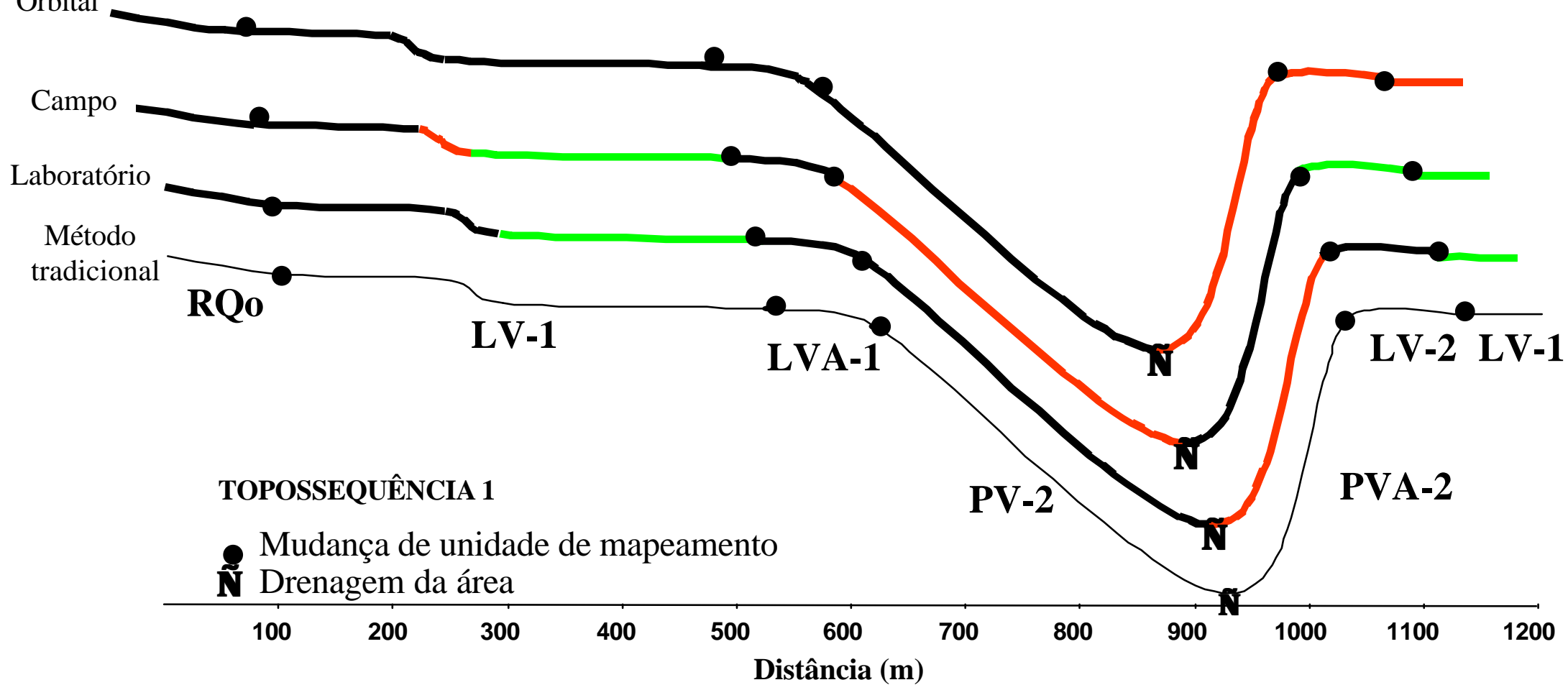

Figura 5 - Representação dos agrupamentos gerados pela análise de cluster para os níveis de laboratório, campo e orbital comparados com o método tradicional. Bem como as curvas espectrais de cada ponto de coleta na topossequência 1. Onde: - (Grupo 1-G1), - (Grupo 2 - G2) e (Grupo 3-G3). 


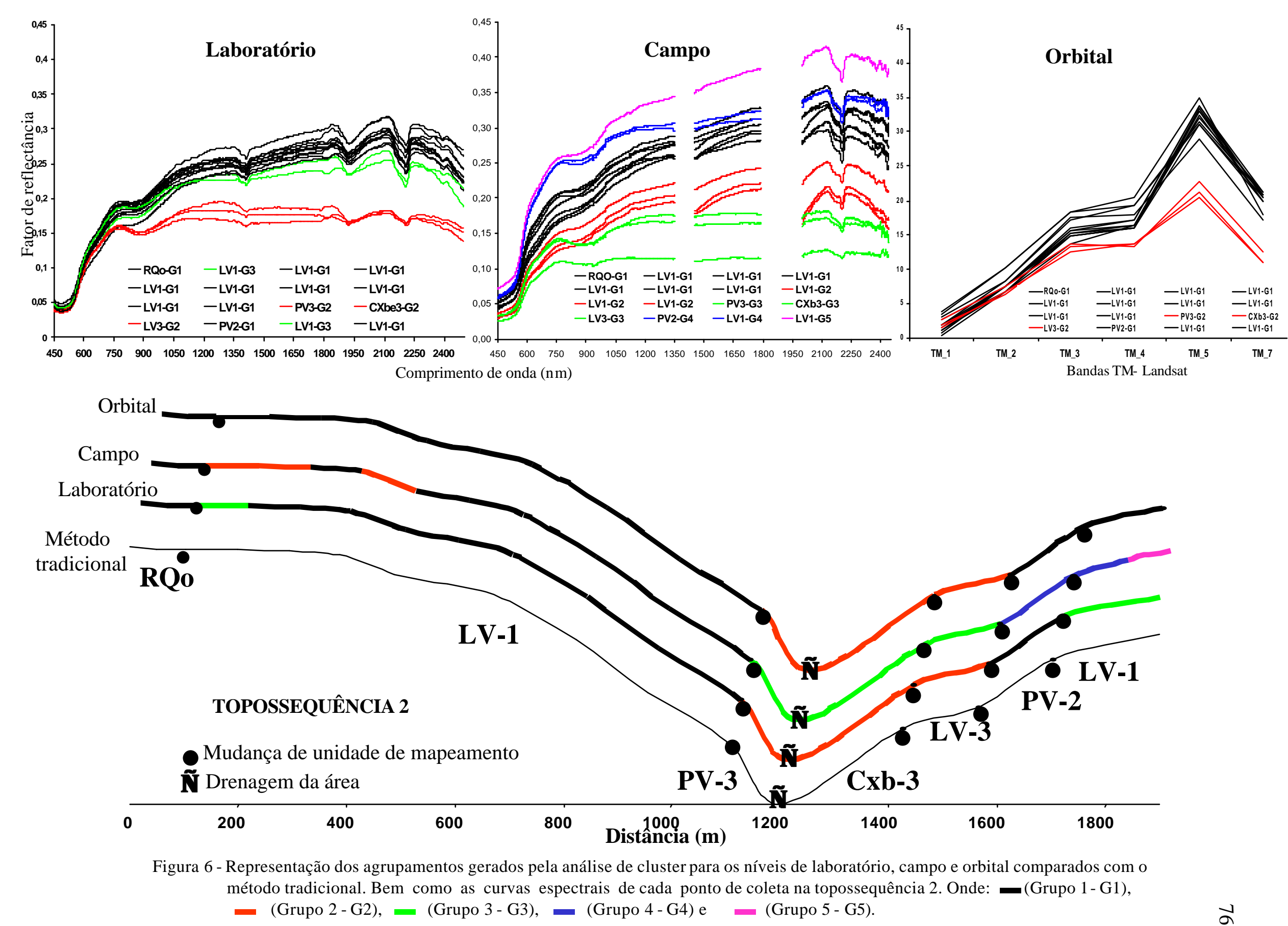




\section{EQUAÇÕES DISCRIMINANTES DE SOLOS UTILIZANDO-SE CARACTERÍSTICAS ESPECTRAIS DE LABORATÓRIO E ORBITAL}

\section{Resumo}

O trabalho teve por objetivo gerar e testar equações discriminantes para cada solo estudado, utilizando-se dados espectrais de laboratório e orbitais. Para tanto, escolheu-se uma área com solo nú, com dois materiais de origem distintos, o arenito com cimento argiloso e o basalto. Foi estabelecida uma grade $(100 \mathrm{~m}$ x $100 \mathrm{~m})$ totalizando 473 pontos de amostragem nas profundidades $0-20$ e $80-100 \mathrm{~cm}$, denominadas de A e B, todos georreferenciados. Com os resultados das análises, gerou se o mapa de solos da área com 28 unidades de mapeamento. A reflectância de laboratório foi obtida pelo espectroradiômetro IRIS, na faixa de 450 a $2500 \mathrm{~nm}$. A reflectância orbital foi obtida após o processamento da imagem e sobreposição das bandas TM-Landsat-5, nos pontos de amostragem. As equações discriminantes foram geradas por tratamento estatístico com o pacote SAS. Das setenta variáveis iniciais dos dados de reflectância de laboratório, cinqüenta e seis foram selecionadas para gerar os modelos das equações discriminantes e das sete bandas TM, foram selecionadas seis. As equações foram testadas obtendo-se matrizes de confusão. As equações discriminantes 
com dados de laboratório apresentaram um acerto de $81 \%$ e as equações com dados orbitais $40 \%$.

\section{DISCRIMINANT EQUATIONS OF SOILS USING SPECTRAL CHARACTERISTICS FROM LABORATORY AND ORBITAL SENSORS}

\section{Summary}

The objective of this work was to generate and test discriminant equations for each studied soil, using spectral data from laboratory and orbital sensors. For this, it was chosen a bare soil area, with two different parent materials, sandstone with loamy cement and basalt. A grid was established $(100 \mathrm{~m}$ x $100 \mathrm{~m})$ totalizing 473 sampling points in the depths $0-20$ and $80-100 \mathrm{~cm}$, all georreferenced. With the analyses results, the soils map of the area was generated with 28 mapping units. The laboratory spectra was obtained by the spectroradiometer IRIS, from (450 to $2500 \mathrm{~nm}$ ). The orbital reflectance was obtained after the image processing and overlaying the TM-Landsat-5 bands, in the sampling points. The discriminant equations were generated by statistical treatment with the SAS software. From the seventy initial variables of laboratory data, fifty six were selected to generate the models of the equations and six of the seven TM bands were selected. The equations were tested and the matrix of confusion were obtained. The discriminant equations of laboratory data presented $81 \%$ success and the equations with orbital data $40 \%$. 


\subsection{Introdução}

O ambiente solo é extremamente susceptível às mudanças impostas pelas ações antrópicas. Essas ações, quando realizadas corretamente, com planejamento prévio, podem minimizar os danos aos recursos naturais, porém uma vez realizadas sem um conhecimento do local a ser trabalhado, geram danos às vezes irreparáveis. Dessa forma, o conhecimento dos atributos dos solos, bem como a sua distribuição espacial e mapeamento, torna-se uma ferramenta imprescindível para a diminuição do impacto ambiental. Isso já foi verificado por Fiorio et al. (2000), onde o avanço desordenado da cana-de-açúcar, sem um planejamento prévio, em solos com alta suscetibilidade a erosão, causou assoreamento na represa da Vila de Arthemis, próximo a Piracicaba, SP.

A caracterização e o estudo dos solos são a base do mapeamento, o qual é de grande importância no uso racional dos solos. O Brasil tem aproximadamente 8,5 milhões de $\mathrm{km}^{2}$, grande parte utilizada para produção agrícola. Entretanto, os levantamentos de solos são em escalas muito generalizadas e não são compatíveis com as necessidades de informações para o emprego de alta tecnologia na agricultura, visando maior produtividade com menor degradação (Demattê \& Garcia, 1999a). Devese empregar cada parcela de terra de acordo com a sua capacidade de sustentação. Comforme descrito em Lepsch (1991), a determinação do método de capacidade de uso pressupõe alto nível de manejo tecnológico sendo necessário mapas de solos mais detalhados.

Com o advento de novos sensores e a intensificação da utilização da tecnologia na agricultura, o desenvolvimento de técnicas de sensoriamento remoto aplicadas ao 
estudo de solos torna-se importante. Demattê (2001) descreve a importância da utilização de novas tecnologias, como o sensoriamento remoto, que no auxílio do mapeamento. Baptista et al. (1999) pela metodologia baseada na manipulação matemática de bandas do sensor hiperespectral AVIRIS, gerou mapa de teores de argila, podendo auxiliar mapeamentos de solos. Nesse aspecto, a avaliação do comportamento espectral dos solos poderia até mesmo por imagens de satélite, auxiliar mais rapidamente na obtenção de informações relativas à sua caracterização e mapeamento (Coleman et al., 1993). Segundo estes autores, vários estudos vêm buscando identificar áreas do espectro eletromagnético que melhor detectem as diferenças entre os solos e identifiquem suas propriedades importantes para o mapeamento, permitindo assim, discriminá-los e classificá-los. Sensores instalados em satélites ou aviões podem obter informações de áreas maiores e de difícil acesso. Entretanto, destaque-se os inúmeros problemas na avaliação desses produtos, como os atmosféricos (Guyot, 1996) e situação de superfície (Huete, 1996). Odeh \& MacBratney (2000) comprovaram que a utilização do sensoriamento remoto e técnicas estatísticas foram as mais eficientes e menos onerosas, na avaliação de solos.

Demattê \& Garcia (1999b) concluíram que as análises discriminantes foram 100 \% eficientes na separação do Latossolo Bruno e da Terra Bruna Estruturada, utilizando dados espectrais de laboratório, com 13 bandas, entre 684 nm e 2.500 nm. Nanni (2000) trabalhando com 43 bandas espectrais, verificou pelas análises discriminantes para 18 unidades de solo, no nível de laboratório, um acerto superior a $80 \%$; porém, para dados orbitais, obteve um acerto de $40 \%$ e quando os solos foram agrupados em função do material de origem, o acerto passou para $70 \%$. Aliás, Demattê \& Garcia (1999a) 
obtiveram melhores resultados quando solos desenvolvidos do mesmo material de origem foram agrupados. Demattê et. al. (2000) concluíram que as analises discriminantes, obtidas com radiometria de laboratório discriminaram $100 \%$ das 26 unidades estudadas e 99,3\% para as discriminantes obtidas com dados orbitais do TMLandsat 5.

A hipótese levantada nesse trabalho está relacionada com a possibilidade do sensoriamento remoto, utilizando-se de dados de reflectância, discriminar solos com diferentes materiais de origem em diferentes níveis de aquisição de dados. Para tanto o objetivo desse trabalho foi o de gerar equações discriminantes para cada solo desenvolvido numa área da região de Barra Bonita, SP, utilizando-se dados espectrais obtidos por sensor em laboratório e orbital e testar a separabilidade destes solos.

\subsection{Material e Métodos}

\subsubsection{Caracterização da área de estudo}

A área localiza-se ao sudoeste do Estado de São Paulo, na região de Barra

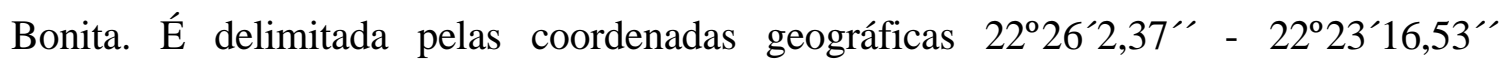
latitude sul e $48^{\circ} 31^{\prime} 24,22^{\prime \prime}$ - 48 $27^{\prime} 51,77^{\prime \prime}$ longitude oeste. Apresenta 473 ha cultivados com cana-de-açúcar em altitudes variando entre 520 e 710 metros do nível médio do mar. O clima da região, com base na classificação de Köppen, é do tipo Cwa, clima mesotérmico (Sentelhas et al., 1998). A litologia é representada principalmente pela ocorrência da Formação Serra Geral, a qual se caracteriza por compreender um 
conjunto de derrames de basalto, entre os quais se intercalam arenitos com as mesmas características da Formação Botucatu. Aparece ainda a Formação Itaqueri do grupo Bauru que se caracteriza por arenitos com cimento argiloso, folhelhos e conglomerados, predominando os arenintos (IPT, 1981).

Foi estabelecida uma grade regular de $100 \mathrm{~m}$ x $100 \mathrm{~m}$. Os locais dos pontos foram estaqueados, georreferenciados e coletadas amostras de terra nas profundidades 020 e 80-100 cm denominadas de A e B, respectivamente, totalizando 946 amostras de solos. A cor do solo foi obtida na forma úmida com o equipamento Minolta CR 300 com chip para cor de Munsel (Post et al., 1994; Campos, 2002). Foram realizadas análises químicas (Raij et al., 1987), granulométricas e de ataque sulfúrico (Camargo et al., 1987). Com o resultado das análises foram descritos 6 perfis de solos (Lemos \& Santos, 1996) como base para a classificação (Embrapa, 1999), obtendo-se o mapa detalhado por textura da área de estudo (Figura 1).

\subsubsection{Obtenção dos dados espectrais}

Foi utilizada uma cena TM-Landsat-5 nas bandas 1, 2, 3, 4, 5 e 7. Após definida a área foi realizado o corte na imagem no programa IMPIMA (INPE, 1999). A imagem de satélite apresenta para cada pixel um valor de níveis de cinza (Crósta, 1992). Os dados de níveis de cinza foram transformados em reflectância, conforme comentários de Epiphanio \& Formaggio (1988). Estes autores descrevem que a análise quantitativa de imagens digitais sobre o comportamento espectral de alvos deve ser feita com os dados

em reflectância, por ser uma grandeza física intrínseca dos alvos, ao passo que os 
números digitais são valores transformados para a obtenção das imagens orbitais. Segundo Ben-Dor (2002), os valores de níveis de cinza obtidos das cenas do sensor TMLandsat devem ser devidamente ajustados aos efeitos atmosféricos e posteriormente os números digitais convertidos em valores de reflectância real. Para tanto, foi utilizado o modelo 5S (Simulação do Sinal do Satélite dentro do Espectro Solar) (Tanré et al., 1992) e detalhadamente descrito por Zullo Jr. (1994). Após o processo de conversão e correção, o nível de cinza zero presente na imagem passou a corresponder à reflectância 0 \% e o nível de cinza 255 à reflectância $100 \%$.

Para adequar o posicionamento da imagem com a verdade de campo a correção geométrica se faz necessária. Dessa forma, foram utilizadas as cartas planialtimétricas, escala 1:10.000, da Coordenadoria de Ação Regional, Divisão Cartográfica, da secretária de economia e planejamento do Estado de São Paulo. Além disso, pontos obtidos no campo com equipamento GPS (Global Positioning System) com erro submétrico foram utilizados. Objetivando manter o valor do pixel o mais semelhante possível ao seu valor original, utilizourse o método de interpolação denominado vizinho mais próximo, corrigindo apenas as distorções de escala, deslocamento ou rotação existentes entre a imagem e a projeção terrestre (Crósta, 1992). Uma vez registrada, a cena foi visualizada em composição colorida R/G/B, bandas 1/2/3 e 4/5/7. Sobre os planos de informação "imagens", foram sobrepostos os pontos de amostragem da grade. Em cada ponto de amostragem, foram determinados os dados espectrais das referidas bandas.

Para a obtenção dos dados espectrais de laboratório, foi utilizado o sensor InfraRed Intelligent Spectroradiometer, IRIS (Geophysical \& Environmental Research 
Corporation, 1996), que recobre a faixa espectral entre 450 e $2.500 \mathrm{~nm}$. As amostras da camada A (referente ao horizonte A), dos solos foram secas em estufa a $45^{\circ} \mathrm{C}$ por 24 horas, moídas e peneiradas (malha de $2 \mathrm{~mm}$ ), para homogeneização dos efeitos da umidade e rugosidade (Epiphanio et al., 1992). Posteriormente, as amostras foram acondicionadas em placas de petri e iluminadas por uma lâmpada halógena de $650 \mathrm{~W}$. A energia alimentadora da lâmpada foi estabilizada com uma fonte de potência de $1 \%$. Utilizou-se a placa padrão branca, com 100 \% de reflectância calibrada pela Labsphere (1996). A geometria utilizada foi: $61 \mathrm{~cm}$ lâmpada-alvo e alvo-sensor: $27 \mathrm{~cm}$; inclinação da lâmpada $20^{\circ}$ ao nadir (Baumgardner et al., 1985). Posteriormente, os dados passaram por um software (Conviris), que regularizou os dados da placa de referência e realizou uma filtragem destes, eliminando o excesso de ruídos, para facilitar a interpretação. A relação entre a energia refletida pelo alvo e a energia refletida pela placa de referência gerou o fator de reflectância bidirecional (Nicodemus et al., 1977). Foram realizadas três leituras em cada amostra, sendo utilizada a curva espectral média.

\subsubsection{Análise estatística dos dados espectrais}

Para os dados orbitais foram obtidos os dados de reflectância da camada superficial dos solos, das bandas do TM-Landsat-5, sendo (em nm): B1: 450-520, B2: 520-600, B3: 630-690, B4: 760-900, B5: 1150-1750, B7: 2080-2350. Foram utilizados 227 dados de reflectância para a gerar os modelos, sendo outras 227 amostras para teste. 
A escolha dos pontos para gerar os modelos foi aleatória, porém, representativa de toda a área de estudo.

Os dados espectrais obtidos com o IRIS em laboratório, permitem uma maior resolução radiométrica, podendo-se estabelecer um maior número de bandas. Foram selecionadas 22 bandas (B) e 13 alturas (H), seguindo metodologia de Nanni \& Demattê (2001b), sendo elas (em nm): B1: 450-481, B2: 481, B3: 481-596, B4: 596-710, B5: 710-814, B6: 814-975, B7: 975-1350, B8: 1350-1417, B9: 1417, B10: 1417-1449, B11: 1449-1793, B12: 1793-1831, B13: 1865-1927, B14: 1927, B15: 1927-2102, B16: 21012139, B17: 2139-2206, B18: 2206, B19: 2206-2258, B20: 2258, B21: 2258-2389, B22: 2389-2498, H1: 469-532, H2: 532-768, H3: 768-876, H4: 876-1353, H5: 1353-1411, H6: 1411-1439, H7: 1439-1783, H8: 1860-1923, H9: 1923-2120, H10: 2120-2206, H11: 2206-2258, H12: 2258-2389, H13: 2389-2498. Essa seleção baseia-se em observações empíricas, pela literatura e automatizadas da atuação dos dados espectrais.

As análises discriminantes partiram de grupos de solos pré-determinados, sendo reagrupadas algumas classes de solos, onde LVef 3 e 4 passaram para LVef, NV 3 e 4 para $\mathrm{NV}, \mathrm{CXb} 2,3$ e 4 para $\mathrm{CXb}$, totalizando 23 classes de solos das 28 classes inicias (Figura 1). Num primeiro momento, foram realizadas as seleções das variáveis preditoras, o programa verifica dentro do conjunto dos solos a serem discriminados, quais variáveis espectrais são significativas a $1 \%$ de probabilidade na discriminação desses solos, para os dados de laboratório e orbital. Para não permitir nenhuma tendenciosidade na análise, passou-se para o procedimento de avaliação de colinearidade das variáveis para que não houvesse duas ou mais variáveis que pudessem estar sobrepondo-se. Para reforçar a análise discriminante, o programa selecionou $80 \%$ das 
amostras para gerar o modelo, deixando $20 \%$ para testá-lo cinqüenta vezes consecutivas, gerando erros e acertos.

\subsection{Resultados e Discussão}

\subsubsection{Análise discriminante}

Foram analisadas vinte e três classes de solos das vinte e oito iniciais, encontradas no levantamento detalhado por textura (Figura 1). Em alguns casos agruparam-se classes de solos para aumentar a representatividade de algumas classes e por serem estes muito semelhantes, como já descrito na metodologia. Segundo Nanni (2000), é de se esperar que as classes que contenham um número muito pequeno de indivíduos tenham uma menor amplitude ou variabilidade de atributos.

Para os dados de laboratório, dentre as setenta variáveis estabelecidas (vinte e duas bandas e treze alturas, para as camadas A e B), cinqüenta e seis variáveis foram selecionadas para os modelos pelo STEPEDISC do SAS (SAS, 1999) (Tabela 1). Nanni (2000) obteve para os modelos 39 variáveis, das setenta variáveis estabelecidas para a camada A e B, em uma área com grande heterogeneidade de solos, diferindo assim dos resultados encontrados nesse trabalho com um número bem maior de variáveis, em uma área com maior homogeneidade de solos (Figura 1). O número de variáveis preditoras, bandas e alturas, selecionadas na camada A (26), foi menor que o número para a camada B (30) (Tabela 1). Tal fato pode estar associado à menor diferenciação dos solos na camada A por toda área de estudo. Predomina como material de origem o arenito com 
cimento argiloso, o que origina texturas mais arenosas e médias nas camadas superficiais, em menores porções o basalto, com solos mais argilosos (Tabela 2).

Para a camada A, a banda 8 e as alturas 4 e 11, foram retiradas do modelo por não se apresentarem significativas a $1 \%$ de probabilidade (STEPEDISC); para a camada B apenas a banda 16 foi retirada. As demais bandas e alturas que foram retiradas do modelo apresentaram colinearidade, ou seja, duas variáveis ou mais explicam o mesmo fator no modelo concordando com observações de Ben-Dor (2002). Para a camada A as bandas $2,14,16,18$ e 20 e a altura 13, para a camada B as bandas 2, 6, 9, e 18, foram retiradas por colinearidade. É interessante de se notar que as bandas $2(481 \mathrm{~nm})$ e 18 (2.206 nm) não entraram em nenhum dos modelos, tanto para a camada $\mathrm{A}$, como para a camada B, o que pode ser devido a um recobrimento da banda 2 pelas bandas 1 e 3 e a banda 18 pela 17 e 19 .

Para as seis variáveis dos dados orbitais apenas a banda 2 não foi selecionada, o que difere dos resultados obtidos por Nanni (2000), onde todas as variáveis orbitais foram necessárias.

As equações lineares discriminantes geradas para os dados de laboratório podem ser observadas na Tabela 3a,b e os obtidos para os dados orbitais na Tabela 4. As equações têm por objetivo nortear os resultados de classificação de solos utilizando dados de reflectância. Concordando com Colemam et al. (1991).

Segundo Gerbermann \& Neher (1979), obtendo-se uma coleção de dados de forma automatizada, deverá ser consumido um tempo menor para a produção de mapas de solos do que com os métodos convencionais. Pressupondo o conhecimento das reflectâncias de laboratório ou orbitais de uma determinada amostra sem que se saiba 
qual é o solo, pode-se calcular as bandas e alturas ou bandas TM devidamente processadas, e aplicá-las nas equações (Tabela 3a, b e Tabela 4). Aquela que resultar em um maior valor, terá maior probabilidade de representar o solo desconhecido.

\subsubsection{Análise das equações discriminantes geradas}

Tanto as equações discriminantes de laboratório como as dos dados orbitais foram geradas com $80 \%$ das amostras da área e testadas com $20 \%$ das amostras restantes, sendo que a escolha das amostras foi aleatória, determinada pelo SAS. O procedimento foi testado cinqüenta vezes, ou seja, o sistema escolheu os $80 \%$ para gerar o modelo discriminante e testou com os $20 \%$ restantes por cinqüenta vezes consecutivas. Após os testes, foram geradas matrizes de confusão, resumidas nas Tabelas 5 e 6.

Para os dados de laboratório das 473 amostras, 385 foram classificadas corretamente obtendo-se um acerto total de $81,4 \%$, o que perfaz uma confusão de 18,6 \% com 88 amostras (Tabela 5). Esses valores estão próximos aos obtidos por Nanni (2000) com acerto global acima dos $80 \%$. Demattê \& Garcia (1999) apresentaram um acerto de $100 \%$ para três solos estudados e Coleman et al. (1991) chegaram a obter

erros de até 55,6 \%, provavelmente pela heterogeneidade da área de estudo. Demattê et al. (2000) para radiometria de laboratório obtiveram $100 \%$ de acerto em 6 unidades de solos estudados na região de Lençóis Paulista.

As classes de solos com números de observações iguais ou menores que sete, apresentaram acertos de $100 \%$, como pode ser verificado para CXef1, LVA2, LVA3, 
PA1, PA2, PVA1, PVA2, PVA3 e PVA4 (Tabela 5). Isto está de acordo com Oliveira et al. (1982), os quais consideram que sete deve ser o número mínimo de amostras por classe de solo, para que as análises estatísticas não tenham influência marcante no erro padrão da média. Nanni (2000) considera também que as classes com número reduzido de amostras podem não contemplar a variabilidade existente na classe, ou possuir características muito semelhantes a outra classe, o que poderia gerar uma análise pouco confiável. Aliás, Ben-Dor (2002) descreveram a importância de ter amostras representativas de toda uma área na qual se pretende elaborar modelos. O PVA1 é a única classe com $100 \%$ de acerto e número mínimo de observações igual a sete (Tabela 5). O LVA2, com seis observações apresentou um acerto de 83,3\%, sendo confundido com LV3.

Para o PV4, obteve-se um acerto e um erro de $50 \%$. Esse solo apresentou apenas duas observações na área de estudo, sendo confundido no teste das equações com o LV4, que difere apenas na textura da camada A $\left(54 \mathrm{~g} \mathrm{~kg}^{-1}\right)$ maior que a do PV4 $(34,5 \mathrm{~g}$ $\mathrm{kg}^{-1}$ ), sendo que a relação textural é um dos fatores mais importantes na diferenciação entre as duas ordens, LATOSSOLOS e ARGISSOLOS (Tabelas 2 e 5). O pequeno número de observações dentro de uma mesma classe pode elevar muito o erro, como verificado por Nanni (2000).

Vários solos apresentaram acertos próximos ou maiores que $80 \%, \mathrm{LV} 1, \mathrm{LV} 3$, LVA1, LVA2, NVef, PV1, PV2, PV3 (Tabela 5). Das quatorze observações do NVef, apenas duas foram confundidas com o LVef, sendo esses solos muito semelhantes (Tabela 2), diferindo no campo principalmente pela presença de cerosidade no NVef (Embrapa, 1999). O LV1 é o solo com maior representatividade na área de estudo, com 
213 amostras, sendo 182 corretamente classificadas e 31 confundidas (Figura 1 e Tabela 5). Das 31 amostras confundidas, dois solos apresentaram maior freqüência, o LVA1 com 10 amostras, que difere do LV1 apenas na cor em sub-superfície, com matiz 3.0 YR amarelo (LVA1) e 1.5 YR vermelho (LV1) (Tabela 2) e o PV1, também com 10 amostras, difere do LV1 na diferença textural das camadas no Argissolo (Tabela 2). A confusão entre o LV1 e o RQo, com cinco observações é justificável, uma vez que as texturas estão muito próximas de $15 \mathrm{~g} \mathrm{~kg}^{-1}$ que define a mudança de textura arenosa para média (Tabela 2). O PV2 e o LV2 também se confundem, com menor freqüência, com o LV1, sendo que a variabilidade dos atributos químicos e físicos dentro de uma mesma classe pode estar próxima aos limites que diferenciam os solos encontrados na área de estudo, diferindo principalmente nas texturas (Tabelas 2 e 5), o que está de acordo com Nanni (2000). As mesmas considerações se aplicam para os PV1, PV2, PV3, LV3, LVA2 e LVA1 os quais foram confundidos com solos de texturas muito semelhantes independente da ordem (Tabela 5 e 2).

A menor porcentagem de acerto foi de $62 \%$, com 31 amostras classificadas corretamente das 50 observações do RQo (Tabela 5). Esse solo foi confundido em 19 observações com solos de textura muito semelhante à arenosa ou média provenientes do arenito com cimento argiloso, justificando a confusão, com exceção de uma amostra de PVA3 com textura arenosa na camada A e argilosa no B. Outros solos apresentaram porcentagens de acertos entre 62,5 - $73 \%$; em ordem crescente de acertos, há os solos $\mathrm{NV}$, LV2, LVef e $\mathrm{CXb}$ e também foram confundidos com outros solos com características muito semelhantes (Tabelas 5 e 2). 
Para os dados orbitais das 473 amostras, 191 foram classificadas corretamente, obtendo-se um acerto total de 40,4 \%, o que perfaz um erro de 59,6\% com 282 amostras (Tabela 6). Esses valores estão próximos aos obtidos por Nanni (2000) com acerto global próximo de $40 \%$. Demattê et. al. (2000) observaram um acerto de 99, $3 \%$ para 26 unidades de mapeamento da região de Piracicaba, avaliada por imagens Landsat. O alto índice de acerto pode estar relacionado com a metodologia detalhada para a detecção de solos expostos.

Para as classes com número de observações menores ou iguais a sete, há os CXef, PA1, PA2 e PVA3, que apresentaram $100 \%$ de acerto. Verificourse também 100 \% de confusão paras as classes Cxb e PV4, apesar de serem confundidos com solos de texturas semelhantes, mais argilosas (Tabelas 6 e 2). O PVA4, para as suas duas observações, apresentou um acerto de $50 \%$, sendo confundido com o LV4; esses solos, para a camada A não apresentam diferenças (Tabela 2). Os demais solos com menor número de observações, LVA2, LVA3, PVA2 e PVA1, obtiveram baixas porcentagens de acerto, e na maioria dos casos foram confundidos com solos semelhantes, para a camada A, (Tabelas 6 e 2). Apesar das classes estarem sendo confundidas com solos semelhantes, os resultados gerados com números reduzidos de observações podem ser pouco confiáveis.

Os resultados mais satisfatórios obtidos para o nível orbital são para as classes LV1 com 69,4\% de acerto e para NVef com 57,1\%. O LV1, tem como material de origem o arenito com cimento argiloso, apresenta textura média $\left(15-25 \mathrm{~g} \mathrm{~kg}^{-1} \mathrm{de}\right.$ argila) e predomina em áreas de topo do relevo. Com exceção do PV3, os demais solos confundidos no teste da equação discriminante, apresentam características químicas e 
físicas em superfície semelhantes (Tabela 6 e 2). Tal fato se repete para o solo NVef, o qual é originado do basalto e apresenta-se em relevos mais ondulados e textura mais argilosa. A discriminação de solos desenvolvidos de basalto, concorda com Nanni \& Demattê (2001 a) que estudaram solos do Paraná.

É importante destacar que apesar dos dados orbitais não terem apresentado uma maior porcentagem de acerto, os resultados podem ser considerados satisfatórios uma vez que a maioria dos solos confundidos, em superfície, são muito semelhantes, podendo ser agrupados em dois grandes grupos, o primeiro de textura arenosa - média, provenientes do arenito de cimento argiloso, e o segundo mais argiloso originado do basalto. Nanni (2000) verificou que classes de solos com teores de ferro mais elevados, material de origem diabásio, tiveram pouca ou nenhuma confusão com as classes oriundas do arenito.

Mesmo em condições de campo, para a porção superficial, as características químicas e físicas são muito semelhantes dentro de cada um desses dois grandes grupos, tais como teores de ferro, matéria orgânica, argila, areia e cor, o que dificultaria a sua separabilidade, concordando com Nanni (2000).

A utilização das equações discriminantes dos dados orbitais, é uma ferramenta importante em uma primeira avaliação mais rápida de solos de diferentes regiões do país, concordando com Coleman \& Montgomery (1990). 


\subsection{Conclusões}

1- É possível discriminar solos por meio do sensoriamento remoto em laboratório, utilizando-se de amostras de terra de superfície e subsuperficie.

2 - Para os dados de laboratório das áreas com solos mais homogêneos, o número de variáveis preditoras tende a ser maior que para áreas com solos mais heterogêneos, devido à maior dificuldade de diferenciá-los.

3 - Das setenta variáveis iniciais, apenas cinqüenta e seis foram selecionadas para o modelo, com maior participação das variáveis em sub-superfície. Para os dados orbitais a banda 2 não participou do modelo.

4 - Para os dados de laboratório as equações obtiveram um acerto de $81 \%$, contra $40 \%$ dos dados das equações orbitais.

5- A discriminação de solos previamente classificados apresenta dificuldades, pois o sensor do satélite capta as informações de superfície. Nesse caso, os sensores em órbita auxiliam na discriminação das características de superfície dos solos.

6 - Os resultados orbitais, apesar de apresentarem baixos valores de acertos, mostraram eficiência em separar os solos de acordo com o material de origem, sendo uma classe de solos mais argilosa e outra mais arenosa. As maiores confusões foram observadas entre os solos de textura média e arenosa, sendo suas características físicas e químicas semelhantes. 
Tabela 1. Relação das variáveis preditoras utilizadas para análise discriminante das classes de solos da área de estudo.

\begin{tabular}{|c|c|c|c|c|c|c|c|}
\hline \multicolumn{2}{|c|}{ Bdas $^{1}$} & \multirow{2}{*}{$\begin{array}{l}\lambda^{2} \\
\mathrm{~nm}\end{array}$} & \multicolumn{2}{|c|}{ Alturas $^{3}$} & \multirow{2}{*}{$\begin{array}{c}\lambda \\
\mathrm{nm}\end{array}$} & \multirow{2}{*}{$\frac{\mathrm{TM}^{4}}{\mathrm{~A}}$} & \multirow{2}{*}{$\begin{array}{c}\lambda \\
\mathrm{nm}\end{array}$} \\
\hline $\mathrm{A}^{5}$ & $\mathrm{~B}^{6}$ & & A & $\mathrm{B}$ & & & \\
\hline $\bar{B} \_1^{7}$ & B_1 & $401-481$ & $\mathrm{H} 1^{8}$ & H1 & $469-532$ & 1 & $450-520$ \\
\hline B_3 & B_3 & $481-596$ & $\mathrm{H} 2$ & $\mathrm{H} 2$ & $532-768$ & 3 & $630-690$ \\
\hline B_4 & B_4 & $596-710$ & H3 & H3 & $768-876$ & 4 & $760-900$ \\
\hline B_5 & B_5 & $710-814$ & & $\mathrm{H} 4$ & $876-1353$ & 5 & $1150-1750$ \\
\hline B_6 & & $814-975$ & H5 & H5 & $1353-1411$ & 7 & $2080-2350$ \\
\hline \multirow[t]{2}{*}{ B_7 } & B_7 & $975-1350$ & H6 & H6 & $1411-1439$ & & \\
\hline & B_8 & $1350-1417$ & $\mathrm{H} 7$ & $\mathrm{H} 7$ & $1439-1783$ & & \\
\hline B_9 & & 1417 & H8 & H8 & $1860-1923$ & & \\
\hline B_10 & B_10 & $1471-1449$ & H9 & H9 & $1923-2120$ & & \\
\hline B_11 & B_11 & 1449-1793 & H10 & H10 & $2120-2206$ & & \\
\hline B_12 & B_12 & $1793-1831$ & & H11 & $2206-2258$ & & \\
\hline \multirow[t]{2}{*}{ B_13 } & B_13 & 1865-1927 & H12 & H12 & 2258-2389 & & \\
\hline & B_14 & 1927 & & H13 & 2389-2498 & & \\
\hline B_15 & B_15 & $1927-2102$ & & & & & \\
\hline B_17 & B_17 & 2139-2206 & & & & & \\
\hline \multirow[t]{2}{*}{ B_19 } & B_19 & $2206-2258$ & & & & & \\
\hline & B_20 & 2258 & & & & & \\
\hline B_21 & B_21 & 2258-2389 & & & & & \\
\hline B_22 & B_22 & 2389-2498 & & & & & \\
\hline
\end{tabular}

'Bandas selecionadas entre as 22 bandas estabelecidas, variáveis preditoras, dos modelos discriminantes dos solos da área de estudo

${ }^{2}$ Comprimento de onda das bandas selecionadas para o modelo

${ }^{3}$ Alturas selecionadas entre as 13 alturas estabelecidas, variáveis preditoras, dos modelos discriminantes dos solos da área de estudo

${ }^{4}$ Dados orbitais do TM-Landsat-5, selecionados entre as 6 Bandas, variáveis preditoras, dos modelos discriminantes dos solos da área de estudo

${ }^{5}$ Amostras da camada A, referente ao Horizonte A

${ }^{6}$ Amostras da camada B, referente ao Horizonte B

${ }^{7}$ Banda selecionada, considerado a média dos valores de reflectância entre o comprimento de onda de 401 $481 \mathrm{~nm}$

${ }^{8}$ Altura selecionada, considerado como a diferença entre o ponto de maior reflectância e o menor dentro do comprimento de onda selecionado, sendo esse valor sempre positivo 
Tabela 2. Dados médios dos atributos químicos e granulométricos das unidades de mapeamento da área de estudo.

\begin{tabular}{|c|c|c|c|c|c|c|c|c|c|c|c|c|c|c|c|c|c|c|c|c|}
\hline \multirow{2}{*}{$\begin{array}{c}\text { Sigla }^{1} \\
\text { Solo }\end{array}$} & \multirow[t]{2}{*}{$\mathrm{N}^{2}$} & \multirow[t]{2}{*}{ Camada } & \multirow{2}{*}{$\begin{array}{l}\mathrm{MO}^{4} \\
\mathrm{~g} / \mathrm{kg}\end{array}$} & $\mathrm{K}$ & $\mathrm{Ca}$ & $\mathrm{Mg}$ & $\overline{\mathrm{Al}}$ & $\mathrm{H}$ & SB & $\mathrm{T}$ & $\mathrm{V}$ & $\mathrm{m}$ & Areia & Silte & Argila & \multicolumn{3}{|c|}{ Cor úmida } & \multirow{2}{*}{$\begin{array}{c}\mathrm{Fe}_{2} \mathrm{O}_{3} \\
\mathrm{~g} / \mathrm{kg}\end{array}$} & \multirow[t]{2}{*}{$\mathrm{Ki}$} \\
\hline & & & & \multicolumn{9}{|c|}{------------------------------ mmolc/kg--------------- } & \multicolumn{3}{|c|}{---------g/kg--------- } & Matiz & Valor & Croma & & \\
\hline \multirow[t]{2}{*}{ CXBE3 } & 7 & A & 18,7 & 3,5 & 40,3 & 12,7 & 0,7 & 32,3 & 56,5 & 88,8 & 64,0 & 1,3 & 28,7 & 20,0 & 51,3 & 4,2 & 3,6 & 1,7 & 144 & 1,75 \\
\hline & & $\mathrm{B}$ & 9,3 & 0,5 & 32,3 & 18,3 & 0,0 & 7,3 & 51,1 & 58,5 & 86,7 & 0,0 & 40,0 & 14,0 & 46,0 & 2,7 & 3,6 & 2,2 & 149 & 1,52 \\
\hline \multirow[t]{2}{*}{ CXEF1 } & 2 & A & 32,0 & 6,7 & 97,0 & 38,0 & 1,0 & 58,0 & 141,7 & 199,7 & 71,0 & 1,0 & 33,0 & 25,0 & 42,0 & 2,8 & 3,6 & 2,0 & 153 & 1,52 \\
\hline & & B & 4,5 & 8,2 & 66,0 & 62,5 & 0,0 & 33,5 & 136,7 & 170,2 & 80,5 & 0,0 & 52,5 & 26,5 & 21,0 & 7,6 & 4,1 & 2,4 & 216 & 1,44 \\
\hline \multirow[t]{2}{*}{ LVD1 } & 213 & $A$ & 12,2 & 2,0 & 13,1 & 5,0 & 1,3 & 18,3 & 20,1 & 38,4 & 53,0 & 8,0 & 81,2 & 3,6 & 15,2 & 2,7 & 3,5 & 1,9 & 21 & 2,06 \\
\hline & & $B$ & 11,7 & 1,1 & 3,6 & 1,7 & 7,7 & 21,6 & 6,4 & 27,9 & 22,9 & 56,1 & 78,9 & 2,4 & 18,7 & 1,5 & 3,6 & 2,4 & 27 & 1,78 \\
\hline \multirow[t]{2}{*}{ LVD2 } & 13 & A & 13,3 & 1,9 & 12,6 & 5,1 & 1,9 & 22,6 & 19,7 & 42,3 & 48,8 & 9,5 & 77,5 & 4,5 & 18,0 & 2,0 & 3,4 & 1,8 & 30 & 2,12 \\
\hline & & $B$ & 12,1 & 0,8 & 5,6 & 1,6 & 11,5 & 26,6 & 8,1 & 34,7 & 23,5 & 55,1 & 70,1 & 3,0 & 26,9 & 1,9 & 3,7 & 2,6 & 38 & 1,99 \\
\hline \multirow[t]{2}{*}{ LVD3 } & 26 & A & 19,0 & 3,4 & 18,2 & 7,2 & 1,6 & 33,2 & 28,8 & 62,0 & 46,3 & 6,0 & 53,7 & 9,0 & 37,3 & 2,9 & 3,5 & 2,0 & 122 & 1,56 \\
\hline & & B & 13,0 & 0,5 & 9,1 & 3,7 & 5,4 & 28,0 & 13,3 & 41,3 & 31,7 & 25,8 & 44,0 & 8,9 & 47,1 & 2,0 & 3,6 & 2,1 & 134 & 1,72 \\
\hline \multirow[t]{2}{*}{ LVE4 } & 12 & $A$ & 23,3 & 3,8 & 46,1 & 16,3 & 0,3 & 39,1 & 66,2 & 105,4 & 61,7 & 0,6 & 32,0 & 14,0 & 54,0 & 2,6 & 3,5 & 2,0 & 185 & 1,08 \\
\hline & & $B$ & 9,9 & 1,2 & 39,4 & 13,6 & 0,1 & 13,7 & 54,2 & 67,9 & 78,4 & 0,4 & 22,9 & 11,6 & 65,6 & 1,8 & 3,5 & 1,9 & 185 & 1,01 \\
\hline \multirow[t]{2}{*}{ LVAD1 } & 20 & A & 12,1 & 2,3 & 15,8 & 5,7 & 1,1 & 16,2 & 23,7 & 39,9 & 60,5 & 6,7 & 77,8 & 5,0 & 17,3 & 3,1 & 3,7 & 2,1 & 24 & 1,93 \\
\hline & & $B$ & 11,3 & 1,0 & 6,4 & 2,3 & 7,1 & 28,1 & 9,7 & 37,8 & 24,0 & 47,9 & 76,2 & 3,1 & 20,7 & 3,0 & 3,7 & 2,4 & 35 & 1,81 \\
\hline \multirow[t]{2}{*}{ LVAE2 } & 6 & A & 17,0 & 1,6 & 30,0 & 8,0 & 1,0 & 20,0 & 39,6 & 59,6 & 66,0 & 2,0 & 64,0 & 8,0 & 28,0 & 2,6 & 3,7 & 2,3 & 79 & 1,57 \\
\hline & & B & 9,0 & 0,7 & 35,0 & 5,0 & 0,0 & 10,0 & 40,7 & 50,7 & 80,0 & 0,0 & 58,0 & 8,0 & 34,0 & 2,8 & 3,6 & 1,6 & 89 & 1,68 \\
\hline \multirow[t]{2}{*}{ LVAE3 } & 4 & $A$ & 21,3 & 4,7 & 25,0 & 9,8 & 1,5 & 26,3 & 39,4 & 65,7 & 59,3 & 4,3 & 56,3 & 11,0 & 32,8 & 3,3 & 3,5 & 1,8 & 69 & 2,76 \\
\hline & & $B$ & 9,3 & 2,1 & 31,5 & 6,8 & 0,0 & 9,5 & 40,3 & 49,8 & 80,0 & 0,0 & 51,3 & 8,8 & 40,0 & 3,4 & 3,7 & 2,1 & 86 & 1,62 \\
\hline \multirow[t]{2}{*}{ LVEF4 } & 11 & $A$ & 24,6 & 3,3 & 33,0 & 11,6 & 0,9 & 40,3 & 47,9 & 88,1 & 55,4 & 1,9 & 25,9 & 15,6 & 58,5 & 2,1 & 3,5 & 1,7 & 190 & 1,70 \\
\hline & & $B$ & 23,8 & 0,4 & 34,4 & 9,4 & 0,0 & 14,0 & 44,2 & 58,2 & 75,3 & 0,0 & 17,3 & 13,0 & 69,8 & 1,8 & 3,5 & 1,8 & 200 & 1,46 \\
\hline \multirow[t]{2}{*}{ NVE4 } & 16 & A & 29,4 & 4,4 & 39,7 & 14,9 & 0,9 & 47,9 & 59,0 & 107,0 & 54,1 & 1,9 & 22,0 & 18,6 & 59,4 & 2,3 & 3,4 & 1,8 & 202 & 1,53 \\
\hline & & $B$ & 12,1 & 0,8 & 37,7 & 12,0 & 0,2 & 15,8 & 50,6 & 66,3 & 75,6 & 0,6 & 19,9 & 11,6 & 68,6 & 1,9 & 3,5 & 1,8 & 178 & 1,66 \\
\hline
\end{tabular}


Tabela 2. Dados médios dos atributos químicos e granulométricos das unidades de mapeamento da área de estudo.

\begin{tabular}{|c|c|c|c|c|c|c|c|c|c|c|c|c|c|c|c|c|c|c|c|c|}
\hline Sigla $^{1}$ & $\mathrm{~N}^{2}$ & Camada & $\mathrm{MO}^{4}$ & $\mathrm{~K}$ & $\mathrm{Ca}$ & $\mathrm{Mg}$ & Al & $\mathrm{H}$ & SB & $\mathrm{T}$ & $\mathrm{V}$ & $\mathrm{m}$ & Areia & Silte & Argila & \multicolumn{3}{|c|}{ Cor úmida } & $\mathrm{Fe}_{2} \mathrm{O}_{3}$ & $\mathrm{Ki}$ \\
\hline Solo & & & $\mathrm{g} / \mathrm{kg}$ & \multicolumn{7}{|c|}{ 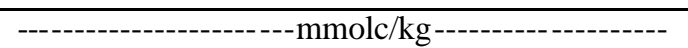 } & \multicolumn{2}{|c|}{$\%$} & \multicolumn{3}{|c|}{-------------g/kg---------- } & Matiz & Valor & Croma & $\mathrm{g} / \mathrm{kg}$ & \\
\hline \multirow[t]{2}{*}{ NVEF4 } & 14 & A & 24,2 & 4,2 & 42,4 & 15,0 & 1,0 & 37,2 & 61,6 & 98,8 & 61,3 & 1,9 & 21,3 & 17,9 & 60,8 & 3,0 & 4,2 & 1,5 & 171 & 1,58 \\
\hline & & $B$ & 15,8 & 1,5 & 37,1 & 10,9 & 0,0 & 13,1 & 49,5 & 62,6 & 78,9 & 0,0 & 18,7 & 11,8 & 69,5 & 1,7 & 3,5 & 1,9 & 150 & 1,72 \\
\hline \multirow[t]{2}{*}{ PAD1 } & 1 & $A$ & 5,0 & 1,4 & 4,0 & 3,0 & 0,0 & 12,0 & 8,4 & 20,4 & 41,0 & 0,0 & 88,0 & 2,0 & 10,0 & 2,5 & 3,4 & 1,6 & - & - \\
\hline & & $B$ & 11,0 & 1,1 & 1,0 & 1,0 & 11,0 & 30,0 & 3,1 & 33,1 & 9,0 & 78,0 & 72,0 & 4,0 & 24,0 & 6,6 & 3,8 & 1,4 & - & - \\
\hline \multirow{2}{*}{ PAD2 } & 1 & $A$ & 12,0 & 1,1 & 7,0 & 3,0 & 3,0 & 10,0 & 11,1 & 21,1 & 53,0 & 21,0 & 86,0 & 2,0 & 12,0 & 2,5 & 3,3 & 1,4 & - & - \\
\hline & & $B$ & 5,0 & 0,6 & 10,0 & 4,0 & 12,0 & 19,0 & 14,6 & 33,6 & 43,0 & 45,0 & 72,0 & 2,0 & 26,0 & 7,2 & 4,2 & 2,3 & - & - \\
\hline \multirow[t]{2}{*}{ PVD1 } & 19 & $A$ & 15,1 & 1,7 & 10,4 & 4,6 & 2,1 & 23,0 & 16,8 & 39,8 & 43,4 & 12,2 & 86,1 & 3,4 & 10,5 & 2,8 & 3,5 & 1,8 & 23 & 2,17 \\
\hline & & $B$ & 9,8 & 1,3 & 6,1 & 2,2 & 4,8 & 21,9 & 9,5 & 31,5 & 30,1 & 34,4 & 75,9 & 2,6 & 21,4 & 1,6 & 3,6 & 2,4 & 28 & 1,92 \\
\hline \multirow[t]{2}{*}{ PVD2 } & 30 & $A$ & 12,8 & 1,9 & 9,5 & 4,4 & 2,5 & 21,2 & 15,8 & 36,9 & 42,8 & 14,1 & 84,3 & 4,6 & 11,1 & 2,7 & 3,6 & 2,0 & 25 & 2,05 \\
\hline & & $B$ & 7,2 & 1,4 & 9,4 & 3,0 & 6,2 & 25,7 & 13,8 & 39,5 & 35,2 & 27,2 & 69,5 & 2,5 & 28,1 & 1,8 & 3,7 & 2,5 & 38 & 1,81 \\
\hline \multirow[t]{2}{*}{ PVE3 } & 13 & $A$ & 18,6 & 2,7 & 15,8 & 6,7 & 1,8 & 34,5 & 25,2 & 59,7 & 42,0 & 7,3 & 71,1 & 7,9 & 21,0 & 3,3 & 3,5 & 2,0 & 83 & 1,77 \\
\hline & & B & 12,5 & 0,6 & 32,6 & 6,4 & 1,1 & 16,1 & 39,6 & 55,7 & 71,9 & 2,7 & 50,7 & 5,9 & 43,4 & 2,0 & 3,6 & 2,1 & 136 & 0,98 \\
\hline \multirow[t]{2}{*}{ PVE4 } & 2 & $A$ & 25,5 & 4,5 & 116,5 & 57,0 & 0,0 & 38,5 & 178,0 & 216,5 & 73,0 & 0,0 & 43,0 & 22,5 & 34,5 & 3,3 & 3,6 & 2,2 & - & - \\
\hline & & $B$ & 11,0 & 0,8 & 36,5 & 10,5 & 0,0 & 18,5 & 47,8 & 66,3 & 72,0 & 0,0 & 27,5 & 9,5 & 63,0 & 1,8 & 3,5 & 2,0 & - & - \\
\hline \multirow[t]{2}{*}{ PVAD1 } & 7 & $A$ & 13,3 & 1,6 & 12,8 & 7,0 & 2,2 & 15,2 & 21,4 & 36,6 & 60,2 & 11,3 & 84,7 & 3,7 & 11,7 & 2,5 & 3,5 & 1,8 & - & - \\
\hline & & B & 10,3 & 0,8 & 11,8 & 4,0 & 7,5 & 28,3 & 16,6 & 44,9 & 35,3 & 33,0 & 73,7 & 3,0 & 23,3 & 3,3 & 3,8 & 2,4 & - & - \\
\hline \multirow[t]{2}{*}{ PVAD2 } & 3 & $A$ & 10,5 & 1,4 & 9,5 & 4,0 & 3,0 & 13,0 & 14,9 & 27,9 & 53,0 & 17,5 & 85,0 & 3,0 & 12,0 & 2,2 & 3,4 & 1,6 & 25 & 2,41 \\
\hline & & $B$ & 9,5 & 1,5 & 11,0 & 3,5 & 3,0 & 17,5 & 16,0 & 33,5 & 44,0 & 25,0 & 68,5 & 3,0 & 28,5 & 2,8 & 3,7 & 2,4 & 40 & 1,91 \\
\hline \multirow[t]{2}{*}{ PVAD3 } & 1 & $A$ & 6,0 & 1,6 & 9,0 & 3,0 & 3,0 & 12,0 & 13,6 & 25,6 & 53,0 & 18,0 & 86,0 & 4,0 & 10,0 & 2,5 & 3,5 & 1,7 & - & - \\
\hline & & B & 6,0 & 0,4 & 8,0 & 3,0 & 3,0 & 24,0 & 11,4 & 35,4 & 32,0 & 21,0 & 57,0 & 2,0 & 41,0 & 4,3 & 3,7 & 2,2 & - & - \\
\hline \multirow[t]{2}{*}{ PVAE4 } & 2 & $A$ & 36,0 & 2,2 & 50,0 & 17,0 & 0,5 & 31,0 & 69,2 & 100,2 & 70,0 & 0,5 & 41,0 & 16,0 & 43,0 & 2,5 & 3,5 & 1,7 & 166 & 1,57 \\
\hline & & B & 12,5 & 1,0 & 48,0 & 16,5 & 0,0 & 12,5 & 65,5 & 78,0 & 84,0 & 0,0 & 22,0 & 11,5 & 66,5 & 2,6 & 3,5 & 1,8 & 186 & 1,48 \\
\hline \multirow[t]{2}{*}{ RQO } & 50 & $A$ & 11,0 & 1,6 & 10,9 & 4,3 & 1,5 & 16,9 & 16,8 & 33,8 & 52,0 & 9,6 & 84,0 & 3,4 & 12,6 & 3,1 & 3,6 & 2,0 & 17 & 2,22 \\
\hline & & $B$ & 8,8 & 1,1 & 4,3 & 1,8 & 6,5 & 17,3 & 7,2 & 24,5 & 29,9 & 50,3 & 84,7 & 3,1 & 12,2 & 2,9 & 3,7 & 2,3 & 19 & 2,09 \\
\hline
\end{tabular}

${ }^{\mathrm{T}}$ Descrição dos solos, Figura 1, Representação do mapa de solos detalhado por textura; ${ }^{2}$ Número de Repetições para cada unidade de mapeamento da área de estudo;

3 Camada A, referente ao Horizontes A $(0-20 \mathrm{~cm})$, Camada B, referente ao Horizonte B $(80-100 \mathrm{~cm}) ;{ }^{4}$ Matéria Orgânica; $(-)$ não determinado. 
Tabela 3. Exemplos de equações lineares discriminantes da área de estudo, solo textura arenosa (RQo), textura média (LV1) e textura argilosa (LVef), em função da reflectância dos dados de laboratório com o sensor IRIS.

\begin{tabular}{|c|c|}
\hline Solo' & Equações Discriminantes $^{2}$ \\
\hline RQo & 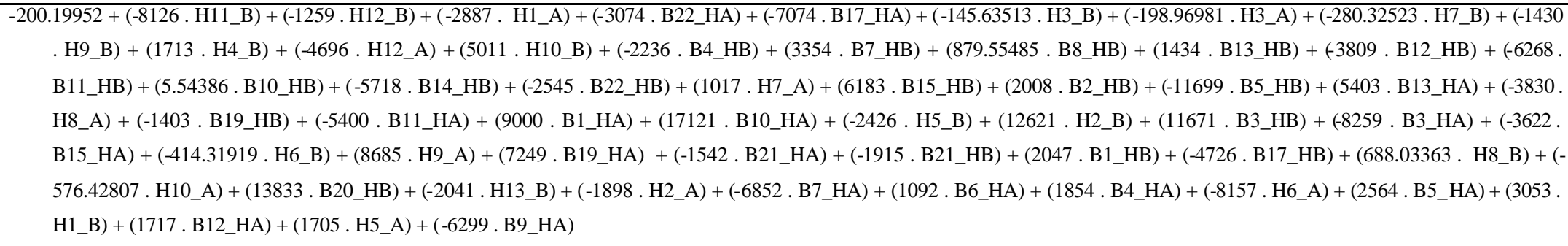 \\
\hline LV1 & 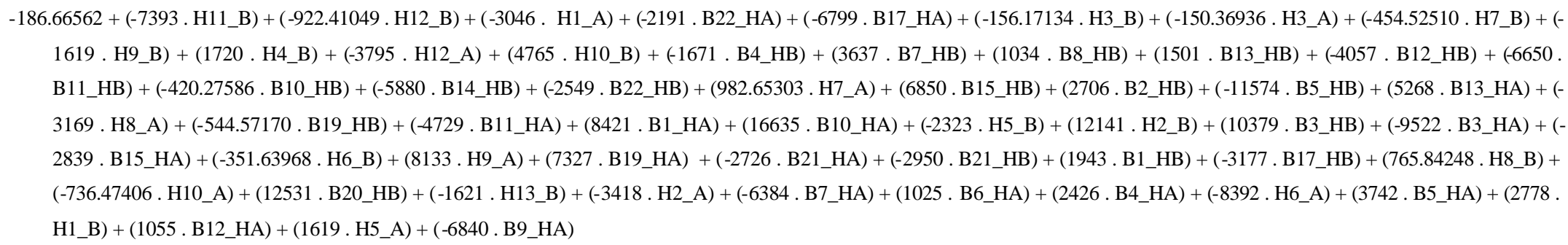 \\
\hline LVef & 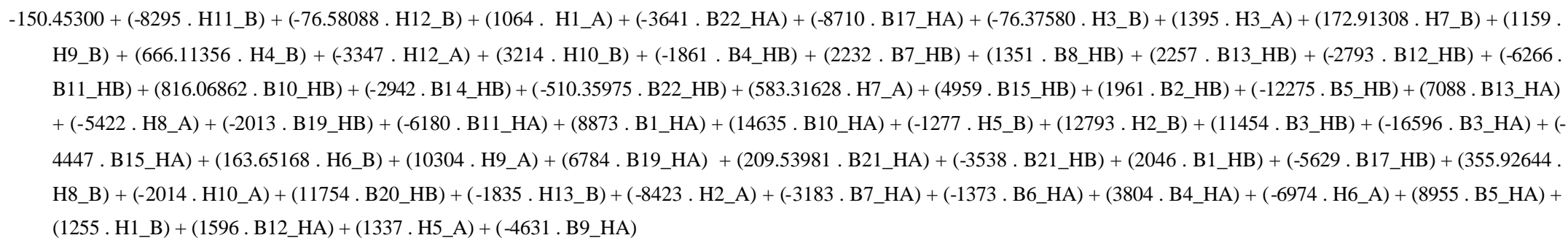 \\
\hline
\end{tabular}

${ }^{1}$ Classes de solos presentes na área de estudo, descritos na Figura 1, desse trabalho; ${ }^{2}$ Equações discriminantes geradas pelo SAS, para cada classe de solo da área de estudo 
Tabela 4. Equações lineares discriminantes em função da reflectância dos dados TM-Landsat -5, para as 23 unidades de mapeamento da área de estudo.

\begin{tabular}{|c|c|}
\hline Solo & Equação discriminante $^{2}$ \\
\hline $\mathrm{CXB}$ & $-38,10391+\left(-8,17651 . T M \_1\right)+\left(4,47090 . T M \_3\right)+\left(1,02498 . T M \_4\right)+\left(1,40815 . T M \_5\right)+\left(-0,94640 . T M \_7\right)$ \\
\hline CXEF1 & $-48,11706+\left(-8,26581 . T M \_1\right)+\left(5,06632 . T M \_3\right)+\left(1,07090 . T M \_4\right)+\left(1,62464 . T M \_5\right)+\left(-1,28670 . T M \_7\right)$ \\
\hline LV1 & $-66,45214+\left(-10,75198 . T M \_1\right)+\left(4,21188 . T M \_3\right)+\left(1,01808 . T M \_4\right)+\left(2,46033 . T M \_5\right)+\left(-0,26887 . T M \_7\right)$ \\
\hline LV2 & $-63,31388+\left(-9,36366 . T M \_1\right)+\left(4,84026 . T M \_3\right)+\left(1,26616 . T M \_4\right)+\left(1,56273 . T M \_5\right)+\left(0,04240 . T M \_7\right)$ \\
\hline LV3 & $-39,02309+\left(-8,25114 . T M \_1\right)+\left(3,99626 . T M \_3\right)+\left(1,14479 . T M \_4\right)+\left(1,56435 . T M \_5\right)+\left(-0,76423 . T M \_7\right)$ \\
\hline LV4 & $-36,09287+\left(-7,83021 . T M \_1\right)+\left(4,17374 \cdot T M \_3\right)+\left(0,81787 . T M \_4\right)+\left(1,69626 \cdot T M \_5\right)+\left(-1,14290 . T M \_7\right)$ \\
\hline LVA1 & $-61,86856+\left(-9,16350 \cdot T M \_1\right)+\left(4,21113 \cdot T M \_3\right)+\left(1,00373 . T M \_4\right)+\left(2,26389 . T M \_5\right)+\left(-0,36794 . T M \_7\right)$ \\
\hline LVA2 & $-57 \cdot 36781+\left(-7,98193 . T M \_1\right)+\left(3,68121 . T M \_3\right)+\left(0,90358 . T M \_4\right)+\left(2,31255 . T M \_5\right)+\left(-0,31288 . T M \_7\right)$ \\
\hline LVA3 & $-40,49953+\left(-7,45012 . T M \_1\right)+\left(4,34788 . T M \_3\right)+\left(0,79666 . T M \_4\right)+\left(1,49535 . T M \_5\right)+\left(-0,61865 . T M \_7\right)$ \\
\hline LVEF & $-37,40379+\left(-8,60542 \cdot T M \_1\right)+\left(4,60951 \cdot T M \_3\right)+\left(0,98553 . T M \_4\right)+\left(1,37065 \cdot T M \_5\right)+\left(-0,98014 . T M \_7\right)$ \\
\hline NV & $-36,89305+\left(-9,03373 . T M \_1\right)+\left(4,49752 \cdot T M \_3\right)+\left(1,21486 . T M \_4\right)+\left(1,33747 . T M \_5\right)+\left(-1,08183 . T M \_7\right)$ \\
\hline NVEF & $-39,89299+\left(-9,79817 . T M \_1\right)+\left(5,23224 . T M \_3\right)+\left(1,03169 . T M \_4\right)+\left(1,30794 . T M \_5\right)+\left(-1,28979 . T M \_7\right)$ \\
\hline PA1 & $-96,65936+\left(-10,88925 . T M \_1\right)+\left(2,74009 . T M \_3\right)+\left(2,40357 . T M \_4\right)+\left(3,35678 . T M \_5\right)+\left(-0,75881 . T M \_7\right)$ \\
\hline PA2 & $-45,46696+\left(-6,91843 \cdot T M \_1\right)+\left(3,87519 \cdot T M \_3\right)+\left(0,61275 \cdot T M \_4\right)+\left(2,23689 . T M \_5\right)+\left(-1,01751 . T M \_7\right)$ \\
\hline PV1 & $-65,29949+\left(-9,35034 . T M \_1\right)+\left(4,45727 . T M \_3\right)+\left(1,02412 . T M \_4\right)+\left(2,18996 . T M \_5\right)+\left(-0,26972 . T M \_7\right)$ \\
\hline PV2 & $-62,04446+\left(-8,61380 . T M \_1\right)+\left(4,44971 . T M \_3\right)+\left(0,94951 . T M \_4\right)+\left(2,07696 . T M \_5\right)+\left(-0,29018 . T M \_7\right)$ \\
\hline PV3 & $-40,70583+\left(-7,74146 . T M \_1\right)+\left(3,87025 . T M \_3\right)+\left(1,03635 . T M \_4\right)+\left(1,67351 . T M \_5\right)+\left(-0,64575 . T M \_7\right)$ \\
\hline PV4 & $-46,76365+\left(-10,77422 . T M \_1\right)+\left(5,00996 \cdot T M \_3\right)+\left(1,28553 . T M \_4\right)+\left(1,63239 . T M \_5\right)+\left(-1,19860 . T M \_7\right)$ \\
\hline PVA1 & $-67,22319+\left(-9,07418 . T M \_1\right)+\left(3,20247 . T M \_3\right)+\left(1,80733 \cdot T M \_4\right)+\left(2,43214 . T M \_5\right)+\left(-0,41339 . T M \_7\right)$ \\
\hline PVA2 & $-66,95143+\left(-9,06706 \cdot T M \_1\right)+\left(4,59002 \cdot T M \_3\right)+\left(0,93375 \cdot T M \_4\right)+\left(2,20629 \cdot T M \_5\right)+\left(-0,28323 \cdot T M \_7\right)$ \\
\hline PVA3 & $-70,73395+\left(-6,91075 \cdot T M \_1\right)+\left(4,01980 . T M \_3\right)+\left(0,99096 . T M \_4\right)+\left(2,11327 . T M \_5\right)+\left(0,14164 . T M \_7\right)$ \\
\hline PVA4 & $-38,88580+\left(-6,91880 . T M \_1\right)+\left(3,69984 . T M \_3\right)+\left(1,01860 . T M \_4\right)+\left(1,78492 . T M \_5\right)+\left(-0,97426 . T M \_7\right)$ \\
\hline RQO & $-66,42202+\left(-9,82829 \cdot T M \_1\right)+\left(3,97301 . T M \_3\right)+\left(1,10538 . T M \_4\right)+\left(2,49067 \cdot T M \_5\right)+\left(-0,30785 . T M \_7\right)$ \\
\hline
\end{tabular}

\footnotetext{
Classes de solos presentes na área de estudo, descritos na Figura 1, desse trabalho

${ }^{2}$ Equações discriminantes geradas pelo SAS, para cada classe de solo da área de estudo
} 
Tabela 5. Resultados da análise discriminante, número de observações, classificação e erro para os dados obtidos das bandas e alturas de 473 amostras da área de estudo.

\begin{tabular}{|c|c|c|c|c|c|c|}
\hline \multirow[t]{2}{*}{ Solo ${ }^{1}$} & \multirow{2}{*}{$\begin{array}{c}\text { Total de } \\
\text { Amostras }\end{array}$} & \multicolumn{2}{|c|}{ Acerto $^{3}$} & \multicolumn{2}{|c|}{ Erro $^{4}$} & \multirow[t]{2}{*}{ Solos confundidos } \\
\hline & & Amostras & $\%$ & Amostras & $\%$ & \\
\hline $\mathrm{CXb}$ & 7 & 5 & 71,4 & 2 & 28,57 & LV3(1), NV(1) \\
\hline CXef1 & 2 & 2 & 100,0 & - & - & - \\
\hline LV1 & 213 & 182 & 85,4 & 31 & 14,55 & LV2(3), LVA1(10), PV1(10), PV2(3), RQo(5) \\
\hline LV2 & 13 & 9 & 69,2 & 4 & 30,77 & LV1(1), LVA1(1), PV1(1), PV2(1) \\
\hline LV3 & 26 & 21 & 80,7 & 5 & 19,23 & LV4(2), LVef(2), NVef(1) \\
\hline LV4 & 12 & 12 & 100,0 & - & - & - \\
\hline LVA1 & 20 & 16 & 80,0 & 4 & 20,00 & LV1(1), PVA1(1), RQo(2) \\
\hline LVA2 & 6 & 5 & 83,3 & 1 & 16,67 & LV3(1) \\
\hline LVA3 & 4 & 4 & 100,0 & - & - & - \\
\hline LVef & 11 & 8 & 72,7 & 3 & 27,27 & LV3(2), NVef(1) \\
\hline NV & 16 & 10 & 62,5 & 6 & 37,50 & LV3(1), LV4(2), NVef(2), PVA4(1) \\
\hline NVef & 14 & 12 & 85,7 & 2 & 14,29 & $\operatorname{LVef}(2)$ \\
\hline PA1 & 1 & 1 & 100,0 & - & - & - \\
\hline PA2 & 1 & 1 & 100,0 & - & - & - \\
\hline PV1 & 19 & 15 & 78,9 & 4 & 21,05 & LV1(2), PV2(1), RQo(1) \\
\hline PV2 & 30 & 25 & 83,3 & 5 & 16,67 & LV1(2), LV3(1), PV3(1), PVA1(1) \\
\hline PV3 & 13 & 12 & 92,3 & 1 & 7,69 & $\mathrm{LV} 3(1)$ \\
\hline PV4 & 2 & 1 & 50,0 & 1 & 50,00 & LV4(1) \\
\hline PVA1 & 7 & 7 & 100,0 & - & - & - \\
\hline PVA2 & 3 & 3 & 100,0 & - & - & - \\
\hline PVA3 & 1 & 1 & 100,0 & - & - & - \\
\hline PVA4 & 2 & 2 & 100,0 & - & - & - \\
\hline RQo & 50 & 31 & 62,0 & 19 & 38,00 & $\begin{array}{c}\text { LV1(12), LVA1(1), PV1(3), PVA1(2), } \\
\text { PVA3(1) }\end{array}$ \\
\hline Total & 473 & 385 & 81,4 & 88 & 18,6 & \\
\hline
\end{tabular}

'Classes de solos presentes na área de estudo, descritos na Figura 1, desse trabalho

2 Total de observações de cada classe

${ }^{3}$ Número de amostras e porcentagem classificadas corretamente pela equação discriminante para cada classe de solo

${ }^{4}$ Número de amostras e porcentagem classificadas erroneamente pela equação discriminante para cada classe de solo

${ }^{5}$ Classes de solos que foram confundidas no processo de classificação pelas equações discriminantes 
Tabela 6. Resultados da análise discriminante, número de observações, classificação e erro para os dados obtidos das 6 bandas do TM-Landsat 5 nas 473 amostras da área de estudo.

\begin{tabular}{|c|c|c|c|c|c|c|}
\hline \multirow[t]{2}{*}{ Solo $^{T}$} & \multirow{2}{*}{$\begin{array}{c}\text { Total de } \\
\text { Amostras }\end{array}$} & \multicolumn{2}{|c|}{ Acerto $^{3}$} & \multicolumn{2}{|c|}{ Erro $^{4}$} & \multirow[t]{2}{*}{ Solos confundidos $^{5}$} \\
\hline & & Amostras & $\%$ & Amostras & $\%$ & \\
\hline $\mathrm{CXb}$ & 7 & - & - & 7 & 100,0 & LVA3(1), LVef(2), NV(1), NVef(1), PV4(1), PVA4(1) \\
\hline CXef1 & 2 & 2 & 100,0 & & - & - \\
\hline LV1 & 213 & 148 & 69,4 & 65 & 30,5 & $\begin{array}{l}\text { LV2(7), LVA1(7), LVA2(17), PA1(3), PV1(2), PV2(1), } \\
\text { PV3(2), PV4(1), PVA1(5), PVA2(9), PVA3(4), RQo(7) }\end{array}$ \\
\hline LV2 & 13 & 1 & 7,7 & 12 & 92,3 & $\begin{array}{l}\text { LV1(2), LVA1(1), LVef(1), PA2(1), PV1(1), PV2(1), PV4(2), } \\
\text { PVA2(2), PVA3(1) }\end{array}$ \\
\hline LV3 & 26 & 4 & 15,4 & 22 & 84,6 & $\begin{array}{l}\text { CXB(1), LV4(5), LVA3(4), LVef(2), NV(1), NVef(1), } \\
\text { PA2(1),PV2(1), PV3(1), PV4(2), PVA1(1), PVA4(2) }\end{array}$ \\
\hline LV4 & 12 & 1 & 8,3 & 11 & 91,6 & CXef1(2), LV3(2), LVef(2), NV(1), PA2(1), PV4(1), PVA4(2) \\
\hline LVA1 & 20 & 1 & 5,0 & 19 & 95,0 & $\begin{array}{c}\text { LV1(5), LVA2(3), PA1(1), PA2(1), PV4(1), PVA2(3), } \\
\text { PVA3(4), RQo(1) }\end{array}$ \\
\hline LVA2 & 6 & 2 & 33,3 & 4 & 66,6 & LV1(1), PA2(1), PVA1(1), PVA3(1) \\
\hline LVA3 & 4 & 3 & 75,0 & 1 & 25,0 & $\operatorname{LVef}(1)$ \\
\hline LVef & 11 & 3 & 27,3 & 8 & 72,7 & CXef1(1), LV4(2), LVA3(1), NV(1), NVef(1), PV4(2) \\
\hline NV & 16 & 2 & 12,5 & 14 & 87,5 & CXef1(1), LV4(3), LVef(4), NVef(4), PV4(1), PVA1(1) \\
\hline NVef & 14 & 8 & 57,1 & 6 & 42,8 & CXB(1), LV4(1), LVA3(1), NV(1), PV4(2) \\
\hline PA1 & 1 & 1 & 100,0 & & - & - \\
\hline PA2 & 1 & 1 & 100,0 & & - & - \\
\hline PV1 & 19 & 1 & 5,3 & 18 & 94,7 & $\begin{array}{l}\text { LV1(5), LV2(3), LVA1(1), LVA2(2), PV2(2), PVA2(2) } \\
\text { PVA3(2), RQo(1) }\end{array}$ \\
\hline PV2 & 30 & 2 & 6,7 & 28 & 93,3 & $\begin{array}{l}\text { LV1(1), LV2(3), LV3(1), LVA1(1), LVA2(3), LVA3(1), } \\
\text { PV1(1), PV3(3), PVA1(1), PVA2(5), PVA3(8) }\end{array}$ \\
\hline PV3 & 13 & 1 & 7,7 & 12 & 92,3 & $\begin{array}{c}\text { CXef1(1), LV1(1), LV3(2), LV4(1), LVA3(2), LVef(2), } \\
\text { PA2(1), PV2(1), PVA4(1) }\end{array}$ \\
\hline PV4 & 2 & & - & 2 & 100,0 & $\operatorname{LV} 3(1), \operatorname{NVef}(1)$ \\
\hline PVA1 & 7 & 2 & 28,6 & 5 & 71,4 & LVA2(1), PA1(2), PVA2(1), PVA3(1) \\
\hline PVA2 & 3 & 1 & 33,3 & 2 & 66,7 & LVA1(1), PVA3(1) \\
\hline PVA3 & 1 & 1 & 100,0 & & - & - \\
\hline PVA4 & 2 & 1 & 50,0 & 1 & 50,0 & LV4(1) \\
\hline RQo & 50 & 5 & 10,0 & 45 & 90,0 & $\begin{array}{l}\text { CXef1(2), LV1(21), LV2(2), LVA1(2), LVA2(3), PA1(2), } \\
\text { PV1(1), PV2(2), PVA1(4), PVA2(2), PVA3(3), PVA4(1) }\end{array}$ \\
\hline Total & 473 & 191 & 40,4 & 282 & 59,6 & \\
\hline
\end{tabular}

${ }^{1}$ Classes de solos presentes na área de estudo, descritos na Figura 1, desse trabalho.

2 Total de observações de cada classe.

${ }^{3}$ Número de amostras e porcentagem classificadas corretamente pela equação discriminante para cada classe de solo.

${ }^{4}$ Número de amostras e porcentagem classificadas erroneamente pela equação discriminante para cada classe de solo.

${ }^{5}$ Classes de solos que foram confundidas no processo de classificação pelas equações discriminantes. 


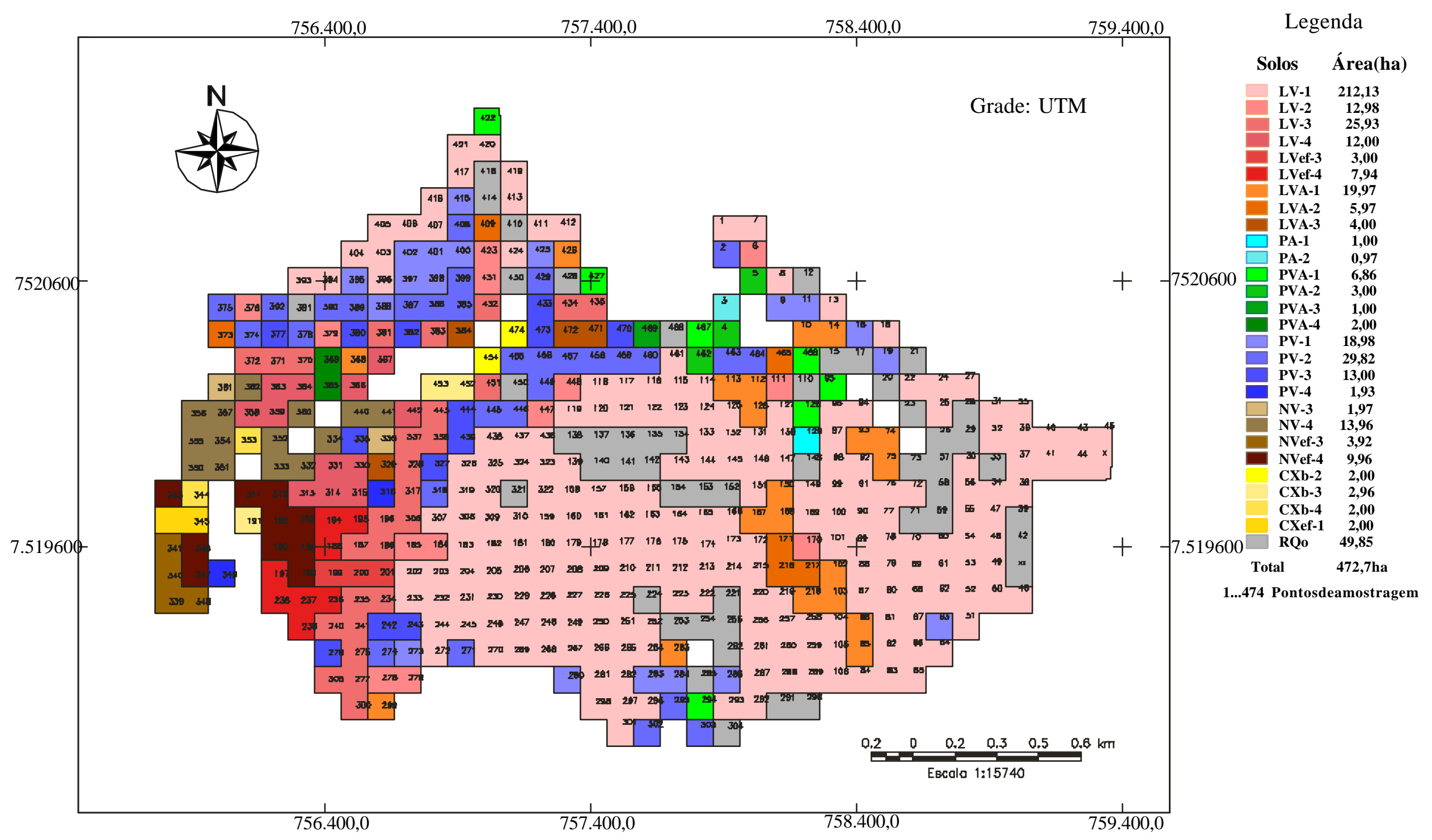

Figura 1 - Represertação do mapa de solos detalhado por textura. Onde(LW) LATOSSOLOS VERMELHOS; (LVe f) LATOSSOLOS VERMELHOS Eutrof AMARELOS; (PV) ARGISSOLOS VERMELHOS; (NVe) NITOSSOLOS VERMELHO Eutrófi cos; (NVef) NI TOSSOLOS VERMELHOS Eutroféricos; (CXb) CAMBISSOLOS HAPLICOS Tb; (CXef) CAMBISSOLOS HAPLICOS Eutrofétricos, (ROO) NEOSSOLOS

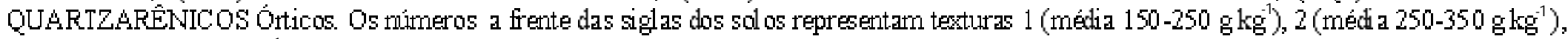
3 (argilosa $350-600 \mathrm{gkg}^{-1}$ ) e 4 (muito aroilosa $>600 \mathrm{gkg}^{-1}$ ). 


\section{REGRESSÕES LINEARES MÚLTIPLAS UTILIZANDO-SE DADOS ESPECTRAIS OBTIDOS POR SENSORES EM LABORATÓRIO E ORBITAL, NA ESTIMATIVA DE ATRIBUTOS DO SOLO}

\section{Resumo}

O objetivo do presente trabalho foi quantificar atributos dos solos por sensores localizados em laboratório e em órbita. A área de estudo localiza-se na região de Barra Bonita, SP, com 473 ha com solo exposto por ocasião do trabalho. Foi estabelecida uma grade de amostragem $(100 \mathrm{~m} \times 100 \mathrm{~m})$, em duas profundidades $(0-20 ; 80-100 \mathrm{~cm})$. Os locais foram georreferenciados, e amostras de terra coletadas e enviadas para análises químicas e físicas em laboratório. Das mesmas amostras foram obtidas leituras de reflectância com o sensor em laboratório (450 a $2.500 \mathrm{~nm}$ ). Nos mesmos locais de amostragem de terra, foram obtidos dados de reflectância de imagens orbitais TMLandsat-5. A maioria das equações geradas apresentaram $r^{2}$ elevados, sendo para $\mathrm{Fe}_{2} \mathrm{O}_{3}$ de 0,82 para radiometria de laboratório e 0,67 para orbital. A comparação nos intervalos de ferro entre valores estimados por radiometria e valores determinados em laboratório apresentou acerto global de 92,2 \% para radiometria de laboratório e 91,3\% para orbital. A comparação para os intervalos de textura, teve um acerto de $65 \%$ para radiometria de 
laboratório e $50 \%$ para orbital, sendo as maioria das confusões observadas entre os valores determinados e os estimados nos intervalos aceitáveis.

\section{MULTIPLE LINEAR REGRESSIONS OBTAINED BY SPECTRAL DATA FROM LABORATORY AND ORBITAL SENSORS, TO QUANTIFY SOIL ATTRIBUTES.}

\section{Summary}

The objective of the present work was to quantify soil attributes by sensor laboratory and orbital sensors. The study area is a 473 ha bare soil field located in the region of Barra Bonita, SP. A sampling grid was established (100 m x $100 \mathrm{~m})$, in two depths $(0-20 ; 80-100 \mathrm{~cm})$. The places were georreferenced, where earth samples were collected for laboratory analyses. The samples reflectance were also obtained with the laboratory sensor (450 to $2500 \mathrm{~nm}$ ). In the same places of earth sampling reflectance data, were obtained from a TM-Landsat-5 image. Most of the generated equations showed high $\mathrm{r}^{2}$ for $\mathrm{Fe}_{2} \mathrm{O}_{3}, 0,82$ for laboratory and 0,67 for orbital. The comparison for the intervals of iron among values esteemed by radiometric and values determined in laboratory presented global success of $92,2 \%$ for laboratory data and $91,3 \%$ for orbital. The comparison for the texture intervals, had a $65 \%$ success for laboratory data and $50 \%$ for orbital, being the majority of the confusions observed between the determined values and the quantified ones in a acceptable interval. 


\subsection{Introdução}

A estimativa de atributos de solos é um desafio que vem sendo buscado por pesquisadores da área de sensoriamento remoto. Vários sistemas com este objetivo vêm sendo desenvolvidos e testados, buscando o seu aperfeiçoamento.

O sistema denominado NIRA (Near-Infrared Analysis) foi desenvolvido baseado nas informações do infravermelho próximo, em laboratório, com o objetivo de avaliar a radiação espectral relacionada aos aspectos químicos de materiais (Stark et al., 1986). Essa metodologia, foi desenvolvida há 30 anos para uma rápida análise da umidade de grãos (Ben-Gera \& Norris, 1968). O início dos estudos do infravermelho data dos anos 50, com maior avanço e interesse nos anos 60 , motivado pelas necessidades de aplicação em agricultura. Os métodos com avaliação espectral mostraram-se bem mais práticos e rápidos que os convencionais na agricultura (Stark et al., 1986). Apesar de iniciado há anos atrás, o uso da aquisição remota de espectros da superfície terrestre aumentou drasticamente na última década. Hoje os métodos do NIRA são bem aceitos e aplicados em várias áreas (Norris, 1988). Este método é conhecido por permitir analisar vários constituintes de um material ao mesmo tempo (Stark et al., 1986).

Em adição ao NIRA, Coleman et al. (1991) utilizaram desde o visível até o infravermelho para avaliação de propriedades do material solo, obtendo bons resultados na estimativa de matéria orgânica, argila e ferro. Ou seja, basicamente, os métodos de estimativa baseiam-se em equações lineares múltiplas, que são constantemente calibradas em função da região de estudo e porção do espectro eletromagnético que se tem em mãos. 
As feições espectrais de materiais de solos no visível e infravermelho (450-2500 nm) estão associadas a vibrações moleculares de grupos específicos. Esses módulos vibracionais são o fundamento dos estudos em faixas (ou bandas) espectrais (Ben-Dor \& Banin, 1995 a,b). Os minerais dos solos têm distintas "impressões digitais espectrais" nesta faixa de comprimento de onda por causa das absorções em bandas específicas ou combinadas, como por exemplo dos grupos $\mathrm{OH}^{-}$e $\mathrm{CO}_{3}$ (Hunt \& Salisbury, 1970).

Portanto, esses métodos assumem que a concentração de um dado constituinte é uma combinação linear de várias feições de absorção. O método é empírico, e nenhum aspecto físico ou químico é realmente necessário. A reflectância espectral de uma dada superfície é extremamente complexa, sendo afetada pelo número e tipos de materiais presentes, sua concentração, tamanho, número, peso e geometria de visada (Clark \& Roush, 1984). Além disso, os métodos de NIRA são baseados na medida de pequenas mudanças de absorbância que ocorrem em múltiplos comprimentos de onda.

Todos os atributos do solo são importantes, porém, em diferentes graus. Cada atributo também está mais diretamente relacionado a uma parte de um planejamento agrícola. Por exemplo, o fósforo é um importante elemento no desenvolvimento das plantas, e por consequiência, o seu teor tem papel de destaque para a recomendação de adubação (planejamento do manejo químico de uma área). Por outro lado, temos elementos que estão relacionados à classificação dos solos, como o $\mathrm{Fe}_{2} \mathrm{O}_{3}$. Os teores deste atributo auxiliam na determinação dos grandes grupos e família da classificação dos solos, de acordo com Embrapa (1999) (base para um planejamento, o levantamento de solos). O tipo e quantidade relativa dos óxidos de ferro tem influência direta nas cores amarela e vermelha dos solos. Predominantemente, solos amarelos apresentam altos 
teores de goethita as quais são responsáveis pela maior adsorsão do fósforo por unidade de peso quando comparados a solos com quantidades similares de hematita, vermelhos (Baumgardner et. al., 1985). De uma certa forma a cor do solo é um indicativo sobre o qual o solo pode reter mais ou menos fósforo. Porém, a quantidade do ferro tem maior importância, na classificação, pois auxiliam na determinação dos grandes grupos para o caráter férrico e família para os demais teores, caracterizando assim o uso dos intervalos de teores de ferro, hipoférrico, mesoférrico, férrico e perférrico (Embrapa, 1999). Porém a análise do ataque sulfúrico é cara, demorada e de resultado ainda sob discussão, o que limita o número de amostras a serem enviadas aos laboratórios e consequentemente, o levantamento de solos.

Faz-se importante, portanto, o desenvolvimento de metodologias que venham a auxiliar na determinação de informações que minimizem esse fator. Ben-Dor \& Banin (1990) foram capazes de determinar correlações significativas entre reflectância espectral e os teores de $\mathrm{Al}_{2} \mathrm{O}_{3}, \mathrm{MgO}$ e $\mathrm{Fe}_{2} \mathrm{O}_{3}$.

Por sua vez, quando se fala em estimativa do elemento $\mathrm{Fe}_{2} \mathrm{O}_{3}$, por sensores instalados em satélites a $800 \mathrm{~km}$ de distância da superfície terrestre, fica a pergunta: é possível? Se for, a sua aplicabilidade poderia ser de valia para os "mapeadores de solos"? Coleman et al. (1993) obteve coeficientes muito baixos nesta empreitada. Descrevem, entretanto, a necessidade de maiores pesquisas desses elementos, visando o aprimoramento e ratificação da técnica, dando maior sustentação a sua aplicabilidade prática. Além disso, com o advento dos sensores hiperespectrais, como o Airborne Visible InfraRed Imaging Spectrometer (AVIRIS), a quantificação de atributos do solo, como o realizado por Galvão et al. (2001) e Baptista (2001) é inevitável. 
Com isso, o presente trabalho tem por objetivo gerar equações lineares de regressão múltipla para os resultados das análises de $\mathrm{Fe}_{2} \mathrm{O}_{3}, \mathrm{Al}_{2} \mathrm{O}_{3}, \mathrm{Al}_{2} \mathrm{O}_{3} / \mathrm{Fe}_{2} \mathrm{O}_{3}, \mathrm{SiO}_{2}, \mathrm{TiO}_{2}$, Ki, Kr e argila, por meio da manipulação das informações eletromagnéticas refletidas em sensores instalados em laboratório e satélite. Com as equações obtidas para $\mathrm{Fe}_{2} \mathrm{O}_{3}$ e argila, pelo sensores, verificar sua utilização na classificação de solos.

\subsection{Material e Métodos}

\subsubsection{Caracterização da área de estudo}

A área localiza-se ao sudoeste do Estado de São Paulo, na região de Barra Bonita. É delimitada pelas coordenadas geográficas $22^{\circ} 26^{\prime} 2,37^{\prime \prime}$ - 22 $22^{\circ} 16,53^{\prime \prime}$ latitude sul e $48^{\circ} 31^{\prime} 24,22^{\prime \prime}$ - 48 $27^{\prime} 51,77^{\prime \prime}$ longitude oeste. Apresenta 473 ha, cultivados com cana-de-açúcar em altitudes variando entre 520 e 710 metros do nível médio do mar. O clima da região, baseada na classificação de Köppen, é do tipo Cwa, clima mesotérmico (Sentelhas et al., 1998). A litologia é representada principalmente pela ocorrência da Formação Serra Geral, a qual se caracteriza por compreender um conjunto de derrames de basalto intercalados por arenitos com as mesmas características da Formação Botucatu. Aparece ainda a Formação Itaqueri do grupo Bauru que se caracteriza por arenitos com cimento argiloso, folhelhos e conglomerados, predominando os arenitos (IPT, 1981).

Foi estabelecida uma grade $(100 \times 100 \mathrm{~m})$ onde os pontos foram demarcados com estacas as quais foram numeradas, totalizando 473 estacas, georreferenciadas e 
coletadas amostras de terra nas profundidades 0-20 (camada A; referente ao horizonte A) e 80-100 cm (camada B; referente ao horizonte B), totalizando 946 amostras de solos. A cor do solo foi obtida na forma úmida com o equipamento Minolta CR 300 com chip para cor de Munsel (Post et al., 1994; Campos, 2002). Foram realizadas análises químicas (Raij et al., 1987) e granulométricas. Para o ataque sulfúrico foi utilizada a metodologia preconizada por Camargo et al. (1987), selecionando-se apenas 103 amostras, do total de 473 amostras da área, totalizando para as duas camadas 206 amostras de solos, representativas da área. Com isso foram obtidos: óxido de alumínio $\left(\mathrm{Al}_{2} \mathrm{O}_{3}\right)$, óxido de ferro $\left(\mathrm{Fe}_{2} \mathrm{O}_{3}\right)$, relação $\mathrm{Al}_{2} \mathrm{O}_{3} / \mathrm{Fe}_{2} \mathrm{O}_{3}$, óxido de silício $\left(\mathrm{SiO}_{2}\right)$, óxido de titânio $\left(\mathrm{TiO}_{2}\right)$, indicativo de estádio de intemperismo $\left(\mathrm{Ki}=\mathrm{SiO}_{2} / \mathrm{Al}_{2} \mathrm{O}_{3}\right)$ e indicativo de intemperismo para solos de textura média bem drenados $\left(\mathrm{Kr}=\mathrm{SiO} 2 / \mathrm{Fe}_{2} \mathrm{O}_{3}+\mathrm{Al}_{2} \mathrm{O}_{3}\right)$.

\subsubsection{Obtenção dos dados espectrais}

Foi utilizada uma cena TM-Landsat-5 nas bandas 1, 2, 3, 4, 5 e 7. Após definida a área foi realizado o corte na imagem no programa IMPIMA (INPE, 1999). A imagem de satélite apresenta para cada pixel um valor de níveis de cinza (Crósta, 1992). Os dados de níveis de cinza foram transformados em reflectância, conforme comentários de Epiphanio \& Formaggio (1988). Estes autores descrevem que a análise quantitativa de imagens digitais sobre o comportamento espectral de alvos deve ser feita com os dados em reflectância, por ser uma grandeza física intrínseca dos alvos, ao passo que os números digitais são valores transformados para a obtenção das imagens orbitais. Segundo Ben-Dor (2002), os valores de níveis de cinza obtidos das cenas do sensor TM- 
Landsat devem ser devidamente ajustados aos efeitos atmosféricos e posteriormente os números digitais convertidos em valores de reflectância real. Para tanto, foi utilizado o modelo 5S, Simulação do Sinal do Satélite dentro do Espectro Solar (Tanré et al., 1992) e detalhadamente descrito por Zullo Jr. (1994). Após o processo de conversão e correção, o nível de cinza zero presente na imagem passou a corresponder à reflectância 0 \% e o nível de cinza 255 à reflectância $100 \%$.

Para adequar o posicionamento da imagem com a verdade de campo a correção geométrica se fez necessária. Dessa forma, foram utilizadas as cartas planialtimétricas, escala 1:10.000, da Coordenadoria de Ação Regional, Divisão Cartográfica, da Secretária de Economia e Planejamento do Estado de São Paulo. Além disso, pontos obtidos no campo com equipamento GPS (Global Positioning System) com erro submétrico foram utilizados. Objetivando manter o valor do pixel o mais semelhante possível ao seu valor original, utilizourse o método de interpolação denominado vizinho mais próximo, corrigindo apenas as distorções de escala, deslocamento ou rotação existentes entre a imagem e a projeção terrestre (Crósta, 1992). Uma vez registrada, a cena foi visualizada em composição colorida R/G/B, nas bandas 1/2/3 e 4/5/7. Sobre os planos de informação "imagens", foram sobrepostos os pontos de amostragem da grade. Em cada ponto de amostragem, foram determinados os dados espectrais das referidas bandas.

Para a obtenção dos dados espectrais de laboratório, foi utilizado o sensor InfraRed Intelligent Spectroradiometer, IRIS (Geophysical \& Environmental Research Corporation, 1996), que recobre a faixa espectral entre 450 e $2.500 \mathrm{~nm}$. As amostras da camada A e B, dos solos foram secas em estufa a $45^{\circ} \mathrm{C}$ por 24 horas, moídas e 
peneiradas (malha de $2 \mathrm{~mm}$ ), para homogeneização dos efeitos da umidade e rugosidade (Epiphanio et al., 1992). Posteriormente, as amostras foram acondicionadas em placas de petri e iluminadas por uma lâmpada halógena de 650 W. A energia alimentadora da lâmpada foi estabilizada com uma fonte de potência de $1 \%$. Utilizou-se a placa padrão branca, com 100 \% de reflectância calibrada pela Labsphere (1996). A geometria utilizada foi: $61 \mathrm{~cm}$ lâmpada-alvo e alvo-sensor: $27 \mathrm{~cm}$; inclinação da lâmpada $20^{\circ}$ ao nadir (Baumgardner et al., 1985). Posteriormente, os dados passaram por um software (Conviris), que regularizou os dados da placa de referência e realizou uma filtragem destes, eliminando o excesso de ruídos, para facilitar a interpretação. A relação entre a energia refletida pelo alvo e a energia refletida pela placa de referência gerou o fator de reflectância bidirecional (Nicodemus et al., 1977). Foram realizadas três leituras em cada amostra, sendo utilizada a curva espectral média.

\subsubsection{Análise estatística e comparação dos resultados}

Para os dados orbitais foram obtidos os dados de reflectância da camada superficial dos solos, das bandas do TM-Landsat-5, sendo (em nm): B1: 450-520, B2: 520-600, B3: 630-690, B4: 760-900, B5: 1150-1750, B7: 2080-2350. Foram utilizados 227 dados de reflectância para a gerar os modelos, sendo outras 227 amostras para teste. A escolha dos pontos para gerar os modelos foi aleatória, porém, representativa de toda a área de estudo.

Os dados espectrais obtidos com o IRIS em laboratório, permitem uma maior resolução radiométrica, podendo-se estabelecer um maior número de bandas. Foram 
selecionadas 22 bandas (B) e 13 alturas (H), seguindo metodologia de Nanni \& Demattê (2001b) (Figura 1), sendo elas (em nm): B1: 450-481, B2: 481, B3: 481-596, B4: 596710, B5: 710-814, B6: 814-975, B7: 975-1350, B8: 1350-1417, B9: 1417, B10: 14171449, B11: 1449-1793, B12: 1793-1831, B13: 1865-1927, B14: 1927, B15: 1927-2102, B16: 2101-2139, B17: 2139-2206, B18: 2206, B19: 2206-2258, B20: 2258, B21: 22582389, В22: 2389-2498, H1: 469-532, H2: 532-768, H3: 768-876, H4: 876-1353, Н5: 1353-1411, H6: 1411-1439, H7: 1439-1783, H8: 1860-1923, H9: 1923-2120, H10: 2120-2206, H11: 2206-2258, H12: 2258-2389, H13: 2389-2498. Essa seleção baseia-se em observações empíricas, pela literatura. Posteriormente é utilizado um sistema automatizado estatístico para determinação das melhores bandas.

Todas as amostras com resultados de ataque sulfúrico (206 amostras) e metade do total das amostras da área para argila (473 amostras), foram submetidos a análise de correlação usando o Sistema de Análise Estatístico SAS (SAS, 1999). Oito atributos dos solos foram correlacionados com as características espectrais de laboratório e orbitais, sendo: óxido de alumínio $\left(\mathrm{Al}_{2} \mathrm{O}_{3}\right)$, óxido de ferro $\left(\mathrm{Fe}_{2} \mathrm{O}_{3}\right)$, relação $\mathrm{Al}_{2} \mathrm{O}_{3} / \mathrm{Fe}_{2} \mathrm{O}_{3}$, óxido de silício $\left(\mathrm{SiO}_{2}\right)$, óxido de titânio $\left(\mathrm{TiO}_{2}\right)$, indicativo de estádio de intemperismo $(\mathrm{Ki}=$ $\left.\mathrm{SiO}_{2} / \mathrm{Al}_{2} \mathrm{O}_{3}\right)$ e indicativo de intemperismo para solos de textura média bem drenados $(\mathrm{Kr}$ $\left.=\mathrm{SiO}_{2} / \mathrm{Fe}_{2} \mathrm{O}_{3}+\mathrm{Al}_{2} \mathrm{O}_{3}\right)$ e apenas argila para granulometria.

Para o desenvolvimento do presente trabalho foram realizadas três etapas fundamentais, sendo elas: (a) Equações lineares de regressão múltipla - foram realizadas as seleções das variáveis preditoras (bandas e alturas "chave"), para os dados de laboratório e orbital. Esse procedimento, realizado pelo Sistema de Análise Estatístico SAS (SAS, 1999), verifica quais variáveis apresentam maior ou menor potencial para o 
desenvolvimento dos modelos. Posteriormente, foi realizada uma avaliação de colinearidade das variáveis, para que não houvesse duas ou mais variáveis que pudessem estar se sobrepondo. Para cada atributo do solo foram estabelecidas equações lineares de regressão múltipla, para dados radiométricos orbitais e de laboratório. (b) Estimativa dos valores de $\mathrm{Fe}_{2} \mathrm{O}_{3}$ e argila - com as equações em mãos, foi possível substituir os valores de radiometria de laboratório ou orbital em cada variável preditora da equação de laboratório ou orbital, gerando os valores estimados (VE) de ferro total e argila para as camadas A e B, de todas as amostras da área de estudo. Para todos os VE na camada A, utilizou-se as equações de regressão múltipla dos dados orbitais (EO). Na camada B, para todos os VE utilizoutse as equações de regressão múltipla dos dados de radiometria de laboratório (EL). Os VE de ferro total e argila foram classificados nos seguintes intervalos. Para ferro total, os resultados dos VE foram classificados em hipoférrico (baixo teor de $\mathrm{Fe}_{2} \mathrm{O}_{3},<80 \mathrm{~g} \mathrm{~kg}^{-1}$ ); Mesoférrico (médio teor de $\mathrm{Fe}_{2} \mathrm{O}_{3}, 80 \mathrm{a}<180 \mathrm{~g} \mathrm{~kg}^{-1}$ ); Férrico (alto teor de $\mathrm{Fe}_{2} \mathrm{O}_{3}, 180 \mathrm{a}<360 \mathrm{~g} \mathrm{~kg}^{-1}$ ) e Perférrico (muito alto teor de $\mathrm{Fe}_{2} \mathrm{O}_{3}$, $\geq$ $360 \mathrm{~g} \mathrm{~kg}^{-1}$ ) (Embrapa, 1999). Os resultados dos VE de argila, foram classificados em classes de textura sendo: Arenosa $\left(\leq 150 \mathrm{~g} \mathrm{~kg}^{-1}\right.$ de argila), Média $\left(151\right.$ a $350 \mathrm{~g} \mathrm{~kg}^{-1} \mathrm{de}$ argila), Argilosa (351 a $600 \mathrm{~g} \mathrm{~kg}^{-1}$ de argila) e Muito argilosa $\left(\ell 600 \mathrm{~g} \mathrm{~kg}^{-1}\right.$ de argila) (Embrapa, 1999). A classe média nesse trabalho, foi dividida em Média 1 (151 a $250 \mathrm{~g}$ $\mathrm{kg}^{-1}$ de argila) e Média 2 (251 a $350 \mathrm{~g} \mathrm{~kg}^{-1}$ de argila).

Os valores determinados (VD) das amostras de ferro total, 206 amostras camada A e B, utilizadas para gerar os modelos, também foram classificados nos intervalos de 
teores de ferro total. Os VD de argila, para todas as amostras da área, também foram classificadas em classes de textura, para as camadas A e B.

(c) Etapa de validação: inicialmente, dentro dessa etapa, foram comparadas ponto a ponto ou seja amostra por amostra, os VD e VE para ferro total e argila, onde foram considerados como acertos as amostras de VD e VE dentro de um mesma classe, obtendo-se também os resultados de confusão entre as classes das amostras com VD e VE. Posteriormente, foram obtidos dois mapas, um para camada A (orbital, EO) e outro para a camada B (laboratório, EL), para intervalos de teores de ferro, sendo estes comparados com o levantamento detalhado, com o objetivo de se verificar a utilidade dos resultados dos VE de ferro total no mapeamento de solos. O mapa detalhado apresenta as seguintes classes de solos: LATOSSOLO VERMELHO (LV), LATOSSOLO VERMELHO Eutroférrico (LVef), LATOSSOLO VERMELHOAMARELO (LVA), ARGISSOLO AMARELO (PA), ARGISSOLO VERMELHOAMARELO (PVA), ARGISSOLO VERMELHO (PV), NITOSSOLO VERMELHO (NV), NITOSSOLO VERMELHO Eutroférrico (NVef), CAMBISSOLO HÁPLICO Tb (Cxb); CAMBISSOLO HÁPLICO Eutroférrico (CXef), NEOSSOLOS QUARTZARÊNICOS Órtico (RQo) (Embrapa, 1999).

\subsection{Resultados e Discussão}

\subsubsection{Equações de regressão múltipla}


Equações lineares de regressão múltipla foram geradas para cada um dos atributos. Para as equações lineares de regressão múltipla com dados orbitais (EO) foram utilizadas apenas as amostras da camada A, totalizando 103 amostras para ataque sulfúrico e 236 amostras de argila. Com os dados radiométricos de laboratório foram geradas equações lineares de regressão múltipla dos dados de laboratório (EL), independente da profundidade em que foi coletada a amostra, totalizando 206 amostras do ataque sulfúrico e 473 amostras de argila. Diferindo do trabalho realizado por Nanni (2000) onde as equações de regressão múltipla foram geradas para cada camada, superficial e subsuperficial.

As EL, para o ataque sulfúrico, podem ser observadas na Tabela 1, das 22 bandas e 13 alturas, perfazendo um total de 35 variáveis, a equação do $\mathrm{Ab}_{2} \mathrm{O}_{3}$ apresenta-se com o maior número de variáveis, 9 entre bandas e alturas. A menor equação é a do $\mathrm{SiO}_{2}$ com 4 variáveis. Para o $\mathrm{Fe}_{2} \mathrm{O}_{3}$ temos 5 variáveis sendo estas só de alturas (Tabela 1). Dessa forma podemos notar que a estatística promoveu a escolha das bandas e alturas mais representativas para cada atributo do solo. As técnicas de análise múltipla permitiram definir as melhores bandas e alturas, que caracterizam melhor cada atributo, concordando com Huete \& Escadafal (1991), Demattê \& Garcia (1999) e Nanni (2000).

Dos 7 atributos estudados, $\mathrm{Al}_{2} \mathrm{O}_{3}, \mathrm{Al}_{2} \mathrm{O}_{3} / \mathrm{Fe}_{2} \mathrm{O}_{3}, \mathrm{Fe}_{2} \mathrm{O}_{3}$ e $\mathrm{TiO}_{2}$ apresentaram altos coeficientes de determinação $\left(\mathrm{r}^{2}\right)$, com valores maiores que 0,8 (Tabela 1), mais elevados que os obtidos por Demattê \& Garcia (1999) com $\mathrm{r}^{2}$ de 0,64 para $\mathrm{Fe}_{2} \mathrm{O}_{3}$. Valores semelhantes aos aqui determinados foram obtidos por Nanni \& Demattê (2001) com valores de $\mathrm{r}^{2}$ maiores que 0,90 para $\mathrm{Fe}_{2} \mathrm{O}_{3}, \mathrm{TiO}_{2}$ e $\mathrm{SiO}_{2}$, para solos da região de Piracicaba. Sendo que o $\mathrm{r}^{2}$ para $\mathrm{SiO}_{2}$ de 0,72 considerado alto para este trabalho, foi 
menor que os encontrados pelos autores acima citados. O presente resultado para esses atributos vêm corroborar relatos de Ben-Dor \& Banin (1990). Aliás este último autor chegou a determinar $\mathrm{r}^{2}$ entre 0,6 e 0,92 para as formas de ferro (total, cristalino e amorfo). Por sua vez, a metodologia de determinação das áreas das concavidades promovidas pelo ferro como base para determinar equações, não foi bem sucedida, conforme relatado por Demattê (1999), com baixos $r^{2}$.

Também foi considerado satisfatório o resultado de 0,67 para $\mathrm{Kr}$. O menor resultado encontrado foi para o $\mathrm{Ki}, \operatorname{com} \mathrm{r}^{2}$ de 0,42 sendo que a utilização dessa equação é pouco confiável (Tabela 1). Valores razoáveis de Ki, também foram observados por Demattê \& Garcia (1999) que trabalharam com solos originados do basalto, $\mathrm{r}^{2}$ para Ki de 0,69, tendo sido estabelecida uma relação entre nível de intemperismo e reflectância espectral. A estimativa do teor de argila apresentou alto coeficiente de determinação, com valores superiores a 0,8 (Tabela 1), concordando com Nanni \& Demattê (2001 b) com $r^{2}$ de 0,91 para argila na superficie. Coleman et al. (1991) já consideravam como alto coeficiente de determinação 0,68 para argila. Os altos coeficientes de significância obtidos para os trabalhos citados, posteriores a Coleman et al. (1991), indicam a importância em se empregar um número significativo de bandas nos modelos. Por outro lado, e concordando com Stark et al. (1986), Demattê \& Garcia (1999) e Ben-Dor (2002), deve-se tomar cuidado para evitar os efeitos de sobreposição de bandas nos modelos através de exames estatísticos prévios. Estes resultados são ratificados por Nanni \& Demattê (2001a). Estes autores testaram modelos pré-estabelecidos (para uma região do Paraná) determinados por Demattê \& Garcia (1999) na estimativa de $\mathrm{Fe}_{2} \mathrm{O}_{3}$, e verificaram a validade em amostras de terra desconhecidas, porém advindas de outra 
região. Os resultados foram positivos, indicando que os modelos estimaram de maneira significativa os teores desse atributo.

As variações de $r^{2}$ são devidas a uma série de fatores, entre eles, a variabilidade dos solos observados, a representatividade das amostras, o número e a especificidade das bandas selecionadas, geometria de aquisição e equipamento utilizado, entre outros.

Uma das discussões que sempre surge refere-se às amostras que devem ser utilizadas para a elaboração dos modelos. Sabe-se que o comportamento espectral das amostras de terra em diferentes camadas ou camadas é diferente, basicamente por causa da matéria orgânica (Coleman \& Montgomery, 1987; Galvão et al., 1997). Então surge a questão: “devemos elaborar modelos utilizando amostras da camada superficial separadamente ou não da camada subsuperficial". Nos primeiros trabalhos foram utilizadas principalmente amostras de terra da camada superficial na elaboração de modelos, como realizado por Coleman et al. (1991) e Demattê \& Garcia (1999). Nanni (2000) estabeleceu modelos da camada superficial e subsuperficial separadamente, obtendo altos coeficientes. Posteriormente, validou os modelos da camada superficial, com amostras desconhecidas da subsuperficial e vice-versa, também obtendo altos coeficientes. O presente trabalho, por sua vez, não se preocupou em separar amostras para gerar modelos ou validar as equações, e também obteve altos coeficientes (Tabelas 1 e 2). Os resultados indicam, portanto, que não é necessário elaborar modelos independentes para cada profundidade de amostragem de terra, mesmo por que, seria por demais complicado colocar em prática. Entretanto, ratifique-se a importância de se ter amostras representativas de toda a área de estudo. 
Para as EO, das 6 variáveis iniciais (TM 1, 2, 3, 4, 5 e 7), com exceção do $\mathrm{SiO}_{2}$ e $\mathrm{Al}_{2} \mathrm{O}_{3} / \mathrm{Fe}_{2} \mathrm{O}_{3}$ com duas variáveis, o restante das equações apresentaram 3 variáveis preditoras (Tabela 2). A banda TM 7, com exceção da relação $\mathrm{Al}_{2} \mathrm{O}_{3} / \mathrm{Fe}_{2} \mathrm{O}_{3}$, foi selecionada para todas as outras equações. A Banda TM 4, aparece em 5 das 8 equações, sendo que sempre junto com a banda TM 7. Nanni (2000) verificou a presença da banda TM 7 para $\mathrm{SiO}_{2}, \mathrm{Fe}_{2} \mathrm{O}_{3}$ e $\mathrm{TiO}_{2}$, porém não foi selecionada a banda $\mathrm{TM}$ 4, o que difere dos resultados obtidos nesse tabalho. Coleman et. al. (1993) para $\mathrm{Fe}_{2} \mathrm{O}_{3}$, também observaram a presença das bandas TM 7 e 4 . A seleção da banda TM 7, deve estar associada a influência de solos mais jovens, com $\mathrm{Ki}>2$, solos mais argilosos, motivo pelo qual a água é mais retida, influenciando juntamente com a caulinita na maior absorção da banda TM 7, a qual apresenta-se em quase todas as equações dos atributos estudados (Tabela 2). A participação ou não de determinada banda, entretanto, está diretamente ligada às características específicas dos solos de uma região, o que explica as variações entre os trabalhos.

$\mathrm{O}$ maior coeficiente de determinação observado foi o do $\mathrm{TiO}_{2}$ com 0,72 (Tabela 2), concordando com os resultados obtidos por Nanni (2000), e confirmados por BenDor \& Banin (1990) e Nanni \& Demattê (2001b). Para $\mathrm{Al}_{2} \mathrm{O}_{3}, \mathrm{Fe}_{2} \mathrm{O}_{3}$ e $\mathrm{SiO}_{2}$, o resultado do $1^{2}$ foi de 0,$678 ; 0,672$ e 0,65 respectivamente. O resultado obtido para $\mathrm{Fe}_{2} \mathrm{O}_{3}$, considerado bom, foi um pouco inferior aos resultados obtidos por Nanni \& Demattê (2001b) e Nanni (2000) com $r^{2}$ de 0,72. Porém, muito superior ao apresentado por Coleman et. al. (1993) os quais obtiveram um $r^{2}$ para $\mathrm{Fe}_{2} \mathrm{O}_{3}$ de 0,288. Para o $\mathrm{SiO}_{2}$ os resultados obtidos nesse trabalho foram superiores aos encontrados por Nanni \& Demattê (2001b) com r ${ }^{2}$ de 0,59 (Tabela 2). 
$\mathrm{O}$ atributo com menor $\mathrm{r}^{2}$ foi o $\mathrm{Ki}$, com 0,31 , seguido pela relação $\mathrm{Al}_{2} \mathrm{O}_{3} / \mathrm{Fe}_{2} \mathrm{O}_{3}$ com 0,479 . Os valores observados de $r^{2}$ para esses atributos restringem o uso dessas equações as quais podem vir a apresentar resultados pouco confiáveis. Apesar de apresentar um $\mathrm{r}^{2}$ de 0,54 o $\mathrm{Kr}$ é considerado como um bom resultado para este trabalho (Tabela 2). Coleman et al. (1993) com o trabalho intitulado "Seria possível quantificar atributos de solos através de sensores instalados em plataformas espaciais ?" apresentaram dados com $\mathrm{r}^{2}$ entre 0,1 e 0,4 para areia, silte, argila, ferro e MO, confirmando essa possibilidade. Podemos agora reafirmar nesse trabalho essa possibilidade, uma vez que os resultados de $\mathrm{r}^{2}$ foram bem mais expressivos que os apresentados por esses autores, principalmente para ferro (Tabela 2).

A variação da significância dos modelos, entre os dados de literatura, mais uma vez estão intimamente ligados à metodologia, principalmente no caso da avaliação de dados orbitais. Os dados extraídos de uma imagem de satélite posicionado a $800 \mathrm{~km}$ de distância, apresentam uma quantidade muito grande de fatores interferentes como, variações geométricas e atmosféricas, rugosidade da superfície, ângulo e intensidade de iluminação, resíduos na superfície, presença de vegetação, equipamento sensor utilizado, entre outras (Guyot et al., 1996). Apesar disso, observa-se que tomando-se os cuidados devidos, conforme estabelecido na metodologia, é possível estimar os teores de ferro.

\subsubsection{Estimativa de ferro por sensores e relação com classificação de solos}

A importância do grau de confiança na estimativa de um determinado atributo do solo está intimamente ligado aos objetivos dessa estimativa. Um atributo pode, portanto, 
ser estimado e avaliado quanto ao valor absoluto, para posterior cálculo de dosagem de fósforo, por exemplo. Por outro lado, um atributo pode ser estimado e avaliado se está dentro de uma faixa de variação utilizada para alguma finalidade. É o caso dos teores de ferro. De acordo com a classificação de solos vigente (Embrapa, 1999), os teores de ferro são importantes na discriminação de algumas classes de solos. Esses teores são utilizados para verificar se estão dentro de uma faixa previamente estipulada. Cada faixa de teor de ferro recebe uma classificação, sendo o caso dos denominados hipoférrico, mesoférrico e férrico, conforme verificado na metodologia.

A Tabela 3 compara a classificação dos níveis de ferro determinada pelas análises tradicionais com as obtidas pelos dados espectrais em laboratório e orbital. Os dados obtidos por sensor em laboratório, referem-se a valores da camada B, subsuperficial, que é a utilizada para classificação de solos. Os dados obtidos pelo satélite referem-se a camada A, superficial, que é a única possível de ser observada por este sensor. Portanto, neste caso, são comparados os teores de ferro obtidos por análises químicas com dados espectrais, porém da camada superficial, que não é a ideal para classificação, mas possível de ser usada pela limitação do sistema. O local da amostra é o mesmo, tanto para a avaliação espectral laboratorial (Equação Laboratorial, EL) quanto orbital (Equação Orbital, EO) num total de 103 amostras analisadas.

De maneira geral, observou-se que os teores de ferro com VD das 103 amostras para cada camada obtiveram 82 e 84 amostras com VD no intervalo hipoférrico, na camada A e B, respectivamente. Para o intervalo mesoférrico, em ambas camadas foi observado 14 amostras com VD e o restante com 7 e 5 amostras no intervalo férrico, para as camadas A e B, respectivamente (Tabela 3). Esses resultados indicam existir 
uma maior incidência de solos hipoférricos e mesoférricos das amostras estudadas, sendo mais representativas para discussão que a classe férrico.

Os dados radiométricos obtidos com sensor em laboratório (IRIS), para os mesmos pontos de amostragens, camada $\mathrm{B}$, foram substituídos na equação, gerando assim os "valores estimados com equações geradas com radiometria de laboratório" (VEL). Para a classe hipoférrico das 82 amostras com VD, 79 foram estimadas na mesma classe com os VEL, obtendo-se $96 \%$ de acerto (Tabela 3). Apenas 3 amostras foram confundidas, ou seja, deveriam ser classificadas como hipoférrico, porém os valores estimados obtidos encontram-se no intervalo mesoférrico. Esse erro ou confusão pode ser associado a proximidade dos valores limites de teores de ferro. Para o intervalo mesoférrico foi obtido $100 \%$ de acerto, ou seja, todas as amostras com VD e VEL foram classificadas no mesmo intervalo (Tabela 3). Já os resultados para o intervalo férrico das 7 amostras com VD, houve $28 \%$ de acerto, tendo confundido o restante com mesoférrico. A confusão dessas amostras, pode ter ocorrido devido a proximidade dos valores limites de ferro entre mesoférrico e férrico. Observou-se que $72 \%$ das amostras avaliadas, apresentaram valores absolutos de ferro até $200 \mathrm{~g} \mathrm{~kg}^{-1}$, ou seja, apenas $20 \mathrm{~g}$ $\mathrm{kg}^{-1}$ próximo do limite da unidade mesoférrico para férrico que é de $180 \mathrm{~g} \mathrm{~kg}^{-1}$.

Os dados radiométricos obtidos das imagens do TM-Landsat-5, para os mesmos pontos de amostragem, avaliando porém a camada $\mathrm{A}$, foram inseridos na equação, gerando os "valores estimados com equações geradas com radiometria orbital"(VEO). Para a classe hipoférrico, das 84 amostras com VD, 80 foram estimadas na mesma classe que os VEO, atingindo $95 \%$ de acerto (Tabela 3). Apenas 4 amostras foram confundidas, ou seja, deveriam ser classificadas como hipoférrico, porém os valores 
estimados obtidos encontram-se no intervalo mesoférrico. Mais uma vez, esse erro ou confusão pode ser associado a proximidade dos valores limites de teores de ferro de uma classe para outra, $<80 \mathrm{~g} \mathrm{~kg}^{-1}$ de ferro para hipoférrico e de 80 a $180 \mathrm{~g} \mathrm{~kg}^{-1}$ para mesoférrico. Outro fator importante a ser considerado é o tamanho do pixel na imagem de satélite, no caso 30 × $30 \mathrm{~m}$, onde o valor de reflectância coletado é a resposta da interação dos elementos dentro do pixel (Ben-Dor, 2002). Para o intervalo mesoférrico foi obtido $100 \%$ de acerto, ou seja, todas as amostras do VD e VEO foram classificadas no mesmo intervalo (Tabela 3), apesar das considerações sobre o pixel. Já os resultados para o intervalo férrico das 5 amostras com VD, as 5 amostras estimadas correspondentes foram classificadas como mesoférrico (Tabela 3). Mais uma vez, o índice de acerto para as amostras classificadas como férrico e mesoférrico não foi adequadamente detectado. Observou-se que $75 \%$ das amostras analisadas, estavam extremamente próximas do limite para a classificação. Tanto para os dados orbitais como os de laboratório, ocorreu o mesmo efeito de confusão para as classes mais saturadas com ferro. Stoner \& Baumgardner (1981) observaram que em solos minerais com teores de ferro acima de $40 \mathrm{~g} \mathrm{~kg}^{-1}$, pode haver mascaramento dos efeitos de outros atributos nos dados espectrais. É possível, portanto, que exista um limite de saturação por ferro, acima do qual o seu efeito não se relaciona mais com o teor.

A utilização dos valores de ferro como apoio na classificação de solos, tem como barreira principal os custos, sendo o dobro ou mais que uma análise química ou granulométrica de rotina realizada nos laboratórios convencionais. Geralmente, tal fato leva a interpretações qualitativas de campo, como a atração magnética, como meio para diminuir estes custos. Entretanto, esse método, apesar de útil, não quantifica, e ge ra 
discrepâncias devido a subjetividade e grau de experiência do pedólogo. Tal fato restringe o número de amostras que possam ser enviadas para análises em laboratório, diminuindo o grau de acuracidade de um mapeamento. Nesse caso, o sensoriamento remoto espectral, principalmente ao nível de laboratório, pode ser utilizado para se determinar valores quantitativos de ferro, sendo de grande valia na classificação. Consequentemente, os resultados permitem inferir que esta técnica diminui os custos com análises deste atributo, permitindo maiores observações numa área, melhorando o detalhamento do trabalho.

Os dados ao nível orbital, por sua vez, apesar de detectar amostras de superfície, apresentaram altíssimos índices de acerto, com os valores originais das mesmas amostras de superfície. Portanto, se por um lado, o valor de ferro da amostra dessa camada, não pode ser utilizada para a classificação, por outro ela pode ser estimada com alto grau de confiabilidade. Por sua vez, e especificamente neste trabalho, houve íntima relação entre a classificação realizada para as amostras de subsuperfície com as de superfície. Podemos inferir, portanto, que a avaliação de dados espectrais orbitais, podem também auxiliar na classificação de solos. O presente trabalho corrobora observações de Coleman et al. (1993). No caso, para os intervalos dos teores de ferro, foi obtido para a camada A, com dados radiométricos orbitais, um acerto geral de 91,3\%. Com os dados radiométricos de laboratório, foi obtido para o camada B um acerto de $92,2 \%$. 


\subsubsection{Espacialização dos teores de $\mathrm{Fe}_{2} \mathrm{O}_{3}$ estimados por sensores e sua relação com solos}

A validação das estimativas de ferro e sua alta relação com a classificação, 91,3 $\%$ de acerto para dados orbitais e 92,2 \% para dados radiométricos de laboratório (Tabela 3), indicaram ser possível obter teores desse atributo. Com isso, os dados de reflectância de todas as amostras de terra da área de estudo, obtidos pelos dois sensores, foram aplicados nas equações de regressão (Tabelas 1 e 2 ). A espacialização da classes de ferro de Embrapa (1999) foram comparadas com o mapa de solos realizado na área pelo método convencional (Figura 2).

A Figura 2a representa a distribuição dos intervalos de ferro para a camada A, sendo os valores obtidos pela EO (Tabela 2). É importante ressaltar que para a classificação de solos o horizonte diagnóstico é o de subsuperficie, porem o camada superficial também e imprescindível na diferenciação das classes de solos (Embrapa, 1999). Predomina na área a classe hipoférrico com 356,30 ha cerca de $75 \%$ do total da área de 472,70 ha. Para este intervalo, na camada superficial, predomina o LV com 263,80 ha, esses solos caracterizam-se por apresentar textura média na maior parte da área, bem próximas a textura arenosa (Figura 1c). Ainda aparecem no intervalo hipoférrico os LVA, PA, PVA, RQo e alguns PV (Figura 2a, c). Para o intervalo mesoférrico temos 115,40 ha cerca de $24,4 \%$ do total da área de estudo, sendo que a maioria dos solos com textura média a argilosa e muito argilosa estão nesse intervalo, entre eles o LVef, NV, NVef, Cxb e CXef. Porém, também ocorre numa menor porção os LV com textura argilosa e muito argilosa. Um exemplo é a amostra 313 com textura 
argilosa na camada A (540 $\left.\mathrm{g} \mathrm{kg}^{-1}\right)$ e muito argilosa na camada B (700 $\left.\mathrm{g} \mathrm{kg}^{-1}\right)$, a qual apresenta-se no intervalo mesoférrico. Apenas a amostra 364, com 1 ha, aparece no intervalo férrico, para LV argiloso, não ocorrendo esse intervalo em subsuperficie.

Para a camada B, com os dados obtidos por radiometria de laboratório, observase que a distribuição dos intervalos em relação a camada A, não muda muito (Figura 2a, b). Predomina na área a classe hipoférrico com 355,43 ha com cerca de $75 \%$ do total da área, com os mesmos solos já descritos para a camada A (Figura 2b,c). Adiferença é mais acentuada para os valores em área do intervalo mesoférrico, que diminuiu em relação a camada A, Figura $2 \mathrm{a}$ e b, com 104 ha cerca de $22 \%$ do total. Ocorreu um aumento em área, no mapa, do intervalo férrico com 13,07 ha cerca de 2,7\% do total da área, que para a camada A era de apenas 1 ha (Figura 2 a, b). Os solos mais argilosos e com maiores teores de ferro encontram-se nesses intervalos (Figura 2c).

Especificamente numa porção dentro da área de estudo outras observações foram realizadas (Figura 2b, c). Essa área escolhida representa a maior concentração de solos argilosos, Figura 2c, LVef, NVef e CXef, todos classificados com caráter férrico, ou seja altos teores de ferro (180 $\mathrm{g} \mathrm{kg}^{-1}$ a $360 \mathrm{~g} \mathrm{~kg}^{-1}$ ), sendo para os NVef, considerado valores > $150 \mathrm{~g} \mathrm{~kg}^{-1}$ de $\mathrm{Fe}_{2} \mathrm{O}_{3}$ para denominação férrico. Para a delimitação das unidades de mapeamento dessas classes de solos no mapa detalhado, algumas amostras, no caso desse estudo apenas 7 amostras (Tabela 3), tornam-se representativas de um grupo de amostras e infere-se esses resultados para a "vizinhança", considerando-se para fins de levantamento de solos o mesmo material de origem, posição no relevo, cor do solo, textura, técnicas de fotopedologia aplicadas em imagem de satélite entre outras características que tem por finalidade corroborar a denominação, no caso, férrico para 
algumas unidades de mapeamento, como foi realizado no levantamento detalhado da área de estudo (Figura 2c). Mas, caso fosse considerado, para delimitação de unidades de mapeamento, os resultados estimados por radiometria, classificados nos intervalos de ferro, principalmente para a camada B, as unidades , LVef, NVef e CXef diminuiriam em área mapeada, aumentando-se as áreas das classes $\mathrm{LV}, \mathrm{NV}$ e $\mathrm{CXb}$, sem a denominação férrico, seguindo os resultados dos intervalos férricos e mesoférricos na Figura 2b. Um bom exemplo disso está na unidade de mapeamento do LVef com 11 ha, “dentro de retângulo" na Figura 2b, onde várias amostras apresentam-se com caráter férrico (Figura 2c). Porém observando a Figura 2b, para a mesma área, apenas a amostra 195, apresenta-se no intervalo para caráter férrico no mapa, o que reduziria a área do LVef para apenas 1 ha. Dessa forma os valores estimados de ferro pelos dados radiométricos de laboratório, poderiam juntamente com as técnicas para delimitação de unidades de mapeamento contribuir no refinamento dos limites de algumas classes de solo.

\subsubsection{Comparação entre classes de textura de valores determinados por análises} físicas e valores estimados por radiometria de laboratório e orbital

Para verificarmos a veracidade das EO e EL, para argila, foram estimados os valores desse atributo, para toda área, sendo utilizada a EO para estimar os valores de argila na camada A e a EL para estimar os valores da camada B. Os valores determinados pelas análises físicas e os resultados estimados pelas equações foram classificados em classes de textura e podem ser observados na Tabela 4. Para os dados 
com radiometria orbital, as 220 amostras com VD, textura arenosa, obteve-se um acerto de $50 \%$, sendo que 110 amostras dos VEO, apresentaram outras classes de textura, sendo que 90 amostras estimadas foram classificadas como textura média 1 (Tabela 4). A textura média 1, foi estabelecida devido a um grande grupo de amostras encontradas na área de estudo com teores de argila muito próximos do limite entre a textura arenosa e média (150 $\mathrm{g} \mathrm{kg}^{-1}$ ), dessa forma amostras com $151 \mathrm{~g} \mathrm{~kg}^{-1}$ de argila são consideradas como textura média 1, porém não apresentam grandes diferenças físicas para tal separação no manejo desses solos. Dessa forma a confusão entre amostras de textura arenosa e média 1 é aceitável, por apresentarem-se no mesmo grupo de manejo. Ainda na textura arenosa, 17 amostras estimadas foram confundidas com média 2 e 3 amostras como argilosa, o que não é aceitável (Tabela 4).

Das 152 amostras com VD, para textura média 1, 62 amostras estimadas encontram-se nesse mesmo grupo, com acerto de $41 \%$ (Tabela 4). A maior confusão ocorreu com os valores estimados na textura arenosa com 70 amostras, sendo como já relatado, uma confusão aceitável, visto a proximidade de textura desses solos. A confusão também foi verificada para as classes média 2 com 15 amostras e argilosa com 5 amostras, o que não é aceitável. Para a classe média 2, com 27 amostras com VD, o acerto foi de $48 \%$, sendo confundida com as classes média 1 com 4 amostras e argilosa com 10 amostras, em ambos os casos alguns desses dados podem estar próximos aos limites de diferenciação de classes de textura sendo aceitáveis. A classe argilosa apresentou um maior acerto, $89 \%$ dos dados estimados, 51 amostras estimadas foram classificadas corretamente com as 57 amostras com VD, sendo a confusão observada por 6 amostras da classe média 2, também aceitável (Tabela 4). A classe muito argilosa foi 
totalmente confundida, argilosa com 16 amostras estimadas e com a média 2 com 1 amostra, sendo aceitáveis a confusão com a classe argilosa uma vez que no campo é difícil de se separar tais classes de textura, principalmente quando as amostras estão próximas ao valor limite da classe $600 \mathrm{~g} \mathrm{~kg}^{-1}$ (Tabela 4).

A textura arenosa, na camada B, apresenta-se com 50 amostras com VD, sendo que 31 amostras estimadas com as EL encontram-se na mesma classe de textura, com um acerto de $62 \%$. As confusões nessa classe ocorreram com 17 amostras estimadas de textura média 1, o que consideramos como sendo aceitável e 2 amostras estimadas com textura média 2 considerado como erro (Tabela 4). A textura média 1, apresentou um acerto de $72 \%$ correspondendo a 193 amostras estimadas classificadas no mesmo intervalo das 269 amostras com VD, sendo a maior confusão de 51 amostras estimadas como arenosa também consideradas como aceitáveis uma vez que muitos dos solos da área apresentam-se muito próximos dos limites de textura, arenosa e média 1, geralmente colocados no mesmo grupo de manejo (Tabela 4). Na textura média 2 o acerto foi de $43 \%$, onde a confusão estabelecida entre as classes média 1 com 17 amostras e argilosa com 8 amostras, podem vir a ser consideradas como aceitáveis, pois a transição das texturas entre os matérias de origem encontrados na área de estudo, arenito com cimento argiloso e basalto é gradual (Tabela 4).

O maior acerto foi para a textura argilosa, com $76 \%$, tendo confundido as classes arenosa com 1 amostra, média 2 com 5 amostras consideradas como erro e muito argilosa com 8 amostras, sendo essa aceitável (Tabela 4). O menor acerto ocorreu para a classe muito argilosa com apenas $39 \%$ de acerto, com 31 amostras confundidas com a classe argilosa, sendo esse erro aceitável (Tabela 4). 
Os resultados obtidos para a camada $\mathrm{B}$, para os dados radiométricos de laboratório foram melhores que os obtidos pelos dados orbitais com acerto geral de 65 $\%$, não levando em consideração as amostras estimadas e com erros aceitáveis (Tabela 4). Os dados orbitais, para a camada A, alcançaram um acerto de $50 \%$, também sem considerar as amostras com erros aceitáveis (Tabela 4).

\subsection{Conclusões}

1 - É possível estimar os teores absolutos de $\mathrm{Fe}_{2} \mathrm{O}_{3}, \mathrm{Al}_{2} \mathrm{O}_{3}$, relação $\mathrm{Al}_{2} \mathrm{O}_{3} / \mathrm{Fe}_{2} \mathrm{O}_{3}, \mathrm{SiO}_{2}$, $\mathrm{TiO}_{2}$ e argila, por meio de modelos de regressão linear múltipla, desenvolvidos a partir da energia eletromagnética refletida por amostras de terra e adquiridas por sensores instalados em laboratório e satélite.

2 - Os resultados indicam que não é necessário elaborar modelos independentes para cada profundidade de amostragem de terra, mesmo por que seria por demais complicado colocá-los em prática. Entretanto, ratifique-se a importância de se ter amostras representativas de toda a área de estudo.

3 - A avaliação quantitativa da reflectância espectral permite obter informações de $\mathrm{Fe}_{2} \mathrm{O}_{3}$ e argila como base para a classificação de solos.

4 - É possível determinar os teores de ferro de amostras de terra desconhecidas a partir de um modelo regional, espacializar esses dados, e obter informações que auxiliem na classificação de solos. 
Tabela 1. Equações lineares de regressão múltipla para estimativa dos atributos dos solos da área de estudo utilizando-se 22 Bdas e 13 alturas, sensor IRIS.

\begin{tabular}{|c|c|c|}
\hline Atributo & Equação múltipla $^{(1)}$ & $\mathbf{r}^{2(2)}$ \\
\hline Argila & $\begin{array}{l}376,23728+(4092,67466 * \mathrm{H} 3)+(10972 * \mathrm{H} 7)+(1409,95843 * \mathrm{H} 2)+(-25070 * \mathrm{~B} 11)+(23006 * \mathrm{~B} 16)+(-23085 * \mathrm{H} 11) \\
+(30702 * \mathrm{~B} 10)+(-19095 * \mathrm{~B} 17)+(8651,36527 * \mathrm{H} 12)+(-2273,14097 * \mathrm{H} 1)+(-4697,25743 * \mathrm{~B} 15)+(-6041,71261 * \mathrm{~B} 8)\end{array}$ & 0,8570 \\
\hline $\mathrm{Al}_{2} \mathrm{O}_{3}$ & $\begin{array}{l}92,36208+(1213,86097 * \mathrm{H} 3)+(-7576,03710 * \mathrm{H} 11)+(2610,00589 * \mathrm{H} 10)+(3890,10521 * \mathrm{H} 12)+(1619,05064 * \mathrm{H} 7)+ \\
(3342,92742 * \mathrm{~B} 7)+(-2264,96298 * \mathrm{~B} 11)+(-888,77054 * \mathrm{H} 8)+(-1251,32151 * \mathrm{~B} 6)\end{array}$ & 0,8728 \\
\hline Al_Fe ${ }^{(3)}$ & $1,29518+(-13,66498 * \mathrm{H} 2)+(21,74558 * \mathrm{~B} 1)+(-9,07322 * \mathrm{H} 4)+(25,97556 * \mathrm{H} 10)+(46,14417 * \mathrm{H} 12)$ & 0,8835 \\
\hline $\mathrm{Fe}_{2} \mathrm{O}_{3}{ }^{(4)}$ & $\begin{array}{l}110,81409+(-9368,27072 * \mathrm{H} 11)+(757,29756 * \mathrm{H} 2)+(-3338,68863 * \mathrm{H} 13)+(9490,32024 * \mathrm{H} 12)+ \\
(-1005,39436 * \mathrm{H} 8)\end{array}$ & 0,8254 \\
\hline $\mathrm{ki}^{(5)}$ & $\begin{array}{l}1,59767+(-20,91352 * \mathrm{H} 4)+(11,99758 * \mathrm{H} 8)+(7,42979 * \mathrm{~B} 18)+(-25,59849 * \mathrm{~B} 2)+(9,96940 * \mathrm{~B} 10)+ \\
(-12,12550 * \mathrm{H} 2)\end{array}$ & 0,4259 \\
\hline $\mathrm{kr}^{(6)}$ & $\begin{array}{l}0,88979+(21,01051 * \mathrm{H} 8)+(50,16260 * \mathrm{H} 11)+(27,06973 * \mathrm{H} 1)+(-29,90358 * \mathrm{H} 5)+(-33,11525 * \mathrm{H} 12)+ \\
(-1,40514 * \mathrm{~B} 19)\end{array}$ & 0,6787 \\
\hline $\mathrm{SiO}_{2}^{(7)}$ & $126,44349+(1547,67871 * \mathrm{H} 3)+(278,76155 * \mathrm{H} 2)+\left(342,13833^{*} \mathrm{~B} 12\right)+\left(-837,78410^{*} \mathrm{~B} 21\right)$ & 0,7205 \\
\hline $\mathrm{TiO}_{2}^{(8)}$ & $\begin{array}{l}35,82973+\left(-541,11648^{*} \mathrm{H} 11\right)+\left(345,09118^{*} \mathrm{H} 3\right)+\left(-505,30168^{*} \mathrm{~B} 21\right)+(229,06336 * \mathrm{~B} 12)+ \\
(-855,81924 * \mathrm{H} 13)+(-199,65289 * \mathrm{~B} 3)+\left(400,56645^{*} \mathrm{~B} 8\right)\end{array}$ & 0,8751 \\
\hline $\begin{array}{l}\text { (1) } \mathrm{B} 1 \ldots . . \mathrm{B} 22 ; \mathrm{H} \\
\text { (2) Significante } \\
\text { (3) Óxido de } \mathrm{Al} \\
\text { (4) Relação } \mathrm{Al} \text { C } \\
\text { (5) Óxido de Fe } \\
\text { (6) Indicativo de } \\
\text { (7) Índice de est } \\
\text { (7) Óxido de Sil } \\
\text { (9) Óxido de Tit }\end{array}$ & $\begin{array}{l}\mathrm{H} 13 \text {, bandas e alturas selecionadas } \\
05 \% \text { e } 0,01 \% \text { de probabilidade } \\
\text { nio } \\
\mathrm{e}_{2} \mathrm{O}_{3} \\
\text { ádio de intemperismo }\left(\mathrm{SiO}_{2} / \mathrm{Al}_{2} \mathrm{O}_{3}\right) \\
\text { de intemperismo }\left(\mathrm{SiO}_{2} /\left(\mathrm{Al}_{2} \mathrm{O}_{3}+\mathrm{Fe}_{2} \mathrm{O}_{3}\right)\right.\end{array}$ & \\
\hline
\end{tabular}


Tabela 2. Equações lineares de regressão múltiplas para estimativa dos atributos dos solos da área de estudo utilizando-se 6 Bandas do TM-Landasat-5.

\begin{tabular}{|c|c|c|}
\hline Atributo & Equação múltipla $^{(\mathrm{I})}$ & $\mathrm{r}^{2(2)}$ \\
\hline Argila & $699,99540+(-13,44352 *$ TM7)+(-12,69294*TM5)+(13,03814*TM2) & 0,6140 \\
\hline $\mathrm{Al}_{2} \mathrm{O}_{3}{ }^{(3)}$ & $189,27590+(2,91733 *$ TM_3 $)+(-3,97853 *$ TM_4 $)+(-6,95007 *$ TM_7 $)$ & 0,6783 \\
\hline $\mathrm{Al} \_\mathrm{Fe}^{(4)}$ & $-0,27048+(-0,27805 *$ TM_1 $)+(0,10476 *$ TM_5 $)$ & 0,4799 \\
\hline $\mathrm{Fe}_{2} \mathrm{O}_{3}^{(5)}$ & $290,71175+\left(12,04310 * \mathrm{TM} \_1\right)+\left(-5,54129 * \mathrm{TM} \_4\right)+\left(-10,24985 * \mathrm{TM} \_7\right)$ & 0,6724 \\
\hline $\mathrm{ki}^{(6)}$ & $1,13241+\left(0,05412 * \mathrm{TM} \_4\right)+\left(-0,05408 * \mathrm{TM} \_5\right)+\left(0,08867 * \mathrm{TM} \_7\right)$ & 0,3169 \\
\hline $\mathrm{kr}^{(7)}$ & $0,17683+\left(-0,11305 * \mathrm{TM} \_1\right)+\left(0,03486 * \mathrm{TM} \_4\right)+\left(0,04700 * \mathrm{TM} \_7\right)$ & 0,5390 \\
\hline $\mathrm{SiO}_{2}^{(8)}$ & $189,49259+\left(-3,18311 * \mathrm{TM}_{-} 4\right)+\left(-4,94352 * \mathrm{TM} \_7\right)$ & 0,6531 \\
\hline $\mathrm{TiO}_{2}^{(9)}$ & $76,88838+\left(2,71784 * \mathrm{TM} \_1\right)+\left(-1,54095 * \mathrm{TM} \_5\right)+\left(-1,34536 * \mathrm{TM} \_7\right)$ & 0,7210 \\
\hline
\end{tabular}

(1) TM1, TM2, TM3, TM4, TM5 e TM7, Bandas do TM- Landsat-5 selecionadas

(2) Significante a $0,01 \%$ de probabilidade

(3) Óxido de Alumínio

(4) Relação $\mathrm{Al}_{2} \mathrm{O}_{3} / \mathrm{Fe}_{2} \mathrm{O}$

(5) Óxido de Ferro

(6) Indicat ivo de estádio de intemperismo $\left(\mathrm{SiO}_{2} / \mathrm{Al}_{2} \mathrm{O}_{3}\right)$

(7) Índice de est ádio de intemperismo $\left(\mathrm{SiO}_{2} /\left(\mathrm{Al}_{2} \mathrm{O}_{3}+\mathrm{Fe}_{2} \mathrm{O}_{3}\right)\right.$

${ }^{(8)}$ Óxido de Silício

${ }^{(9)}$ Óxido de Titânio 
Tabela 3. Resultados obtidos na comparação das faixas de teores de ferro, entre os dados obtidos em laboratório, ataque sulfúrico, e os dados obtidos utilizando-se as equações de regressão múltipla para radiometria orbital e de laboratório sensor IRIS.

\begin{tabular}{|c|c|c|c|c|c|c|c|c|}
\hline \multirow[t]{3}{*}{ Faixas de Ferro $^{(1)}$} & \multirow[t]{3}{*}{ V.D. ${ }^{(2)}$} & \multicolumn{3}{|c|}{ Laboratório IRIS (Horizonte B) $^{(3)}$} & \multirow[t]{3}{*}{ V.D. ${ }^{(2)}$} & \multicolumn{3}{|c|}{ Orbital (Horizonte $\mathrm{A})^{(4)}$} \\
\hline & & \multicolumn{2}{|c|}{ Certas $^{(5)}$} & \multirow[t]{2}{*}{ Confusão $^{(6)}$} & & \multicolumn{2}{|c|}{ Certas $^{(5)}$} & \multirow[t]{2}{*}{ Confusão $^{(6)}$} \\
\hline & & N.A. ${ }^{(7)}$ & $\%$ & & & N.A. ${ }^{(7)}$ & $\%$ & \\
\hline Hipoférrico $(\mathrm{H})$ & 82 & 79 & 96,3 & $3(\mathrm{M})$ & 84 & 80 & 95,2 & $4(\mathrm{M})$ \\
\hline Mesoférrico (M) & 14 & 14 & 100,0 & - & 14 & 14 & 100,0 & - \\
\hline Férrico $(\mathrm{F})$ & 7 & 2 & 28,6 & $5(\mathrm{M})$ & 5 & 0 & 0,0 & $5(\mathrm{M})$ \\
\hline Total & 103 & 95 & 92,2 & & 103 & 94 & 91,3 & \\
\hline
\end{tabular}

${ }^{(1)}$ Classes associadas ao teor de óxidos de ferro (ataque sulfúrico) onde: Hipoférrico ( $80 \mathrm{~g} \mathrm{~kg}^{-1} \mathrm{de} \mathrm{Fe}_{2} \mathrm{O}_{3}$ ), $\mathrm{Mesoférrico}\left(80\right.$ a $180 \mathrm{~g} \mathrm{~kg}^{-1}$ de Fe $\mathrm{O}_{3}$ ) e Férrico ( 180 a $<$ $360 \mathrm{~g} \mathrm{~kg}^{-1}$ de $\left.\mathrm{Fe}_{2} \mathrm{O}_{3}\right)$

${ }^{(2)}$ Número de amostras com valor determinado em laboratório (ataque sulfúrico), nas respectivas faixas de ferro;

(3) Dados estimados pela equação de regressão múltipla, com radiometria de laboratório, sensor IRIS.

${ }^{(4)}$ Dados estimados pela equação de regressão múltipla, com radiometria orbital, TM-Landsat-5.

${ }^{(5)}$ Número de amostras e porcentagens, estimadas pela equação de regressão múltipla, classificadas corretamente, na mesma faixa de teores de ferro dos valores determinados pelo ataque sulfúrico.

(6) Amostras confundidas, classificadas erroneamente, quando comparadas às amostras com valor determinado em laboratório e estimadas por radiometria.

${ }^{(7)}$ Número de amostras estimadas pelas equações de regressão múltipla. 
Tabela 4. Comparação das classes de textura estimadas com dados radiométricos, orbital para horizonte A e laboratório (IRIS) para o horizonte $\mathrm{B}$, com os resultados obtidos pelas análises granulométricas em laboratório.

\begin{tabular}{|c|c|c|c|c|}
\hline Textura $^{(1)}$ & Amostras & & & Confusão $^{(2)}$ \\
\hline \multicolumn{5}{|c|}{ Radiometria orbital (TM -Landsat-5) } \\
\hline Horizonte A & $V D^{(4)}$ & N.A. ${ }^{(5)}$ & $\%$ & \\
\hline Arenosa & 220 & 110 & 50 & 90 Média 1, 17 Média 2 e 3 Argilosa \\
\hline Média 1 & 152 & 62 & 41 & 70 Arenosa, 15 Média 2 e 5 Argilosa \\
\hline Média 2 & 27 & 13 & 48 & 4 Média 1 e 10 Argilosa \\
\hline Argilosa & 57 & 51 & 89 & 6 Média 2 \\
\hline M. Argilosa & 17 & 0 & 0 & 16 Argilosa e 1 Média 2 \\
\hline Total & 473 & 235 & 50 & \\
\hline \multicolumn{5}{|c|}{ Radiometria laboratório (IRIS) ${ }^{(6)}$} \\
\hline Horizonte B & $V^{(4)}$ & N.A. ${ }^{(5)}$ & $\%$ & \\
\hline Arenosa & 50 & 31 & 62 & 17 Média 1 e 2 Média 2 \\
\hline Média 1 & 269 & 193 & 72 & 51 Arenosa, 24 Média 2 e 1 Argilosa \\
\hline Média 2 & 49 & 21 & 43 & 3 Arenosas, 17 Média 1 e 8 Argilosa \\
\hline Argilosa & 54 & 41 & 76 & 1 Arenosa, 5 Média 2 e 8 M. Argilosa \\
\hline M. Argilosa & 51 & 20 & 39 & 31 Argilosa \\
\hline Total & 473 & 306 & 65 & \\
\hline \multirow{5}{*}{\multicolumn{5}{|c|}{$\begin{array}{l}\text { (1) Classes de textura onde: Arenosa ( } \leq 150 \mathrm{~g} \mathrm{~kg}^{-1} \text { de argila), Média } 1\left(151 \mathrm{a} 250 \mathrm{~g} \mathrm{~kg}^{-1} \text { de argila), }\right. \\
\text { Média } 2 \text { ( } 251 \text { a } 350 \mathrm{~g} \mathrm{~kg}^{-1} \text { de argila), Argilosa ( } 351 \mathrm{a} 600 \mathrm{~g} \mathrm{~kg}^{-1} \text { de argila), Muito Argilosa }(>600 \\
\mathrm{g} \mathrm{kg}^{-1} \text { de argila) } \\
\text { (2) Amostras confundidas, classificadas erroneamente, quando comparadas as amostras com valor } \\
\text { determinado em laboratório e estimadas por radiometria } \\
\text { (3) Dados estimados pela equação de regressão múltipla, com radiometria orbital, TM-Landsat } 5 \\
{ }^{(4)} \text { Número de amostras com valor determinado (VD) em laboratório (análise física), nas respectivas } \\
\text { faixas de textura } \\
\text { (5) Número de amostras e porcentagens, estimadas pela equação de regressão múltipla, classificadas } \\
\text { corretamente, na mesma faixa de textura dos valores determinados na análise física }\end{array}$}} \\
\hline & & & & \\
\hline & & & & \\
\hline & & & & \\
\hline & & & & \\
\hline & & & & \\
\hline
\end{tabular}



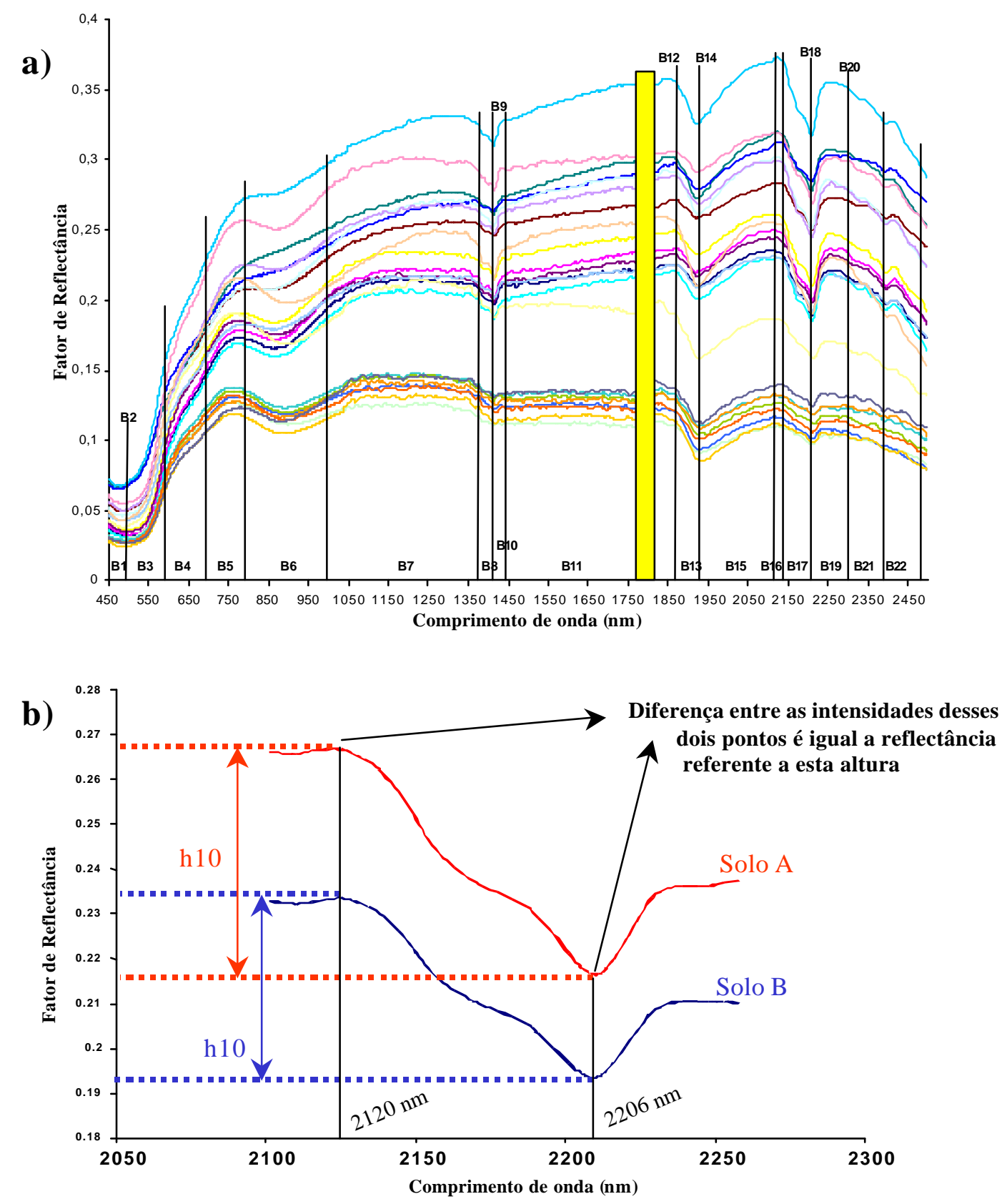

Figura 1 - Representação das 22 bandas e obtenção das 13 alturas onde: a) 22 bandas escolhidas pela interpretação visual de uma série de curvas espectrais obtidas em laboratório, sendo a faixa preenchida em amarelo representa um intervalo do espectro ótico descartado para a análise, por apresentar uma região de inflexão derivado do sistema eletrônico do sistema IRIS. b) obtenção da altura entre a crista e o vale da inflexão observada no intervalo entre 2.120 e 2.206 nm. Fonte:(Nanni, 2000). 

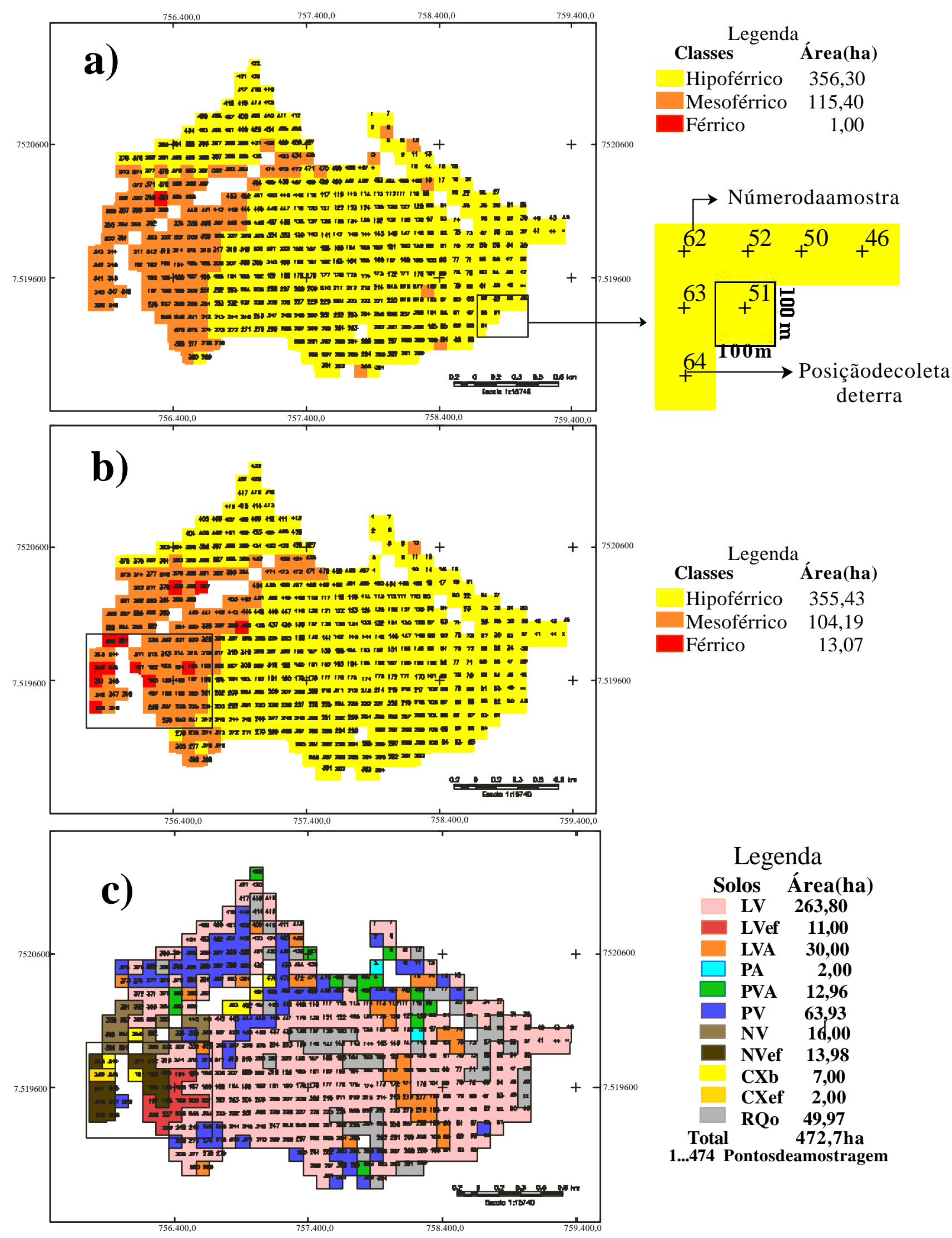

Legenda

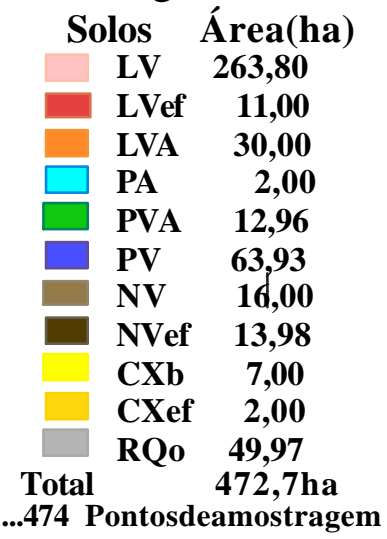

Figura2-.Teores deferroestimados atrávesdedadosradiométricos,orbitalelaboratório: a)mapa representativo das classesde teores deferroestimadoscomdadosorbitais,camada A (0$20 \mathrm{~cm})$, b) mapa representativodas classes deteores de ferro estimados comdados do sensorIRIS,camadaB $(80-100 \mathrm{~cm})$,c)Maparepresentativodolevantamentopedológico detalhadodaáreadeestudo. 


\section{QUATIFICAÇÃO DE ATRIBUTOS DOS SOLOS DA REGIÃO DE BARRA BONITA, SP, POR SUA ENERGIA ELETROMAGNÉTICA REFLETIDA}

\section{Resumo}

O objetivo do presente trabalho foi quantificar atributos dos solos por sensores localizados em laboratório e em órbita. A área de estudo localiza-se na região de Barra Bonita, SP, com 473 ha com solo exposto por ocasião do trabalho. Foi estabelecida uma grade de amostragem (100 m x $100 \mathrm{~m})$, em duas profundidades $(0-20 ; 80-100 \mathrm{~cm})$. Os locais foram georreferenciados, e amostras de terra coletadas e enviadas para análises químicas e físicas em laboratório. Das mesmas amostras foram obtidas leituras de reflectância com o sensor em laboratório (450 a $2.500 \mathrm{~nm}$ ). Nos mesmos locais de amostragem de terra, foram obtidos dados de reflectância de imagens orbitais TMLandsat-5. Em $50 \%$ de um total de 946 amostras de terra, foram desenvolvidas equações lineares de regressão múltipla a partir dos respectivos dados de reflectância obtidos em laboratório e orbital separadamente. Os $50 \%$ de amostras restantes foram utilizadas para testar os modelos, ou seja, comparou-se os valores estimados pelos modelos espectrais e os determinados em laboratório pelos métodos convencionais. Os maiores coeficientes de determinação, para os dados de laboratório foram para argila 
com $r^{2} 0,86$ e areia com $r^{2} 0,82$ e para os dados orbitais para argila e areia foram $r^{2} 0,61$ e 0,63 respectivamente. Para os dados de laboratório foi possível de se estimar os resultados das analises físicas com $84 \%$ de acertos para areia, e $74 \%$ de acerto para argila. Com os dados radiométricos orbitais é possível de se separar áreas mais arenosas com $77 \%$ de acerto.

\section{QUANTITATIVE OF SOIL ATTRIBUTES OF THE AREA OF BARRA BONITA, SP, FROM REFLECTANCE ELETROMAGNETIC ENERGY \\ Summary}

The objective of the present work was to quantify soilattributes by laboratory and orbital sensors. The study area is a 473 ha field located in the region of Barra Bonita, SP, with soil exposed by occasion of the work. A sampling grid was established (100 m x $100 \mathrm{~m})$, in two depths $(0-20 ; 80-100 \mathrm{~cm})$. The places were georreferenced, and earth samples were collected for chemical and physical analyses. Reflectance data were obtained from the same samples with the laboratory sensor (450 to $2.500 \mathrm{~nm}$ ). In the earth sampling places, reflectance data were also obtained from a TM-Landsat-5 image. In 50\% of 946 earth samples, linear equations of multiple regression were developed starting from the respective reflectance data obtained separately in laboratory and orbital. The 50\% remaining samples were used to test the models, that means so that the quantified by the spectral models and the determined in laboratory for the conventional methods were compared. The highest determination coefficients, for the laboratory data was for clay content with $r^{2} 0,86$ and sand 0,82 and for the orbital data $r^{2} 0,61$ and 0,63 respectively. For the laboratory data it was possible to consider the results of the 
physics analysis an $84 \%$ success for sand, and $74 \%$ for clay. With the spectral data from satellite it was possible to separate areas eith different soil textures with $77 \%$ of success.

\subsection{Introdução}

A análise de solo é um instrumento básico de diagnose da fertilidade do solo e ocupa lugar de destaque (Raij et al., 1987). Os métodos realizados em laboratório, já consagrados, são analíticos e levaram bastante tempo para atingir o grau de confiabilidade que possuem. Trata-se de métodos em que as amostras de terra coletadas no campo, passam por uma série de processos visando a determinação de sua constituição química e física. No Brasil citam-se, dentre outras, as metodologias adotadas por Camargo et al. (1987), Raij et al. (1987) e Embrapa (1997). O resultado das análises de solo são utilizados para uma série de atividades, entre elas, a classificação de solos e a recomendação para aplicação de adubos e fertilizantes, ambas de importância no manejo.

A maioria dos testes de análises de solo utilizados comercialmente nos Estados Unidos datam de 1940 (HRMST, 1980). A metodologia para cada atributo do solo foi extensamente debatida e modificada até se chegar a um quase consenso. Mesmo assim, ainda existem divergências. Por exemplo, inicialmente, os 50 Estados americanos conduziram testes com 28 diferentes métodos de extração de potássio. A maioria dos procedimentos foi desenvolvido regionalmente, até que Jones (1973) determinou apenas três métodos para o mesmo cátion, sendo um marco no desenvolvimento metodológico de análise de solo. 
A interpretação das análises de solo, portanto, é a base de todo e qualquer tipo de planejamento agrícola. O planejamento apresenta uma série de passos, tendo início no levantamento e mapeamento de solos. Existem várias fases durante um mapeamento, que vai desde a marcação de locais para coleta de amostras de terra até a interpretação dos resultados e delimitação das unidades. Posteriormente, existe a fase de interpretação de resultados para fins de aplicação de insumos. A coleta de amostras de terra para fins de fertilidade pode ser realizada pelos métodos tradicionais, sendo regra geral 1 amostra de terra composta de 20 subamostras para uma área não maior que 20 ha (Raij et al., 1996), ou pela recém implantada Agricultura de Precisão, que para áreas experimentais, um grid de amostragem de 20 a 30 m. Para áreas comerciais essa coleta de informação cai para 1 a 2,5 pontos por ha, devido ao custo elevado (Fraisse, 1998). Em todos estes casos, está presente a necessidade de coleta de amostras de terra e sua análise, que por sua vez, está diretamente ligado a altos custos. Demattê et al. (2000b) verificaram que os custos com análises de solo foram superiores no processo de agricultura pontual comparada com a convencional. Portanto, a racionalização no estabelecimento de locais para a amostragem de terra torna-se imprescindível. Como estabelecer então, critérios para a determinação da grade de amostragem em agricultura de precisão, sem conhecer a homogeneidade e a heterogeneidade dos solos ocorrentes numa área? Neste aspecto, Demattê (2001) estabelece a importância da utilização de novas tecnologias, como o sensoriamento remoto, que venham a auxiliar nesta empreitada. De fato, Odeh \& MacBratney (2000) comprovaram que a utilização do sensoriamento remoto e técnicas estatísticas, foram as mais eficientes e menos onerosas, na avaliação de solos. 
Entretanto, o histórico dos estudos radiométricos mostra uma sequiência diferente daquela das análises tradicionais. A primeira porção não visível do espectro, o infravermelho próximo, foi descoberto em 1800, por Herschel, citado por Stark et al. (1986). Enquanto outras partes do espectro eletromagnético, como a radiação gamma, eram investigadas e aplicadas pelos métodos analíticos, o infravermelho próximo foi negligenciado. Mesmo após vários autores terem documentado farto embasamento científico sobre a íntima relação entre atributos dos solos e a energia eletromagnética refletida (Bowers \& Hanks, 1965; Hunt et al., 1971; Stoner \& Baumgardner, 1981; Goetz, 1992), os estudos radiométricos, especialmente sobre estimativa, ficaram praticamente no campo da pesquisa. Não se tem notícia de trabalhos desta natureza sendo realizados em larga escala. Entretanto, com o advento da Agricultura de Precisão em meados da década de 80 (Searcy et al., 1989), e sua popularização na década de 90 (Schueller, 2000), os pesquisadores se depararam com um sistema agrícola atrelado à necessidade de automatização e velocidade na obtenção de informações (Hummel et al., 1996). Nesse momento, o sensoriamento remoto passou a ser extremamente importante para a agricultura de precisão (Johannsen et al., 1998), gerando, até o momento, avanços significativos na área de sensores.

O sensoriamento remoto baseia-se na aquisição de informações de um objeto sem haver contato direto (Lillesand \& Kiefer, 1992) por meio de sensores instalados em laboratório, campo ou órbita. A energia eletromagnética, que funciona como um "agente" que interage com todos os componentes do solo, sendo que cada componente está intimamente ligado a um ou mais comprimentos de onda. Trata-se, portanto, de um processo físico. Assim, o sensoriamento remoto apresenta-se como uma técnica não 
destrutiva na avaliação das amostras de terra (Palacios-Orueta \& Ustin, 1996), diferenciado-se dos métodos tradicionais.

Durante a última década, o sensoriamento remoto no estudo do solo em laboratório vem se desenvolvendo. Nestas condições, os parâmetros físicos permanecem constantes, não há problemas atmosféricos e os ruídos espectrais são mínimos, permitindo o uso de técnicas não destrutivas na quantificação dos solos (Ben-Dor \& Banin, 1995a; Madeira Netto, 1996; Campos, 2002). Vários autores também vêm buscando respostas pelas análises de correlação entre atributos do solo e reflectância espectral (Galvão et al., 1997; Demattê \& Garcia, 1999), como base para a quantificação. Da mesma forma, modelos de previsão de atributos dos solos têm apresentado alto potencial (Morra et al., 1991; Ben-Dor et al., 1997).

A quantificação de atributos do solo por sensores no nível orbital, por sua vez, vem a ser um desafio ainda maior, porém, com proporcional amplitude de importância. Sensores instalados em satélites ou aviões podem obter informações de áreas maiores e de difícil acesso. Entretanto, destaque-se os inúmeros problemas na avaliação desses produtos, como os problemas atmosféricos (Guyot, 1996) e situação de superfície (Huete, 1996). Apesar da importância, as dificuldades nesta linha de trabalho são refletidas pelo baixo número de trabalhos e informações sobre o assunto (Ben-Dor, 2002), principalmente sobre os solos tropicais.

Baseado nos conceitos entre reflectância e atributos dos solos determinados com sensores em laboratório, Coleman et al. (1991) obtiveram bons resultados na estimativa de argila. Posteriormente, Coleman et al. (1993) estabeleceram modelos estatísticos para estimativa dos atributos do solo por meio da reflectância obtida pelo sensor TM do 
Landsat. Apesar dos resultados terem sido pouco consistentes, os autores sugerem a continuidade do processo, o que é ratificado por Ben-Dor et al. (1999). Seguindo esta linha de trabalho, Nanni \& Demattê (2001b), implementaram uma metodologia que permitiu quantificar alguns atributos do solo pelo sensor TM em satélite, com alto grau de confiabilidade. Da mesma forma, entretanto, destacam a necessidade de outros trabalhos contribuírem para verificação da repetitividade.

Apesar dos atributos dos solos serem rotineiramente quantificados pelos métodos tradicionais, tanto em levantamentos de solos como em agricultura de precisão, estes estão dependentes da adoção de métodos automáticos para aumentar a eficiência do processo de análise do solo e diminuição dos custos. De fato, Hummel et al. (1996) destacam a importância do uso de sensores na estimativa da CTC, umidade e outros nutrientes no manejo de sítios específicos. Considerando ainda a importância e responsabilidade da quantificação dos solos na agricultura, o assunto continua complexo e sujeito a discussão, evidenciando a necessidade de maiores investigações.

O objetivo do presente trabalho, portanto, foi o de contribuir nessa área, pelo desenvolvimento de uma metodologia que venha a automatizar a quantificação de atributos de solos desenvolvidos na região de Barra Bonita, SP, pela utilização de sensores nos níveis laboratorial e orbital. Para tanto, foram estabelecidos bandas espectrais específicas, nas quais foram obtidos os dados radiométricos, a partir dos quais foram geradas equações de regressão linear múltipla. Espera-se que a avaliação dos dados espectrais obtidos pelos sensores, tenham íntima relação com os atributos dos solos, sendo possível sua quantificação. A quantificação de solos por sensoriamento 
remoto pode abrir novos horizontes no desenvolvimento de práticas em agricultura de precisão (Carey, 1995) e refinamento de mapas de solos (Demattê et al., 2001).

\subsection{Material e Métodos}

\subsubsection{Caracterização da área de estudo}

A área localiza-se ao sudoeste do Estado de São Paulo, na região de Barra Bonita. É delimitada pelas coordenadas geográficas $22^{\circ} 26^{\prime} 2,37^{\prime \prime}-22^{\circ} 23^{\prime} 16,53^{\prime \prime}$ latitude sul e $48^{\circ} 31^{\prime} 24,22^{\prime \prime}$ - 48 $27^{\prime} 51,77^{\prime \prime}$ longitude oeste. Apresenta 473 ha, cultivados com cana-de-açúcar em altitudes variando entre 520 e 710 metros do nível médio do mar. O clima da região, baseada na classificação de Köppen, é do tipo Cwa, clima mesotérmico (Sentelhas et al., 1998). A litologia é representada principalmente pela ocorrência da Formação Serra Geral, a qual se caracteriza por compreender um conjunto de derrames de basalto entre os quais se intercalam arenitos com as mesmas características da Formação Botucatu. Apresenta também a Formação Itaqueri do grupo Bauru caracterizada por arenitos com cimento argiloso, folhelhos e conglomerados, predominando os arenitos (IPT, 1981).

\subsubsection{Grade de amostragem de terra}

Foi estabelecida uma grade regular de $100 \mathrm{~m}$ x $100 \mathrm{~m}$. Os pontos foram estaqueados, georreferenciados e amostrados nas profundidades de 020 e $80-100 \mathrm{~cm}$ 
denominadas de A e B e referentes aos horizontes A e B, respectivamente, totalizando 948 amostras de solos. A cor do solo foi obtida na forma úmida com o equipamento Minolta CR 300 com chip para cor de Munsel (Post et al., 1994; Campos, 2002). Foram realizadas análises químicas (Raij et al., 1987), granulométricas e de ataque sulfúrico (Camargo et al., 1987). Com o resultado das análises foram descritos 7 perfis de solos (Lemos \& Santos, 1996) como base para a classificação (Embrapa, 1999).

\subsubsection{Obtenção dos dados espectrais nível laboratorial}

Para a obtenção dos dados espectrais de laboratório, foi utilizado o sensor InfraRed Intelligent Spectroradiometer, IRIS (Geophysical \& Environmental Research Corporation, 1996), que recobre a faixa espectral entre 450 e $2.500 \mathrm{~nm}$. As amostras da camada A (referente ao horizonte A), dos solos foram secas em estufa a $45^{\circ} \mathrm{C}$ por 24 horas, moídas e peneiradas (malha de $2 \mathrm{~mm}$ ), para homogeneização dos efeitos da umidade e rugosidade (Epiphanio et al., 1992). Posteriormente, as amostras foram acondicionadas em placas de petri e iluminadas por uma lâmpada halógena de $650 \mathrm{~W}$. A energia alimentadora da lâmpada foi estabilizada com uma fonte de potência de $1 \%$. Utilizou-se a placa padrão branca, com $100 \%$ de reflectância calibrada pela Labsphere (1996). A geometria utilizada foi: $61 \mathrm{~cm}$ lâmpada-alvo e alvo-sensor $27 \mathrm{~cm}$; inclinação da lâmpada $20^{\circ}$ ao nadir (Baumgardner et al., 1985). Posteriormente, os dados passaram por um software (Conviris), que regularizou os dados da placa de referência e realizou uma filtragem destes, eliminando o excesso de ruídos, para facilitar a interpretação. A relação entre a energia refletida pelo alvo e a energia refletida pela placa de referência 
gerou o fator de reflectância bidirecional (Nicodemus et al., 1977). Foram realizadas três leituras em cada amostra, sendo utilizada a curva espectral média.

\subsubsection{Obtenção dos dados espectrais nível orbital}

Foi utilizada uma cena TM-Landsat-5 nas bandas 1, 2, 3, 4, 5 e 7. Após definida a área foi realizado o corte na imagem no programa IMPIMA (INPE, 1999). A imagem de satélite apresenta para cada pixel um valor de níveis de cinza (Crósta, 1992). Os dados de níveis de cinza foram transformados em reflectância, conforme comentários de Epiphanio \& Formaggio (1988). Estes autores descrevem que a análise quantitativa de imagens digitais sobre o comportamento espectral de alvos deve ser feita com os dados em reflectância, por ser uma grandeza física intrínseca dos alvos, ao passo que os números digitais são valores transformados para a obtenção das imagens orbitais. Segundo Ben-Dor (2002), os valores de níveis de cinza obtidos das cenas do sensor TMLandsat devem ser devidamente ajustados aos efeitos atmosféricos e posteriormente os números digitais convertidos em valores de reflectância real. Para tanto, foi utilizado o modelo 5S (Simulação do Sinal do Satélite dentro do Espectro Solar) (Tanré et al., 1992) e detalhadamente descrito por Zullo Jr. (1994). Após o processo de conversão e correção, o nível de cinza zero presente na imagem passou a corresponder à reflectância 0 \% e o nível de cinza 255 à reflectância $100 \%$.

Para adequar o posicionamento da imagem com a verdade de campo a correção geométrica se fez necessária. Dessa forma, foram utilizadas as cartas planialtimétricas, escala 1:10.000, da Coordenadoria de Ação Regional, Divisão Cartográfica, da 
Secretária de Economia e Planejamento do Estado de São Paulo. Além disso, pontos obtidos no campo com equipamento GPS (Global Positioning System) com erro submétrico foram utilizados. Objetivando manter o valor do pixel o mais semelhante possível ao seu valor original, utilizourse o método de interpolação denominado vizinho mais próximo, corrigindo apenas as distorções de escala, deslocamento ou rotação existentes entre a imagem e a projeção terrestre (Crósta, 1992). Uma vez registrada, a cena foi visualizada em composição colorida R/G/B, nas bandas 1/2/3 e 4/5/7. Sobre os planos de informação "imagens", foram sobrepostos os pontos de amostragem da grade. Em cada ponto de amostragem, foram determinados os dados espectrais das referidas bandas.

\subsubsection{Análise estatística dos dados espectrais}

Para os dados orbitais foram obtidos os dados de reflectância da camada superficial dos solos, das bandas do TM-Landsat-5, sendo (em nm): B1: 450-520, B2: 520-600, B3: 630-690, B4: 760-900, B5: 1150-1750, B7: 2080-2350. Foram utilizados 227 dados de reflectância para gerar os modelos, sendo outras 227 amostras para teste. A escolha dos pontos para gerar os modelos foi aleatória, porém, representativa de toda a área de estudo.

Os dados espectrais obtidos com o IRIS em laboratório, permitem uma maior resolução radiométrica, podendo-se estabelecer um maior número de bandas. Foram

selecionadas 22 bandas (B) e 13 alturas (H), seguindo metodologia de Nanni \& Demattê (2001b), sendo elas (em nm): B1: 450-481, B2: 481, B3: 481-596, B4: 596-710, B5: 
710-814, B6: 814-975, B7: 975-1350, B8: 1350-1417, B9: 1417, B10: 1417-1449, B11:

1449-1793, B12: 1793-1831, B13: 1865-1927, B14: 1927, B15: 1927-2102, B16: 21012139, B17: 2139-2206, B18: 2206, B19: 2206-2258, B20: 2258, B21: 2258-2389, B22: 2389-2498, H1: 469-532, H2: 532-768, H3: 768-876, H4: 876-1353, H5: 1353-1411, H6: 1411-1439, H7: 1439-1783, H8: 1860-1923, H9: 1923-2120, H10: 2120-2206, H11: 2206-2258, H12: 2258-2389, H13: 2389-2498. Essa seleção baseia-se em observações empíricas, pela literatura. Posteriormente é utilizado um sistema automatizado estatístico para determinação das melhores bandas.

Das 946 amostras dos horizonte de superfície e subsuperfície, 473 foram separadas aleatoriamente (independente da camada de amostragem) para gerar os modelos e as 473 restantes utilizadas para testar o modelo (Figura 1). Os dados foram submetidos a análise de correlação usando o Sistema de Análise Estatística SAS (SAS, 1999). Os teores de areia, silte, argila, matéria orgânica (MO), soma de bases (SB), saturação por bases (V\%), saturação por alumínio (m \%) e capacidade de troca catiônica (CTC) foram correlacionados com as características espectrais.

Inicialmente foram realizadas as seleções das variáveis preditoras, para os dados de laboratório e orbital. Esse procedimento, realizado pelo Sistema de Análise Estatística SAS (SAS, 1999), verifica quais variáveis apresentaram maior ou menor potencial para o desenvolvimento dos modelos. Posteriormente, realizou-se uma avaliação de colinearidade das variáveis, para que não houvesse duas ou mais variáveis que pudessem estar se sobrepondo. Para cada atributo do solo foram estabelecidas equações lineares de regressão múltipla. As equações foram testadas com os dados de reflectância das amostras não utilizadas para gerar os modelos (Figura 1). 
Foi possível, portanto, gerar um banco de dados com valores dos atributos do solo determinados em laboratório pelos métodos tradicionais (VD) e valores estimados por radiometria (VE). VD e VE foram comparados de diferentes maneiras permitindo uma análise mais cuidadosa, sendo:

(1) teste $t$ com $\mathrm{p}<0,05$ entre as médias dos VD e VE para cada atributo, obtidos pelos dados radiométricos nos níveis laboratório e orbital;

(2) Quaggio et al. (1994) desenvolveram um programa para avaliação e desempenho dos laboratórios em análises de rotina. Sendo os dados para este trabalho extraídos do relatório do ano de 2000 (Cantarella \& Abreu 2001), com 77 laboratórios inscritos, onde um dos objetivos foi o de padronizar os resultados dessas análises. Amostras dos mesmos solos são enviadas todos os anos para os laboratórios do programa, e, após tratamento estatístico, obtem-se a média, desvio padrão da média, valor mínimo e máximo para cada um dos atributos do solo analisado em rotina. Dessa forma, o laboratório é considerado dentro do padrão quando seus resultados estão entre os valores mínimos e máximos. Partindo desses resultados, foi gerado um intervalo de tolerância (valores mínimos e máximos) para os VD, considerando como acerto quando os VE apresentassem valores dentro desse intervalo de tolerância.

Como exemplo temos a amostra número 454 da área de estudo. O atributo areia apresentou intervalo de $20 \%$ de acordo com Cantarella \& Abreu (2001), sendo o valor mínimo de $420 \mathrm{~g} \mathrm{Kg}^{-1}$ e valor máximo $640 \mathrm{~g} \mathrm{Kg}^{-1}$. O VD (em laboratório método tradicional) de areia foi de $530 \mathrm{~g} \mathrm{Kg}^{-1}$, e o VE (utilizando equações determinadas a partir da reflectância) $529 \mathrm{~g} \mathrm{Kg}^{-1}$. Tal resultado foi considerado como "acerto" ou "dentro do intervalo" estabelecido pelos laboratórios; 
(3) Como não existe uma regra básica de tolerância de variação das amostras de terra, foram estabelecidos outros intervalos para comparação e discussão. O valor de VE, quando dentro de uma margem de erro em relação à VD, foi classificado como segue: ótimo $0-20 \%$, bom $21-30 \%$, regular $31-40 \%$ e inadequado $>41 \%$.

(4) Para os atributos areia, argila, MO, SB e CTC, foram realizadas correlações entre os VD e VE, observando-se o ${ }^{2}$.

\subsection{Resultados e Discussão}

\subsubsection{Estimativa dos atributos do solo pela resposta espectral obtida com sensor em laboratório}

Foram geradas equações lineares de regressão múltipla para cada um dos oito atributos do solo, utilizando-se metade dos dados da área de estudo, independente da camada selecionada (0-20 cm ou 80-100 cm) (Figura 1). Tal metodologia difere da utilizada no trabalho realizado por Nanni \& Demattê (2001b) onde as equações de regressão foram geradas para cada camada, superficial e subsuperficial separadamente. Estes autores compararam os valores determinados (VD, pela análise de solo para a superfície), com os valores estimados (VE, partindo dos dados radiométricos de subsuperficie e vice-versa).

Das 22 bandas e 13 alturas, perfazendo um total de 35 variáveis, a equação m \% apresenta-se com o maior número de variáveis, 13, entre bandas e alturas (Tabela 1). A equação com 4 variáveis foi a menor, sendo ela referente à CTC e só de alturas, como é 
o caso também da SB com 6 variáveis. As bandas e alturas "chave" para a estimativa de cada atributo, foram determinadas estatisticamente. A técnica de análise múltipla permitiu definir as bandas e alturas melhor correlacionadas a cada atributo, concordando com Huete \& Escadafal (1991) e Nanni (2000).

Argila e areia apresentaram altos coeficientes de determinação, com valores maiores que 0,8 (Tabela 1), concordando com Demattê \& Garcia (1999) com $\mathrm{r}^{2}$ de 0,8 para argila e Nanni \& Demattê (2001b) com $r^{2}$ de 0,91 para argila e 0,74 para areia na superfície. Coleman et al. (1991) já consideravam como alto coeficiente de determinação 0,63 para argila. Para o silte foi obtido $u m r^{2}$ de 0,56 considerado como sendo satisfatório. Demattê \& Garcia (1999) verificaram valores de $\mathrm{r}^{2}$ maiores que 0,75, enquanto Nanni \& Demattê (2001b) obtiveram 0,27 de $r^{2}$ em superfície. Vale nota que basta estimar dois atributos, entre areia, silte e argila, pois o terceiro é por subtração, como realizado pelas análises tradicionais. Para $\mathrm{MO}$ os resultados não foram satisfatórios apresentando baixo coeficiente de determinação, $r^{2}$ de 0,298 (Tabela 1), concordando com Demattê \& Garcia (1999). Ben-Dor \& Banin (1995b) verificaram $r^{2}$ de 0,5 para MO, porém comentam que maior atenção deve ser dada para as predições desse atributo quanto tipo de MO. Demattê et al. (2001) e Nanni \& Demattê (2001b) obtiveram $r^{2}$ de 0,79 para MO.

Para os atributos químicos, SB e m \%, os coeficientes de determinação foram menores que 0,6 (Tabela 1), considerados aqui como satisfatórios. Nanni \& Demattê (2001b) obtiveram resultados diferentes, sendo $\mathrm{r}^{2}$ maior que 0,87 para SB e menor que 0,32 para $\mathrm{m} \%$. Valores próximos de 0,50 foram determinados para CTC e V \% (Tabela 
1), sendo considerados pouco consistentes. Os resultados discordam dos apresentados por Nanni \& Demattê (2001b), onde o $\mathrm{r}^{2}$ para CTC foi alto, 0,90.

Com o objetivo de verificar a possibilidade da utilização das equações geradas nesse trabalho, na predição dos atributos dos solos, metade das amostras da área não participaram do processo para gerar os modelos (473 amostras). Os dados espectrais dessas amostras foram utilizados para testar os modelos, obtendo-se os valores estimados (VE) dos atributos do solo, os quais foram comparados com os valores determinados (VD) em laboratório de análise de solos.

Verifica-se que os resultados obtidos pelas equações na predição dos atributos do solo, representados pelas médias dos conjuntos de dados VE, apresentaram-se estatisticamente semelhantes aos VD, para todos os atributos (Tabela 2). Ou seja, tais resultados nos levam a crer que não ocorreram diferenças significativas entre as análises tradicionais e as obtidas por sensor. Tais resultados diferem parcialmente dos de Nanni \& Demattê (2001a), onde as médias entre VD e VE para areia, MO e m \%, apresentaram diferenças significativas. Por outro lado, os resultados para argila e silte obtidos por estes autores, ratificam os bons resultados do presente trabalho. A estatística do teste $t$ deve ser usada como um resultado preliminar, já que o mesmo trabalha com a média, ou seja, dois conjuntos de dados podem apresentar elementos pontualmente diferentes, porém, com médias semelhantes estatisticamente (SAS, 1999). Esse método também foi realizado por Nanni \& Demattê (2001a) para os quais foi possível estimar o teor de argila com sensor de laboratório.

Com o intuito de melhor avaliar os dados, foi utilizado um critério que compara pontualmente o VD e o VE para as 473 amostras (Tabela 3). Tal critério é fundamentado 
em trabalhos realizados com amostras em laboratórios de rotina, baseado em Quaggio et al. (1994). Os melhores resultados foram observados para areia, com $84 \%$ e argila com $74 \%$ de acertos, ou seja, das 473 amostras testadas, 396 e 351 respectivamente, estão dentro do intervalo de tolerância de variação proposto pelos laboratórios de análise de solo. O silte apresentou um acerto de $52 \%$. Por outro lado, na prática, como areia e argila foram adequadamente estimados, o silte, neste caso, poderia ser obtido por subtração, como realizado em laboratório, de acordo com Raij et al. (1987). Semelhante ao silte, a CTC apresentou $51 \%$ de acerto (Tabela 3). Os dados de SB, MO, m \% e V \%, apresentaram baixas porcentagens de acerto, sendo menor a do V \% com $10 \%$ (Tabela 3). Estes resultados mostram maior potencial em estimar dados físicos como areia e argila, do que os químicos como o $\mathrm{V} \%$.

Como os laboratórios apresentam variações não específicas, fica difícil concluir se os dados de reflectância são adequados ou não. Por este motivo, verificourse outros intervalos de variação para melhor discussão (Tabela 4). Por exemplo, quanto maior o número de amostras VE no intervalo 0-20 \%, melhor é a equação de regressão múltipla. Os resultados obtidos pela equação da areia, apresentou-se com $83 \%$ das amostras nesse intervalo, seguida pela argila com 59,8 \% e CTC com $41 \%$. Os demais resultados apresentaram uma porcentagem muito baixa (Tabela 4). Para o intervalo de 21-30\%, considerado bom, o maior acerto foi o da CTC (21,4\%) e no intervalo de $31-40 \%$, regular, temos a MO com $13 \%$. Supondo que aceitemos os resultados do intervalo de tolerância de 0-40 \%, teríamos para areia de 89,2 \%, argila 87,3\%; CTC 75,1 \%; V \% $67,7 \%$ e MO 63,6 \%. Os resultados acima do intervalo de $40 \%$ (inadequado) não são tão representativos para a maioria dos atributos com exceção da m \% com 50,7 \%; SB 
com $49,3 \%$ e silte com $46,1 \%$, sendo que as equações para estes atributos devem gerar dados duvidosos, devendo-se evitar o seu uso.

Também foram realizadas análises de correlação entre os VD e VE para alguns atributos, eliminando-se alguns pontos extremos “outline” (Tabela 5). Verifica-se que os maiores valores para o coeficiente de correlação $\left(\mathrm{r}^{2}\right)$ são para areia $(0,84)$ e argila $(0,83)$, Ben-Dor \& Banin (1995a) obtiveram um $r^{2}$ para argila de 0,56 e 0,51 para MO, sendo esse valor maior que o obtido nesse trabalho $(0,41)$ (Tabela 5). Os valores obtidos para SB e CTC foram maiores que o 0,64 obtido para CTC por Ben-Dor \& Banin (1995a). É interessante observar que, em todos os casos, os dados estimados pelo sensor ficaram acima da variação tolerada (Tabela 3).

Os modelos empregados neste trabalho são empíricos. Neste caso, assume-se que a concentração de um dado constituinte do solo é proporcional à uma combinação linear das diversas intensidades de reflectância e feições de absorção. Um modelo semelhante empregado é o NIRA, utilizado por Ben-Dor \& Banin (1995 a, b). Este modelo também é empírico e foi testado por vários autores como Ben-Dor et al. (1997) e Malley et al. (1999) na avaliação da matéria orgânica e nutrientes, respectivamente. De acordo com este método, o número de bandas para a estimativa de um atributo do solo pode variar de 25 a 63. A argila, por exemplo, necessitou de 63 bandas para sua estimativa, enquanto no presente trabalho 12 (Tabela 1). Quanto menor o número de fatores na estimativa de um atributo mais fácil é sua aplicabilidade e menores os riscos de haver sobreposição de efeitos de bandas (Ben-Dor, 2002).

Os valores semelhantes entre os VE e os VD, mostram que a metodologia aqui proposta apresentou bons resultados devido a vários fatores, sendo: sensor com alta 
resolução espectral, alta relação sinal/ruído, leituras em ambiente constante e controlado e um detalhado estudo dos solos da área. Neste ambiente, o sensor detecta os efeitos dos atributos do solo, que absorvem energia radiante em discretos níveis de energia.

Por outro lado, diferenças entre os resultados dos trabalhos foram mtados. Por exemplo, Nanni (2000) obteve valores expressivos para a quantificação de matéria orgânica, $r^{2}$ de 0,79 , bem superior ao obtido no presente trabalho com $r^{2}$ de 0,2 . Demattê \& Garcia (1999) também obtiveram baixa correlação para a MO $(0,45)$. O “vácuo" de uniformidade nos métodos determinados pelos diferentes pesquisadores dificulta explicar resultados como estes.

Coleman et al. (1991) obtiveram valores de 0,63 para argila. Demattê \& Garcia (1999) obtiveram, para os mesmos atributos, valores acima de 0,75. Nanni (2000) atingiu 0,91 para a argila, enquanto o presente trabalho foi de 0,86 . O que diferencia estes trabalhos é a metodologia. Além de equipamentos distintos, a diferença principal concentra-se na determinação das bandas para elaboração dos modelos, bem como nos dados dos solos analisados. Coleman et al. (1991) utilizaram oito bandas sendo três no visível, duas no infravermelho próximo, duas no infravermelho médio e uma no infravermelho termal, enquanto que Demattê \& Garcia (1999), usaram bandas um pouco diferentes. Nos trabalhos posteriores, Nanni (2000) já se utilizou de mais bandas espectrais e com amostras de terra com características bastante contrastantes (solos desenvolvidos de basalto, folhelho, arenito, material retrabalhado), o que motivou melhores correlações. O presente trabalho por sua vez, utilizou dados de solos desenvolvidos principalmente de dois materiais, basalto e material retrabalhado, e mesmo assim obteve correlações razoáveis. Tais resultados indicam que os modelos são 
fortemente influenciados pelo número de bandas e os comprimentos de onda selecionados. Além disso, os modelos são regionais, e devem ser assim tratados, concordando com Coleman et al. (1991). Aliás, mesmo as análises químicas em laboratório apresentam metodologias regionalizadas, como descrito em HRMST (1980).

A estimativa de atributos químicos do solo, como a soma dos cátions $\mathrm{Ca}, \mathrm{Mg}$ e K, foi possível com $r^{2}$ de 0,71 em trabalho de Demattê \& Garcia (1999). Nanni (2000) chegou a determinar 0,87, enquanto no presente trabalho 0,63 . Scherier (1977) verificou que os cátions apresentavam boa correlação com dados espectrais.

\subsubsection{Estimativa dos atributos do solo pela resposta espectral de sensor orbital}

Para cada atributo foi gerada uma equação linear de regressão múltipla com metade das amostras da área, totalizando 227 amostras (Tabela 6). Das 6 variáveis iniciais (TM 1, 2, 3, 4, 5 e 7), para os atributos areia, silte e argila, foram selecionadas nos processos estatísticos 3 variáveis, sendo as mesmas bandas para areia e silte $(3,5$ e 7), diferindo para argila a banda 2 ao invés da 3 (Tabela 6). Coleman et al. (1993) obtiveram equações de regressão múltipla, para os mesmos atributos, também com 3 variáveis das 6 iniciais, porém com bandas diferentes (areia-2,3 e 7; silte-1,4, e 7; argila1,3 e 4). Ainda segundo os autores, o maior coeficiente de determinação foi de 0,4 para argila e menores que 0,17 para areia e silte muito abaixo dos determinados nesse trabalho, sendo o maior para areia com 0,63 , seguido por 0,61 para argila e 0,54 para

silte (Tabela 6). Nanni (2000) obteve para areia $r^{2}$ de 0,52 , com as bandas 1,5 e 7 e 0,67 para argila as bandas $1,3,4,5$ e 7 . 
As equações com menor número de variáveis foram para SB, CTC, apenas com a banda 7 e V\% com a banda 1, os atributos que apresentaram 2 variáveis foram MO e m $\%$ esses atributos também apresentaram baixos índices de determinação $(<0,46)($ Tabela 6). Concordando com os valores observados por Nanni (2000) que conclui que essas equações se utilizadas podem vir a gerar erros de estimativa. Coleman et al. (1993) com o trabalho intitulado "Seria possível quantificar atributos de solos através de sensores instalados em plataformas espaciais ?" apresentaram dados com $\mathrm{r}^{2}$ significativos, porém não consistentes, de 0,1 a 0,4 para areia, silte, argila, ferro e MO. Podemos agora reafirmar nesse trabalho essa possibilidade uma vez que os resultados de $r^{2}$ foram bem melhores que os apresentados por esses autores, principalmente para areia e argila (Tabela 6).

Para melhor afirmar a citação acima, as equações geradas com metade das amostras do horizonte superficial, foram testadas com as amostras de solo que não participaram do modelo. A tabela 7 apresenta dados comparativos entre as médias do conjunto de dados VD e VE, pelo teste $t$ com $\mathrm{p}<0,05$. Por esse método foi observada diferença significativa entre VD e VE apenas para V \% e $\mathrm{m} \%$. Observa-se também que os valores das médias significativas entre VD e VE são muito próximas (Tabela 7), porém dois conjuntos de dados podem apresentar elementos pontualmente diferentes (SAS, 1999).

A Tabela 8 representa o critério de comparação pontual entre VD e VE, como realizado para os dados de laboratório, onde para cada amostra georrefereciada foi comparado o VE com o intervalo de VD extraído de Quaggio et al. (1994). Os melhores resultados foram observados para areia com $77 \%$ de acertos, ou seja, das 227 amostras 
testadas, 175 estão dentro do intervalo de tolerância. A CTC, SB e argila, apresentam cerca de $50 \%$ de acerto, seguidos por $48 \%$ do silte. Podemos considerar esses resultados como satisfatórios principalmente nos casos onde temos elementos trocáveis de difícil determinação concordando com Demattê (1999). Para V \% e m \% as porcentagens de acertos foram muito baixas, $8 \%$ e $23 \%$ respectivamente (Tabela 8 ). Mesmo assim é importante reafirmar que os resultados indicam avanços e que novas pesquisas para esses elementos de difícil determinação devem ser realizadas, como também salientam Coleman et al. (1991) e Ben-Dor (2002).

Para os intervalos sugeridos nesse trabalho, Tabela 9, o resultado da areia mantém-se em 76,7 \%, para o intervalo entre 0 - $20 \%$ (ótimo), sendo que os demais atributos não ultrapassam os $45 \%$ de acerto. No intervalo maior que $41 \%$ (inadequados), as maiores porcentagens dos atributos são para a m \%, silte, SB e argila. Caso seja considerado o intervalo de $0-40 \%$, apenas o $\mathrm{m} \%$ ficaria com acertos menores que $50 \%$, sendo que a areia passaria para 87,2 \%, CTC para 74,9\%, MO para $74,4 \%$, V \% para $73,6 \%$, argila para $69,6 \%$ e silte para $51,6 \%$ (Tabela 9). Com exceção da areia os resultados das equações geradas devem originar dados duvidosos devendo-se evitar o seu uso.

Também para os dados orbitais, foram realizadas análises de correlação entre os VD e VE de alguns atributos, eliminando-se alguns pontos extremos "outline" (Tabela 5). Verificamos que os maiores valores para o coeficiente de correlação $\left(r^{2}\right)$ são para areia $(0,72)$ e argila $(0,71)$, Ben-Dor \& Banin (1995a) obtiveram um $r^{2}$ para argila de 0,56 e 0,51 para MO diferindo dos resultados de MO, mais baixos nesse trabalho com 
0,35\% (Tabela 5). Os valores obtidos para SB e CTC foram menores que 0,64 obtido para CTC por Ben-Dor \& Banin (1995a).

Coleman et al. (1993) tentaram estimar teores de areia e argila pelas imagens de satélite, obtendo valores baixos de $\mathrm{r}^{2}$, sendo $0,14,0,40$, respectivamente. Nanni \& Demattê (2001b), por sua vez, obtiveram, para os mesmos atributos 0,52 e 0,67 respectivamente. No presente trabalho os resultados são parecidos, na faixa de 0,6 (Tabela 6). Os valores significativos do presente trabalho podem ser explicados pela metodologia empregada. No presente trabalho, utilizou-se de parte da metodologia de Demattê et al. (2000b) para o diagnóstico de áreas com solo exposto. No caso, são avaliados diversos fatores para se concluir quando um pixel tem maior probabilidade de estar com solo exposto, entre eles, diferentes composições coloridas e índice de vegetação.

Os resultados obtidos pelo sensor orbital foram menos consistentes que os com sensor em laboratório, concordando com resultados de Coleman et al. (1991) e Coleman et al. (1993). Isto ocorreu por que os dados em laboratório foram adquiridos em ambiente controlado, geometria, iluminação, sem problemas atmosféricos, enquanto que os de imagens apresentam inúmeros fatores interferentes como rugosidade do solo, resolução espectral e espacial, baixa relação sinal/ruído, problemas atmosféricos, variações nos ângulos de visada e iluminação (Ben-Dor, 2002). Baptista et al. (1999) trabalharam com sensor hiperespectral AVIRIS (JPL/NASA), obtendo um $\mathrm{r}^{2}$ de 0,8 para argila, bem superior aos apresentados nesse trabalho, mostrando assim a evolução dos sensores orbitais. Os autores ainda comentam que todo trabalho envolvendo dados de sensoriamento remoto pode dar um rumo, mas as quantificações necessitam de trabalhos 
de campo para que os parâmetros obtidos pela manipulação das imagens possam ser correlacionadas com os dados obtidos in loco, o que está de acordo com as linhas gerais apresentadas no presente trabalho.

\subsection{Conclusões}

1- É possível quantificar atributos do solo como teor de argila, areia e CTC utilizando-se de dados da energia eletromagnética refletida obtidos com sensor em laboratório. Tal fato está baseado na íntima relação existente entre os valores do solo estimados pelas equações de dados espectrais e os determinados em análises de rotina em laboratório.

2 - A utilização de equações lineares de regressão múltipla, determinadas por sensor em laboratório, como meio para quantificação de atributos do solo, mostrou-se eficiente, obtendo entre 84 e $89 \%$ de acerto para os teores de areia e 74 a $87 \%$ para a argila. Parâmetros químicos como saturação por alumínio e soma de bases, mostraram equações significativas com $r^{2}$ de 0,68 e 0,63 , respectivamente.

3- É possível estimar teores de argila utilizando-se equações de regressão linear múltipla $\left(\mathrm{r}^{2}\right.$ de 0,61$)$ geradas com dados espectrais obtidos de satélite, com índice de acerto entre 77 e $87,2 \%$.

4 - Os dados espectrais com sensor terrestre foram substancialmente mais significativos que os dados orbitais.

5- As médias comparativas entre os valores determinados em laboratório e os valores estimados com dados radiométricos, devem ser utilizados como análises preliminares, pois dois conjuntos de dados podem apresentar elementos pontualmente diferentes e 
médias semelhantes. Sendo que para os dados de laboratório nenhum dos atributos apresentou médias diferentes, porém os resultados das análises pontuais mostraram existir grandes diferenças entre os grupos analisados.

6- Para a área de estudo é possível de se separar áreas com solos de textura arenosa das demais utilizando-se as equações lineares de regressão múltipla geradas com dados orbitais, com acertos de $77 \%$ no intervalo de $20 \%$ e 87,2 \% para um intervalo de 0 - 40 $\%$. 
Tabela 1. Equações de regressão múltipla para sensor em laboratório na estimativa dos atributos dos solos da área de estudo utilizando-se 22 bandas e 13 alturas.

\begin{tabular}{|c|c|c|}
\hline Atributo & Equação múltipla ${ }^{(\mathrm{I})}$ & $\mathrm{r}^{2(2)}$ \\
\hline Areia total & $\begin{array}{l}409,59806+(-3346,58558 * \mathrm{H} 3)+(20887 * \mathrm{~B} 11)+(-14543 * \mathrm{~B} 16)+(-10890 * \mathrm{H} 7)+(-9824,77554 * \mathrm{~B} 19)+(-19212 * \mathrm{~B} 10)+(13431 * \mathrm{H} 12) \\
+(26675 * \mathrm{~B} 21)+(-3035,10462 * \mathrm{~B} 7)\end{array}$ & 0,8174 \\
\hline Silte & $129,83933+(-1943,40654 * \mathrm{H} 10)+(-2624,05031 * \mathrm{H} 9)+(1916,57891 * \mathrm{H} 8)+(2353,36975 * \mathrm{H} 5)+(2162,49950 * \mathrm{H} 1)$ & 0,5672 \\
\hline Argila & $\begin{array}{l}376,23728+(4092,67466 * \mathrm{H} 3)+(10972 * \mathrm{H} 7)+(1409,95843 * \mathrm{H} 2)+(-25070 * \mathrm{~B} 11)+(23006 * \mathrm{~B} 16)+(-23085 * \mathrm{H} 11)+(30702 * \mathrm{~B} 10) \\
+(-19095 * \mathrm{~B} 17)+(8651,36527 * \mathrm{H} 12)+(-2273,14097 * \mathrm{H} 1)+(-4697,25743 * \mathrm{~B} 15)+(-6041,71261 * \mathrm{~B} 8)\end{array}$ & 0,8570 \\
\hline $\mathrm{MO}^{(3)}$ & $29,00804+(-141,76148 * \mathrm{H} 2)+(-225,82107 * \mathrm{H} 3)+(-517,81987 * \mathrm{H} 13)+(746,61657 * \mathrm{~B} 1)+(-476,15447 * \mathrm{~B} 3)+(332,27114 * \mathrm{H} 5)$ & 0,2988 \\
\hline $\mathrm{SB}^{(4)}$ & $455,20858+(-25577 * \mathrm{H} 11)+(23797 * \mathrm{H} 12)+(-3138,20686 * \mathrm{H} 3)+(5295,62046 * \mathrm{H} 1)+(-7983,39289 * \mathrm{H} 5)+(4108,62012 * \mathrm{H} 8)$ & 0,6345 \\
\hline $\mathrm{V} \%{ }^{(5)}$ & $\begin{array}{l}79,81023+(-1016,67292 * \mathrm{~B} 1)+(2892,46819 * \mathrm{~B} 8)+(-2560,16606 * \mathrm{~B} 7)+(-1067,64273 * \mathrm{H} 4)+(3300,62458 * \mathrm{H} 12)+(-919,36419 * \mathrm{H} 10) \\
+(488,23896 * \mathrm{H} 3)+(-1480,00508 * \mathrm{H} 11)\end{array}$ & 0.5055 \\
\hline $\mathrm{m} \%{ }^{(6)}$ & $\begin{array}{l}-22,14932+(3801,42681 * \mathrm{H} 5)+(-2050,46588 * \mathrm{H} 8)+(2082,39681 * \mathrm{~B} 1)+(-6728,15162 * \mathrm{~B} 3)+(-4326,51343 * \mathrm{~B} 10)+(-699,51724 * \mathrm{H} 3) \\
+(6123,58955 * \mathrm{~B} 2)+(1570,79618 * \mathrm{H} 13)+(3540,68221 * \mathrm{H} 1)+(960,41493 * \mathrm{H} 2)+(-995,46185 * \mathrm{H} 12)+(1273,60350 * \mathrm{~B} 11)+(2584,29549 * \mathrm{~B} 9)\end{array}$ & 0,6802 \\
\hline $\mathrm{CTC}^{(7)}$ & $753,20475+(-32058 * \mathrm{H} 11)+(26746 * \mathrm{H} 12)+(-4921,96650 * \mathrm{H} 3)+(5686,79082 * \mathrm{H} 1)$ & 0,5358 \\
\hline
\end{tabular}

(1) $\mathrm{B} 1 \ldots . . \mathrm{B} 22 ; \mathrm{H} 1 \ldots \mathrm{H} 13$, bandas e alturas selecionadas

(3) Matéria Orgânica

(4) Soma de Bases

(5) Saturação por Bases

(6) Saturação por Alumínio

(7) Capacidade de Troca Catiônica 
Tabela 2. Avaliação entre os valores atribuídos dos solos determinados em laboratório e estimados por equações de regressão múltipla com sensor em laboratório com 22 bandas e 13 alturas, utilizando-se as 473 amostras que não participaram do modelo.

\begin{tabular}{|c|c|c|c|c|c|c|c|c|}
\hline & Areia & Silte & Argila & $\mathrm{MO}^{(\mathrm{I})}$ & $\mathrm{SB}^{(2)}$ & $\mathrm{CTC}^{(3)}$ & $\mathrm{V}^{(4)}$ & $\mathrm{m}^{(5)}$ \\
\hline & -------------- & -------- & -------- & ------ & -------. & $1^{-3}---$ & 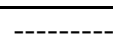 & ------ \\
\hline $\mathrm{VD}^{(6)}$ & $701,10 \mathrm{a}^{(8)}$ & $52,64 \mathrm{a}$ & $256,33 a$ & $13,26 \mathrm{a}$ & $223,23 a$ & $440,82 \mathrm{a}$ & $45,18 \mathrm{a}$ & 22,76 \\
\hline $\mathrm{VE}^{(7)}$ & $691,01 \mathrm{a}$ & $52,78 \mathrm{a}$ & $244,56 \mathrm{a}$ & $13,35 \mathrm{a}$ & $212,50 \mathrm{a}$ & $428,70 \mathrm{a}$ & $45,15 \mathrm{a}$ & 23,70 \\
\hline
\end{tabular}

(1) Matéria Orgânica

(2) Soma de Bases

(3) Capacidade de Troca Catiônica

(4) Satura ção por Bases

(5) Saturação por Alumínio

(6) Valor Determinado em análises de laboratório

(7) Valor Estimado pelas equações múltiplas utilizando 22 bandas e 13 alturas, radiometria de laboratório, sensor IRIS

${ }^{(8)}$ Student $t$ teste, a $1 \%$ de significância, onde as médias com as mesmas letras, na coluna, não diferem entre si 
Tabela 3. Resultados da comparação entre o intervalo de valores, mínimos e máximos, dos dados obtidos nas análises químicas e físicas, comparadas com os modelos de radiometria de laboratório.

\begin{tabular}{|c|c|c|c|c|c|c|c|c|}
\hline \multirow[b]{2}{*}{ Intervalo $^{(1)}$} & \multicolumn{2}{|c|}{ Areia } & \multicolumn{2}{|c|}{ Silte } & \multicolumn{2}{|c|}{ Argila } & \multicolumn{2}{|c|}{$\mathrm{MO}^{(6)}$} \\
\hline & \multicolumn{2}{|c|}{20,0} & \multicolumn{2}{|c|}{36,8} & \multicolumn{2}{|c|}{27,8} & \multicolumn{2}{|c|}{20,15} \\
\hline & Amostras $^{(2)}$ & $\%$ & Amostras & $\%$ & Amostras & $\%$ & Amostras & $\%$ \\
\hline Abaixo ${ }^{(3)}$ & 17 & 4 & 67 & 14 & 55 & 12 & 120 & 25 \\
\hline Dentro $^{(4)}$ & 396 & 84 & 245 & 52 & 351 & 74 & 163 & 34 \\
\hline \multirow[t]{4}{*}{$\operatorname{Acima}^{(5)}$} & 61 & 13 & 162 & 34 & 68 & 14 & 191 & 40 \\
\hline & \multicolumn{2}{|c|}{$\mathrm{SB}^{(7)}$} & \multicolumn{2}{|c|}{$\mathrm{V}^{(8)}$} & \multicolumn{2}{|c|}{$\mathrm{m}^{(9)}$} & \multicolumn{2}{|c|}{$\mathrm{CTC}^{(10)}$} \\
\hline & \multicolumn{2}{|c|}{28,34} & \multicolumn{2}{|c|}{4,08} & \multicolumn{2}{|c|}{31,80} & \multicolumn{2}{|c|}{24,54} \\
\hline & Amostras ${ }^{(2)}$ & $\%$ & Amostras & $\%$ & Amostras & $\%$ & Amostras & $\%$ \\
\hline Abaixo & 115 & 24 & 182 & 38 & 143 & 30 & 91 & 19 \\
\hline Dentro & 178 & 38 & 49 & 10 & 137 & 29 & 241 & 51 \\
\hline Acima & 181 & 38 & 243 & 51 & 194 & 41 & 142 & 30 \\
\hline
\end{tabular}

(1) Intervalo de confiança estimado em porcentagem, para análises de laboratório. Extraído do Programa de Controle de Qualidade de Laboratórios com o Sistema IAC de Análise de Solo, Segundo Cantarella \& Abreu (2000)

(2) Número de amostras, de um total de 473, para amostras abaixo, dentro e acima dos intervalos propostos

(3) Número de amostras abaixo do intervalo de confiança (Ex: Areia, amostra 102, Valor Determinado $=720 \mathrm{~g} \mathrm{~kg}^{-1}$; Valor mínimo $=571 \mathrm{~g} \mathrm{~kg}^{-1}$ intervalo de $20 \%$; Valor máximo $=869 \mathrm{~g} \mathrm{~kg}^{-1}$ intervalo de $20 \%$; Valor Estimado $=527 \mathrm{~g} \mathrm{~kg}^{-1}$ equação múltipla radiométrica)

(4) Número de amostras dentro do intervalo de confiança (Ex: Areia, amostra 454, Valor Determinado $=530 \mathrm{~g} \mathrm{~kg}^{-1}$; Valor mínimo $=420 \mathrm{~g} \mathrm{~kg}^{-1}$ intervalo de $20 \%$; Valor máximo $=640 \mathrm{~g} \mathrm{~kg}^{-1}$ intervalo de $20 \%$; Valor Estimado $=529 \mathrm{~g} \mathrm{~kg}^{-1}$ equação múltipla radiométrica)

(5) Número de amostras acima do intervalo de confiança (Ex: Areia, amostra 239, Valor Determinado $=270 \mathrm{~g} \mathrm{~kg}^{-1}$; Valor mínimo $=214 \mathrm{~g} \mathrm{~kg}^{-1}$ intervalo de $20 \%$; Valor máximo

$=326 \mathrm{~g} \mathrm{~kg}^{-1}$ intervalo de $20 \%$; Valor Estimado $=388 \mathrm{~g} \mathrm{~kg}^{-1}$ equação múltipla radiométrica)

(6) Matéria Orgânica

(7) Soma de Bases

${ }^{(8)}$ Saturação por Bases

${ }^{(9)}$ Saturação por Alumínio

(10) Capacidade de Troca Catiônica 
Tabela 4. Resultados da comparação dos valores relativos entre os valores de Laboratório (valor real) com os obtidos pela regressão múltipla para sensor em laboratório, de 474 amostras da área de estudo, para as 22 bandas e 13 alturas.

\begin{tabular}{|c|c|c|c|c|c|c|c|c|}
\hline & Areia & Silte & Argila & $\mathrm{MO}^{(1)}$ & $\mathrm{SB}^{(2)}$ & $\mathrm{CTC}^{(3)}$ & $\mathrm{V}^{(4)}$ & $m^{(5)}$ \\
\hline Intervalos de tolerância $^{(6)}$ & ------- & $-\cdots$ & - & ------- & ------- & ------- & ------- & $-\cdots---$ \\
\hline $0-20 \%$ & 83,5 & 29,2 & 59,8 & 35,5 & 25,4 & 41,2 & 38,5 & 24,6 \\
\hline $21-30 \%$ & 4,7 & 14,2 & 18,4 & 14,6 & 15,6 & 21,4 & 17,3 & 13,0 \\
\hline $31-40 \%$ & 1,1 & 10,6 & 9,1 & 13,5 & 9,7 & 12,5 & 11,8 & 11,6 \\
\hline$>41 \%$ & 10,8 & 46,1 & 12,7 & 36,4 & 49,3 & 24,9 & 32,3 & 50,7 \\
\hline Total (473 amostras) & 100,0 & 100,0 & 100,0 & 100,0 & 100,0 & 100,0 & 100,0 & 100,0 \\
\hline
\end{tabular}

(1) Matéria Orgânica

(2) Soma de Bases

(3) Capacidade de Troca Catiônica

(4) Saturação por Bases

(5) Saturação por Alumínio, o valor 0 vindos das análises de laboratório não foram considerados para efeito dos cálculos dos valores relativos (divisão por zero), sendo o conjunto de amostras nesse caso de 353.

(6) Determinado no prente trabalho, utilizando o seguinte citeis: Valor relativo = ((VD-VE)/VD)* 100 onde: VD; valor determinado em laboratório; VE; valor estimado na regressão múltipla. Calculado para cada amostra. 
Tabela 5. Correlação entre Y (Valor Determinado) e X (Valor Estimado) para os dados de laboratório e orbital da área de estudo.

\begin{tabular}{ccc}
\hline Atributo & Correlação & $\mathbf{r}^{2(1)}$ \\
\hline & Dados de Laboratório & \\
Areia & $\mathrm{Y}=0,8168 \mathrm{X}+134,89$ & 0,84 \\
Argila & $\mathrm{Y}=0,8099 \mathrm{X}+36,30$ & 0,83 \\
$\mathrm{MO}^{(2)}$ & $\mathrm{Y}=0,3986 \mathrm{X}+7,67$ & 0,41 \\
$\mathrm{SB}^{(3)}$ & $\mathrm{Y}=0,6459 \mathrm{X}+72,11$ & 0,65 \\
$\mathrm{CTC}^{(4)}$ & $\mathrm{Y}=0,6383 \mathrm{X}+139,52$ & 0,66 \\
& Dados Orbitais \\
Areia & $\mathrm{Y}=0,5818 \mathrm{X}+305,02$ & 0,72 \\
Argila & $\mathrm{Y}=0,5425 \mathrm{X}+104,04$ & 0,71 \\
MO $^{(2)}$ & $\mathrm{Y}=0,4839 \mathrm{X}+7,95$ & 0,35 \\
SB $^{(3)}$ & $\mathrm{Y}=0,5969 \mathrm{X}+116,14$ & 0,60 \\
$\mathrm{CTC}^{(4)}$ & $\mathrm{Y}=0,7940 \mathrm{X}+108,01$ & 0,59 \\
\hline${ }^{(1)}$ Coeficiente de correlação & & \\
${ }^{(2)}$ Matéria Orgânica & & \\
${ }^{(3)}$ Soma de Bases & & \\
${ }^{(4)}$ Capacidade de Troca Catiônica &
\end{tabular}


Tabela 6 . Equações de regressão múltipla para estimativa dos atributos dos solos da área de estudo utilizando-se 6 bandas do TM-Landsat-5.

\begin{tabular}{|c|c|c|}
\hline Atributo & Equação múltipla $^{(1)}$ & $\mathrm{r}^{2(2)}$ \\
\hline Areia total & $128,57173+(-14,26920 * \mathrm{TM} 3)+(13,13981 * \mathrm{TM} 5)+(26,11687 * \mathrm{TM} 7)$ & 0,6356 \\
\hline Silte & $205,73234+(4,47412 * \mathrm{TM} 3)+(-2,51728 * \mathrm{TM} 5)+(-8,37651 * \mathrm{TM} 7)$ & 0,5435 \\
\hline Argila & $699,99540+(-13,44352 * \mathrm{TM} 7)+(-12,69294 * \mathrm{TM} 5)+(13,03814 * \mathrm{TM} 2)$ & 0,6140 \\
\hline $\mathrm{MO}^{(3)}$ & $32,93323+(1,03425 * \mathrm{TM} 1)+(-1,21937 * \mathrm{TM} 7)$ & 0,41 \\
\hline $\mathrm{SB}^{(4)}$ & $794,50072+(-31,18313 *$ TM7) & 0,3466 \\
\hline $\mathrm{V}^{(5)}$ & $58,97640+(-2,19535 * \mathrm{TM} 1)$ & 0,013 \\
\hline $\mathrm{m}^{(6)}$ & $-9,25324+(0,69115 * \mathrm{TM} 4)+(0,27464 * \mathrm{TM} 7)$ & 0,1374 \\
\hline $\mathrm{CTC}^{(7)}$ & $1348,94022+(-50,85760 *$ TM7) & 0,4595 \\
\hline \multicolumn{3}{|c|}{$\begin{array}{l}\text { (1) TM1, TM2, TM3, TM4, TM5 e TM7, Bandas do TM-Landsat-5 } \\
\text { (2) Significante a 0,01 \% de probabilidade } \\
\text { (3) Matéria Orgânica } \\
\text { (4) Soma de Bases } \\
\text { (5) Saturação por Bases } \\
\text { (5) Saturação por Alumínio } \\
\text { (7) Capacidade de Troca Catiônica }\end{array}$} \\
\hline
\end{tabular}


Tabela 7. Avaliação entre os valores atribuídos dos solos determinados em laboratório e estimados através das equações de regressão múltiph com 6 bandas do TM-Landsat-5, utilizando-se as 473 amostras que não participaram do modelo.

\begin{tabular}{|c|c|c|c|c|c|c|c|c|}
\hline & Areia & Silte & Argila & $\mathrm{MO}$ & $\mathrm{SB}^{(2)}$ & $\mathrm{CTC}^{(3)}$ & $\mathrm{V}^{(4)}$ & $\mathrm{m}^{(5)}$ \\
\hline & \multicolumn{4}{|c|}{ 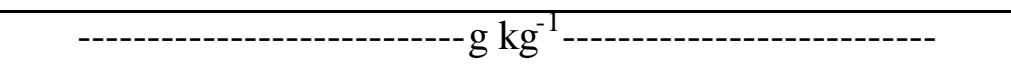 } & \multicolumn{2}{|c|}{--------mmol $\mathrm{dm}^{-3}-------$} & \multicolumn{2}{|c|}{------------ \%----------- } \\
\hline $\mathrm{VD}^{(6)}$ & $712,99 a^{(8)}$ & $64,18 \mathrm{a}$ & $222,82 \mathrm{a}$ & $15,24 \mathrm{a}$ & $279,74 \mathrm{a}$ & $517,14 \mathrm{a}$ & $51,40 \mathrm{a}$ & $8,16 \mathrm{a}$ \\
\hline $\mathrm{VE}^{(7)}$ & $715,48 \mathrm{a}$ & $63,84 a$ & $220,68 a$ & $14,98 \mathrm{a}$ & $281,16 a$ & $511,72 \mathrm{a}$ & $54,47 b$ & $6,85 b$ \\
\hline
\end{tabular}

(1) Matéria Orgânica

(2) Soma de Bases

(3) Capacidade de Troca Catiônica

(4) Saturação por Bases

(5) Saturação por Alumínio

(6) Valor Determinado em análises de laboratório

(7) Valor Estimado pelas equações múltiplas utilizando 6 bandas do TM-Landsat-5

${ }^{(8)}$ Student $t$ teste, a $1 \%$ de significância, onde as médias com as mesmas letras, na coluna, não diferem entre si. 
Tabela 8. Resultados da comparação entre o intervalo de valores, mínimos e máximos, dos dados obtidos nas análises químicas e físicas, comparadas com os modelos de radiometria do TM-Landsat-5.

\begin{tabular}{|c|c|c|c|c|c|c|c|c|}
\hline \multirow{3}{*}{ Intervalo $^{(1)}$} & \multicolumn{2}{|c|}{ Areia } & \multicolumn{2}{|c|}{ Silte } & \multicolumn{2}{|c|}{ Argila } & \multicolumn{2}{|c|}{$\mathrm{MO}^{(6)}$} \\
\hline & \multicolumn{2}{|c|}{20,00} & \multicolumn{2}{|c|}{36,80} & \multicolumn{2}{|c|}{27,83} & \multicolumn{2}{|c|}{20,15} \\
\hline & Amostras ${ }^{(2)}$ & $\%$ & Amostras & $\%$ & Amostras & $\%$ & Amostras & $\%$ \\
\hline Abaixo $^{(3)}$ & 19 & 8 & 41 & 18 & 44 & 19 & 56 & 25 \\
\hline Dentro ${ }^{(4)}$ & 175 & 77 & 108 & 48 & 112 & 49 & 102 & 45 \\
\hline \multirow[t]{4}{*}{$\operatorname{Acima}^{(5)}$} & 33 & 15 & 78 & 34 & 71 & 31 & 69 & 30 \\
\hline & \multicolumn{2}{|c|}{$\mathrm{SB}^{(7)}$} & \multicolumn{2}{|c|}{$\mathrm{V} \%^{(8)}$} & \multicolumn{2}{|c|}{$\mathrm{m} \%{ }^{(9)}$} & \multicolumn{2}{|c|}{$\mathrm{CTC}^{(10)}$} \\
\hline & \multicolumn{2}{|c|}{28,34} & \multicolumn{2}{|c|}{4,08} & \multicolumn{2}{|c|}{31,80} & \multicolumn{2}{|c|}{24,54} \\
\hline & Amostras & $\%$ & Amostras & $\%$ & Amostras & $\%$ & Amostras & $\%$ \\
\hline Abaixo & 29 & 13 & 75 & 33 & 83 & 37 & 39 & 17 \\
\hline Dentro & 113 & 50 & 18 & 8 & 53 & 23 & 120 & 53 \\
\hline Acima & 85 & 37 & 134 & 59 & 91 & 40 & 68 & 30 \\
\hline
\end{tabular}

(1) Intervalo de confiança estimado em porcentagem, para analises de laboratório. Extraído do Programa de Controle de Qualidade de Laboratórios com o Sistema IAC de Análise de Solo, Segundo Cantarella \& Abreu (2000)

${ }^{(2)}$ Número de amostras, de um total de 474, para amostras abaixo, dentro e acima dos intervalos propostos

(3) Número de amostras abaixo do intervalo de confiança (Ex: Areia, amostra 102, Valor Determinado $=720 \mathrm{~g} \mathrm{~kg}^{-1} ; \mathrm{Valor}$ mínimo $=571 \mathrm{~g} \mathrm{~kg}^{-1}$ intervalo de $20 \%$;

Valor máximo $=869 \mathrm{~g} \mathrm{~kg}^{-1}$ intervalo de $20 \%$; Valor Estimado $=527 \mathrm{~g} \mathrm{~kg}^{-1}$ equação múltipla radiométrica)

(4) Número de amostras dentro do intervalo de confiança (Ex: Areia, amostra 454, Valor Determinado $=530 \mathrm{~g} \mathrm{~kg}^{-1} ; \mathrm{Valor}^{-1}$ mímo $^{-1} 420 \mathrm{~g} \mathrm{~kg}^{-1}$ intervalo de $20 \%$;

Valor máximo $=640 \mathrm{~g} \mathrm{~kg}^{-1}$ intervalo de $20 \%$; Valor Estimado $=529 \mathrm{~g} \mathrm{~kg}^{-1}$ equação múltipla radiométrica)

${ }^{(5)}$ Número de amostras acima do intervalo de confiança (Ex: Areia, amostra 239, Valor Determinado $=270 \mathrm{~g} \mathrm{~kg}^{-1} ; \mathrm{Valor}^{\mathrm{mínimo}}=214 \mathrm{~g} \mathrm{~kg}^{-1}$ intervalo de $20 \%$;

Valor máximo $=326 \mathrm{~g} \mathrm{~kg}^{-1}$ intervalo de $20 \%$; Valor Estimado $=388 \mathrm{~g} \mathrm{~kg}^{-1}$ equação múltipla radiométrica)

(6) Matéria Orgânica

(7) Soma de Bases

(8) Saturação por Bases

(9) Saturação por Alumínio

(10) Capacidade de Troca Catiônica 
Tabela 9 . Resultados da comparação dos valores relativos entre os valores de Laboratório (valor real) com os obtidos pela regressão múltipla, de 227 amostras da área de estudo, para as 6 bandas do TM-Landsat-5.

\begin{tabular}{|c|c|c|c|c|c|c|c|c|}
\hline & Areia & Silte & Argila & $\mathrm{MO}^{(1)}$ & $\mathrm{SB}^{(2)}$ & $\mathrm{CTC}^{(3)}$ & $\mathrm{V} \%{ }^{(4)}$ & $\mathrm{m} \%{ }^{(5)}$ \\
\hline Intervalos de tolerância $^{(6)}$ & $---\cdot$ & 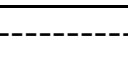 & 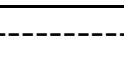 & --- & $\%--$ & 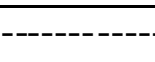 & $-\cdots$ & 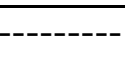 \\
\hline $0-20 \%$ & 76,7 & 26,0 & 39,6 & 44,9 & 37,4 & 44,1 & 40,5 & 13,6 \\
\hline $21-30 \%$ & 7,9 & 15,0 & 13,7 & 18,1 & 14,1 & 17,6 & 18,9 & 16,7 \\
\hline $31-40 \%$ & 2,6 & 10,6 & 16,3 & 11,5 & 9,3 & 13,2 & 14,1 & 10,5 \\
\hline$>41 \%$ & 12,8 & 48,5 & 30,4 & 25,6 & 39,2 & 25,1 & 26,4 & 59,3 \\
\hline Total (227 amostras) & 100,0 & 100,0 & 100,0 & 100,0 & 100,0 & 100,0 & 100,0 & 100,0 \\
\hline
\end{tabular}

(1) Matéria Orgânica

(2) Soma de Bases

${ }^{(3)}$ Capacidade de Troca Catiônica

${ }^{(4)}$ Saturação por Bases

${ }^{(5)}$ Saturação por Alumínio, o valor 0 vindo das análises de laboratório não foram considerados para efeito dos cálculos dos valores relativos (divisão por zero), sendo o conjunto de amostras nesse caso de 162

(6) Determinado no presente trabalho, utilizando o seguinte critério: Valor relativo $=((\mathrm{VD}-\mathrm{VE}) / \mathrm{VD})^{*} 100$ onde: VD; valor determinado em laboratório; VE; valor estimado na regressão múltipla. Calculado para cada amostra 


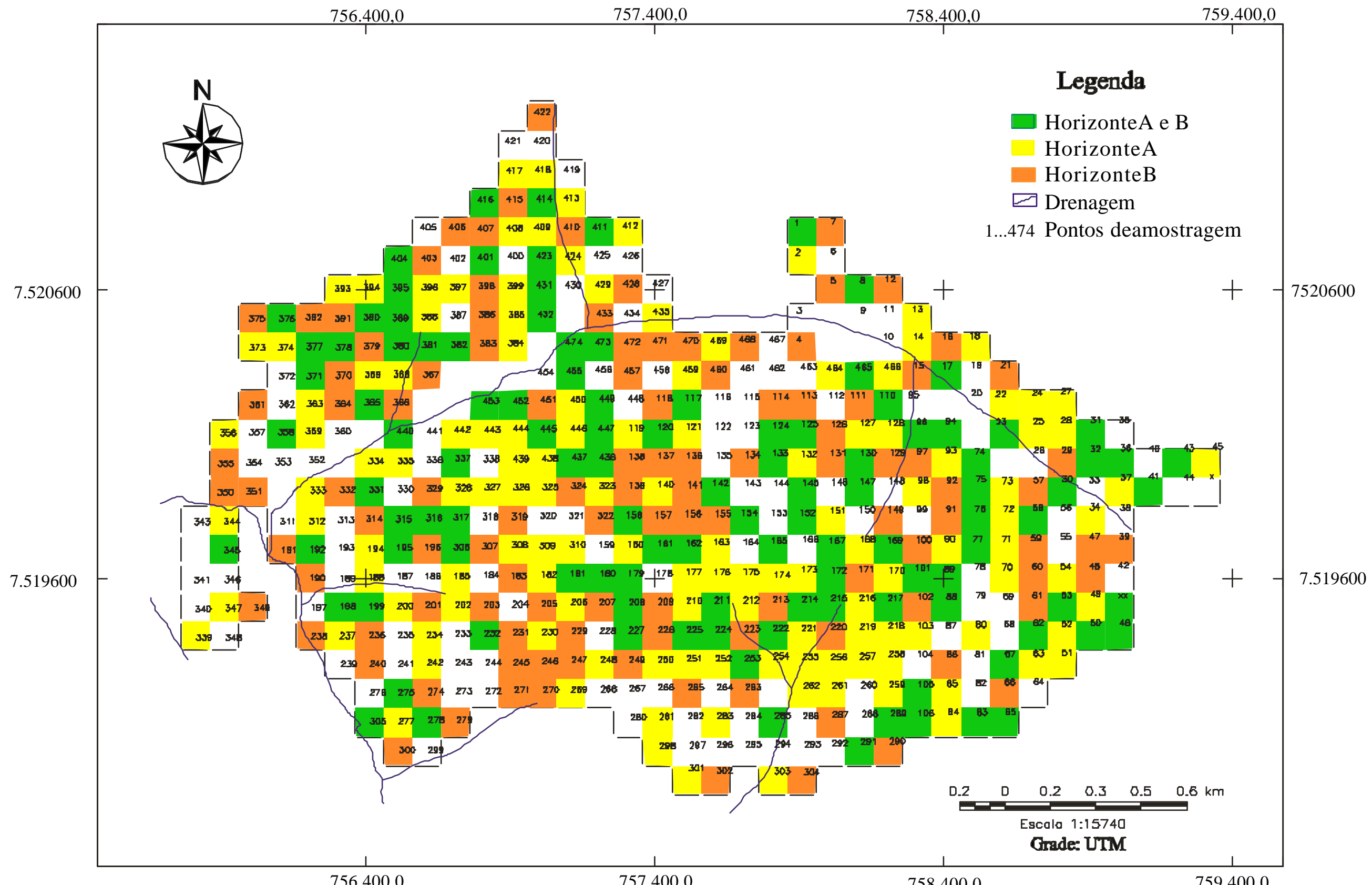

Figura 1- Representação da distribuição dos 473 pontos de coleta, totalizando 948 amostras de solo, coletadas em grade de $100 \mathrm{X} 100 \mathrm{~m}$, da área de estudo, bem como os pontos selecionadados para gerar os modelos dos atributos químicos e físicos. Onde: Verde: pontos de coletas onde as amostras das camadas A e B foram selecionadas para gerar os modelos: Amarelo: amostras do horizonte A selecionadas para gerar os modelos; Laranja: amostras do horizonte B selecionadas para gerar os modelos. 


\section{CONCLUSÕES GERAIS}

1- A comparação do mapas detalhado "tradicional" e detalhado por textura, com o mapa semidetalhado evidenciou a grande necessidade de levantamentos de solos em escalas maiores. O mapa semidetalhado diferiu, na comparação das unidades de mapeamento, em $56 \%$ com o mapa detalhado " tradicional" e $65 \%$ com o mapa detalhado por textura. As unidades de solos com maiores riscos de erosão não foram detectadas no levantamento semidetalhado.

2- Ao longo das topossequências, foi possível verificar mudanças nas curvas espectrais, nos três níveis de obtenção de dados, as quais auxiliaram na determinação dos pontos de ruptura dos limites das unidades de solo. As curvas espectrais de laboratório e de campo apresentaram maiores diferenciações entre os solos. As curvas espectrais orbitais separaram solos com o mesmo material de origem em arenosos e argilosos.

3- Foi possível de se discriminar as unidades de solos por meio de sensoriamento remoto em laboratório e orbital. Sendo que as equações de laboratório obtiveram um acerto de $81 \%$ e $40 \%$ para as equações orbitais. Os dados orbitais apesar do menor acerto, mostraram-se eficientes em separar os solos pelo material de origem (arenoso e argiloso).

4- A metodologia utilizada mostrourse de grande valia na quantificação de atributos do solo, podendo auxiliar no refinamento das unidades de mapeamento. Obtendo-se 
bons resultados na quantificação dos teores de $\mathrm{Fe}_{2} \mathrm{O}_{3}$ e argila, nos intervalos propostos na classificação dos solos.

5- Foi possível utilizando-se de dados espectrais de laboratório e orbital, quantificar atributo de solo, sendo os melhores resultados obtidos para areia e argila. 


\section{REFERÊNCIAS BIBLIOGRÁFICAS}

AGBU, P. A.; FEHRENBACHER, D.; JANSEN, I. J. Soil property relationships with SPOT satellite digital data in east central Illinois. Soil Science Society of America Journal, v.54, p.807-812, 1990.

ANDRONIKOV, V.L.; DOBROLVSKIY, G.V. Theory and methods for the use of remote sensing in the study of soils. Mapping Sciences \& Remote Sensing, v.28, n.2, p.92-101, 1991.

BAPTISTA, G. M. M. Mapeamento e quantificação da relação mineralógica caulinita/(caulinita+gibbsita) de solos tropicais, por meio dos dados do sensor hiperespectral AVIRIS (JPL/NASA). Brasília, 2001. 139 p. Tese (Doutorado) Universidade de Brasília.

BAPTISTA, G. M. M.; MADEIRA NETO, J. S.; CARVALHO JUNIOR, O. A.; MARTINS, E. S. Mapeamento dos teores de argila de solos tropicais, por meio de dados de sensoriamento remoto hiperespctral (compact disc). In: CONGRESSO BRASILEIRO DE CIÊNCIA DO SOLO, 2, Brasília, 1999. Brasília, 1999

BARET, F.; JACQUEMOUND, S.; HANOCQ, J. F. The soil line concept in remote sensing. Remote Sensing of Environment, v.7, n.1, p.1-18, 1993. 
BAUMGARDNER, M. F.; KRISTOF, S. J.; JOHANNSEN, C. J.; ZACHARY, A. L. Effects of organic matter on the multiespectral properties of soils. Proceedings of the Indiana Academy of Science, v.79, p.413-422, 1970.

BAUMGARDNER, M. F.; STONER, E. R. Soil mineralogical studies by remote sensing. In: INTERNATIONAL CONGRESS OF SOIL SCIENCE, 12., New Delhi 1982. Proceedings. New Delhi, ISSS, 1982. p.419-441.

BAUMGARDNER, M.F.; SILVA, L.F.; BIEHL, L.L.; STONER, E.R. Reflectance properties of soils. Advances in Agronomy, v.38, p.1-44, 1985.

BEN-DOR, E. Quantitative remote sensing of soil properties. Advances in Agronomy, v.75, p.173-243, 2002.

BEN-DOR, E.; BANIN, A. Near-Infrared reflectance analysis of carbonate concentration in soils. Applied Spectroscopy, v.44, n.6, p.1064-1069, 1990.

BEN-DOR, E.; BANIN, A. Near-Infrared analysis (NIRA) as a rapid method to simultaneously evaluate several soil properties. Soil Science Society of America Journal, v.59, p.364-372, 1995.

BEN-DOR, E.; BANIN, A. Near-Infrared analysis (NIRA) as a rapid method to simultaneously evaluate several soil properties. Soil Science Society of America Journal, v. 59, p.364-372, 1995a.

BEN-DOR, E.; BANIN, A. Near-Infrared analysis as a simultaneously method to evaluate spectral featureless constituents in soils. Soil Science, v.159, p.259-269, $1995 \mathrm{~b}$. 
BEN-DOR, E.; INBAR, Y.; CHEN, Y. The reflectance spectra of organic matter in the visible near infrared and short wave infrared region (400-2500 nm) during a control decomposition process. Remote Sensing of Environment, v.61, p.1-15, 1997.

BEN-DOR, E.; IRONS, J.R.; EPEMA, G.F. Soil reflectance. In: ANDREW N. R. (Ed.), Remote sensing for the earth sciences: manual of remote sensing, 3. ed. Danvers: John Wiley, 1999. v.3, p. 111-188.

BEN-GERA, I.; NORRIS, K. Determination of moisture content in soybeans by direct spetrophotometry. Israeli Journal of Agricultural Research, v.18, p.124-132, 1968.

BERG, M. van den; KLAMT, E. Variabilidade espacial de características de solos na região do planalto médio, RS:I. Análise da variância por amostragem aninhada. Revista Brasileira de Ciência do Solo, v. 21, p. 393-399,1997a.

BERG, M. van den; KLAMT, E. Variabilidade espacial de características de solos na região do planalto médio, RS:II. Análise da semivariância da variância. Revista Brasileira de Ciência do Solo, v. 21, p. 401-408, 1997 b.

BERG, M. van den; OLIVEIRA, J. B. Variability of apparently homogeneous soils capes in São Paulo State, Brazil: I. Spatial Analysis. Revista Brasileira de Ciência do Solo, v. 24, n.2, p. 377-391, 2000.

BISWAS, R. R.; SINGH, C. P. Capability of TM data for evaluation of soil an land resources in the Malwa Plateau (Chambal and Mahi catchment) in Madhya Pradesh, India. International Journal of Remote Sensing, v.12, n.9, p.1905-1913, 1991. 
BORGES, M. H.; PFEIFER, R. M.; DEMATTÊ, J. A. M. Evolução e mapeamento do uso da terra, através de imagens aerofotogramétricas e orbitais em Santa Bárbara D'Oeste (SP). Scientia Ag ricola, v.50, n.3, p.365-371, 1993.

BOUMA, J. Using soil survey data for quantitative land evaluation. Advances in Soil Science, v.9, p.177-213, 1989.

BOWERS, S. A.; HANKS, R. J. Reflection of radiant energy from soils. Soil Science, v.100, n.2, p.130-138, 1965.

BRASIL. Ministério da Agricultura. Centro Nacional de Ensino e Pesquisa Agronômica. Comissão de Solos. Levantamento de reconhecimento de solos do Estado de São Paulo. Rio de Janeiro, 1960. 634 p. (SNPA. Boletim, 12).

BURROUGH, P. A. Soil variability: a late $20^{\text {th }}$ century view. Soils and Fertility, v.56, p.529-562, 1993.

CAMARGO, M. N.; KLANT, E.; KAUFFMAN, J. H. Classificação de solos usada em levantamentos pedológicos no Brasil. Campinas. Boletim Informativo da Sociedade Brasileira de Ciência do Solo, v.12. n.1, p.11-13, jan./abr. 1987.

CAMPOS, R. C. Determinação da cor do solo e sua utilização na estimativa dos teores de hematita. Piracicaba, 2002. 59 p. Dissertação (Mestrado) - Escola Superior de Agricultura "Luiz de Queiroz", Universidade de São Paulo.

CANTARELlA, H.; ABREU, C. A. Avaliação do desempenho dos laboratórios no ano de 2000. In: REUNIÃO ANUAL DO PROGRAMA DE CONTROLE DE QUALIDADE DE LABORATÓRIOS COM O SISTEMA IAC DE ANÁLISE DE SOLO, 16., Campinas, 2001. Campinas: IAC, 2001. p.1-65.

CAREY, J. Tilling the soil by satellite. Business Week, v.11, p.62-63, 1995. 
CIPRA, J. E.; BAUMGARDNER, M. F.; STONER, E. R.; MACDONALD, R. B. Measuring radiance characteristics of soil with a field spectroradiometer. Soil Science Society of America Proceedings, v.35, p.1014-1017, 1971.

CIPRA, J. E.; FRANZMEIER, M. E.; BAUER, M. E.; BOYD, R. K. Comparison of multispectral measurements from some nonvegetative soils using Landsat digital data and a spectroradiometer. Soil Science Society of America Journal, v.44, p.80-84, 1980.

CLARK, R.N.; ROUSH, T.L. Reflectance spectroscopy: Quantitative analysis techniques for remote sensing applications. Journal of Geophysics Research, v.89, p.6329-6340, 1984.

COLEMAN, T. L.; MONTGOMERY, O. L. Soil moisture, organic matter and iron content effect on the espectral characteristics of selected Vertisols and Alfisols in Alabama. Photogrammetric Engineering \& Remote Sensing, v.53, p.1659-1663, 1987.

COLEMAN, T. L.; MONTGOMERY, O. L. Assessment of spectral characteristics for differentiating among soil categories in the southeastern united States. Photogrammetric Engineering \& Remote Sensing, v.52, p.1659-1663, 1990.

COLEMAN, T. L.; AGBU, P. A.; MONTGOMERY, O. L. Spectral differentiantion of soils and soil properties: is it possible from space plataforms?. Soil Science, v.155, p.283-293, 1993.

COLEMAN, T. L.; AGBU, P. A.; MONTGOMERY, O. L.; GAO, T.; PRASAD, S. Spectral band selection for quantifying selected properties in highly weathered soils. Soil Science, v.151, n.5, p.355-361, 1991. 
CONDIT, H. R. The spectral reflectance of american soils. Photogrammetric Engineering, v.36, n.9, p.955-968, 1970.

COURAULT, D.; GIRARD, M.C. Relationships between the soil composition and their spectral signature. In: SYMPOSIUM OF THE WORKING GROUP REMOTE SENSING, 5., Budapest, 1988. Proceedings. Budapest, 1988. p. 178-185.

CRÓSTA, A. P. Processamento digital de imagens de sensoriamento remoto. Campinas : UNICAMP, 1992. $170 \mathrm{p}$.

CSILlIAG, F.; PASZTOR, L.; BIEHL, L.L. Spectral band selection for the characterization of salinity status of soils. Remote Sensing of Environment, v.43, p.231-242, 1993.

DALMOLIN, R.S.D. Faltam pedólogos no Brasil. Boletim Informativo da Sociedade Brasileira de Ciência do Solo, v.24, n.4, p.13-15, out./dez.,1999.

DAVIS, P.A.; BERLIN, G.L.; CHAVEZ JR., P.S. Discrimination of altered basaltic rocks in the southwestern United States by analysis of LANDSAT Thematic Mapper data. Photogrammetric Engineering \& Remote Sensing, v.53, n.1, p.45-55, 1987.

DEMATTÊ, J. A. M. Relações entre dados espectrais e características físicas, químicas e mineralógicas de solos desenvolvidos de rochas eruptivas. Piracicaba, 1995. 265 p. Tese (Doutorado) - Escola Superior de Agricultura "Luiz de Queiroz", Universidade de São Paulo.

DEMATTÊ, J. A. M. Reflectância espectral de solos. Piracicaba, 1999. 452p. Tese (Livre Docência) - Escola Superior de Agricultura “Luiz de Queiroz”, Universidade de São Paulo. 
DEMATTÊ, J.A. M. O pedólogo e agricultura de precisão. Boletim Informativo da Sociedade Brasileira de Ciência do Solo, v.26, n.1 , p.17-19, jan./mar, 2001.

DEMATTÊ, J.A.M.; GARCIA, G.J. Alteration of soil properties through a weathering sequence as evaluated by spectral reflectance. Soil Science Society of America Journal, v.63, n.2, p. 327-342, 1999.

DEMATTÊ, J.A.M.; GARCIA, G.J. Alteration of soil properties through a weathering sequence as evaluated by spectral reflectance. Soil Science Society of America Journal, v.63, n.2, p. 327-342, 1999a.

DEMATTÊ, J.A.M.; GARCIA, G.J. Avaliação de atributos de Latossolo Bruno e de Terra Bruna Estruturada da região de Guarapuava, Paraná, por meio de sua energia refletida Revista Brasileira de Ciência do Solo, v.23, p.343-355, 1999 b.

DEMATTÊ, J.A.M.; CAMPOS, R.C.; ALVES, M.C. Evaluation of soil Survey by spectral reflectance. In: INTERNATIONAL CONFERENCE ON APPLIED GEOLOGIC REMOTE SENSING, 13, Vancouver:1999, Proceedings. British Columbia, Canada : Erim, 1999. v.2, p.126-133.

DEMATTÊ, J. A. M.; MAFRA, A. L.; BERNARDES, F. F. Comportamento espectral de materiais de solos e de estruturas biogênicas associadas. Revista Brasileira de Ciência do Solo. v.22, p.621-630, 1998c.

DEMATTÊ, J. A. M.; SOUSA, A. A.; NANNI, M. R. Avaliação espectral de amostras de solo e argilo-minerais em função de diferentes níveis de hidratação (Compact Disc). In: SIMPÓSIO BRASILEIRO DE SENSORIAMENTO REMOTO, 9., Santos, 1998. Anais. Santos: INPE/SELPER, 1998a. 
DEMATTÊ, J.A. M.; COOPER, M.; MAULE, R. F.; FIORIO, P. R. Caracterization des sols dans une toposéquence sun diabase atravers la réflectance spectrale. (compact disc) In: CONGRES MONDIAL DE SCIENCE DU SOL, Montpellier, France, 1998b.

DEMATTÊ, J.A. M.; COOPER, M.; MAULE, R. F.; FIORIO, P. R. Caracterization des sols dans une toposéquence sun diabase atravers la réflectance spectrale. (compact disc) In: CONGRES MONDIAL DE SCIENCE DU SOL, Montpellier, France, 1998.

DEMATTÊ, J. A. M.; CAMPOS, R. C.; NANNI, M. R.; FIORIO, P. R.; ALVES, M. C. Modelagem de dados espectrias visando a quantificação de atributos do solo (compact disc). In: AVANÇOS NA AGRICULTURA DE PRECISÃO NO BRASIL NO PERÍODO DE 1999-2001. Piracicaba, São Paulo, Março, 2001.

DEMATTÊ, J. A. M.; DEMATTÊ, J. L. I.; CAMARGO, W. P.; FIORIO, P. R.; NANNI, M. R. Remoto sensing in the recognition and mapping of tropical soils developed on topographic sequences. Mapping Sciences \& Remote Sensing, v.38, p.79-102, 2001.

DEMATTÊ, J.A.M.; HUETE A.R.; FERREIRA Jr. L.G.; ALVES M.C.; NANNI M.R.; CERRI C.E. Evaluation of tropical soils through ground and orbital sensors. In: INTERNATIONAL CONFERENCEM OF GEOSPATIAL INFORMATION IN AGRICUltURE AND FORESTRY, 2. Lake Buena Vista, 2000. Proceedings. Lake Buena Vista: Erim, 2000. v.2, p. 34-41.

DEMATTÊ, J.L.I. A pedologia direcionada ao manejo de solos. Boletim Informativo da Sociedade Brasileira de Ciência do Solo, v.24, n.4, p.16-17, out.dez 1999. 
DEMATTÊ, J.L.I.; MARCONI, A. A drenagem na mineralogia de solos desenvolvidos de diabásio em Piracicaba (SP). Revista Brasileira de Ciência do Solo, v.15, p.1-8, 1991.

DENT, D.; YONG, A. Soil survey and land evaluation London: G. Allen \& Unwin, 1981. 278p.

DONZELI, P. L.; VALÉRIO FILHO, M.; NOGUEIRA F. P.; PEREZ FILHO, A.;

KOFFLER, N. F. Imagens orbitais e de radar na definição de padrões fisiográficos aplicados a solos. Revista Brasileira de Ciência do Solo, v.7, p.8994, 1983.

DRURY, S.A.; HUNT, G.A. Remote sensing of laterized Archaean Greenstone terrain: Marshall Pool Area, Northeastern Yilgarn Block, Western Australia. Photogrammetric Engineering \& Remote Sensing, v.54, n.12, p.1717-1725, Dec. 1988.

DWIVEDI, R. S. The utility of data from various airborne sensors for soil mapping. International Journal of Remote Sensing, v.6, n.1, p.89-100, 1985.

EMPRESA BRASILEIRA DE PESQUISA AGROPECUÁRIA. Centro Nacional de Pesquisa de Solos. Manual de métodos de análise de solo. 2.ed. Rio de Janeiro: Serviço de Produção, 1997. 212 p.

EMPRESA BRASILEIRA DE PESQUISA AGROPECUÁRIA. Centro Nacional de Pesquisa de Solos. Sistema brasileiro de classificação de solos. Brasília: Serviço de Produção. 1999. 412 p. 
EMPRESA BRASILEIRA DE PESQUISA AGROPECUÁRIA. Serviço Nacional de Levantamento e Conservação de Solo. Procedimentos normativos de levantamentos pedológicos: normas em uso pelo SNLCS. Brasília: EMBRAPA, SPI, 1989, 101p.

EMPRESA BRASILEIRA DE PESQUISA AGROPECUÁRIA. Serviço Nacional de Levantamento e Conservação de Solo. Procedimentos normativos de levantamentos pedológicos: normas em uso pelo SNLCS. Brasília: EMBRAPA, SPI, 1995, p.101.

EPEMEA, G.F. Multitemporal analysis of Thematic Mapper data for soil survey in

Southeastern Tunisia. In: SYMPOSIUM ON REMOTE SENSING FOR RESOURCES DEVELOPMENT AND ENVIRONMENTAL MANAGEMENT, Enchede, 1986. Proceedings. Enchede: Vestappen, 1986. v.1, p.245-249.

EPIPHANIO, J. C. N.; FORMAGGIO, A. R. Abordagens de uso de número digital e de reflectância em sensoriamento remoto com dados de satélites. In: SIMPÓSIO BRASILEIRO DE SENSORIAMENTO REMOTO, 5., Natal, 1988. Anais. São José do Campos : INPE, 1988. p.400-405.

EPIPHANIO, J. C. N.; FORMAGGIO, A. R. Estudo de umidade do solo através de dados de reflectância. In: SIMPÓSIO BRASILEIRO DE SENSORIAMENTO REMOTO, 6., Manaus, 1990. Anais. São José dos Campos : INPE, SBC, 1990. p.269- 285 .

EPIPHANIO, J. C. N.; FORMAGGIO, A. R.; VALERIANO, M.; OLIVEIRA, J. B. Comportamento espectral de solos do Estado de São Paulo. São José dos Campos: INPE, 1992.131p. 
ESTADOS UNIDOS. Department of Agriculture. Soil Survey Division. Soil Conservation Sevice. Soil Survey Staff. Soil taxonomy: a basic system of soil classification for making and interpreting soil survey. Washington, 1975. 754 p. (USDA. Soil Conservation Service, 18).

ESTADOS UNIDOS. Department of Agriculture. Soil Survey Division. Soil Conservation Sevice. Soil Survey Staff. Keys to soil taxonomy. 6. ed. Washington, 1994. $306 \mathrm{p}$.

FEDCHENKO, P. P.; KONDRATYEV, K. Y.; VASMYEV, O. B. An experirnent in soil mapping from soil reflection spectra., In: SHAHROKHI, F.; TULLAHO, T. M. (Ed.) Remote sensing of earth resources. Tenessee: Technical papers, 1976, p. 453-460.

FIORIO, P. R.; DEMATTÊ, J. A. M.; SPAROVEK, G. Cronologia do uso da terra e seu impacto ambiental na microbacia hidrográfica do Córrego do Ceveiro, Piracicaba (SP). Pesquisa Agropecuária Brasileira, v.35, n.4, p.671-679, abr. 2000.

FIORIO, P. R.; DEMATTÊ, J. A. M.; MÉlEM JUNIOR, N. J.; MAZZA, J. A. Potencialidade do uso da terra na microbacia hidrográfica do Córrego do Ceveiro na região de Piracicaba. Scientia Agricola, v. 56, n.4, p. 1273-1280, out./dez. 1999.

FORMAGGIO, A.R. Comportamento espectral de quatro solos do Estado de São Paulo nos níveis orbital, de campo e de laboratório. São José dos Campos, 1983. 90p. Dissertação (Mestrado) - Instituto Nacional de Pesquisas Espaciais.

FORMAGGIO, A. R.; EPIPHANIO, J. C. N.; VALERIANO, M. M.; OLIVEIRA, J. B. Comportamento espectral $(450-2.450 \mathrm{~nm})$ de solos tropicais de São Paulo. Revista Brasileira de Ciência do Solo, v.20, p.467-474, 1996. 
FRAISSE, C.W. Agricultura de precisão: a tecnologia de GIS/GPS chega às fazendas. www.fatorgis.com.br. (ago., 1998).

FRANÇA, G. V.; DEMATTÊ, J. A. M. Levantamento de solos e interpretação fotográfica dos padrões desenvolvidos em solos originados do arenito de bauru. Scientia Agricola, v. 50, n.1, p. 77-86, 1993.

FRASIER, S. J. Discrimination and identification of iron oxides using satellite thematic Mapper data: A Newman case study. International Journal of Remote Sensing, v.12, p.635-641, 1991.

FRAZIER, B. E.; CHENG, Y. Remote sensing of soils in the eastern Palouse region with Landsat Thematic Mapper. Remote Sensing of Environment, v.28, p.317$325,1989$.

GALVÃO, L. S.; VITORELLO, I. Variability of laboratory measured soil lines of soil from southeastern Brazil. Remote Sensing of Environment, v.6, n.2, p.166-181, 1998.

GALVÃO, L. S.; PIZZARO, M. A.; EPIPHANIO, J.C.N. Variations in reflectance of tropical soils: spectral-chemical composition relationships from AVIRIS data. Remote Sensing of Environment, v.75, p.245-255, 2001.

GALVÃO, L. S.; VITORELlO, I.; FORMAGGIO, A.R. Relationships of spectral reflectance and color among surface and subsurface horizons of tropical soil profiles. Remote Sensing of Environment, New York, v.61, p. 24-33, 1997.

GEOPHYSICAL ENVIRONMENTAL RESEARCH. Mark V Dual Field of View IRIS Manual: version 1.3. Milbook. New York, 1996. 63 p. 
GERBERMANN, A. H.; NEHER, D. D. Reflectance of varying mixtures of a clay soil and sand. Photogrammetric Engineering \& Remote Sensing, v.45, n.8, p.1145$1151,1979$.

GERRARD, A.J. Soils and landforms. London: George Allen \& Unwin, 1981. 219 p.

GOETZ, A.F.H. Principles of narrow band spectrometry in the visible and IR: Instruments and data analysis. In: TOSELLI, F; BODECHTEL, J. (Ed.) Imaging spectroscopy: fundamentals and prospective applications. Bxussels/Luxembourg: Chairman, 1992. p. 21-31.

GOOSEN, D. Interpretacion de fotos aereas y su importancia en levantamiento de suelos. Roma : FAO, 1968. 55 p. (FAO. Boletin sobre Suelos, 6).

GROVE, C. I.; HOOK, S. J.; TAYLOR, E. D. Laboratory reflectance spectra of 160 minerais, 0.4 to 2.5 micrometers. Passadena: National Aeronautics and Space Administration, 1992. 355p.

GUYOT, G.; GU, X.F.; WEISS, M; BARET, F. Du signal satellitaire à la reflectance au sol: pròblemes direct et inverse. Photo Interpretation, v.32, n.2, p.119-137, 1996.

HAUFF, P. L.; KRAUSE, F. A.; TIURY, M. Spectral identification and characterization of kaolinite/smectite clays in weathering environments. In: AUSTRALIAN REMOTE SENSING CONFERENCE， 5., Perth, 1990. Proceedings. Perth,1990. p.898-905.

HENDERSON, T.L.; BAUNGARDNER, M.F.; FRANSMEIER, D. High dimensional reflectance analysis of soils organic matter. Soil Science Society of America Journal, v.56, p. 865-72, 1992. 
HENDERSON, T.L.; SZILAGYI, A.; BAUMGARDNER, M.F.; CHEN, C.T.; LANDGREBE, D. Spectral band selection for classification of soil organic matter content. Soil Science Society of America Journal, v.53, p.1778-1784, 1989.

HILWIG, F. W.; GOOSEN, D.; KATSIERIS, D. Preliminary results of the interpretation of ERTS-1 imagery for a soil survey of the Mérida Region, Spain. ITC Journal, v.3, p.289-312, 1974.

HANDBOOK ON REFERENCE METHODS FOR SOIL TESTING. The Council on Soil Testing and Plant Analysis, Chairman, 1980. 130p.

HUETE, A. R. Soil influences in remotely sensed vegetation-canopy spectra. In: ASRAR, G. (Ed.) Theory and application of optical remote sensing. New York: Wiley Interscience, 1989. p.107-141.

HUETE, A. R. Extension of soil spectra to the satellite: atmosphere, geometric, and sensor considerations. Photo Interpretation, v.34, p.101-114, 1996.

HUETE, A. R.; ESCADAFAL, R. Assessment of biophisical soil properties through spcetral decomposition techniques. Remote Sensing of Environment, v. 35, p. 149-159, 1991.

HUMMEL, J.W.; GAULTNEY, L.D.; SUDDUTH, K.A. Soil property sensing for siteespecific management. Computers and Electronics in Agriculture, v.14, p.121136, 1996.

HUNT, G. R. SALISBUNY, J. W.; LENHOFF, C. J. Visible and near infrared spectra of minerals and rocks: III. Oxides and hidroxides. Modern Geology, v.2, p.195295, 1971. 
HUNT, G. R.; SALISBURY, J. W. Visible and infrared spectra of minerais and rocks.

II Carbonate. Modern Geology, v. 2, p.23-30, 1970.

INSTITUTO NACIONAL DE PESQUISAS ESPACIAIS. Tutorial Spring: spring básico. http:// www.inpe.br. (maio, 1999).

INSTITUTO DE PESQUISAS TECNOLÓGICAS. Divisão de Minas e Geologia Aplicada. Mapa geológico do Estado de São Paulo. São Paulo, 1981. Escala $1: 1000.000$

IRONS, J. R; WEISMILLER, R. A.; PETERSEN, G. W. Soil reflectance. In: ASRAR, G. (Ed.) Theory and application of optical remoto sensing. New York: Wiley Interscience, 1989. p.66-106.

JOHANNSEN, C.J.; CARTER, P.G.; WILLIS, P.R.; OWUBAH, E.; ERICKSON, B.; ROSS, K.; TARGULIAN, N. Applying remote sensing techology to precision agriculture. In: INTERNATIONAL CONFERENCE OF PRECISION AGRICUltURE, 4., St. Paul, 1998. Proceedings. St. Paul, 1998. v.2, p. 14131422.

JONES, J.B. Soil Testing in the United States. Communications in Soil Science and Plant Analysis, v.4, p.307-322, 1973

KING, C. Étude des sols et des formations superficielles par teledetection: Approche de leurs caractéristiques spectrales, spatiales et temporelles dans le visible et le proche Infra-Rouge. Paris, 1985. 174p. Tese (Docteur) - Institut National Agronomique.

KOFFLER, N.F. Uso das terras da Bacia do Rio Bauru (SP): situação atual e potencialidade agrícola. Mimesis, v.17, n.1, p.99-125, 1996. 
KOSMAS, C. S.; CURI, N.; BRYANT, R. B.; FRANZIEIER, D. P. Characterization of iron oxide minerais by second-derivative visible spectroscopy. Soil Science Society of America Journal, v.48, n.2, p.401-405, 1984.

KRISTOF, S. J.; ZACHARY, A.L. Mapping soil features from multiespectral scanner data. Photogrammetric Engineering, v.40, n.12, p.1427-1434, 1974.

KRUSE, F. A.; TIERY, M.; HAUFF, P. L. Spectral identification (1,2-2,5 nm) and characterization of Paris Basin kaolinite/smectite clays using a field spectrometer. In: INTERNATIONAL COLLOQUIUM - PHYSICAL MEASUREMENTS AND SIGNATURES IN REMOTE SENSING, 5., Courchevel, 1991. Proceedings. Courchevel, 1991. p.181-184.

LABSPHERE, REFLECTANCE CALIBRATION LABORATORY. Spectral reflectance target calibrated from $0.25-2.5 \mu \mathrm{m}$ reported in $0.050 \mu \mathrm{m}$ intervals. Sutton, 1996. 5p.

LEMOS, R. C. de; SANTOS, R. D. dos. Manual de descrição e coleta de solo no campo. 3. ed. Campinas: Sociedade Brasileira de Ciência do Solo, 1996. 84p.

LEPSCH, I.F. BELLINAZZI, J.R.; BERTOLINI, D.; ESPÍNDOLA, C.R. Manual para levantamento utilitário do meio físico e classificação de terras no sistema de capacidade de uso. Campinas: Sociedade Brasileira de Ciência do Solo, 1991. 175p.

LILLESAND, T.M.; KIEFER, R.W. Remote sensing and image interpretation New York: John Wiley, 1992. 750 p. 
MACEDO, J.; BRIANT, R. B. Morphology mineralogy and genesis of a hydrosequence of oxisols in Brazil. Soil Scince Society of America Journal, v. 51, p. 690-698, 1987.

MADEIRA NETTO, J. S. Étude quantitative des relations constituants minéralogiques - réflectance diffuse des latosols brésiliens: applications à l'utilization pédologique des donées satellitaires TM (région de Brasilia). Paris, 1993. 236p. Tese (Docteur) L'ORSTOM .

MADEIRA NETTO, J.S. Spectral reflectance properties of soils. Photo Interpretation, Paris, v.34, p. 59-70, 1996.

MADEIRA NETTO, J. S. M.; POUGET, M.; BEDIDI, A. Estimativa de teores de hematita em latossolos com imagens TM. In: SIMPÓSIO BRASILEIRO DE SENSORIAMENTO REMOTO 7., Curitiba, 1993. Anais. São José dos Campos : INPE, 1993. v. 3, p. 242-248.

MALLEY, D.F.; YESMIN, L.; WRAY, D.; EDWARDS, S. Applications of near-infrared spectroscopy in analysis of soil mineral nutrients. Communications in Soil Science and Plant Analysis, 30, 999-1012, 1999.

MATHEWS, H. L.; CUNNIGHAM, R. L.; PETERSEN, G. W. Spectral reflectance of selected Pennsylvania soils. Soil Science Society of America Proceedings, v.37, p.421-424, 1973.

MONTGOMERY, O. L. An investigation of the relationship between spectral reflectance and chemical, physical and genetic characteristics of soils. West Lafayette, 1976. p.132, Thesis (PhD) - Purdue University. 
MORAES, E. C. Comportamento espectral. In: SIMPÓSIO BRASILEIRO DE SENSORIAMENTO REMOTO, 8., Santos, 1996. Anais. São José dos Campos: INPE, 1996. v. 1, p.1-26.

MORAN, M.S.; IONOUE, Y.; BARNES, E.M. Opportunities and limitations for imagebased remote sensing in precision crop management. Remote Sensing of Environment, v.61, p.319-346, 1997.

MORRA, M.J.; HALL, M.H.; FREEBORN, L.L. Carbon and nitrogen analysis of soil fractions using near-infrared reflectance spectroscopy. Soil Science Society of America Journal, v.55, p.288-291, 1991.

MORSE, D. 100 Years old. Resourse: Engineering \& Technology for a Sustainable World. v.6, n.8, p. 11-12, 1999.

MULDERS A. M.; EPEMA, G. F. The thematic mapper : a new tool for soil mapping in arid areas. ITC Journal, v.1, p.24-29, 1986.

MYERS, V. I. Crops and soils. In: AMERICAN SOCIETY OF PHOTOGRAMMETRY. Manual of remote sensing. Fall Church, 1975. cap. 22, p.1715-1807.

MYERS, V. I. Remote sensing applications in agriculture. In: AMERICAN SOCIETY OF PHOTOGRAMMETRY. Manual of remote sensing. 2. ed. Fall Church, 1983. cap. 33, p.2119-2136.

NANNI, M. R. Dados radiométricos obtidos em laboratório e no nível orbital na caracterização e mapeamento de solos. Piracicaba, 2000. 366p. Tese (Doutorado) Escola Superior de Agricultura Luiz de Queiroz, Universidade de São Paulo. 
NANNI, M. R. Delimitação de unidades fisiográficas para estudo de solos utilizando análise multivariada e técnicas de sensoriamento remoto. Curitiba, 1995, 196p. Dissertação (Mestrado) - Universidade Federal do Paraná.

NANNI, M. R.; DEMATTÊ, J. A. M. Quantification and discrimination of soils developed from basalt as evaluated by terrestrial, airborne and orbital sensors (compact disc). In: SIMPÓSIO BRASILEIRO DE SENSORIAMENTO REMOTO, 10., Foz do Iguaçu, 2001. Anais. São José dos Campos, INPE, 2001a.

NANNI, M. R.; DEMATTÊ, J. A. M. Is it possible estimate physicalchemical soil attributes by using laboratory and orbital sensors (compact disc). In: INTERNATIONAL CONFERENCE OF GEOSPATIAL INFORMATION IN AGRICUltURE AND FORESTRY, 3., Denver, 2001. Proceedings, Colorado, $2001 b$

NANNI, M. R.; DEMATTÊ, J. A. M. Is it possible estimate physicalchemical soil attributes by using laboratory and orbital sensors (compact disc). In: INTERNATIONAL CONFERENCE OF GEOSPATIAL INFORMATION IN AGRICUlture AND FORESTRY, 3., Denver, 2001. Proceedings, Colorado, 2001.

NANNI, M. R.; ROCHA, H. O. da. Integration of GIS technology, remote sensing and multivariate analysis in the delimitation of physiographic units for pedological mapping. Boletim IG-Universidade de São Paulo - Série Científica, v.28, p.129-143, 1997. 
NICODEMUS, F. E.; RICHMOND, J. C.; HSIA, J. J.; GINSBERG, I. W.; LIMPERIS, T. Geometrical considerations and nomenclature for reflectance. Washington: U.S. Department of Commerce, 1977. 52 p. (NBS Monograph, 160).

NORRIS, K. H. History, present state, and future, prospects for near infrared spectroscopy. In: CREASER, C.S.; DAVISE, A.M.C. (Ed.) Analytical aplication of spectroscopy. London: Royal Society of Chemistry, 1988. p.3-8.

OBUKHOV, A. I.; ORLOV, O. S. Spectral reflectance of major soil groups and possibility of using diffuse reflections in soil investigations. Soviet Soil Science, v.1, p.174-184, 1964.

ODEH, I. O. A.; MacBRATNEY, A. B. Using AVHRR images for spatial prediction of clay content in the lower Namoi Valley of eastern Australia. Geoderma, p. 237$254,2000$.

OKAMOTO, K.; FUKUHARA, M.; HATANAKA, T. Mapping method of soil organic matter content of Ohiro area using Landsat TM data. Photogrammetry and Remote Sensing, v.29, p.45-52, 1993.

OLIVEIRA, J. B. Evolução dos trabalhos de levantamentos de solos e dos estudos de variabilidade espacial no Estado de São Paulo. O Agronômico, v.40, n.2, p.138$148,1988$.

OLIVEIRA, J. B.; PRADO, H. do. Carta pedológica semi detalhada de Piracicaba. Campinas: IAC, 1999. Escala 1:100.000.

OLIVEIRA, J. B.; CAMARGO, M. N.; ROSSI, M. Mapa pedológico do Estado de São Paulo: legenda expandida, Campinas: IAC; Rio de Janeiro: EMBRAPA, SOLOS, 1999. 64p. 
OLIVEIRA, J. B.; JACOMINE, P.K.T.; CAMARGO, N. C. Classes gerais de solos do Brasil: guia auxiliar para o seu reconhecimento. Jaboticabal, FUNEP, 1992. 201p.

OLIVEIRA, J. B.; MENCK, J.R.F.; BARBIERI, J.L. Levantamento pedológico semidetalhado do Estado de São Paulo : quadrícula de Araras. Campinas : IAC, 1982. 180 p. (IAC. Boletim Técnico, 71).

OLIVEIRA, J. B.; PRADO, H. do; ALMEIDA, C. L. F. Carta pedológica semi detalhada de Brotas. Campinas, IAC, 1981a. Escala: 1:100.000.

OLIVEIRA, J. B.; PRADO, H. do.; ALMEIDA, C. L. F. Carta pedológica semidetalhada de Jaú. Campinas, IAC, 1981b. Escala: 1:100.000.

OLMOS ITURRI LARACH, J.; SOUZA, J.L.R.; SILVEIRA, C.O. Levantamentos pedológicos no Brasil executados pelo SNLCS - EMBRAPA. In: SIMPÓSIO BRASILEIRO DE SOLOS TROPICAIS EM ENGENHARIA, 1981. Rio de Janeiro, p.13-29.

PALACIOS-ORUETA, A.; USTIN, S. Multivariate statistical classification of soil spectra. Remote Sensing of Environment, v. 57, p. 108-118, 1996.

POST, D.F.; HORVATR E.H.; LUCAS, W.M.; VV]RTE, S.A.; EHASZ, M.J.; BATCFULY, A.K. Relationship between soil color and Landsat reflectance on semiarid Rangelands. Soil Science Society of America Journal, v.58, p.1809$1816,1994$.

PRADO, H. do. Os solos do Estado de São Paulo: mapas pedológicos. Piracicaba: Edição do autor, 2000. 205p. 
QUAGGIO, J. A.; CANTARELLA, H.; RAIJ, B. van. Evolution of analutical quality of soil testing laboratories integrated in a sample exchange program. Communications in Soil Science and Plant Analysis, v. 25, p. 1007-1014, 1994.

RAIJ, B. van.; QUAGGIO, J.A.; CANTARELLA, H.; FERREIRA, M. E.; LOPES A. S.; BAtAGliA. C.O. Análise química do solo para fins de fertilidade. Campinas: Fundação Cargill, 1987. 170 p.

RAIJ, B. van.; CANTARELlA, H.; QUAGGIO, J.A.; FURLANI, A.M.C. Recomendações de adubação e calagem para o Estado de São Paulo, 2 ed. Campinas: Instituto Agronômico \& Fundação IAC, 1996. 285 p.

RIEDEL, P. S.; RUEDA, J. R. J.; STURARO, J. R.; MATTOS, J. T. Relação entre os níveis de cinza e teores de ferro, titânio e alumínio na caracterização das formações superficiais de uma região do centro leste paulista. In: SIMPÓSIO BRASILEIRO DE SENSORIAMENTO REMOTO 5., Natal, 1988. Anais. São José dos Campos : INPE, 1988. p. 334-340.

ROCHA, H. O. Integração de dados através da análise de agrupamentos e interpretação de imagens orbitais para levantamento de solos. Curitiba, 1993. 106 p. Tese (Professor Titular) - Universidade Federal do Paraná.

ROSA, R. Introdução ao sensoriamento remoto. Uberlândia : Editora da Universidade Federal de Uberlândia, 1990. 136 p.

SABINS Jr., F. F. Remote sensing : principles and interpretations. San Francisco : W. H. Freeman, 1987. 449 p. 
SAHA, S.K.; KUDRAT, M.; BHAN, S. K. Digital processing of Landsat TM data for wasteland mapping in parts of Aligarh disetrict (Uttar Paradesh), India. International Journal of Remote Sensing, v.11, n.3, p.485-492, 1990.

SANTOS, M. J. dos; MENINO, I. B; FERNANDES, M. F. Caracterização das unidades de mapeamento de solos da folha de Itaporanga SB. 24-Z-C-II, com base em imagem de satélite e trabalho de campo. In : SIMPÓSIO BRASILEIRO DE SENSORIAMENTO REMOTO 6., Manaus, 1990. Anais. São José dos Campos : INPE, 1990. v. 1, p.892-902.

SCHERMAN, D. M.; WAITE, T. D. Eletronic spectra of $\mathrm{Fe}^{3+}$ oxides and oxid hidroxides in the near IR to near U.V. American Mineraslogist, v.70, p.1272$1279,1985$.

SCHREIER, H. Quantitative predictions of chemical soil conditions from multi-spectral airbome, ground and laboratory measurements. In: CANADIAN SYMPOSIUM ON REMOTE SENSING, 4., Ottawa, 1977. Proceedings. Ottawa: Canadian Aeronautics \& Space Institute, 1977. p.106-112.

SCHULLER, J.K. O estado-da-arte da agricultura de precisão nos Estados Unidos da América (compact disc). In: BALASTREIRE, L. A. (Ed.) O estado-da-arte da agricultura de precisão no Brasil. Piracicaba, 2000. p. 8-16.

SCHWERTMANN, U.; TAYLOR, R.M. Iron oxides. In: DIXON, J.B.; WEED, S.B. (Ed.) Minerals in soil environments. Madison: Soil Science Society of America, 1977. p.145-180. 
SEARCY, S.W.; SCHULLER, Y.H.; BAE, S.C.; BORGELT, S.C.; STOUT, B.A. Mapping of spatially-variable yield during grain combining. Transactions of the ASAE, v.32, n.3, p.826-829, 1989.

SENTELHAS, P.C.; MARIN, F.R.; PEREIRA, R.; ANGELOCCI, L.R.; VILA NOVA, N.A.; BARBIERI, V. Análise de dados climáticos e do balanço hídrico climatológico de Piracicaba (1917-1997). Piracicaba: DFM,ESALQ, 1998.81p.

SINGH, A. N.; DWIVEDI, R. S. The utility of LANDSAT imagery as an integral part of the data base for small-scale soil mapping. International Journal of Remote Sensing, v.7, n.9, p.1099-1108, 1986.

SINGH, A. N.; DWIVEDI, R. S. Delineation if salt affected soils through digital analysis of Landsat MSS data. International Journal of Remote Sensing, v.10, n.1, p.83-92, 1989.

STARK, E.; LUCHTER, K.; MARGOSHES, M. Near-infrared analysis (NIRA): A technology for quantitative and qualitative analysis. Applied Spectroscopy Reviews, v.22, n.4, p.335-399, 1986.

STATISTICAL ANALYSIS SYSTEM INSTITUTE. SAS, software: user's guide, version 8.2. Cary, 1999. 291p.

STONER, E. R.; BAUMGARDNER, M. F. Characteristics variations in reflectance of surface soils. Soil Science Society of America Journal, v.45, n.6, p.1161-1165, 1981.

STONER, E. R.; BAUMGARDNER, M. F.; WEISMILLER, R. A.; BIEHL, L. L.; ROBINSON, B. F. Extension of laboratory-measured soil spectra to field conditions. Soil Science Society of America Journal, v.44, p.572-574, 1980. 
STREUS, R.G. F.; WOOD, B. F. Diffuse reflectance spectra and optical properties of some iron and titanium oxides and oxyhydroxides. Mineralogical Magazine, v.43, p.347-354, 1979.

TANRÉ, D.; HOLBEN, B.N.; KAUFMAN, Y.J. Atmospherie correction algorithm for NOAA-AVHRR products: theory and application. IEEE Transactions Geoscience Remote Sensing, v.30, p.231-248. 1992.

VALERIANO, M. M.; EPIPHANIO, J. C. N.; FORMAGGIO, A. R.; OLIVEIRA, J. B. Bi-directional reflectance factor of 14 soil classes from Brazil. International Journal of Remote Sensing, v.16, n.1, p.113-128, 1995.

VANE, G.; GREEN, R. O.; CHRIEN, T. G.; ENMARK, H. T.; HANSEN, E. G.; POSTER, W. N. The Airborne Visible/Infrared Imaging Spectrometer (AVIRIS). Remote Sensing of Environment, v.44, p.127-143, 1993.

VENKATARATNAM, L. Delineation and mapping of agricultural soil limitation/hazards in arid and semi-arid tropies using Landsat data: an Indian experience. In: INTERNATIONAL SYMPOSIUM ON REMOTE SENSING ENVIRONMENT, 14., Ann Arbor, 1980. Proceedings. Ann Arbor: Environmental Research Institute of Michigan, 1980. p.905-914.

VETORAZZI, C. A. Interpretação de imagens TM/Landsat - 5, em duas escalas, na caracterização fisiográfica para mapeamento de solos. Piracicaba, 1988. 184 p. Tese (Doutorado) - Escola Superior de Agricultura Luiz de Queiroz, Universidade de São Paulo. 
VETtORAZZI, C. A.; COUTO, H. T. Z. Análise da exatidão de classificação em mapas de solos obtidos através da interpretação de imagens orbitais em duas escalas. In: SIMPÓSIO BRASILEIRO DE SENSORIAMENTO REMOTO 6., Manaus, 1990. Anais. São José dos Campos : INPE, 1990. p.769-775.

VINCENT, R. K. Expanding horizons for geological application of multispectral and hyperspectral remote sensing data. In: INTERNATIONAL CONFERENCE, APPLIED GEOLOGIC REMOTE SENSING, 13., Vancouver, 1999. Proceedings. Ann Arbor: ERIM International, 1999. v.1, p.33-40.

VINOGRADOV. B.V. Remote sensing of the humus content of soils. Soviet Soil Science, v.13, p.103-13, 1981.

VITORELLO, I.; GALVÃO, L. S. Spectral properties of geologic materials in the 400 to $2500 \mathrm{~nm}$ range: review for applications to mineral exploration and lithologic mapping. Photo Interpretation, v.34, n.2, p.77-99, 1996.

WEISMILLER, R.A.; PERSINGER, L. O.; MONTGOMERY, O. L. Soil inventory from digital analysis of satellite scanner and topographic data. Soil Science Society of America Journal, v.41, p.1166-1173, 1977.

WESTIN, F. C.; FRAZEE, C. J. Landsat data, its use in a soil survey program. Soil Science Society of America Journal, v.40, p.81-89, 1976.

ZERMIANI, M. J. T.; NANNI, M. R.; COMUNELlO, E.; DEMATTÊ, J. A. M. Analysis of the ocupation and land use in medium terrace of the Paraná river Brazil by GIS and remote sensing. In: INTERNATIONAL CONFERENCE ON APPLIED GEOLOGIC REMOTE SENSING, 13., Vancouver, 1999. Proceedings. Ann Arbor: ERIM-International., 1999. v.2, p.161-167. 
ZHANG, R.; WARRIACK, A.W.; MYERS, D.E. Improvement of the prediction of soil particle size fractions using spectral properties. Geoderma, v.52, p.223-234, 1992.

ZULLO Jr, J. Correção atmosférica de imagens de satélite e aplicações. Campinas, 1994. 191p. Tese (Doutorado) - Instituto de Física Universidade Estadual de Campinas. 